\title{
Towards an Occupant-centric Simulation-aided Building Design Process
}

by

Tareq Abuimara

A thesis submitted to the Faculty of Graduate and Postdoctoral Affairs in partial fulfillment of the requirements for the degree of

Doctor of Philosophy

in

Civil Engineering

Carleton University

Ottawa, Ontario

(C) 2020, Tareq Abuimara 


\section{Abstract}

Occupant-related uncertainty has been recognized as one of the main challenges that building designers face. Current occupant modelling practices are based on simple assumptions that are typically made based on codes, standards, and rules-of-thumb. Designers assume occupants have homogeneous temporal and spatial distribution. This approach does not recognize differences among tenants or buildings and can lead to suboptimal design solutions that can compromise energy and comfort performance. Therefore, this doctoral research aims at developing a practical improved method for occupant modelling that recognizes occupant-related uncertainty. The method was developed based on a thorough qualitative and quantitative investigation. To this end, a deeper understanding of the current approaches, challenges and needs of occupant modelling throughout the design process was obtained and documented through a stakeholders' workshop and interviews with a case study design stakeholders. Then, a simulation-based investigation was conducted on a real case study office building located in Toronto, Canada. The simulation-based investigation included conducting a parametric analysis under variable occupant scenarios, developing an occupant-centric design optimization method, and evaluating the impact of occupants' spatial distribution on energy and comfort performance. The documentation of current occupant 
modelling practice indicated the need to improve the current approach by carefully considering occupant-related assumptions in early design stages. In addition, it indicated the need to improve communicating occupant-related assumptions among design stakeholders. The results of the simulation-based investigation indicated that occupant-related assumptions can influence the outcomes of design parametric analysis and design optimization. Notably, assumptions about occupants' spatial distributions demonstrated substantial impact on occupants' thermal comfort and the indoor air quality. 


\section{Preface}

This is an integrated thesis that consists of three journal papers and three conference papers, that are either published or under review.

The articles are listed below in the same order they appear in the thesis:

Article 1 (Chapter 2): Abuimara T., O'Brien W, Gunay BH, Burpee H, Day J (2018). Designing for Occupants: A Review of the Integrated Design Practice.

ACEEE Summer Study on Energy Efficiency in Buildings. August 12-17, 2018. Pacific Grove, CA, USA.

Article 2 (Chapter 3): Abuimara, T., O'Brien, W., Gunay, H.B., Abdelalim, A., Ouf, M. and Gilani, S., (2018), May. Modelling Occupants in Buildings: Stakeholders' Workshop on Current Barriers, Challenges and Needs. In Proceedings of eSim Conference, Montreal, QC.

Article 3 (Chapter 4): Abuimara, T., O’Brien, W., Gunay, B., Carrizo, J. S. (2019). Towards occupant-centric simulation-aided building design: a case study. Building Research \& Information, 47(8), 866-882.

Article 4 (Chapter 5): Abuimara, T., Gunay, B., \& O'Brien, W. (2020). An occupant-centric method for window and shading design optimization in office 
buildings, Science and Technology for the Built Environment, 27:2, 181-194, DOI: 10.1080/23744731.2020.1840217.

Article 5 (Chapter 6): Abuimara, T., O'Brien, W., \& Gunay, B. (2021). Quantifying the impact of occupants' spatial distributions on office buildings energy and comfort performance. Energy and Buildings, 233, 110695.

Article 6 (Chapter 7): Abuimara, T., O'Brien, W., Gunay, B (2020). A Method for Exploring Occupant-related Uncertainty during Simulation-aided Office Building Design. eSim 2021, Vancouver (2021).

In the co-authored articles, Tareq Abuimara was the principal contributor to the research methodology conception and design, experiment/monitoring set up and conduct, data acquisition, data analysis and interpretation, and preparing and writing the material presented in the articles, under the supervision of William O'Brien and H. Burak Gunay. Juan Sebastián Carrizo, Mohamed Ouf, Aly Abdelalim, Sara Gilani, Heather Burpee, and Julia Day provided critical review of and feedback on the manuscript of the articles for which they are co-authors. 


\section{Acknowledgements}

Firstly, I would like to express my thanks and appreciation to my Ph.D. thesis supervisors Dr. Liam O'Brien and Dr. Burak Gunay for their support, guidance and motivation.

I also would owe much to my caring and supportive friends and office mates in Human Building Interaction Lab (HBI Lab) and Data-driven Building Operation and Maintenance Lab (DBOM) who helped me stay strong and moving forward during my Ph.D. studies.

I am also thankful to the government and industry partners for their generous support of my Ph.D. research: NRCan, Rowan Williams Davies \& Irwin Inc (RWDI), Autodesk, and NRC.

I also would like to acknowledge the financial support provided by the National Sciences and Engineering Research Council Canada (NSERC) Alexander Graham Bell Scholarship (CGS). Special thanks also go to ASHRAE for the Grant-in Aid Award, Carleton for the internally administrated awards, and IBPSA-Canada for the travel award.

Besides, special thanks go to my colleagues in IEA-EBC Annex 79 for their feedback and collaboration.

Finally, I am so grateful to my family for their unconditional love and support throughout my studies. 


\section{Contents}

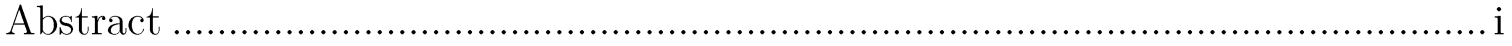

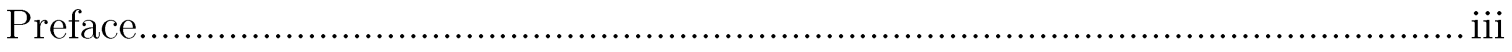

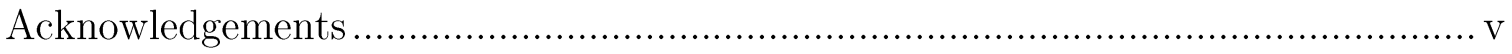

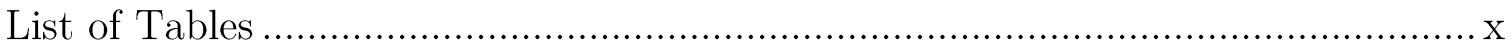

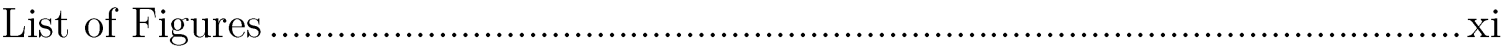

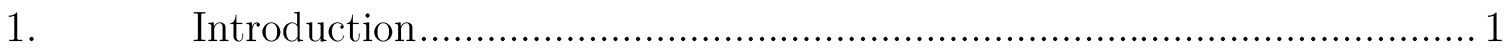

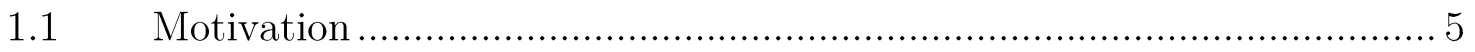

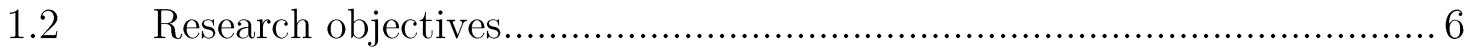

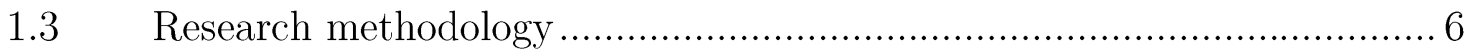

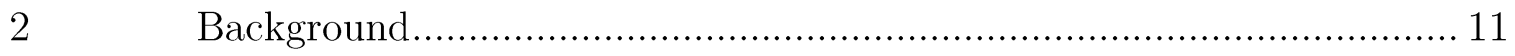

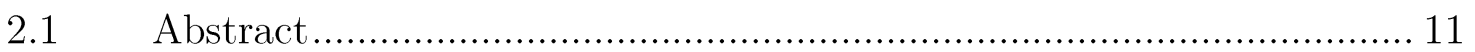

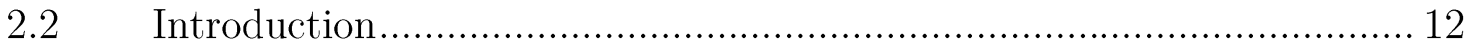

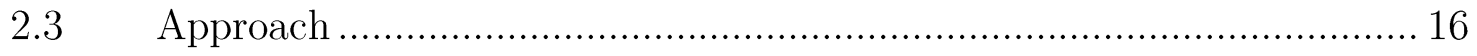

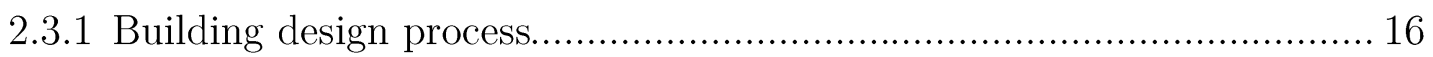

2.3.2 The integrated design process (IDP) ................................................. 18

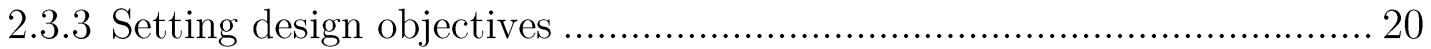

$2.4 \quad$ Occupant assumptions during the pre-design phase ……..................... 20

2.5 Occupant assumptions in the design concept phase.............................. 22

2.6 Occupant assumptions in the design development phase....................... 24

$2.7 \quad$ Occupant assumptions in construction documents/detailing phase .......27

2.8 The role of occupant in construction phase........................................ 28

2.9 The role of occupant during the post construction phase ...................... 30

2.10 Discussion, recommendations, limitations and conclusion .................... 31

3 The status of occupant modelling ……............................................. 36

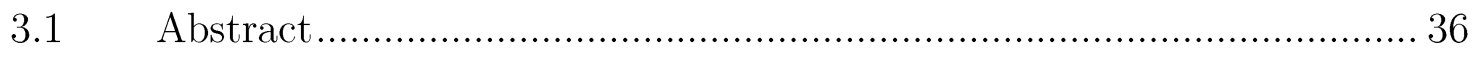

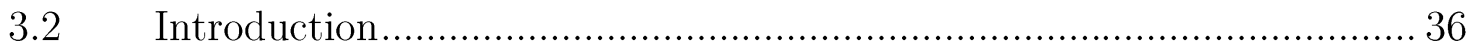

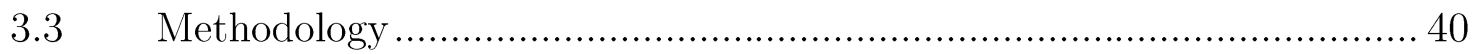




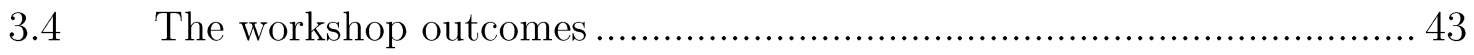

3.4.1 Status of occupants' modelling in building design practice................... 45

3.4.2 Occupants' modelling in building codes and standards......................... 48

3.4.3 BPS tools features and capabilities ....................................................... 49

3.4.4 Uncertainty in simulation-aided design ................................................52

3.5 Recommendation and future work ………...................................... 55

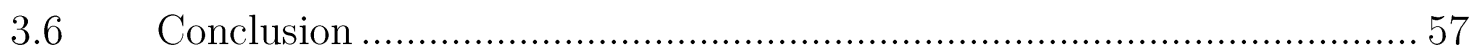

$4 \quad$ Case study documentation and parametric analysis ............................ 59

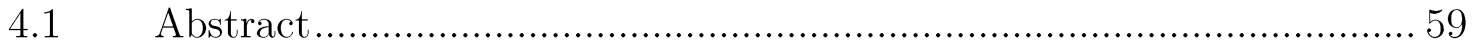

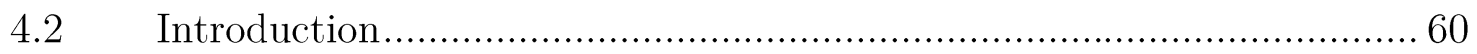

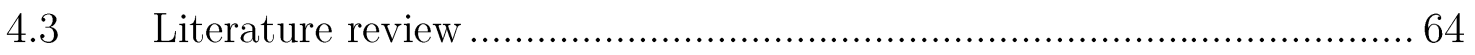

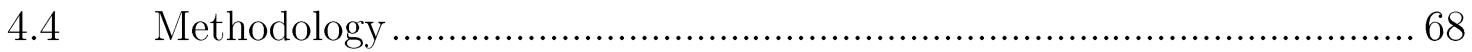

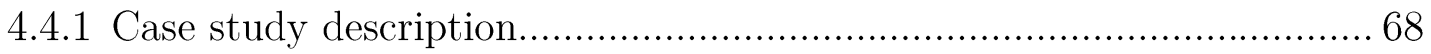

4.4.2 Data collection from stakeholders ......................................................... 70

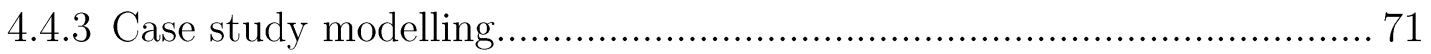

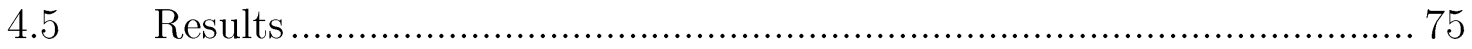

4.5.1 The case study design documentation.................................................. 75

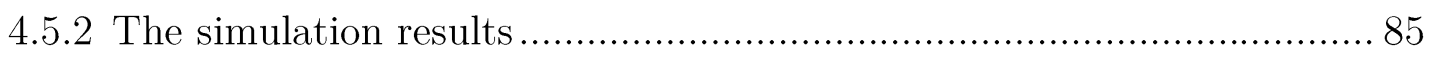

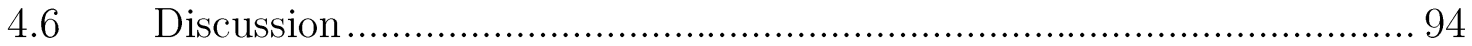

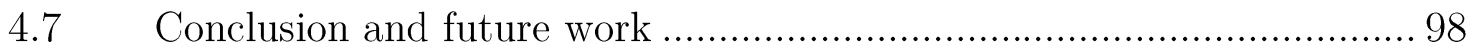

$5 \quad$ Occupant-centric design optimization ..............................................102

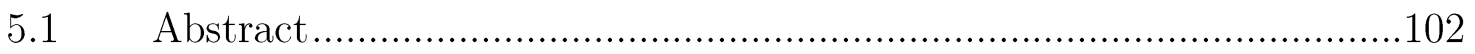

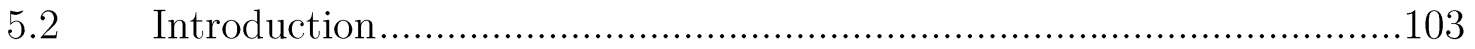

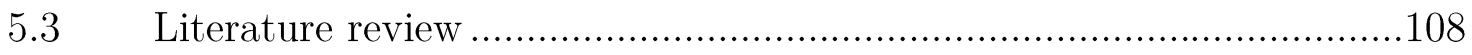

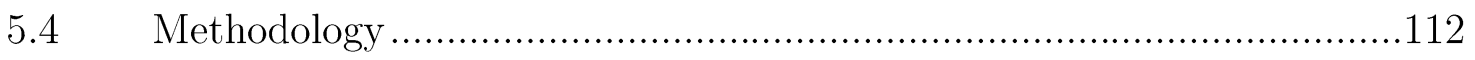

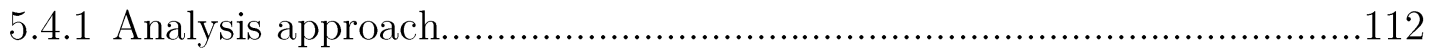

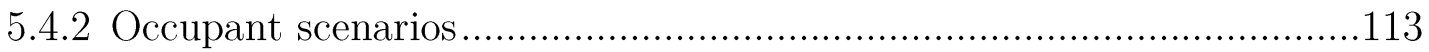

5.4.3 Optimization settings and design parameters ......................................117 


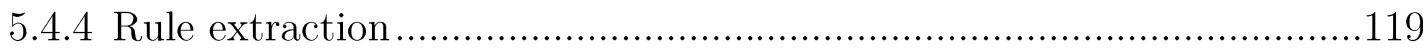

5.4.5 Case study building ............................................................................119

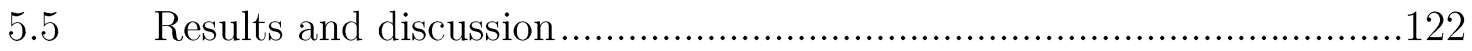

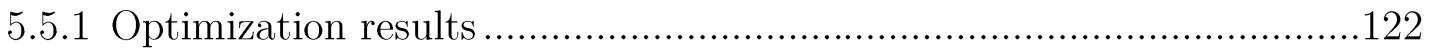

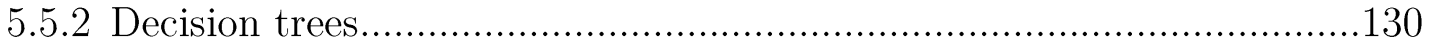

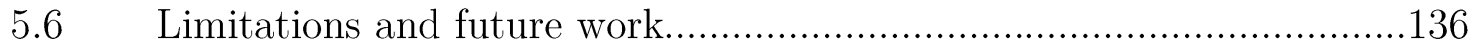

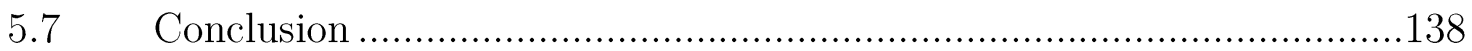

$6 \quad$ Evaluating the impact of occupants' spatial distribution on performance 141

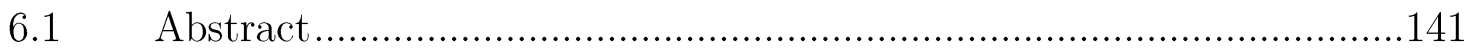

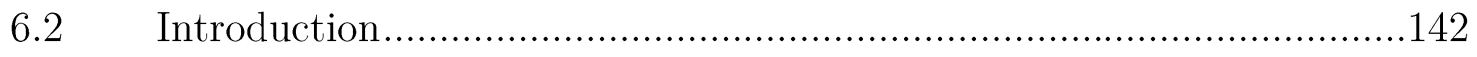

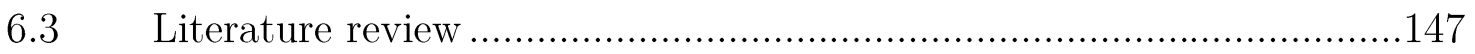

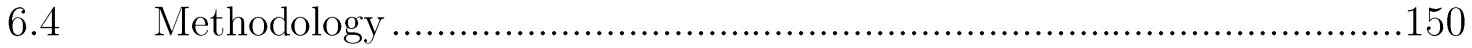

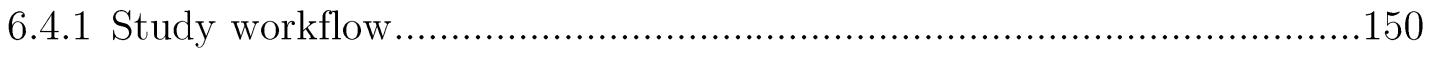

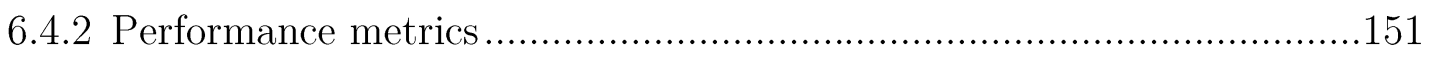

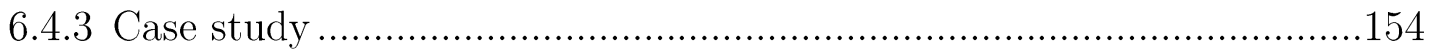

6.4.4 Occupants' distribution scenarios (ODSs) ............................................157

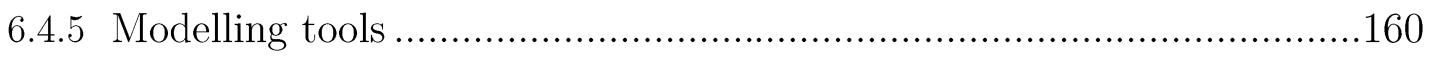

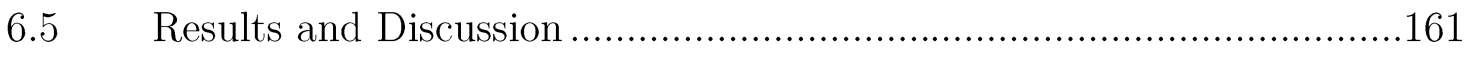

6.5.1 Implications of ODSs on energy use..................................................161

6.5.2 Implications of ODSs on comfort .....................................................163

6.5.3 Impact on indoor air quality (IAQ) ................................................170

6.6 Benefits of adaptive technologies....................................................171

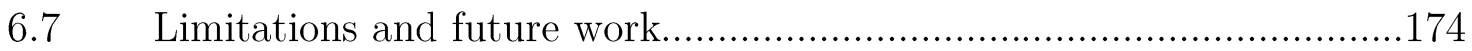

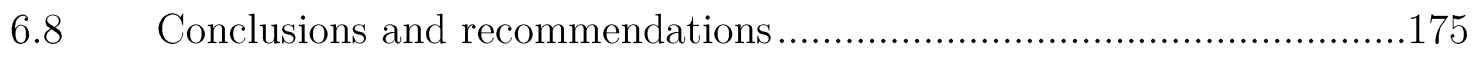

$7 \quad$ A method for exploring occupant-related uncertainty during building design 178

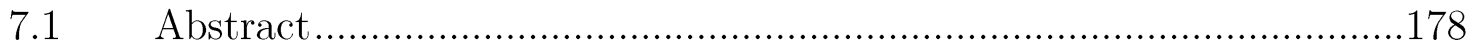




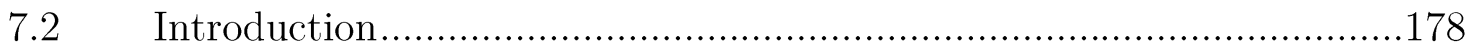

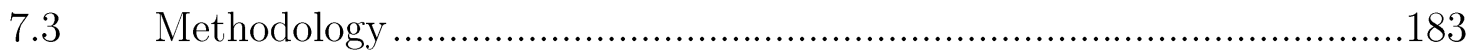

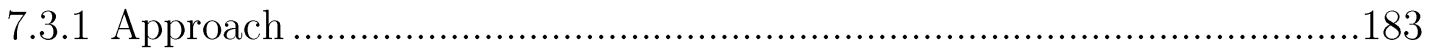

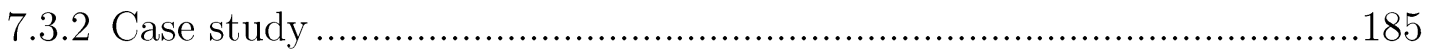

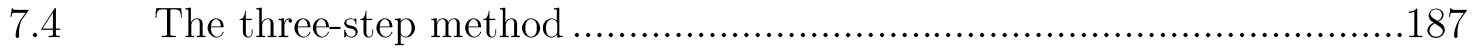

7.4.1 Establishing and communicating assumptions ..................................188

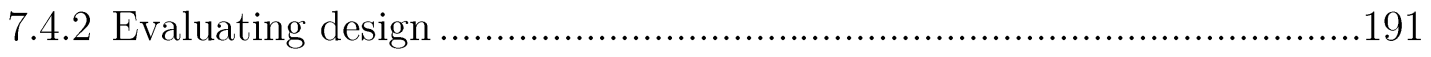

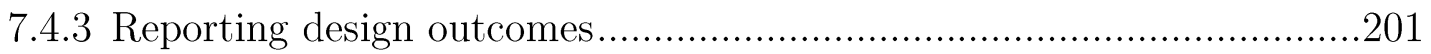

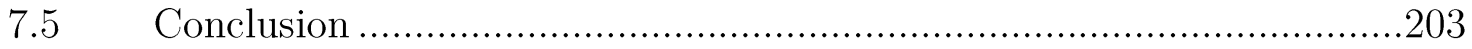

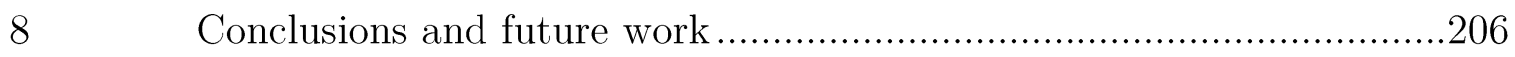

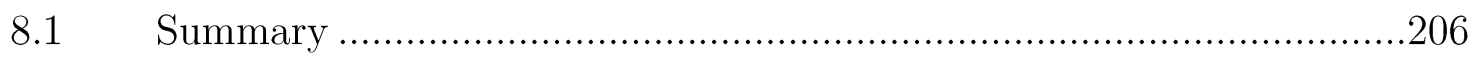

8.1.1 The status of occupant modelling ……............................................206

8.1.2 Case study documentation and parametric analysis ............................207

8.1.3 Occupant-centric design optimization ...............................................209

8.1.4 Evaluating the impact of occupants' spatial distribution on performance 210

8.1.5 A Method for exploring occupant-related uncertainty during building

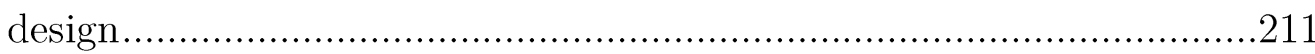

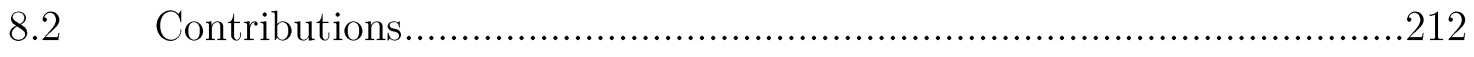

8.2.1 Contributions to the existing literature..............................................212

8.2.2 Contributions to architecture and engineering profession .....................214

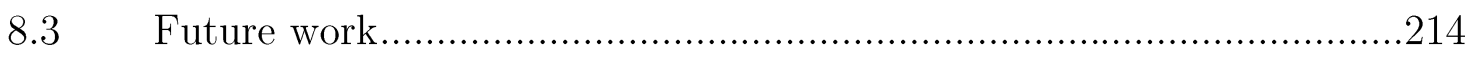

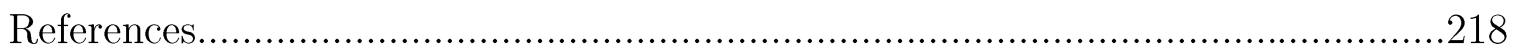

Appendix A: Stakeholders' interviews questions...................................................224 


\section{List of Tables}

Table 2.1: Uses of occupant assumption by the different design team members.... 14

Table 3.1: Stakeholders workshop discussion structure ................................... 41

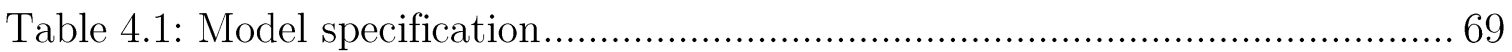

Table 4.2: Occupant-related assumptions ................................................... 72

Table 4.3: Design parameters........................................................ 74

Table 4.4: Occupant-related assumptions made by design stakeholders during the

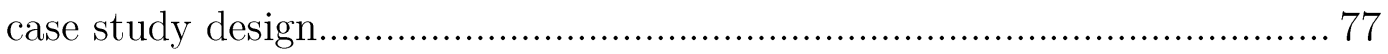

Table 4.5: Sources of assumptions per stakeholder .................................. 79

Table 6.1: Description of the case study ............................................. 155

Table 7.1: Case study specifications................................................. 186

Table 7.2: Occupant related assumption in practice vs reality.........................189 


\section{List of Figures}

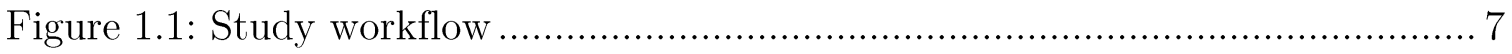

Figure 1.2: The case study energy model by the energy modeller.......................... 8

Figure 2.1: Scholarly published work on IDP vs occupant behaviour (2000-2017).

Search keywords were: "integrated design

process" AND building OR" IDP" AND building, "occupant modelling" OR

"occupant modeling" OR "occupant behaviour" OR "occupant behavior". 17

Figure 2.2: Impact of occupant assumptions on the design process (IDP) ............ 19

Figure 3.1: Stakeholders workshop, Ottawa May 1st, 2017................................. 39

Figure 3.2: Current simulation-based design domain............................................ 44

Figure 3.3: Proposed improvements to current occupant modelling approaches .... 57

Figure 4.1: The actual role of occupants in buildings ........................................... 62

Figure 4.2: The case study: An office building in Toronto, Canada...................... 69

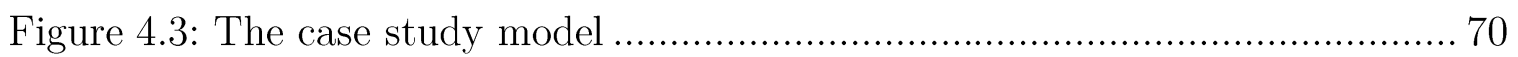

Figure 4.4: The workflow of the stakeholders' interviews..................................... 71

Figure 4.5: The simulation-based investigation workflow..................................... 72

Figure 4.6: People, lighting and equipment profiles used for energy modelling...... 78

Figure 4.7: Occupant-related assumptions by different design stakeholders........... 81

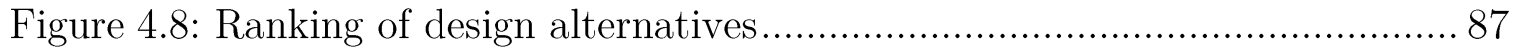

Figure 4.9: (a) The impact of changes in schedules on the energy savings of design alternatives, (b) The impact of changes in setpoints on the ranking and energy savings of design alternatives, (c) The impact of changes in number of people on the energy savings of design alternatives, (d) The impact of changes in blind use on the energy savings of design alternatives, 
(e) The impact of changes in equipment loads on the energy savings of design alternatives.

Figure 5.1: The three-step method for occupant-centric building design optimization

Figure 5.2: Occupancy schedule scenarios

Figure 5.3: Generating occupant scenarios workflow

Figure 5.4: Occupancy-lighting mathematical relationship: an example set of alternatives using the building energy code stated values. Each point represents the fraction of lighting load at a given occupied fraction. 116

Figure 5.5: Occupancy-equipment mathematical relationship: an example set of alternatives using the building energy code stated values. Each point represents the fraction of equipment load at a given occupied fraction. ....117

Figure 5.6: An overview of the base case EnergyPlus model, occupancy scenarios, lighting and equipment scenarios, and the design parameters for optimization processes.

Figure 5.7: Design optimization results under the sixty-four occupant scenarios..125

Figure 5.8: Heating energy use intensity of optimization runs under the sixty-four occupant scenarios. 126

Figure 5.9: Cooling energy use intensity of optimization runs under the sixty-four occupant scenarios.

Figure 5.10: Detailed optimization results for each occupant scenario. Each plot has 16 scatter plots. Each scatter plot represents an optimization run for an occupant scenario. The length of the scatter plot indicates where the optimization run converged to the optimal solution. The end part of each 
scatter plot shows a group of design solutions with similar energy

performance

Figure 5.11: Example optimal design solution for two different occupant scenarios: (A) occupant scenario 01 (code occupancy and option 01 of equipment and lights as shown in Figure 5.4 and Figure 5.5) and (B) occupant scenario 33 (morning peak occupancy and option 01 of equipment and lights as shown in Figure 5.4 and Figure 5.5)....

Figure 5.12: Decision trees derived based on the results of the optimization process.

Figure 5.13: Sensitivity analysis for the use of overhang shading on south-facing windows

Figure 6.1: Example from an institutional building real occupancy data demonstrating variable spatial and temporal occupancy across building zones 145

Figure 6.2: (A) The case study model; a fifteen-zone typical office floor, (B) model zone numbering. 155

Figure 6.3: Plan view of a sample of ODSs including standard (scenario 1-code), highly-populated south-facing zones (scenario 2), highly-populated core zones (scenario 3), highly-populated west-facing zones (scenario 4), highlypopulated north-facing zones (scenario 5) and highly-populated east-facing zones distribution scenarios (scenario 6)

Figure 6.4: Violin plot of the EUI of the case study model under the 75 ODSs....162 Figure 6.5: Unmet hours of the case study model under the 75 ODSs as per ASHRAE Standard 90.1 definition. 164

Figure 6.6: Overheating ODH under the 75 ODSs. .167 
Figure 6.7: Overcooling ODH results under the 75 ODSs.

Figure 6.8: Results of sensitivity analysis demonstrates a decrease in total overcooling $\mathrm{ODH}$ with decreased airflow rates in a core zone with high ODH range. This zone has low occupant density $\left(0.009\right.$ person $\left./ \mathrm{m}^{2}\right)$................168

Figure 6.9: Sample results of six different ODSs demonstrating the impact on the value of $\mathrm{ODH}$

Figure 6.10: A boxplot of the $\mathrm{OHcO}_{2}$ under the 75 ODSs............................170

Figure 6.11: A comparison of EUI without and with DCV ...........................172

Figure 6.12: A comparison of overcooling ODH without and with DCV .............173

Figure 7.1: Occupants' actual impact on building performance. .......................180

Figure 7.2 :The case study models................................................... 186

Figure 7.3: An illustration of how the proposed three-step occupant modelling process can feed in and improve the design process. ..............................187

Figure 7.4: Discrepancy in occupant-related assumptions among design stakeholders.

Figure 7.5: Sensitivity of energy-saving potential from three window assemblies to the different occupant related assumptions. $\mathrm{W} 1\left(\mathrm{U}=1.62 \mathrm{~W} / \mathrm{m}^{2} \cdot \mathrm{K}\right.$, $\mathrm{SHGC}=0.39), \mathrm{W} 2\left(\mathrm{U}=2.04 \mathrm{~W} / \mathrm{m}^{2} \cdot \mathrm{K}, \mathrm{SHGC}=0.58\right)$, and $\mathrm{W} 3(\mathrm{U}=1.47$ $\left.\mathrm{W} / \mathrm{m}^{2} \cdot \mathrm{K}, \mathrm{SHGC}=0.25\right)$

Figure 7.6: Sensitivity of energy-saving potential from DCV to the different occupant related assumptions.

Figure 7.7: HVAC EUI of design optimization from four optimization runs using four different occupancy schedule scenarios. Each scatter point represents an optimization run for an occupant scenario. The length of the scatter plot 
indicates the number of simulation runs before the optimization algorithm terminates the search for a given scenario.................................................196

Figure 7.8: A sample decision tree demonstrating guidelines for selecting optimal sidefin shading size on west-facing façade................................................197

Figure 7.9: A sample decision tree demonstrating guidelines for selecting optimal window assembly material for west-facing façade.....................................198

Figure 7.10: Optimization results distribution for sixty-four different occupant scenarios. The distribution is based on the sixty-four optimal designs.......198

Figure 7.11: Impact of occupants' distribution on energy (top) and comfort performance (bottom)

Figure 8.1: A vision of occupant-centric design workflow 


\section{Nomenclature}

\begin{tabular}{|c|c|}
\hline Abbreviation & Full name \\
\hline $\mathrm{ACH}$ & Air changes per hour \\
\hline $\mathrm{AHU}$ & Air-handling unit \\
\hline BPS & Building performance simulation \\
\hline $\mathrm{COP}$ & Coefficient of performance \\
\hline $\mathrm{DCV}$ & Demand-controlled ventilation \\
\hline EPD & Equipment power density \\
\hline IAQ & Indoor air quality \\
\hline HVAC & Heating, ventilation, and air conditioning \\
\hline LEED & Leadership in energy and environmental design \\
\hline LPD & Lighting power density \\
\hline $\mathrm{OB}$ & Occupant behaviour \\
\hline $\mathrm{M}+\mathrm{V}$ & Measurement and verification \\
\hline $\mathrm{ODH}$ & Occupant discomfort hours \\
\hline ODS & Occupant distribution scenario \\
\hline PPP or P3 & Public private partnership \\
\hline VAV & Variable air volume \\
\hline Symbols & Full name \\
\hline$A_{i}$ & Floor area of zone $i$ \\
\hline $\mathrm{CO}_{2} h_{z, t}$ & An hour with $\mathrm{CO}_{2}>1000 \mathrm{ppm}$ in zone $z$ at timestep $t$ \\
\hline$h_{z, t}$ & Discomfort hour in zone $z$ at timestep $t$ \\
\hline $\mathrm{ODH}_{z}$ & Occupant discomfort hours in zone $Z$ \\
\hline $\mathrm{OH}_{\mathrm{co} 2}$ & Occupant carbon dioxide hours \\
\hline$O_{i}$ & Number of occupants in zone $i$ \\
\hline$O_{z, \max }$ & Maximum number of occupants assigned to zone $Z$ \\
\hline$O_{z, t}$ & Number of occupants in zone $z$ at timestep $t$ \\
\hline
\end{tabular}




\section{Introduction}

Achieving the national and international energy efficiency goals and greenhouse gas (GHG) emissions and pollution reduction require a collaborative national and international effort from different national and international stakeholders. Emissions from buildings construction and operation account for significant portion of the local and global energy use and GHG emissions. According to the United Nations Environment program, buildings and construction are responsible for $36 \%$ of energy use and $40 \%$ of energy-related carbon dioxide $\left(\mathrm{CO}_{2}\right)$ emissions globally (UN Environmental Programme 2018). Energy is used in buildings mostly for ventilation, heating, cooling, lighting, plug-in equipment, and domestic hot water (DHW). Therefore, there have been ongoing efforts to reduce the energy consumed in buildings.

Researchers and the architecture, engineering, and construction (AEC) industry have been developing and employing different means to achieve these objectives. Designing energy-efficient buildings has been an area of interest for building designers for the last few decades. Building design is a complex process that takes place in an extended period. The complexity is a result of being a multi-stakeholder process that requires a high level of coordination and collaboration throughout the process (El-Diraby et al. 2017; Gagnon et al. 2018). Hence, the success or failure of the design process is 
CHAPTER 1

determined by how successful the design stakeholders are in achieving the required coordination and collaboration (Mok et al. 2018). Discrepancies in assumptions made by design stakeholders can misinform the design process and lead to suboptimal design decisions (Abuimara et al. 2020b).

Besides the role of stakeholders, designing energy-efficient buildings require tools and techniques that enable designers to predict the performance of buildings under design. Building performance simulation (BPS) is considered one of the most effective means to evaluate buildings and systems design (Attia et al. 2012b; Loonen et al. 2017; Moazami et al. 2019). However, the BPS-aided design process involves a high degree of uncertainty due to a number of factors, such as the absence of reliable information about occupants and the absence of accurate weather data (Hopfe \& Hensen 2011; Li et al. 2019; Wate et al. 2020).

Occupants are recognized as a major source of uncertainty (Gaetani et al. 2016b; Hoes et al. 2009; Hong et al. 2017; IEA-EBC 2014). Occupancy varies across building types, sizes, and locations. Occupants spend $90 \%$ of their time in buildings (Babu \& Suthar 2020; EPA 1997; Liu et al. 2019) and influence energy use in buildings in different ways: by their presence (e.g. increasing internal gains), and by their interactions with building components (e.g. opening windows) and systems (e.g. adjusting thermostats), which consequently influence the energy use in buildings 
CHAPTER 1

(Dong et al. 2018; Hong et al. 2017; Yan et al. 2017). Occupants can affect energy use in commercial buildings by a factor of two or more (Clevenger et al. 2014; Haldi et al. 2011).

Current BPS tools offer limited flexibility in modelling occupants (Ouf et al. 2018). However, designers are not always fully aware of all the features and capabilities of BPS tools (Abuimara et al. 2018a; O'Brien et al. 2016). The current occupant modelling practice relies on simplistic, static and homogenous occupant-related inputs per building type which do not recognize the differences between different buildings, different occupancy patterns, and activities in buildings (Gilani et al. 2019). This modelling approach increases uncertainty and widens the gap between the simulated and actual building performance.

Therefore, modelling occupants in buildings is a challenging task for building design team members and has been the focus of many researchers for the past two decades. Researchers have focused on different aspects of occupant behaviour and modelling. Some researchers have focused on developing dynamic occupant models using occupant-related data collected through observational studies from existing buildings using different sensing technologies such as passive infrared sensors (PIR). Examples of data-driven models are window opening model by Haldi and Robinson (2009a), blind use model by Zhang and Barrett (2012), light switch model by Reinhart (2004), 
CHAPTER 1

plug-in equipment load prediction model by Gunay et al. (2016a), and office tenant electricity use model by O'Brien et al. (2019). However, the dynamic occupant models are yet to be adopted by designers as they are not easy to implement and requires special skills and training. In addition, these dynamic models are facing the question of generalizability and applicability (Schweiker et al. 2011).

Other studies were published to demonstrate the influence of occupant modelling approaches on building design decision making such as studies by Abuimara et al. (2018c), Sun \& Hong (2017a), Sun \& Hong (2017b), Gaetani et al. (2016a) and Ding et al. (2016). Additionally, the final report of the International Energy Agency Energy in Buildings and Communities (IEA-EBC) Annex 66 "Definition and simulation of Occupants Behaviour in Buildings" - Subtask E concluded that there is a need for the establishment of an occupant modelling framework and design guidelines (Yan et al. 2017). In addition, IEA-EBC Annex 79 entitled "OccupantCentric Building Design and Operation" is dedicated to further investigating and developing occupant modelling in building design (O'Brien et al. 2020). The overall goal of Annex 79 is to promote the implementation of improved occupant modelling in buildings design and operation to improve energy and comfort performance (IEAEBC 2018). 
CHAPTER 1

\subsection{Motivation}

Occupant-related assumptions used by practitioners in the AEC industry are typically simple and static and do not consider differences between buildings and occupants. This practice is unable to represent multiple possible occupant scenarios during the design process and leads to suboptimal design decisions. On the other hand, existing dynamic occupant models were built on relatively small datasets from a small number of occupants and only a few buildings that cannot be generalized for other buildings (Schweiker et al. 2011). In addition to the issue of the complexity of these models, there are not any widely used implementations despite some early efforts to implement these dynamic models in BPS tools, such as the study by Gunay et al. (2016c). The advanced occupant modelling approaches also require significant inputs and complicated setup that is not practical, especially during the early design stages (O'Brien et al. 2018). Moreover, the advanced models yield stochastic results, for which the industry does not have an appetite (O'Brien et al. 2016).

Hence, more practical approaches - those that are well understood by practitioners, can work with existing BPS tools and their capabilities, and serve as a good intermediate step towards better modelling of occupants - are needed. Therefore, this thesis exploits the untapped existing resources and BPS features to handle occupant-related uncertainty better. 
CHAPTER 1

\subsection{Research objectives}

Considering the critical role occupants and occupant-related assumptions play during the building design process, this research aims at (1) documenting and evaluating the current occupant modelling approaches, (2) developing a comprehensive occupant modelling workflow, and (3) demonstrating the developed workflow on a real case study an improved occupant modelling approach. This research's ultimate objective is to develop an improved occupant modelling method that can be easily adopted by building design practitioners.

\subsection{Research methodology}

In order to develop an improved method for handling occupant-related uncertainties, several consecutive analyses were conducted. The analysis included two main approaches. First, documentation of occupant modelling status, and then a simulation-based investigation of the case study building. The simulation-based investigation included a parametric analysis, an occupant-centric design optimization study, and study of comfort and energy implications of occupants' spatial distributions. The study workflow is provided in Figure 1.1.

The analysis to develop and implement an improved occupant modelling method was conducted on a real case study building located in Toronto, Canada. The building 
was designed to be a multi-tenant office building with retails ground floor (see Figure 1.2). The building was in the construction phase during the study. The study was initiated based on information obtained from drawings, details, design reports, and the project energy model. Additional occupant-related data was obtained from key design stakeholders (architect, energy modeller, mechanical engineer, and building owner) through semi-structured interviews. The interviews are documented in Chapter 4 .

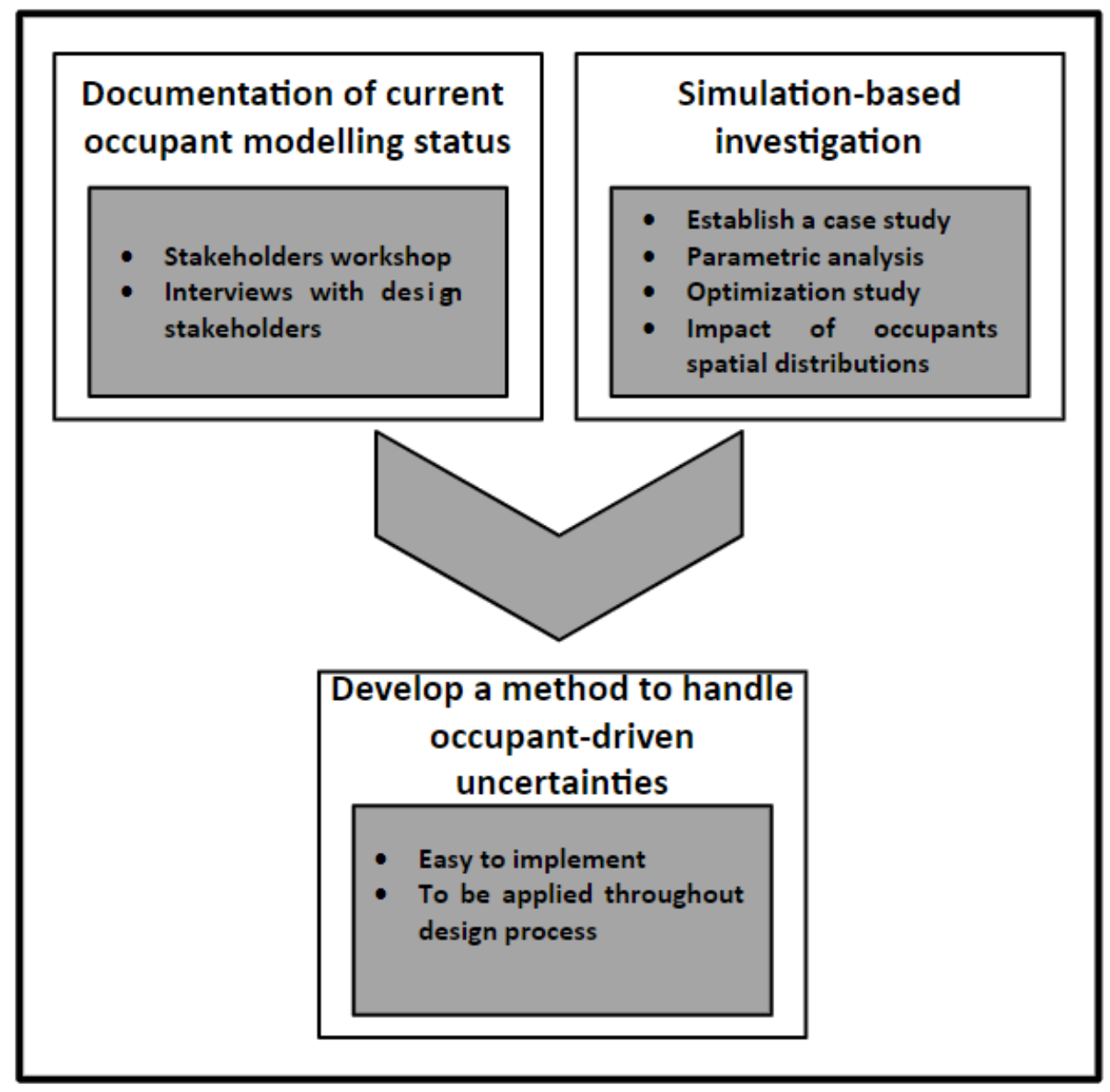

Figure 1.1: Study workflow 


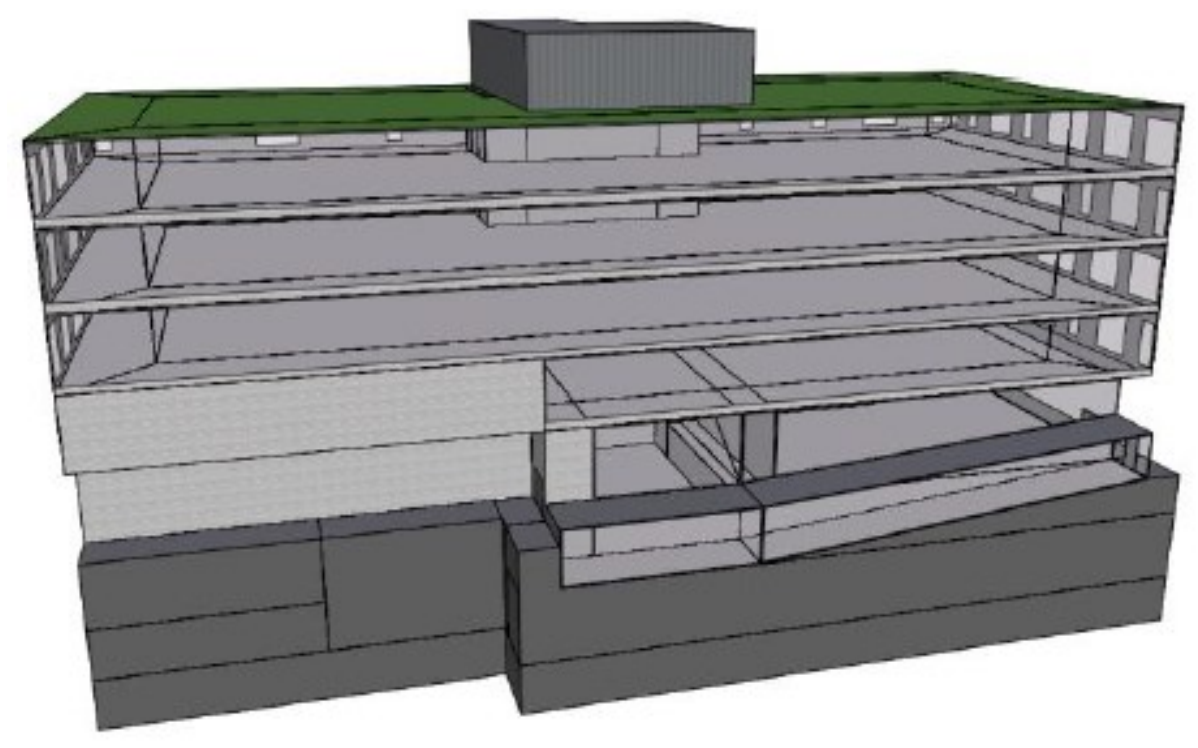

Figure 1.2: The case study energy model by the energy modeller.

The study objectives were pursued through the below listed steps:

(1) Explore and document the current occupant modelling practices and assumptions to obtain a better understanding of the needs, barriers, challenges, and possible improvements. For this purpose, a thorough literature review was conducted and reported in article 1 (Chapter 2). Then, a one-day stakeholders' workshop was organized to obtain designers' feedback on the status of occupant modelling. The workshop approach and outcomes were documented in article 2 (Chapter 3). Finally, semi-structured interviews with the case study design stakeholders were conducted. The outcomes of the interviews were documented in article 3 (Chapter 4). 
(2) Demonstrate the sensitivity of the building design and optimization process to occupant-related assumptions and modelling approaches. To this end, an energy model for the case study building was created and a parametric analysis was conducted under thirteen different occupant scenarios. The parametric analysis approach and outcomes are presented in detail in article 3 (Chapter 4).

(3) Demonstrate how occupant-related assumptions influence the outcomes of building design optimization. To this end, an occupant-centric design optimization method was developed and implemented using the case study model. The method included generating occupant scenarios, running the optimization process, and deriving design parameters selection rules. The findings are reported in article 4 (Chapter 5).

(4) Evaluate the impact of occupants' spatial distribution on energy and comfort performance. In account of this, a model for the case study with hard-sized HVAC equipment was used for the investigation. The energy and comfort performance of the model was tested under variable occupant distribution scenarios (ODSs) to simulate the inter-tenant diversity. Results were reported and submitted in article 5 (Chapter 6). 
CHAPTER 1

(5) Develop a practical improved occupant modelling method. A three-step method was developed upon the findings of the comprehensive investigations in previous chapters. The method is presented in article 6 (Chapter 7). 


\section{Background}

\section{This chapter has been published as:}

Abuimara T., O'Brien W., Gunay H.B., Burpee H., Day J. (2018). Designing for Occupants: A Review of the Integrated Design Practice. ACEEE Summer Study on Energy Efficiency in Buildings. August 12-17, 2018. Pacific Grove, CA, USA

\subsection{Abstract}

The uncertainty in occupant-related assumptions (i.e. occupant presence and behaviour) plays a major role in the building design process. However, research efforts, let alone practice, have yet to reach the required integration of occupants into the building design process. Occupant assumptions are critical for major design decisions such as HVAC sizing and envelope design (e.g. window type, shading type, and types of controls). Nonetheless, occupant assumptions used during simulationaided design are either typical values obtained from standards such as ASHRAE Standard 90.1 or modeller assumptions based on experience and with minimal customized feedback from the building owner. This paper aims to track occupantrelated assumptions and occupants' engagement and their implications on the building energy performance during the different phases of the integrated design process (IDP) for buildings. The main goal is to identify the current practice and its shortcomings and to discuss the opportunities to address them. Recommendations 
CHAPTER 2

for how to improve occupant modelling approaches within the different phases of the integrated design process are presented.

\subsection{Introduction}

Occupants play a major role in a building's life cycle. The primary objective of any building is to serve as shelter, a place to offer services, or a workplace for its users/occupants. Hence, building designs should suit and satisfy the needs of its occupants. Occupant needs can vary greatly from functional needs and safety to wellbeing and comfort.

The building design process has evolved over the last few decades to become more holistic and complex. This evolution has been primarily driven by the worldwide pursuit of environmental, social, economic and cultural sustainability. The term integrated design process (IDP) was introduced in the early 1990s to serve as an advanced approach to achieve sustainability in buildings (NRCan 2016). The IDP replaces and addresses the inefficiency of the conventional design process in designing sustainable buildings. The IDP encourages the involvement of all stakeholders during building design (Busby Perkins \& Will \& Stantec 2007). However, the representation of occupants and occupants' behaviour is still largely simplistic, and these importantly - arguably critical - factors are underweighted throughout the design process.. This under-representation is carried out through all design phases and 
causes a considerable degree of uncertainty that can result in forgoing profound opportunities to make better design decisions (Gunay et al. 2016c). Designers often assume that occupants behave in line with their design objectives, which is often not the case in real settings (Andrews et al. 2011). Consequently, on the one hand, occupants' comfort and productivity can be compromised, and on the other hand, energy efficiency targets are frequently not met.

Design decisions and energy conservation measures (ECMs) can be sensitive to occupant assumptions (Abuimara et al. 2018c). Occupant-dependent design decisions can vary from a very basic early design decisions to more advanced decisions. Hence, occupant-dependent design decisions can have a long-term impact, and these decisions are mostly irreversible (Zhuang et al. 2016).

Occupant assumptions for building design are mostly obtained from either default values specified in building codes and standards such as ASHRAE Standard 90.1 or based on the building designers' experience. Occupant-related assumptions can take different forms during the design process. They can be in the form of people density per floor area (person $/ \mathrm{m}^{2}$ ) (Government of Ontario 2018), number of people per building or static schedules for presence and operations for energy modelling purpose, as shown in Table 2.1. These standardized assumptions are generally approximate and outdated; thus, do not necessarily represent the actual impact on building 
CHAPTER 2

performance and energy efficiency. This approach of representing occupants

disregards the fact that every building is unique in its composition, context and

operation. In addition, it neglects the diverse and stochastic nature of occupants and

their actions (Gaetani et al. 2016b).

Table 2.1: Uses of occupant assumption by the different design team members.

\begin{tabular}{|c|c|c|}
\hline $\begin{array}{l}\text { Design team } \\
\text { member }\end{array}$ & Purpose & $\begin{array}{l}\text { Example occupant-related } \\
\text { metrics }\end{array}$ \\
\hline Architect & $\begin{array}{l}\text { Building size;program; type of space (open } \\
\text { spaces, cubicle);orientation, form, WWR; } \\
\text { egress; daylighting and lighting; shading; } \\
\text { accessible facilities; scheduling; controls, } \\
\text { finishing (hospitals, schools); handicap } \\
\text { access (barrier-free access) }\end{array}$ & $\begin{array}{l}\text { Number of people per } \mathrm{m}^{2} \text {; type of } \\
\text { occupants }\end{array}$ \\
\hline $\begin{array}{l}\text { Interior } \\
\text { designer }\end{array}$ & $\begin{array}{l}\text { Interior shading design, daylighting and } \\
\text { lighting design; acoustics, colour, } \\
\text { furnishings; egress; accessibility and } \\
\text { building code compliance; controls, } \\
\text { scheduling; occupant safety; material } \\
\text { selection }\end{array}$ & $\begin{array}{l}\text { Number of people, type of people } \\
\text { (e.g. student, doctor, teacher); } \\
\text { hours of operation }\end{array}$ \\
\hline $\begin{array}{l}\text { Landscape } \\
\text { architect }\end{array}$ & $\begin{array}{l}\text { Parking lots; sidewalks; outdoor activity } \\
\text { areas; exterior lighting }\end{array}$ & Number of people \\
\hline $\begin{array}{l}\text { Structural } \\
\text { engineer }\end{array}$ & $\begin{array}{l}\text { Live load; type of activity (impact resistant } \\
\text { structures) }\end{array}$ & Number of people. \\
\hline $\begin{array}{l}\text { Mechanical \& } \\
\text { HVAC } \\
\text { engineers }\end{array}$ & $\begin{array}{l}\text { Equipment sizing (boilers, chillers, fans, } \\
\text { pumps; cooling towers); domestic water } \\
\text { tanks sizing (hot and cold); number of } \\
\text { elevators; emergency exits, number of fire } \\
\text { alarms; controls, scheduling }\end{array}$ & $\begin{array}{l}\text { Occupancy schedules, } \\
\text { plug loads schedules and power } \\
\text { densities, } \\
\text { lighting schedules and power } \\
\text { densities; number of people }\end{array}$ \\
\hline $\begin{array}{l}\text { Electrical and } \\
\text { IT engineers }\end{array}$ & $\begin{array}{l}\text { Plug-in loads; lights and lighting loads, } \\
\text { transformers; electric panels and meters; } \\
\text { lighting control; controls; power metering }\end{array}$ & $\begin{array}{l}\text { Number of people, hours of } \\
\text { operation, types of equipment. }\end{array}$ \\
\hline
\end{tabular}


CHAPTER 2

Researchers have been developing better ways to understand, represent, and model occupant assumptions during the building design process. Andrews (2011) established a framework for designing buildings for occupants and came to the conclusion that the more detailed data are used during design, the better design results we will get. This highlights the importance of higher accuracy of occupant assumptions when designing a building. Bennet and O'Brien (2017) conducted a field study on plug-in equipment and lighting loads in two commercial buildings in Ottawa, Canada. The study revealed that the actual energy use patterns and magnitudes were significantly different from the default assumptions often used when designing buildings. This raises concerns about whether the appropriate decisions were made during the building design process.

The current study aims at tracking the way occupant assumptions are used and how the occupants are engaged throughout the design process. It also presents the potential implications of these assumptions and engagement on the different building design phases. In addition, it identifies the potential benefits of improving the resolution of occupant assumptions to be more accurate and case-specific. The intention is not to present or criticize the IDP, but to demonstrate the form and the impact of occupant assumptions throughout the IDP and to introduce potential 
CHAPTER 2

improvements to the current approach and the possible implications of these improvements.

\subsection{Approach}

The paper is organized to start with defining the current building design approaches including the conventional process and the IDP followed by presenting the current design approaches qualities and objectives. Then, the role of occupant assumptions and the level of occupants' engagement in the different phases of the IDP including post occupancy and retrofitting options are discussed.

\subsubsection{Building design process}

There has been growing attention to the implications of occupant assumptions on building design and performance within the research community. Nevertheless, there is a lack of research that investigates the implications of occupant assumptions and occupants' engagement throughout the IDP. Consider Figure 2.1, which shows a major surge of papers related to occupant modelling in the past decade, but a decline in IDP-related papers in the past five years. The material included in the search is comprised of scholarly literature, building codes and standards and a number of industry publications such as magazine articles and technical reports. The material was compiled, organized and analysed to only use the topic-relevant data. 
CHAPTER 2

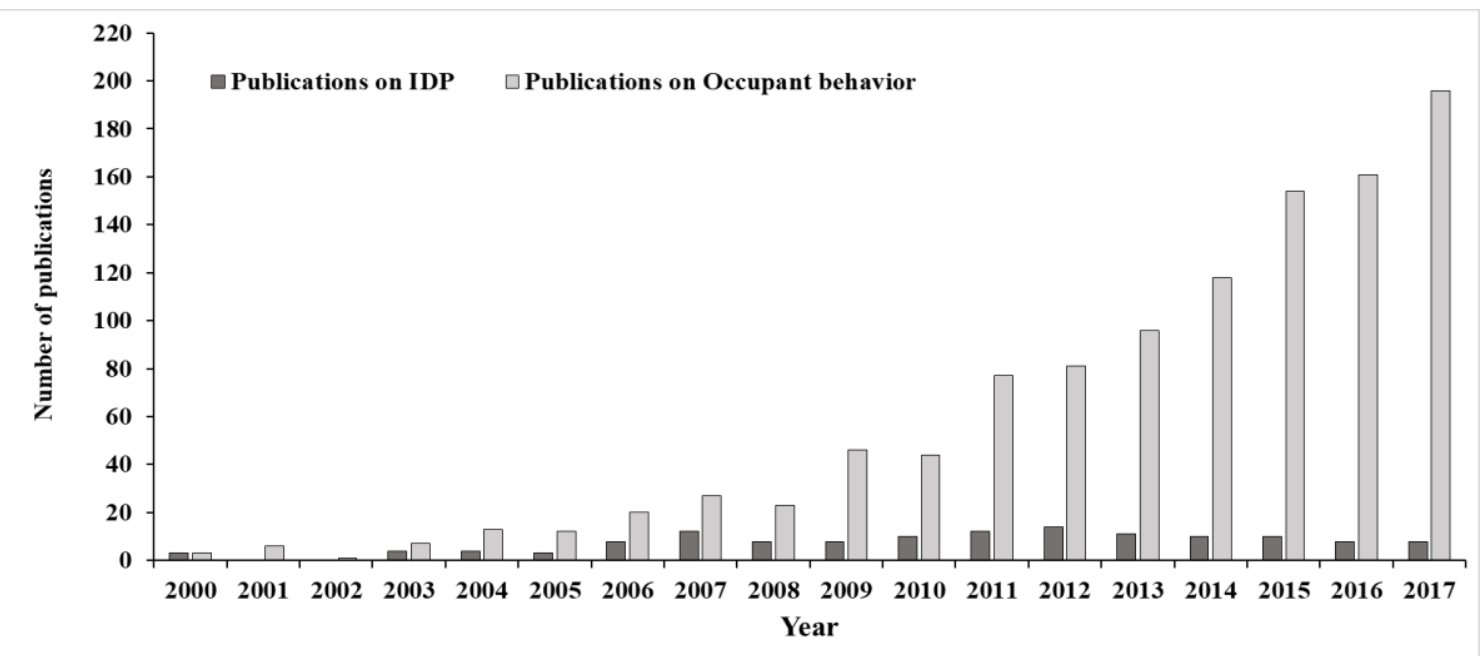

Figure 2.1: Scholarly published work on IDP vs occupant behaviour (2000-2017). Search keywords were: "integrated design process" AND building OR" IDP" AND building, "occupant modelling" OR "occupant modeling" OR "occupant behaviour" OR "occupant behavior"

To better understand the IDP, the conventional design approach needs to be outlined

first. The conventional design process is primarily characterized as a linear process

for which tasks take place mostly in one direction. The process starts with the client/owner hiring the architect to perform the architectural design. The architect launches his work with design concept including massing, orientation, and fenestration placement (Pearl 2004). Then, engineers are asked to perform their calculations and apply their systems (e.g., structural system, HVAC, etc.)(Busby Perkins \& Will \& Stantec 2007). The nature of the conventional design process can result in high building operation costs and occupants' discomfort (Pearl 2004). The incurred high operation costs are because of the loss of the potential saving opportunities in the early design phases where decisions for the main components of 
CHAPTER 2

the buildings are made based on conservative occupant assumptions resulting from uncertainty and risk aversion. This can affect major building components such as the sizing of the HVAC and the sizing of the building itself.

\subsubsection{The integrated design process (IDP)}

The IDP was introduced first in the 1990s, though it does not have a standardized definition (Zimmerman 2006). In North America, the IDP stands for an interdisciplinary collaboration that takes place throughout the design process but could extend to cover the construction and operation of a given project (CEC 2015). Generally, IDP is a holistic approach for designing a sustainable building with different designers' perspectives and expertise. However, designers have an agreement on IDP features that are listed below as per Zimmerman (2006):

(1) Goal-driven: the IDP should have a well-defined design goal agreed upon by the entire team.

(2) Inclusive: all stakeholders should participate in decision making. This ideally means including building occupants or their representatives and/or operators; however, in reality, this does not happen often.

(3) Collaborative: the design is a result of the collaboration of team members. 
(4) Facilitated: the process is led by a facilitator who is chosen by the design team to coordinate between disciplines and mediate team meetings and design charrettes.

(5) Structured: the process should allow for structured decision-making processes in order, and to avoid irreversible decisions.

(6) Iterative: it allows refining and enhancing decisions when additional data are acquired. Hence, the design process is conducted in loops as shown in Figure
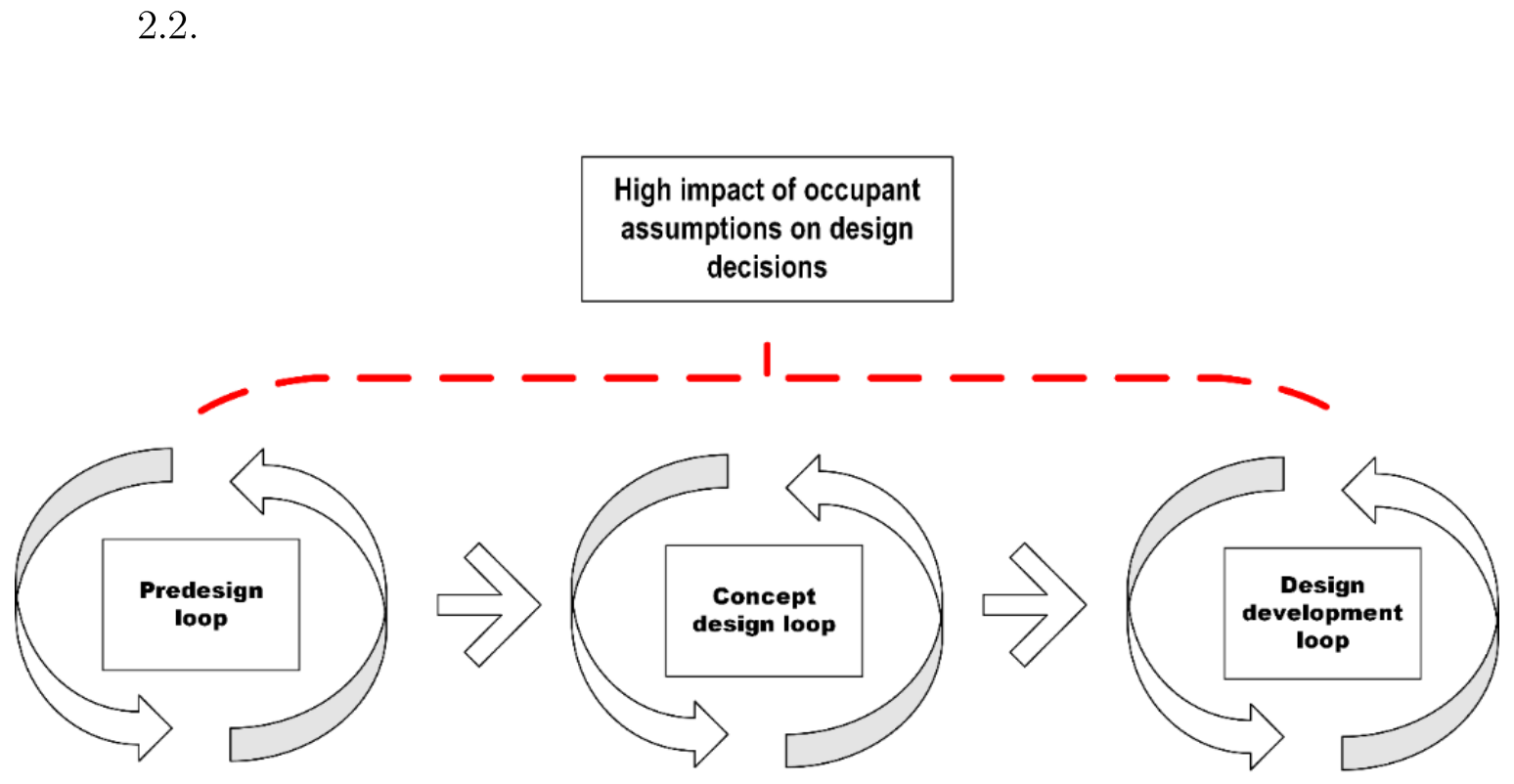

Figure 2.2: Impact of occupant assumptions on the design process (IDP)

(7) Clear decision-making: the methodology of making decisions is clear and reasonable.

(8) Holistic thinking: the team should think of the whole project's impacts when making decisions about individual design components. 
(9) Whole building budget setting: the design team sets up a budget that considers all building aspects and allows for trade-offs.

(10) Non-traditional expertise: non-traditional experts are invited, if needed, to join the design team and enrich the process.

\subsubsection{Setting design objectives}

Setting clear design objectives and maintaining them throughout the process is the first step in a successful design process (Hayter et al. 2000). The design objectives should be as comprehensive as possible in a way that covers all stakeholders' needs and preferences.

The traditional approach of building design is to design buildings that satisfy the following qualities: (1) fit-for-function, (2) aesthetics, (3) safety/security, (4) accessibility, (5) cost-effectiveness (6) historic preservation, and, (7) sustainablity (WBDG 2018). These qualities are of different degrees of importance; however, they do not include the interaction between the building systems and the building occupants and the implications on occupants' comfort.

\subsection{Occupant assumptions during the pre-design phase}

Decisions at this stage are crucial as they provide the opportunity of substantial initial and operation cost savings (Attia et al. 2012a). At this phase, the project 
CHAPTER 2

design team is formed, the project objectives are set, and the plan for the design, construction, and turn over are initiated. The project team should consist of the architect, the client, the engineers and the energy modeller.

At this phase, high-level design decisions are made. These decisions include setting up a project budget, the project timeline, type, function and program of the intended building, the required size of the building and the location and relationship to the surroundings(NRCan 2016).

During the pre-design phase, the project budget, the intended function and the timeline are the main issues that are usually tabled at this phase. Nature and the number of occupants (e.g. students, workers, administrative staff) are often discussed at this design phase. However, accurate occupant-related assumptions are often absent from decision making and occupants are not usually engaged in decision making during this phase.

However, early informed decisions can make significant saving and changes to design strategies. For example, O'Brien et al. (2017) demonstrated that simultaneous peak occupancy occurrence is much lower than the assumed full occupancy which offers an opportunity for hoteling-style space management. Based on such research 
CHAPTER 2

findings, designers, if well-informed about occupants, can make crucial decisions regarding building size during the pre-design phase.

The same concept can be applied to the building surrounding landscape and services like parking lots. Using accurate occupant assumptions helps designers make better decisions regarding the number of required parking spaces and bike racks, which are often dependent on the intended occupancy of the building and the building floor area (Government of Ontario 2018).

\subsection{Occupant assumptions in the design concept phase}

During this design phase, designers produce a conceptual design that meets the general client requirements. The design includes the building form, orientation and basic organization of spaces. A simplified version of building systems design might also be prepared. Having more than one architectural design alternative is also a common practice. A basic energy model is usually prepared at this design phase to assist in making decisions about the proposed design. This early-stage energy model is normally basic and is usually a box with the same building size and volume, with simple zoning and the windows are distributed equally on facades. This base model is prepared to at least meet the code requirements and is intended to identify the energy-saving opportunities (Hayter et al. 2000). Parametric analysis can be also 
CHAPTER 2

performed to determine the most influential ECMs in terms of energy-saving and cost-effectiveness.

Occupant assumptions at this phase are basic and are often in the form of the number of people, the default operation schedules in addition to the typical values of lighting power density (LPD) and equipment power density (O'Brien et al. 2015). These simplified assumptions enable designers to produce their first energy model but can lead designers to inappropriate design decisions. These decisions can influence building energy use and occupants comfort (Gilani et al. 2016).

Comfort should be the core focus of the design team as it enhances the satisfaction and productivity of occupants (Levin 2003). However, achieving comfort is a challenging task for designers and requires adequate knowledge of building occupants, their preferences, and their activities in addition to detailed information about building envelope and building systems.

Occupant-related decisions at the conceptual design phase can be crucial in determining occupant comfort and well-being. For instance, a design team will need to make decisions about the level of control occupants have on building components and systems such as windows (fixed vs operable), shading (exterior/interior, fixed/operable, manual/automated), lighting controls and HVAC controls. These 
decisions are anticipated to influence the building envelope design, orientation and zoning of the building. A common design practice is to keep building systems and components out of occupants' control due to a lack of trust in occupants' behaviour as designers and owners assume that the higher the level of control given to occupants, the more energy consumption will be (Leaman \& Bordass 1999).

To achieve better occupant comfort, the resolution of occupant modelling at this phase needs to be increased. For example, the impact of highly glazed facades on operative temperature throughout a building can be assessed by using simple tools such as ASHRAE's Comfort Tool. Data for detailed modelling can be obtained through different ways including having the occupants' representatives on board and surveying their needs through a structured questionnaire that covers all the aspects required for modelling. In addition, seeking data from similar buildings in operation can be used at this design phase as well.

\subsection{Occupant assumptions in the design development phase}

The design development phase comes after the schematic design has been finalized, selected and approved by the client. In this phase, the design of the different building systems and components is performed in detail, including the selection of material and construction assemblies. In addition, the architectural, mechanical and electrical 
CHAPTER 2

systems performance and feasibility are assessed. Furthermore, building controls are established at this phase (e.g. lighting controls, air and temperature controls).

Detailed energy modelling is performed at this stage, and the thermal, daylight and acoustic performance of the design should be assessed (O'Brien et al. 2015). Design optimization is carried out at this stage identifying the most efficient design scenario to proceed with. The optimization process usually tackles both envelope components and HVAC. Designers can consider trade-offs between design decisions, such as compensating a poor performance of a given system by increasing the efficiency of another one. For instance, increasing the efficiency of HVAC to compensate for any incurred discomfort from oversized windows. Interior design should be developed during this phase from concept to detailed design in parallel to material selection and the building performance simulation.

Occupant assumptions in this design phase play a major role in performing the building performance simulations. Inputs of the number of people, types of expected activities, presence schedules, clothing insulation levels and operation schedules are required to perform the energy and daylight modelling. These data are required to determine the internal heat gain, the lighting loads, the plug-in loads, heating loads, cooling loads and to size HVAC equipment accordingly. 
CHAPTER 2

Currently, designers mostly use static, fixed schedules and power densities stated in ASHRAE Standard 90.1 or any corresponding local energy standard (Hoes et al. 2009). These schedules were produced nearly three decades ago, based on limited, outdated data, and mostly code's committees' discretions. The schedules assume that buildings are occupied during the working/operating hours and do not consider any differences between buildings, staffing variations, or business cultures. In addition, occupants are considered passive agents that emit about 100 Watts each and do not interact with building components (ASHRAE 2013). This modelling approach can be highly influential in building construction and operation costs. For instance, conservative assumptions made by HVAC designers tend to oversize the HVAC equipment to avoid the risk of under-sizing the HVAC equipment (Djunaedy et al. 2011). This imposes an increase on the building capital cost and on operation costs as well.

On another front, an accurate representation of the occupant-related assumption at this design phase would help the design team select the appropriate indoor climate control technologies based on the control strategies developed in earlier design phases. The selection of a fit-for-purpose control technology would help achieve both building energy efficiency and occupants' comfort. For example, Gilani \& O'Brien (2017) conducted a study to assess the impact of different lighting control systems 
CHAPTER 2

on lighting electricity use in office spaces. The results revealed a reduction of $91 \%$ in the annual lighting loads by using manual on and vacancy off lighting control system.

These results encourage designers to look for innovative control strategies that can satisfy the occupant need to have control over their space components and, at the same time, mitigates or eliminates the unintentional wasteful behaviours. Yet, such considerations tend to receive relatively little attention in the design process relative to attention on architecture and equipment.

On a different front, interior design should integrate with the energy and daylight modelling process in order to achieve efficiency besides aesthetics (Athienitis \& O'Brien 2015). Informed interior design can help achieve the design objectives of energy efficiency and occupant comfort.

\subsection{Occupant assumptions in construction documents/detailing phase}

After the developed design is agreed on by the design team and approved by the building owner, the design team moves forward and proceeds with the construction detailing and documentation. This phase includes producing detailed architectural, structural, mechanical and electrical drawings. In addition, the project specification and bills of quantities are also prepared at this phase. On the other hand, tender 
CHAPTER 2

documents, contracts and commissioning plans are prepared during this design phase.

A crucial task at this design phase is coordinating the design documents and drawings to avoid any possible clashes of services or any discrepancies in the design (Busby Perkins \& Will \& Stantec 2007). During the coordination, changes are common to address discrepancies and clashes. The design team often proceed with these changes if it seems technically sound. However, these changes might compromise the occupants' comfort.

Therefore, careful consideration of occupants should always be given when applying any design change. Field studies have proven that occupants can make comfortdriven actions that might compromise the building energy performance (Day \& O'Brien 2017). Hence, consultation with the project stakeholders including occupants' representatives, operators and the client is highly recommended.

\subsection{The role of occupant in construction phase}

The construction phase begins once the construction documentation and detailing are finalized and the project is assigned to a contractor or a builder. This phase is critical since all the on-paper designs are applied to real settings and the cost of reversing any action during construction is significant. During this phase, the contractor and the specialized subcontractors start working on producing detailed shop drawings for every component in collaboration with specialized equipment 
CHAPTER 2

manufacturers and installers (e.g. HVAC contractor and supplier, elevator manufacturer and installers). Testing and commissioning of a building is the last step in the construction phase. This process is defined as checking whether the building is functioning the way it was designed and involves holistic testing of all the systems and components (Mills 2009).

Design changes requested by clients or authorities are very common at this phase. The changes can occur for several reasons, such as changes to local bylaws, additions or deletions requested by clients, material availability or cost. Hence, building performance should be re-evaluated using the appropriate modelling tool to quantify the positive and negative impacts of these changes on the overall performance including the possible implications on occupants. Therefore, it is very important that the design team make sure that those changes are done in a way that does not compromise the occupants' comfort or the efficiency of the building. Inviting occupant representatives and getting their feedback can benefit the construction process and the building operation. A possible scenario would be holding a meeting similar to design charrettes on-site and have all stakeholders on board.

Another important aspect during the construction phase is the quality assurance and quality control (QA/QC). The QA/QC during construction is important to occupants as it affects their use of the building and their comfort. For example, 
CHAPTER 2

improperly sealed windows will result in air infiltration, which compromises the occupants' thermal comfort and the infiltrated draft can cause noise, affect occupants' acoustic comfort and increase energy use.

\subsection{The role of occupant during the post construction phase}

Buildings are long-lasting engineered products that are dependent on costly resources (e.g. electricity and natural gas) to operate. Thus, the post-construction or postoccupancy phase is considered a crucial phase in the building life cycle cost. In this phase, if managed poorly, an efficient building can quickly become inefficient and wasteful of resources.

At this building phase, occupants are the major players in determining the building performance. They use the building on a daily basis, interact with building components such as lights, plug-in equipment, thermostats, windows, shading devices and probably room-level heating and cooling equipment. Thus, educating building occupants and operators regarding the intent and proper operation of the building systems at the beginning of this phase is of great importance.

Furthermore, establishing criteria for occupant feedback can help address future issues in a building through maintenance and operation practices. Lessons learned from occupants' feedback can be beneficial in two different ways; firstly, by leading 
CHAPTER 2

to improvements in a building's operation and secondly, by informing the design of buildings (Leaman \& Bordass 1999). Another benefit of collecting occupant feedback is that it helps inform the building retrofits in the future. This feedback plays a major role in retrofitting decisions (Yan et al. 2015). The retrofit process needs to be an integrated process as well as it should take a holistic approach instead of the traditional single system replacement approach (Billhymer \& Riz 2015). Occupants needs and complains should be the major driver for the planned retrofit.

\subsection{Discussion, recommendations, limitations and conclusion}

This study tracked the current and the potential level of resolution of occupant assumptions during the IDP process. The study presented the features, and the characteristics of the IDP and the role occupants play during the different design and post-design phases.

The nature and the features of IDP make it a great approach to build upon in improving the level of occupant engagement in the design process and the resolution of occupant assumptions used in producing the design. The IDP originally tended to be an inclusive approach that engaged all stakeholders in the design process including occupants. However, in reality this may not happen often for various reasons. For example, practitioners tend to do what is required by codes and standards, which currently do not require high-resolution occupancy data. Another reason could be 
that occupants might be unknown at the time of design and owners may not have a comprehensive perspective of the occupancy pattern and occupant behaviour. Another reason is that the design team does not put enough effort into approaching owners or occupants with appropriate questions about occupant assumptions and choose to use default values to perform the design. An approach designer can use, but they often do not, is to look for similar buildings in operation and use their occupancy data to inform the design. This approach will help base any design decision on realistic occupancy data, though every building is a unique case.

Indoor environmental quality (IEQ) should be the core focus of the design team in making design decisions. On the other hand, since IEQ has several aspects (i.e. indoor air quality, thermal comfort, visual comfort and acoustics comfort) and it differs from one person to another, occupants should be consulted to get their feedback on their needs and preferences. Another approach for achieving comfort can be providing more adaptive opportunities in the design by allowing occupants to have a higher degree of control of their space (Brager \& Arens 2015).

On another front, designers should be driven by the fact that occupants can be the key to the success or the failure of their design. Inaccurate occupant assumptions can lead to suboptimal designs and operation. In addition, unexpected energy- 
intensive behaviour greatly diminishes the performance of a building that is designed to be high- efficiency.

Based on the outcomes of this paper, following recommendations were developed to improve energy efficiency and occupant comfort:

(1) Engage occupants or their representatives in all design phases. The earlier the engagement is, the higher the potential of achieving an efficient and comfortable building.

(2) If occupants are unknown, designers should look for similar buildings in operation and seek their occupants' feedback. In addition, modellers can perform sensitivity analyses with the models to ensure that the designs are robust against different occupancy scenarios.

(3) Ensure that sufficient sensing and metering infrastructure is installed to draw quantitative, action-oriented information about occupants.

(4) Clients and building owners are a great source of information in establishing occupant specifications or guidance for assumptions if designers ask the right detailed questions.

(5) Building operators and operators log of complaints are also a useful source of information (Gunay et al. 2018). Operators can help inform the design team about occupants' complaints and the common faults they encounter on a daily 
bases. Complaint logs can help quantify the number and the nature of occupant complaints.

(6) Considering occupants is a necessary component in making any design changes or modifications that happen during construction detailing or execution. Some changes can trigger comfort-driven action and compromise the building performance.

(7) On-site meetings with occupants or their representatives help occupants visualize the building and address the potential concerns.

This study is limited to providing an overview of the occupant-related assumptions and occupants' engagement in the IDP process and the potential ways of improvements. However, more concrete evidence that this study recommendations would result in substantially better buildings is needed. Therefore, testing the recommendation on a case study to quantify the energy and cost implications of the improved occupant-related assumptions is needed. In addition, future research should focus on developing metrics that can better quantify the implications of occupants during the design process to enable practitioners to make appropriate design decisions.

This study points out the need to incorporate the research-proven implication of accurate occupant modelling in codes, standards and building regulatory bodies by 
CHAPTER 2

broadening the requirements of occupant modelling in building design practice. On another front, similar recommendations should also be made to BPS tool developers, which should lead to the improvement of tools capabilities and resilience to accommodate detailed modelling of occupants easily. 


\section{The status of occupant modelling}

\section{This chapter has been published as:}

Abuimara, T., O'Brien, W., Gunay, H.B., Abdelalim, A., Ouf, M. and Gilani, S., 2018, May. Modelling Occupants in Buildings: Stakeholders' Workshop on Current Barriers, Challenges and Needs. In Proceedings of eSim Conference, Montreal, QC.

\subsection{Abstract}

This paper documents the findings of a workshop on occupant modelling in building performance simulation (BPS)-based design practice. Upon discussions with expert BPS users, researchers, and software developers in Canada, the current state and future needs of occupant modelling for BPS-based design were identified. These discussions identified the need for improving the occupancy, lighting, and plug load schedules and intensities in design codes and standards. It was reported that the capabilities of the BPS tools should be tailored for the needs of state-of-the-art occupant modelling. In addition, the need for training opportunities to raise awareness about the importance of occupant modelling in the BPS-based design practice was noted.

\subsection{Introduction}

Currently occupant behaviour is recognized as one of the most important sources of uncertainty during simulation-based building design process (Hoes et al. 2009; Yan 
et al. 2015). It is considered as one of the main reasons for the gap between the simulated and measured performance (Gunay et al. 2013). However, occupant behaviour modelling in simulation-based design practice has not been evolving at the same pace it has in research (O'Brien et al. 2016).

Presently, occupant behaviour is represented in building simulation in terms of simple static temporal schedules that do not account for the dynamic nature of occupants (Sun \& Hong 2017b). For instance, the schedules indicate the fraction of the building occupancy present and the fraction of electric lighting that is on. The schedules are often considered ineffective as they fail to account for the behavioural differences expected in different building design alternatives. For example, changes in the window to wall ratio are expected to affect the way occupants use their shades and lighting (Gilani et al. 2016), but the schedules do not account for the impact of design on the occupants' behaviour.

Designers and modellers often assume that occupants will behave in favour of the design objectives, while reality indicates a different situation (Andrews et al. 2011; O'Brien \& Gunay 2015). For instance, designers and modellers may assume when selecting operable windows that occupants are going to open them for favourable natural ventilation when the outdoor temperature allows and close them otherwise. However, what happens, in reality, is that some occupants either leave windows 
closed or opened for a long time. These simplifications in modelling (i.e. using static schedules) would lead to an inaccurate representation of occupants in simulationbased design. Contrary to these common simplifying assumptions, it is generally accepted that occupants' behaviours are random and diverse and can be modelled stochastically (Lee et al. 2014). The accuracy in modelling occupancy and occupants' behaviour is essential to achieve more reliable simulation predictions and to appropriately select from available design options (Gilani et al. 2016).

Therefore, occupant modelling has gained considerable attention over the past two decades. Researchers have been working on developing better ways to represent occupants in simulation-aided design. Occupant modelling has been studied through numerous research projects (e.g., IEA EBC Annex 66, ASHRAE Task Group OBB), and the findings have been documented in more than three-hundred articles according to a recent survey of the literature (Gaetani et al. 2016b).

As a part of these efforts, researchers have developed statistical models that predict occupants' interactions with various building components - e.g., electric lighting, operable windows, thermostats, window shades. Often, these models have been built upon longitudinal data gathered from shared or private office spaces and homes using various sensing technologies such as PIR detectors, photo-sensors and contact sensors (Gilani \& O'Brien 2016). Nevertheless, occupant modelling research has generally 
not been transferred to the BPS-aided design practice (e.g., for code compliance and design).

In an effort to bridge the gap between research and practice with regards to occupant modelling, a stakeholders' workshop was organized at Carleton University in Ottawa, Canada. Twenty-five experts with diverse backgrounds attended the workshop, see Figure 3.1. The participants were expert BPS users, researchers, software developers, architects, and educators. It should be noted that the perspective expressed by the authors of this paper do not necessarily reflect those of workshop participants.

The objectives of the workshop were to better understand the status of occupant modelling in the BPS community and to put forward a roadmap for future work in occupant modelling research, development, and education.

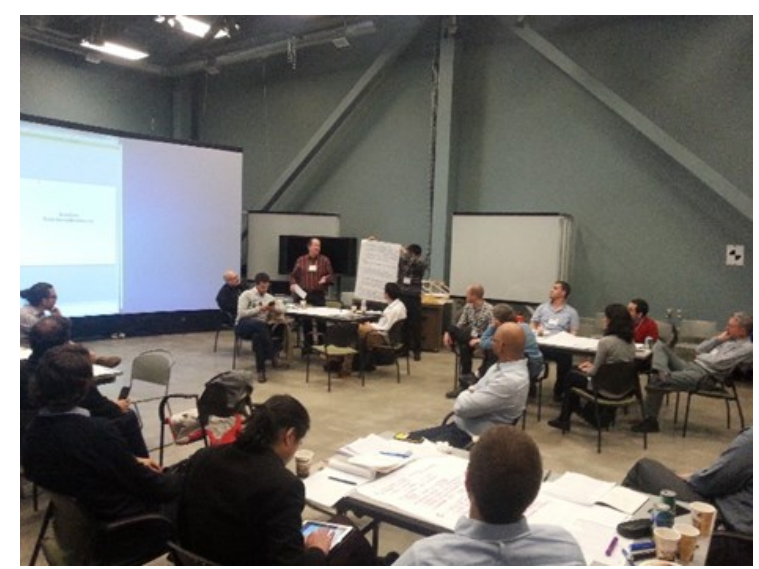

Figure 3.1: Stakeholders workshop, Ottawa May 1st, 2017

The workshop was organized to be the first step in a large two-year research project aiming at: (1) establishing and documenting a ten-year plan showing to what extent 
can occupant modelling penetrate in the BPS community and building codes, (2) identifying the gaps in the BPS users' knowledge and the barriers against achieving this goal, (3) establishing and documenting, detailed incremental targets to achieve the end goal, and (4) identifying the most critical gaps, barriers and milestones to achieve these goals. The project is led by Carleton University researchers in collaboration with RWDI, Autodesk, Natural Resources Canada, and the National Research Council.

This paper starts by describing the structure and methodology of the workshop. Then, a summary of the workshop results and findings are presented. The current practice in simulation-aided design regarding occupant modelling is identified, followed by stating the occupant modelling status in building codes and design standards. The capabilities and features of BPS tools related to occupant presence and behaviour are discussed, and recommendations for future work and research are developed.

\subsection{Methodology}

To achieve the workshop objectives, experts in the field of BPS and tangential fields were selected and invited to share their experience and vision to accomplish progress in occupant modelling. Stakeholders with many years of experience in building design, modelling, and building codes were invited to participate. The workshop was 
organized into three breakout sessions. Each session started with a presentation and ended with an open discussion. The presentations provided an overview of the stateof-the-art in occupant modelling research, BPS tools features and capabilities and simulation-aided design processes and performance uncertainty. The breakout sessions were structured to cover three primary areas related to modelling occupants in buildings: (1) identifying the current practice and challenges in modelling occupants in the building design, (2) occupant modelling in building codes/standards, and (3) BPS tools capabilities and limitations. Each breakout session consisted of four groups of approximately five participants and a facilitator (i.e. a Carleton University researcher). Participants, through discussions and brainstorming, tried to find answers to the questions, as shown in Table 3.1. To summarize the workshop outcomes, participants' feedback was categorized under four main topics, as shown in Table 3.1. Different opinions were qualitatively presented and compared to each other in the context of the workshop.

Table 3.1: Stakeholders workshop discussion structure

\begin{tabular}{|l|l|}
\hline TOPIC & BRAINSTORMING QUESTIONS \\
\hline $\begin{array}{l}\text { State-of-the-art in } \\
\text { occupant modelling } \\
\text { research }\end{array}$ & $\begin{array}{l}\text { I. } \begin{array}{l}\text { In brief, how does occupant modelling affect the various } \\
\text { professions (architects, engineering consultants, } \\
\text { modellers, code officials, code developers)? }\end{array} \\
\text { 2. On the scale of purely academic to mainstream practice, } \\
\text { where are we at on occupant modelling and where should } \\
\text { we be now? }\end{array}$ \\
\hline
\end{tabular}




\begin{tabular}{|c|c|}
\hline & $\begin{array}{l}\text { 3. What are the current gaps and barriers (practical, } \\
\text { theoretical, political) to incorporating occupant } \\
\text { modelling into building code and design practice? } \\
\text { 4. What should we set as short term ( } 3 \text { year) and long-term } \\
\text { (10 year) goals regarding occupant modelling and } \\
\text { simulation in practice? } \\
\text { 5. What are the priorities on this theme regarding research, } \\
\text { building code, and simulation tools? }\end{array}$ \\
\hline $\begin{array}{l}\text { Canadian building energy } \\
\text { codes and standards }\end{array}$ & $\begin{array}{l}\text { 1. What are current obstacles and solutions to } \\
\text { incorporating occupant modelling into code and } \\
\text { standards? } \\
\text { 2. How would we/could we model uncertainty in the } \\
\text { context of code? } \\
\text { 3. What is the appetite for occupant modelling from code } \\
\text { officials, modellers, and clients? } \\
\text { 4. How should we go about advancing the state of specific } \\
\text { occupant-related schedules and densities? }\end{array}$ \\
\hline $\begin{array}{l}\text { Building performance } \\
\text { simulation (BPS) tools } \\
\text { features and capabilities }\end{array}$ & $\begin{array}{l}\text { 1. What modelling tool features are required for or would } \\
\text { encourage better occupant modelling? } \\
\text { 2. Are we doing an adequate job of modelling occupant } \\
\text { comfort? } \\
\text { 3. How should we go about addressing uncertainty (e.g., } \\
\text { Monte Carlo simulation with hundreds of runs, a few } \\
\text { extreme cases, etc.)? } \\
\text { 4. How should we manage risk/uncertainty for buildings } \\
\text { with absolute performance targets (e.g., net-zero } \\
\text { energy)? } \\
\text { 5. Is the stakeholder community (especially architects and } \\
\text { building owners) prepared for full declaration of } \\
\text { uncertainty? }\end{array}$ \\
\hline $\begin{array}{l}\text { Simulation-aided design } \\
\text { processes and performance } \\
\text { uncertainty }\end{array}$ & $\begin{array}{l}\text { 1. What role does occupant modelling have in building } \\
\text { design (and retrofit analysis)? } \\
\text { 2. What role could/should occupant modelling have in } \\
\text { building design (and retrofit analysis)? } \\
\text { 3. Should occupant modelling approaches vary by scale } \\
\text { (e.g., room vs. building vs. community) and purpose } \\
\text { (e.g., code compliance vs. design support)? } \\
\text { 4. How can we exploit uncertainty of occupants? } \\
\text { 5. How should we deal with the risk of inappropriate } \\
\text { occupant assumptions? }\end{array}$ \\
\hline
\end{tabular}


CHAPTER 3

\subsection{The workshop outcomes}

The workshop results indicated the need for more research and development in two major areas. Of them, one is to prove the sensitivity of simulation predictions and design decisions to occupant modelling. The other is to improve the current modelling approach by updating codes and standards, developing BPS tools, educating designers and increasing the building owners', operators' and energy managers awareness.

The workshop participants indicated that the current occupant-related schedules are known to be inaccurate and needs to be improved. However, the absence of a more reliable alternative - with a substantial source of data- has prevented the adoption of improved occupant modelling methods. Moreover, the purpose behind the modelling or simulation process may not require a detailed representation of the occupants.

Currently, BPS tools are used for one of six purposes: code compliance (most cases), building certification (e.g. LEED), private-public partnership (P3) projects (PPP Canada 2017), HVAC design, building design (e.g. net-zero building) and measurement and verification $(\mathrm{M}+\mathrm{V})$ as shown in Figure 3.2. Modelling for code compliance or building certification generally does not require detailed occupant modelling, unless it is specifically asked for by the client. 
Besides, the scope of state-of-the-art occupant modelling needs to be expanded to cover different building types, sizes and functions.

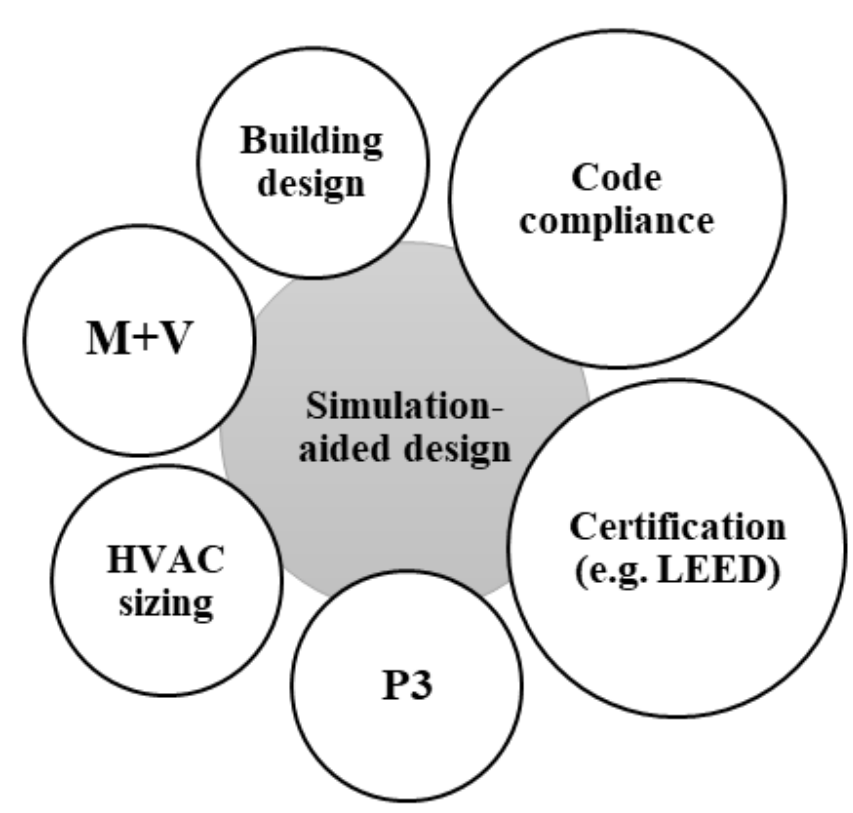

Figure 3.2: Current simulation-based design domain.

Then, improved occupant models and the corresponding functionality will have to be incorporated in the existing BPS tools. This will provide practitioners with readyto-use and more realistic approaches for modelling occupants.

Participants also emphasized the importance of increasing the awareness of BPS users on occupant modelling and its related features in the commonly used BPS tools. Also, they expressed the need to educate building owners, operators and energy managers on the role occupants play in determining the energy performance of a given building. 
The participants also proposed short-term and long-term goals to improve the current occupant modelling practice. Proving the sensitivity of simulation predictions and design decisions to changes in occupant modelling approaches was the first proposed short-term goal. The next step will be updating the current outdated schedules to a better-informed schedule to better represent occupancy and occupants' behaviour.

For long-term goals, the participants expressed the need to update the codes and standards regarding occupant modelling. Another long-term goal was to make the state-of-the-art occupant models available for practitioners by incorporating them in the BPS tools.

\subsubsection{Status of occupants' modelling in building design practice}

The status of occupant modelling in practice was the focus of the first session of the workshop. Some participants argued that occupant modelling might have an impact on their work depending on the purpose of the building performance simulation (BPS) and the goals of the modeller. For example, architects are generally concerned about occupant densities and egress. Engineers treat occupants as a source of internal heat gain which in turn affects the peak loads and HVAC sizing. 
CHAPTER 3

Attendees concurred that standard static schedules are found to be solely used to represent occupancy (i.e. presence) and occupancy related aspects (e.g. lights, plug loads, etc.). This means neglecting the fact that building design affects occupant behaviour. Some added that there is a slow movement towards a more detailed representation of occupants and occupant behaviour. This can be seen in some netzero building projects as occupancy needs to be represented accurately to achieve the performance targets. P3 projects also require detailed occupant models as the whole building life cycle is evaluated against the design objectives (PPP Canada 2017). On the other hand, participants agreed that the state-of-the-art occupant models are solely used in research and are not yet used in design practice. Some argued that these occupant models can not be generalized as they were developed for specific buildings and validated under certain conditions.

Some participants expressed their belief that the current practice ignores the diverse nature of occupants. However, they also do not have more accurate models to use since occupancy and occupant behaviour are dynamic and diverse, so it is not easy to quantify in many cases. This ambiguity allows designers' and modellers' assumptions to be unregulated and inconsistent. For instance, they may rely on their experience or use schedules from similar buildings or the default ones. Using occupant modelling assumptions that do not ultimately correspond with reality could lead to 
inappropriate design decisions. They also indicated that the clients are not aware of the uncertainty associated with occupancy related aspects and their impact on building performance. However, the majority of designers or energy modellers are not willing to jeopardize the trust of their clients by mentioning or emphasizing this uncertainty and its implications on the actual performance (O'Brien et al. 2016).

On another front, other workshop participants stated that engineers usually do not use the same building model developed for code compliance to design and size the HVAC. Instead, they conduct independent HVAC design calculations, and in case they do use BPS, they tend to use conservative assumptions to avoid the risk of under-sizing (Djunaedy et al. 2011).

It was also stated that modellers often have limited time and budget to perform the required simulation process. This time and budget limitation play a major role in determining the level of modellingdetails. In other words, building modellers will typically not spend additional time or effort on modelling unless it is required by code or paid by building owners.

Overall, the participants agreed that the current occupant modelling practice is not optimal and needs to be improved. The required improvement should include codes/standards and BPS tools as well. 


\subsubsection{Occupants' modelling in building codes and standards}

Building codes and standards concerning occupancy and occupants' behaviour were the second topic discussed in the workshop. Current building codes require the use of simple schedules with constant values based on designer's assumptions about occupants in both reference buildings and design alternatives. This approach might lead to inaccurate performance predictions and may negatively impact the design alternative selection. Hence, the existing codes and standards related to occupancy and occupants' behaviour need to be updated, given that practitioners are guided by these codes and standards.

Participants stated that the existing codes and standards do not offer alternative approaches for occupant modelling and do not have incentives to reward buildings on the accuracy and detailing of performance predictions. This means designers and modellers will carry on using the current approaches until more accurate approaches are introduced.

Furthermore, participants argued that current codes and standards include only schedules for presence, lights and electrical equipment, occupant densities, and power densities for lights and electrical equipment. This simple treatment is inadequate as it ignores the dynamic nature of occupants and their continuous pursuit for comfort (O'Brien \& Gunay 2015). Therefore, codes and standards should consider the 
CHAPTER 3

interactions between occupants and the building. For example, current codes and standards do not account for building occupants' interactions with thermostats, operable windows, window shades, etc.

One group of participants stated that any proposed changes to codes will be scrutinized if it is not supported with a concrete evidence. Another group in the room questioned whether modelling occupants in buildings is so important that codes and standards should require more detailed approaches.

The attendees agreed that to improve codes and standards related to occupant modelling, practitioners (e.g. designers and BPS users) need to be actively involved in code development committees to convey the actual market needs to the concerned authorities. This can happen through workshops, meetings and surveys to get the practitioners feedback that identifies the gaps that need to be addressed and the areas need to be covered in the codes and standards. Moreover, it was also stated that the updated schedules should be developed for a number of different building archetypes.

\subsubsection{BPS tools features and capabilities}

Most prevalent BPS tools include occupant modelling features with a varying level of freedom to represent occupants and occupants' behaviour. For instance, 
CHAPTER 3

EnergyPlus (DOE 2012) enables moderate level of modelling details about window operation, shading operation, clothing level and lighting use. However, without the guidance of standards, practitioners will have to either keep the tool defaults or make assumptions based on their experience. In order to deviate from defaults BPS users must have a rationale, as doing so is associated with some degree of perceived or real risk.

The attendees indicated that they are not utilizing all features of their selected BPS tool and sometimes they are not fully aware of these features. They also agreed that there are several features in BPS tools that enable users to perform a more detailed modelling of occupants and occupants' behaviour. This includes using data from clients or similar buildings in operation to create schedules for presence, lights, electrical equipment, shading, clothing, etc. Another approach would be performing a co-simulation by integrating more than one BPS tool to perform the simulation. This approach enables modeller benefit from a wide range of capabilities offered by different simulation tools. Users also can modify the BPS tool to accommodate the state-of-the-art occupant models. For example, EMS (energy management system) in EnergyPlus enables user to write custom scripts to incorporate new occupant models into the building energy model. However, using these capabilities requires additional skills, time, and budget which are not always available. On another front, 
CHAPTER 3

building owners are not prepared to shoulder extra costs that are required for further detailed building models. Therefore, practitioners are not assigning any additional time or effort for modelling occupants unless it is worthy in return.

Participants suggested that adequate efforts are not being done to model occupant comfort. Some argued that modelling indoor air quality had advanced to a decent level while modelling visual, acoustic and thermal comfort is still immature and need more effort and research to be incorporated in simulation tools. This emphasizes the aforementioned fact that occupants' behaviour is often driven by occupants' discomfort.

One more driver behind under utilizing the capabilities of the BPS tools is the BPS user. A substantial portion of the workshop participants learned to use tools they use by themselves or through a one to two-day workshops. This does not provide the necessary knowledge of the tool and its features and capabilities particularly with regards to more detailed aspects such as occupant behaviour. Therefore, in order to achieve the desired level of modelling skills, modellers need to receive a complete professional training on their selected tool. The training should be comprehensive and cover all features of the BPS tool. This will equip users with the necessary skills to utilize all useful features of a tool and detect faults. The training can be provided through the BPS tool developers, educational and professional institutions, or 
CHAPTER 3

organizations like International Building Performance Simulation Association (IBPSA).

Another proposal was tabled by some participants is to develop a tool that can generate custom schedules. The way this tool should work is the building owner will have to complete a survey about occupancy and operation aspects then this data will be used to generate custom schedule. This approach would require clients/owners that have better knowledge of their building function and are able to predict the occupancy pattern.

\subsubsection{Uncertainty in simulation-aided design}

The simulation-aided design process and the occupants' associated uncertainty were the next topic of discussion. Simulation- aided design is always associated with a certain magnitude of uncertainty. This uncertainty is dependant on several factors such as occupant behaviour, weather, tool algorithms, user errors and material properties.

According to the workshop participants, code compliance is the most popular reason for conducting building performance simulation. The focus of this type of simulation is proving that a given design alternative meets the energy consumption targets set by the code. In this kind of simulation, occupants are simply represented using the 
CHAPTER 3

static schedules and are considered sources of internal heat gain rather than active agents in the building. Some workshop participants mentioned that occupancy data is illegitimately manipulated by some modellers to achieve design goals.

In addition to code compliance, BPS is rarely used for HVAC design and sizing (Djunaedy et al. 2011). When used, HVAC designers use the peak values and add a high factor of safety and create their own model for sizing purpose. BPS is also used as well to model P3 project, measurement and verification $(\mathrm{M}+\mathrm{V})$ and net-zero projects where the whole life cycle of the building is considered and monitored.

It was also argued that the way occupants behave is largely influential in building energy use. Occupants, while seeking to achieve or recover their comfort, will interact with building components: opening windows, closing shades, changing thermostat setpoints, switching lights on/off, etc. These occupants' actions are often used to restore comfort but then left in the state for an extended period (O'Brien \& Gunay 2015). The occupant might open a window to ventilate the space and may leave it open for days or weeks or switch the lights on when daylight level is low and leave it on for a long time. These actions affect the building energy use significantly and are not considered by designers or energy modellers when using the traditional approaches of modelling occupants. Thus, the aforementioned stochastic and diverse 
nature of occupants is challenging for designers and modellers as they have to deal with this great uncertainty and mitigate its effects.

Turning the uncertainty to an opportunity was suggested by some workshop participants. An opportunity of producing a more robust design that mitigates the impact of occupants' behaviour on building performance. This approach requires a better understanding of building occupancy and occupants' behaviour. Engaging building owners in the design and from collected post-occupancy data from similar buildings are ways that help understand occupants' behaviour.

Some experts stated that the uncertainty of occupancy, if identified, can be used to achieve saving by avoiding equipment over-sizing (e.g. HVAC) when designing for the actual occupancy and occupant behaviour. Another group of participants suggested that adding a margin of errors to the design assumptions can help offset the uncertainty in prediction. Another proposal was tabled to produce a range of performance predictions instead of fixed-value predictions that would help planning for uncertainty. This means the modeller needs to perform simulation multiple times using inputs low, medium, and high energy-using occupants. Alternatively, a continuous distribution representing the spectrum of occupant types could be sampled using Monte Carlo simulation. Results will be in the form of a range of performance predictions from the worst to the best scenario. However, this approach 
CHAPTER 3

might encounter time and budget restrictions as it requires more time and effort compared to the typical simulation process.

Some participants recommended having a built-in uncertainty feature in the BPS tools would help account for uncertainty and reduce inaccuracy in building performance predictions.

Generally, attendees agreed that uncertainty in the simulation-aided design should be avoided. However, if uncertainties are identified and quantified, there will be opportunities to produce more robust and realistic performance predictions and hence rely on calculation risks.

\subsection{Recommendation and future work}

The workshop was the first step of a larger project that aims to produce a long-term vision to reach advanced standardized occupant modelling in simulation-aided building design practice.

The outcomes of the workshop indicated the need to:

(1) Collect data from buildings in operations to better understand the occupancy patterns and occupants' interactions with buildings.

(2) Broaden the scope of data collection and analysis to include different building types, sizes and functions and to consider different climates and cultures. 
CHAPTER 3

(3) Update the current occupancy and occupancy related schedules based on research findings.

(4) Standardize a way for clients/owners to report information.

(5) Create a tool that can generate custom schedules based on information provided by building owners. To standardize data collection from building owners, a survey should be developed.

(6) Engage practitioners actively in the code committees and development process.

(7) Incorporate the state-of-the-art occupant models in BPS tools.

(8) Develop training material (user manuals, hands-on workshops, etc.) to teach BPS users about theory and application of occupant modelling.

For future work, the first step will be conducting sensitivity analysis to verify the impact of occupant modelling alternative on simulation predictions and design decisions. There after, a road map will be established for the planned incremental advances including setting priorities, overcoming the barriers and filling the gaps in knowledge, technology and users regarding occupant modelling as shown in Figure 3.3 . 


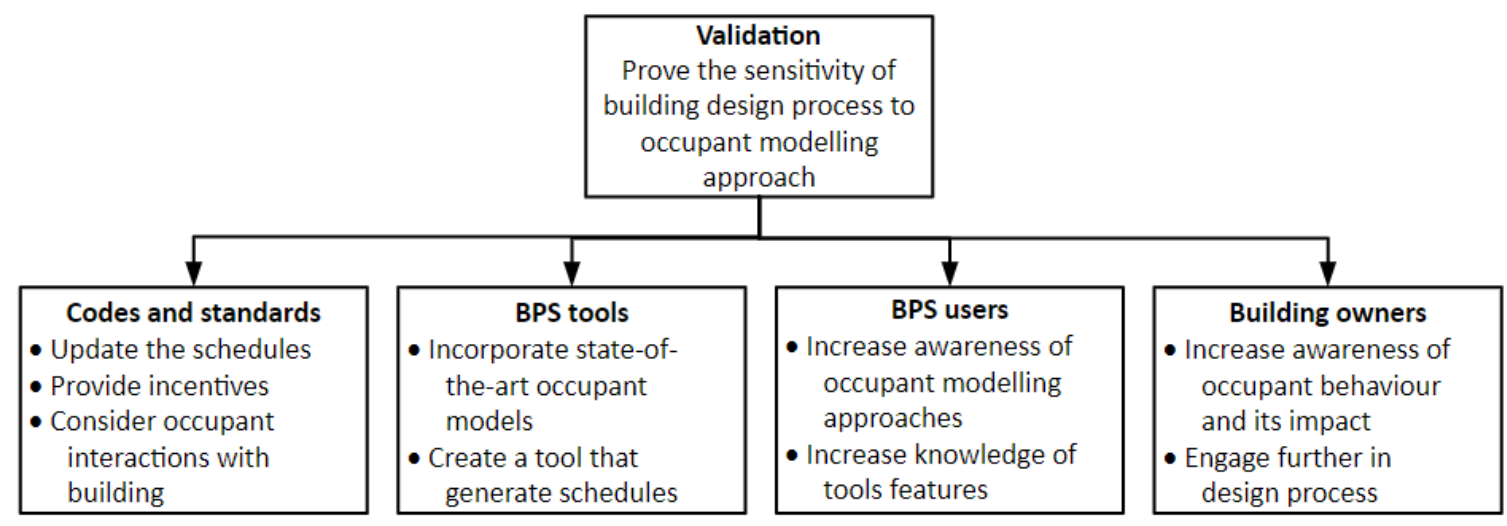

Figure 3.3: Proposed improvements to current occupant modelling approaches

\subsection{Conclusion}

This paper summarizes the key findings of a stakeholder workshop on occupant modelling in simulation-based design practice to identify its status in simulationbased design. This field is still considered in its infancy in terms of research and implementation despite its proven impact on building performance predictions (Gaetani et al. 2016b).

The purpose of the workshop was to obtain the feedback from a sample of stakeholders based on their experience in modelling buildings, developing related codes and standards and their vision on how the occupant modelling approaches and development should advance. This will assist in establishing the required technology roadmap that guides the development and advancement in the field of modelling occupants in the long term. 
The workshop tackled the key issues related to modelling occupants in buildings. The participants feedback indicated the need to take the first step immediately by proving the sensitivity of simulation predictions and design decisions to different occupant modelling approaches. This should be associated with post occupancy data collection to enable further research and more analysis to occupancy and occupant behaviour patterns.

As a short-term plan, workshop participants proposed using the collected and analyzed data for updating the existing occupancy schedules with more informed and up to date ones. The scope of updated schedules to consider different building types, sizes and functions. Moreover, they proposed the need for developing a tool that can generate custom schedules based on client-filled survey.

In the long term, the attendees concurred that there is a need to update the related codes and standards to include more details and to account for occupancy aspects other than presence and loads (e.g. equipment and lights). In addition, BPS tools needs to be developed to accommodate the state-of-the-art models in an easy to apply way to make it convenient for practitioners to use. 


\section{Case study documentation and parametric analysis}

\section{This chapter has been published as:}

Abuimara, T., O'Brien, W., Gunay, B., \& Carrizo, J. S. (2019). Towards occupantcentric simulation-aided building design: a case study. Building Research \& Information, 47(8), 866-882.

\subsection{Abstract}

This paper aims at illustrating the importance of occupant modelling for decisionmaking during the building design process. It identifies the energy implications of conventional ways of modelling occupants for the design of office buildings. Furthermore, it presents a step towards bridging the gap between the research efforts and conventional practices within the field of building performance simulation (BPS) aided design. The paper first describes occupant-related assumptions that were made during the design process of a case study office building, obtained via stakeholder interviews. Then, the impact of these assumptions on the design decisions is examined through a simulation-based investigation. The stakeholder interviews revealed that professionals from each design discipline made significantly different assumptions about occupants. The simulation results showed that assumptions about occupants and their behaviour impacted predicted energy savings of some design decisions by a factor of five or more. 
CHAPTER 4

\subsection{Introduction}

Building performance simulation (BPS) is increasingly being used during the building design process (Attia et al. 2012b; Day 2018; Guerra-Santin \& Silvester 2017). Designers use BPS for various purposes including code compliance, building certification (e.g. LEED), and to support the design and sizing of heating, ventilation and air-conditioning (HVAC) and renewable energy system (Loonen et al. 2017). BPS tools equip designers with the ability to make informed decisions that rely on the predicted performance of a building under design. However, despite the substantial uncertainty of the inputs of BPS models, modellers routinely consider just one set of assumptions (Hopfe \& Hensen 2011). As a result, BPS results can misinform designers and lead to inappropriate decisions (Gilani et al. 2016). Further, poor modelling assumptions can lead to a performance gap between the actual and simulated performance (Cole 2010; Hoes et al. 2009). This uncertainty and discrepancy occur due to a number of factors such as BPS user errors, the accuracy of weather data, occupant behaviour and the accuracy of the BPS tool (de Wit \& Augenbroe 2002).

Occupants are recognized as a major source of uncertainty in simulation-aided design (Delzendeh et al. 2017). Occupant behaviour accounts for great uncertainty in building energy use (Clevenger et al. 2014; Gram-Hanssen 2010; Haldi \& Robinson 
CHAPTER 4

2011; Maier et al. 2009). Occupant actions are diverse and appear random, and they often have multiple drivers (Dong et al. 2018; Hong et al. 2017). Some behaviours are driven by events and activities (e.g. departure, arrival, computer work) while others are driven by discomfort (e.g. open window when feeling stuffy). Given the stochasticity associated with occupant behaviour, modelling occupants in buildings is a challenging task. Many researchers, such as the participants of IEA-EBC Annex 66 and 79, have been studying occupant behaviour for the last few years to understand their impact on building performance (Yan \& Hong 2018). Different forms of data-driven occupant behaviour models have been developed to predict occupant interactions with building components (Gaetani et al. 2016a; Gilani et al. 2016; Yan et al. 2015). However, building energy codes and standards still rely on relatively simple methods to represent occupants in BPS (Sun \& Hong 2017a). Building energy codes and standards such as ASHRAE Standard 90.1 and National Energy Code of Canada for Buildings (NECB) represent occupant-driven thermal loads through schedules and densities for lighting and equipment per unit of floor area (ASHRAE Standard 90.1 2016; National Research Council of Canada 2015). These schedules and densities are outdated and not necessarily representative of the occupancy and operation in today's buildings. 
In addition, while it is standard for engineers to consider occupants as a constant source of heat and air contaminants (ASHRAE et al. 2011), a paradigm shift is required towards occupant-centric design that recognizes the diversity of occupancy and its implications on the design process (e.g. Figure 4.1).

To this end, simulation-aided design practice currently underestimates and oversimplifies the impact of occupant behaviour (Chen et al. 2017). Practitioners also tend to make conservative assumptions with little consideration of the differences between buildings and of the occupant-driven thermal loads (Djunaedy et al. 2011). In addition, the current approach in design practice does not recognize the implications of these assumptions on design decisions (Bonte et al. 2014).

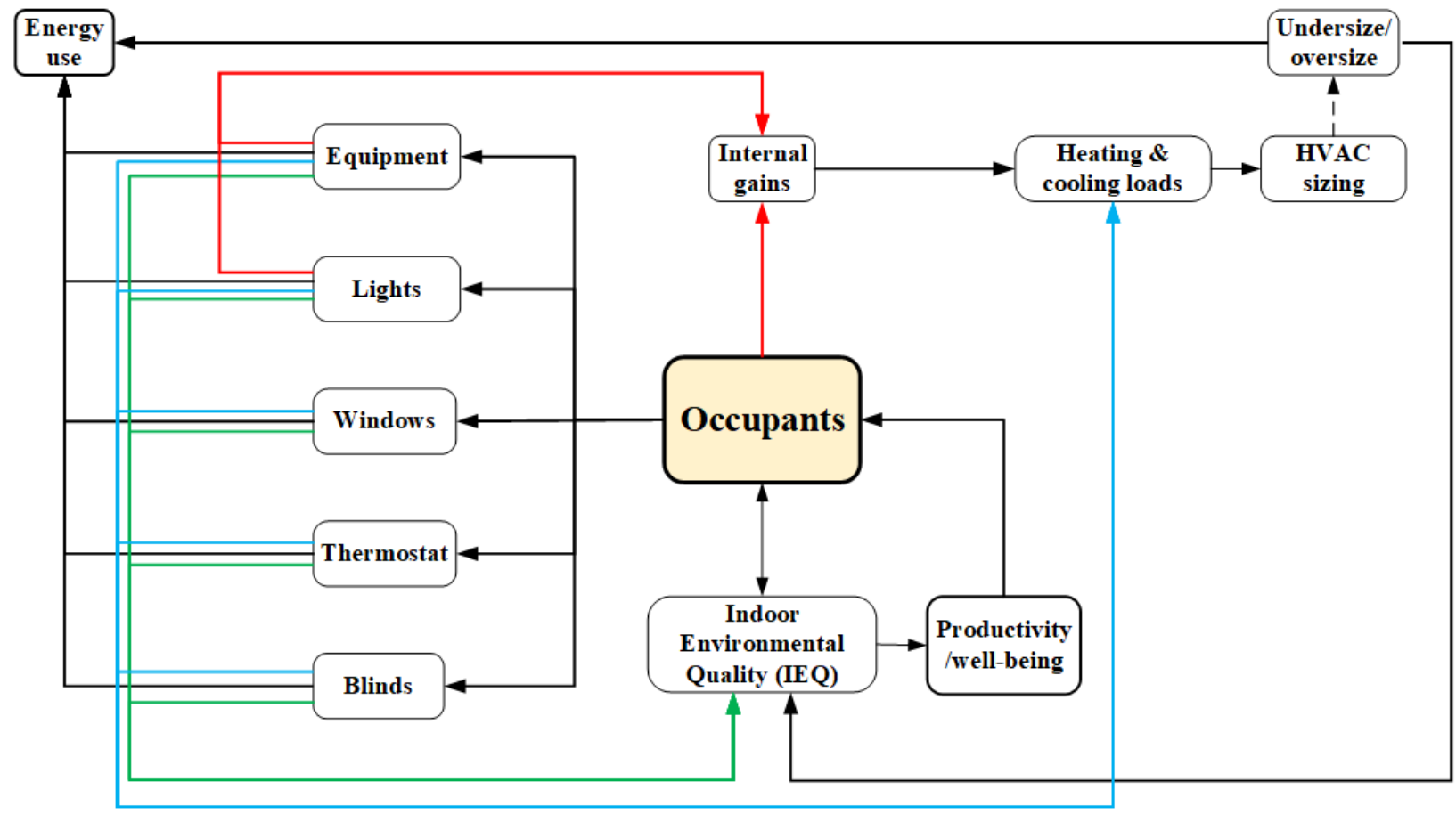

Figure 4.1: The actual role of occupants in buildings 
On another front, the published literature has been mainly focused on modelling occupant behaviours using statistical models using data from existing buildings such as studies by Reinhart (2004), Wang, Federspiel, and Rubinstein (2005), and Haldi \& Robinson (2010). Only a few studies looked at the implications of occupants on the design process. The main contributions of this study are that it documents the occupant-related assumptions made in a real building, and it studies the impact of those assumptions on a list of design alternatives.

Therefore, the objectives of this paper are to:

(1) Document the current state, highlight the shortcomings and propose potential improvements in occupant modelling during the BPS-aided building design process. To this end, we have conducted interviews with the owner, architect, mechanical engineer and energy modeller of a case study building to better understand current practice.

(2) Demonstrate the sensitivity of design decisions to different occupant-related assumptions. To this end, we conducted a simulation-based investigation on the documented case study building energy model and demonstrated how occupant-related assumptions affect the potential of design parameters. 
CHAPTER 4

\subsection{Literature review}

Occupant behaviour and its implications on building performance have been the focus of many researchers over the last few decades (Zhang et al. 2018). Many studies have been published highlighting the impact of occupants' actions on building performance. Some studies were observational studies that monitored occupant actions using different sensing technologies trying to develop statistical models that represent occupant actions. Based on field data, researchers have developed numerous occupant models such as Lightswitch-2002 model developed by Reinhart (2004) that predicts the likelihood of switching on lights and closing blinds based on workplace illuminance. Another example is the window opening model developed by Haldi and Robinson (2009b) that predicts the likelihood of occupants opening a window based on the outdoor weather conditions. However, these research findings are rarely used by practitioners for a number of reasons such as time and budget limitations, the complexity of their application and the limitations of the existing models, as most of them were developed for single spaces in certain locations and the generalization can be questionable.

Building design is a complex process that involves numerous stakeholders, with a wide range of expertise, collaborating to achieve a set of design objectives (El-Diraby et al. 2017). This collaboration and coordination are essential to the success of 
projects and to overcome any challenges that might emerge during their design process (Azari \& Kim 2014; Gagnon et al. 2018). Uncertainty is considered one of the major challenges that faces building design stakeholders. Uncertainty can occur during any design process phase and can have a tangible impact on design decisions. The adoption of BPS in the building design process is intended to reduce uncertainty by predicting the performance of the design. However, the BPS-aided design process still involves a considerable degree of uncertainty (de Wit \& Augenbroe 2002) due to factors such as the quality of the different assumptions (e.g. occupant-related assumptions) used, the accuracy of the BPS tool, and the experience of the BPS user (Beausoleil-Morrison 2019; Zhao \& Magoulès 2012).

Designers typically use BPS tools to evaluate design alternatives created by applying design parameters or energy conservation measures (ECMs) to a base case design (Attia et al. 2012a). Design parameters can vary from building fabric-related parameters (e.g. walls R-values) to building systems and system components types and efficiencies (e.g. type and efficiency of heating system). The BPS process can start as early as the conceptual design stage and can involve one or more of the design disciplines. The inputs of the BPS process can be critical as they influence the predictions and consequently, design decisions. These inputs include the characteristics of building envelope, systems and occupancy. 
CHAPTER 4

Uncertainty regarding occupancy is recognized as a major design process challenge (Gaetani et al. 2018; Hoes et al. 2009; Kim et al. 2017). Designers typically base their assumptions on building codes and standards, which can be inaccurate or unsuitable for every case. Occupant-related assumptions play a significant role in the building design process. They are used to determine: size of the building (e.g. total floor area and floor layouts), predicted energy performance, HVAC equipment sizing, electrical panels and transformers capacity, water supply and storage, sewer discharge and number of parking lots.

Several studies have looked at occupant-related assumptions in buildings and demonstrated how influential these assumptions are. For example, Wang, Ding, Deng, Yang, and Zhu (2018) conducted a study of three campus buildings to evaluate and compare the loads used in the design (occupant numbers and plug loads) against the actual loads. The study revealed that the chillers were sized $50 \%$ larger than required due to overestimated occupant-related heat gains during the design process. Knight and Dunn (2004) concluded that occupant-related assumption made during HVAC sizing are typically overestimated and often lead to calculated peak demand needs of more than twice of the actual peak heating/cooling demand. These overestimations can have consequences on initial cost, life cycle cost and comfort. Clevenger et al. (2014) conducted a simulation-based study on two building models: 
a residential and a commercial building in the USA. The results indicated that annual energy use can vary as a result of changing occupant-driven parameters such as loads and schedules related to cooling/heating setpoints, activity level and number of occupants, by as much as $150 \%$ in the commercial buildings and $75 \%$ in the case of the residential building. Sun and Hong (2017b) assessed the impact of occupant behaviour measures on building energy use by using site-specific data for lighting, plug-in equipment loads and occupancy. The behaviour measures included lighting control, plug-in equipment control, HVAC control and window use control. They concluded that when measures were applied one at a time, a $22.9 \%$ reduction in energy use was achievable. Meanwhile, when a combination of measures was applied, $41 \%$ energy use savings was achieved. Bonte et al. (2014) conducted eight case studies to assess the impact of occupants' actions on building energy use. The study considered six behaviour types: use of blinds, lighting systems, windows, fans, thermostats and clothing adjustments. The study concluded that the occupant actions have significant impact on a building's energy demand. For example, the study found that a $4^{\circ} \mathrm{C}$ change in indoor temperature setpoint, which is a representation of occupants' interaction with thermostats, can lead to a $35-55 \%$ variation in total energy demand. In the same way, the study pointed out that 
CHAPTER 4

window blind use can increase the heating energy use by $35 \%$ and the overall energy use by $20 \%$.

\subsection{Methodology}

This section provides a description of the case study, interviews with the designers and the case study building modelling approach. A mixed-method (qualitative and quantitative) research approach was taken in this study.

\subsubsection{Case study description}

The case study office building is currently under construction in Toronto, Canada, and is designed to be a typical speculative mid-rise office building that has a retail ground floor and typical multi-storey open plan office spaces. Building occupants/users were unknown during design and construction which magnifies the role of occupants as a source of uncertainty during design. Figure 4.2 shows the case study model created by the energy modeller and the ongoing construction of the building. Table 4.1 provides the building envelope and system specifications. Figure 4.3 shows the energy model used for the simulations in this study. 

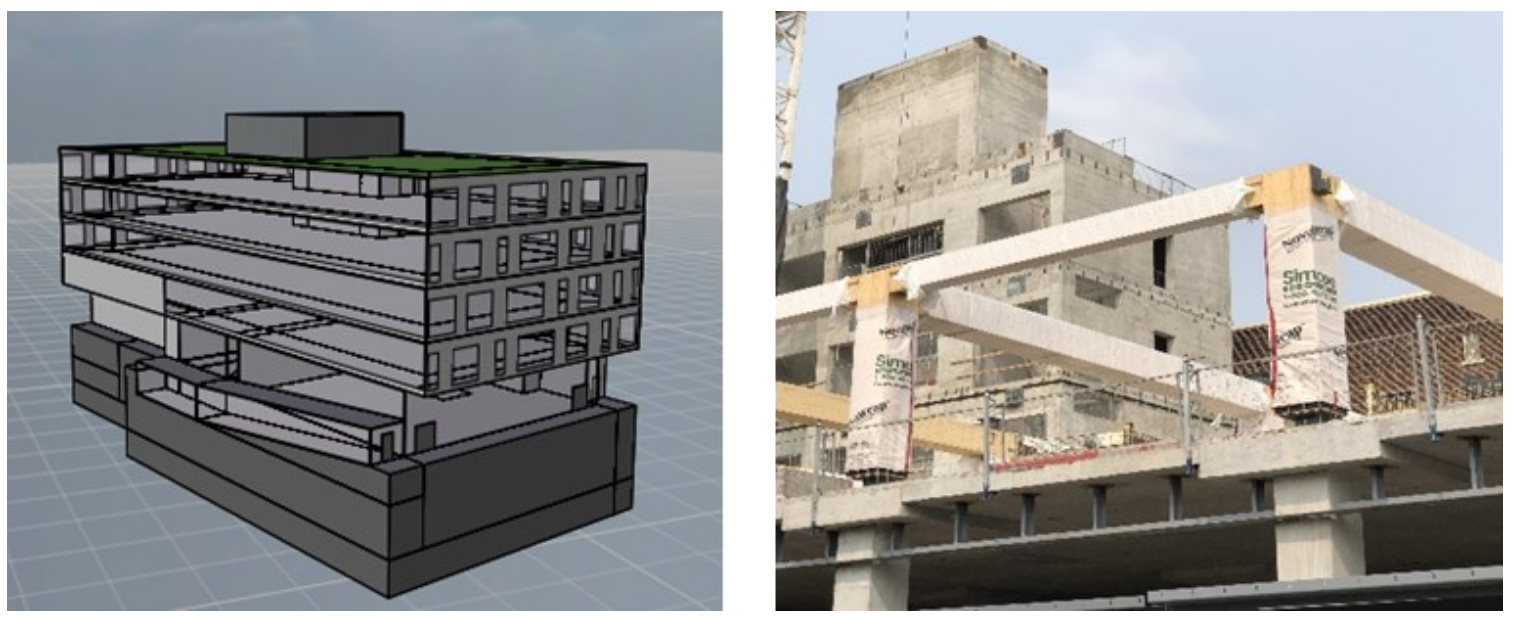

Figure 4.2: The case study: An office building in Toronto, Canada

Table 4.1: Model specification

\begin{tabular}{|c|c|c|}
\hline Category & Item & Specs \\
\hline $\begin{array}{l}\text { Floor } \\
\text { area }\end{array}$ & Floor & $1728 \mathrm{~m}^{2}$ \\
\hline \multirow{3}{*}{ Envelope } & Walls & $\mathrm{RSI}=4.6 \mathrm{~K} \cdot \mathrm{m}^{2} / \mathrm{W}$ \\
\hline & Roof & $\mathrm{RSI}=5.28 \mathrm{~K} \cdot \mathrm{m}^{2} / \mathrm{W}$ \\
\hline & Glazing & $\mathrm{USI}=1.9 \mathrm{~W} / \mathrm{m}^{2} \mathrm{~K}, \mathrm{SHGC}=0.33$ \\
\hline \multirow{4}{*}{ HVAC } & Packaged roof top unit & $\begin{array}{l}\text { Under floor air distribution and zone reheat } \\
\text { coils }\end{array}$ \\
\hline & $\begin{array}{c}\text { Airside heat recovery } \\
\text { effectiveness }\end{array}$ & $85 \%$ sensible, $70 \%$ latent \\
\hline & Space heating & Hydronic baseboard, reheat coils at zone level \\
\hline & Economizer & Enabled (controlled by differential enthalpy) \\
\hline \multirow{2}{*}{ Plant } & $\begin{array}{l}\text { Heating efficiency (Natural } \\
\text { gas) }\end{array}$ & $90 \%$ \\
\hline & $\begin{array}{c}\text { DHW boiler efficiency } \\
\text { (natural gas) }\end{array}$ & $90 \%$ \\
\hline \multirow{3}{*}{$\begin{array}{l}\text { Internal } \\
\text { loads }\end{array}$} & Air leakage & 0.19 ach @ $5 \mathrm{~Pa}\left(0.22 \mathrm{~L} / \mathrm{s} \cdot \mathrm{m}^{2}\right.$ of facade $)$ \\
\hline & $\begin{array}{l}\text { Plug-in equipment power } \\
\text { density }\end{array}$ & $9.87 \mathrm{~W} / \mathrm{m}^{2}$ \\
\hline & Lighting power density & $3.87 \mathrm{~W} / \mathrm{m}^{2}$ \\
\hline
\end{tabular}




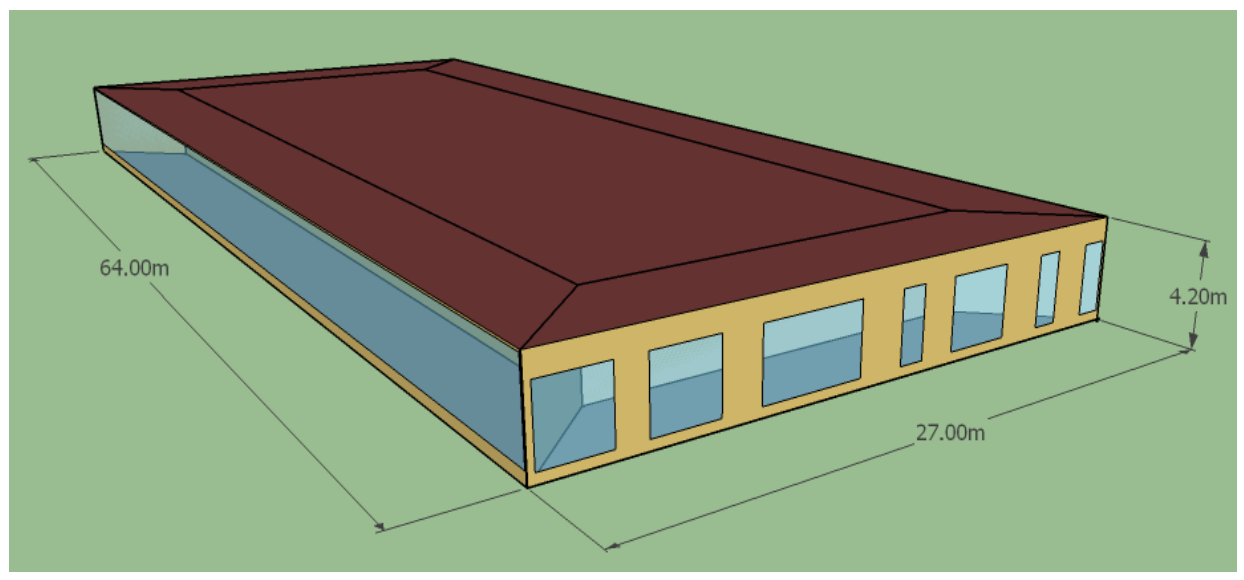

Figure 4.3: The case study model

\subsubsection{Data collection from stakeholders}

The four key stakeholders involved in the design of the case study building were interviewed: the owner, architect, mechanical engineer and energy modeller. The interviews were conducted using written questionnaires followed by semi-structured interviews (see Figure 4.4). The questionnaire items were designed to better understand different stakeholders' workflow and how they handle occupant-related assumptions. The questionnaires were customized for each stakeholder and contained questions relevant to each of their roles in the design process. The responses were analysed to prepare for the interviews. The interviews were Administered by two to three interviewers (i.e. the authors of this paper) to promote brainstorming and fill any possible gaps from the questionnaires. Finally, a review and analysis of the overall outcomes of the whole process were conducted to draw conclusions and 
document the current status of occupant-related assumptions throughout the design process.

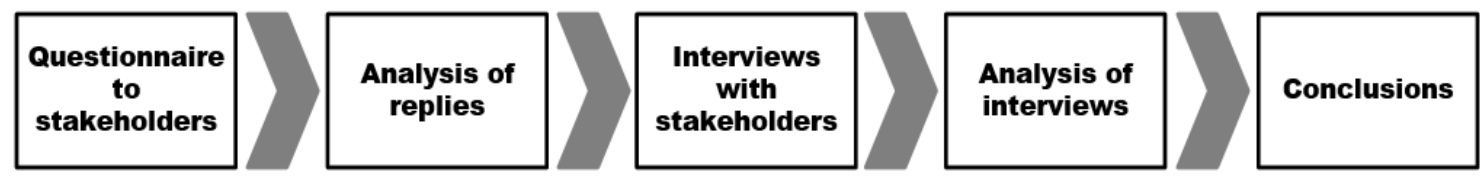

Figure 4.4: The workflow of the stakeholders' interviews

\subsubsection{Case study modelling}

The case study building is comprised of two underground parking stories, a retail ground storey, and four typical open plan office stories. The simulation work was performed based on information obtained from the original design documents (drawings and specifications), the energy modeller report and the building energy model created for the project by the energy modeller.

A base design model was created using the assumptions provided by the energy modeller in their modelling report. A wide variety of occupant-related assumptions listed in Table 4.2 were applied to the original design base model to create 13 unique scenarios (original design +12 occupant scenarios). Then, the design parameters were applied to each of the base case scenarios to generate design alternatives. Subsequently, the design alternatives were simulated, and the results were analysed and ranked with regard to annual energy use reduction compared to the base case design. Figure 4.5 shows the workflow of the simulation-based investigation process. 
CHAPTER 4

Table 4.2: Occupant-related assumptions

\begin{tabular}{|l|l|l|}
\hline Assumptions & $\begin{array}{l}\text { Energy modeller } \\
\text { assumptions }\end{array}$ & Values \\
\hline $\begin{array}{l}\text { Schedules (people, lights, } \\
\text { equipment) }\end{array}$ & Default schedules & $\begin{array}{l}\text { multipliers }(0.4,0.6,0.8,1.2) \\
\text { times default }\end{array}$ \\
\hline $\begin{array}{l}\text { Plug-in equipment power } \\
\text { density }\end{array}$ & $9.8 \mathrm{~W} / \mathrm{m}^{2}$ & $7.4,14.8 \mathrm{~W} / \mathrm{m}^{2}$ \\
\hline Occupant density & $20.0 \mathrm{~m}^{2} /$ person & $\begin{array}{l}13.3 \mathrm{~m}^{2} / \text { person, } 40.0 \\
\mathrm{~m}^{2} / \text { person }\end{array}$ \\
\hline Setpoints/setbacks & $\begin{array}{l}\text { Option } 1 \text { cooling setpoint } \\
22^{\circ} \mathrm{C} \text { with } 26.7^{\circ} \mathrm{C} \text { afterhours } \\
\text { setback, heating setpoint } 22^{\circ} \mathrm{C} \\
\text { with a } 15.6^{\circ} \mathrm{C} \mathrm{afterhours} \\
\text { setback) } \\
\text { Heating setpoints } 16^{\circ} \mathrm{C}, \\
22^{\circ} \mathrm{C}\end{array}$ & $\begin{array}{l}\text { Option } 2 \quad(\text { constant cooling } \\
\left.\text { and heating setpoints at } 22^{\circ} \mathrm{C}\right)\end{array}$ \\
\hline Blind & $\begin{array}{l}\text { Closed, basic solar-triggered } \\
\text { control }\left(50 \mathrm{~W} / \mathrm{m}^{2}\right) .\end{array}$ \\
\hline
\end{tabular}

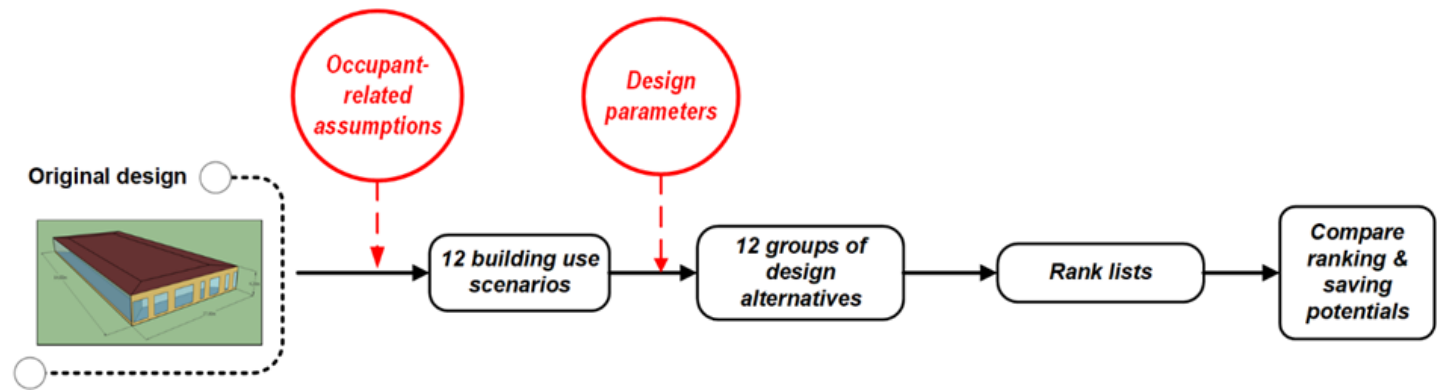

Figure 4.5: The simulation-based investigation workflow

The model geometry was created using SketchUp 2017 and the geometry was

exported to OpenStudio 2.5.0. The different components of the HVAC system were

created in OpenStudio. EnergyPlus 8.9.0, a whole building simulation engine, was

used to simulate the energy performance of the model. Since the study involved 416 
CHAPTER 4

simulation runs (13 building use scenarios and 32 design alternatives), MATLAB

R2017a was used to automate the parametric runs.

To assess the impact of occupants on the design process, several occupant-related assumptions listed in Table 4.2 were used to replace the energy modeller's occupantrelated assumptions. The occupant-related assumptions included multiple scenarios of occupant presence and building operations. The selected occupant-related assumptions aim at representing typical Canadian office buildings. For example, operable windows were not considered as they are not a common design feature in Canadian office buildings. The selected modelling methodology was intended to avoid complexity arising from the use of stochastic modelling of occupants and rather adopt a simplistic occupant modelling approach (static inputs: schedules, densities and values) so it can be easily adopted and performed by the practitioners. In addition, recent research by Gilani, O'Brien, and Gunay (2018a) showed that the effect of individual occupants at larger scale (buildings with 85 occupants and more) is not as significant as it is at a smaller scale. A set of design parameters were used to develop design scenarios (see Table 4.3). The parameters were selected from the commonly used parameters in the AEC industry and based on a review of similar buildings design charettes. Some of these design parameters are related to building envelope (e.g. insulation, window U-factor) while others relate to building systems 
CHAPTER 4

(e.g. HVAC). The parameters were also chosen based on the typical stage of design that they are decided upon. Some, such as window to wall ratio (WWR) and exterior overhang shading that are considered during the early design phase, whereas others, such as window properties such as U-Factor and solar heat gain coefficient (SHGC) are defined during the design development phase.

Table 4.3: Design parameters

\begin{tabular}{|c|c|c|c|c|c|}
\hline Design Parameters & Base model value & \multicolumn{4}{|c|}{ Alternatives } \\
\hline $\begin{array}{l}\text { South window to } \\
\text { wall ratio (WWR) }\end{array}$ & $85 \%$ & $30 \%$ & \multicolumn{2}{|l|}{$50 \%$} & $70 \%$ \\
\hline $\begin{array}{l}\text { Window properties } \\
\text { (U-factor \& SHGC) }\end{array}$ & $\begin{array}{l}\mathrm{U}=1.9 \mathrm{~W} / \mathrm{m}^{2} \mathrm{~K} \\
\mathrm{SHGC}=0.33\end{array}$ & $\begin{array}{l}\mathrm{U}=1.47 \\
\mathrm{~W} / \mathrm{m}^{2} \mathrm{~K} \\
\mathrm{SHGC}= \\
0.25\end{array}$ & \multicolumn{2}{|c|}{$\begin{array}{l}\mathrm{U}=2.04 \\
\mathrm{~W} / \mathrm{m}^{2} \mathrm{~K} \\
\mathrm{SHGC}= \\
0.58\end{array}$} & $\begin{array}{l}\mathrm{U}=1.62 \\
\mathrm{~W} / \mathrm{m}^{2} \mathrm{~K} \\
\mathrm{SHGC}= \\
0.39\end{array}$ \\
\hline $\begin{array}{l}\text { Exterior window } \\
\text { overhang }\end{array}$ & NA & \multicolumn{4}{|c|}{$\begin{array}{l}\text { Projection factor: } \\
\text { South }=0.7 \text { ( } 2.5 \mathrm{~m} \text { deep }) \\
\text { West }=0.85 \text { ( } 2.5 \mathrm{~m} \text { deep })\end{array}$} \\
\hline Window Blinds & $\begin{array}{l}* \text { Blinds always } \\
\text { closed } \\
\text { Reflectance }= \\
0.75 \\
\text { Transmittance = } \\
0.05\end{array}$ & \multicolumn{2}{|c|}{$\begin{array}{l}\text { Reflectance }=0.8 \\
\text { Transmittance }=0.1\end{array}$} & \multicolumn{2}{|c|}{$\begin{array}{l}\text { Reflectance }=0.6 \\
\text { Transmittance }= \\
0.15\end{array}$} \\
\hline Wall insulation & $\begin{array}{l}\mathrm{RSI}=3.1 \\
\mathrm{~m}^{2} \cdot \mathrm{K} / \mathrm{W}\end{array}$ & $\begin{array}{l}\mathrm{RSI}=4 \\
\mathrm{~m}^{2} \cdot \mathrm{K} / \mathrm{W}\end{array}$ & \multicolumn{2}{|c|}{$\begin{array}{l}\mathrm{RSI}=5 \\
\mathrm{~m}^{2} \cdot \mathrm{K} / \mathrm{W}\end{array}$} & $\begin{array}{l}\mathrm{RSI}=7 \\
\mathrm{~m}^{2} \cdot \mathrm{K} / \mathrm{W}\end{array}$ \\
\hline Roof insulation & $\begin{array}{l}\mathrm{RSI}=5.26 \\
\mathrm{~m}^{2} \cdot \mathrm{K} / \mathrm{W}\end{array}$ & $\begin{array}{l}\mathrm{RSI}=7 \\
\mathrm{~m}^{2} \cdot \mathrm{K} / \mathrm{W}\end{array}$ & \multicolumn{2}{|c|}{$\begin{array}{l}\mathrm{RSI}=9 \\
\mathrm{~m}^{2} \cdot \mathrm{K} / \mathrm{W}\end{array}$} & $\begin{array}{l}\mathrm{RSI}=11 \\
\mathrm{~m}^{2} \cdot \mathrm{K} / \mathrm{W}\end{array}$ \\
\hline Air infiltration & 0.19 ach & $0.15 \mathrm{ach}$ & \multicolumn{2}{|c|}{$0.2 \mathrm{ach}$} & $0.25 \mathrm{ach}$ \\
\hline $\begin{array}{l}\text { Demand controlled } \\
\text { ventilation }\end{array}$ & Disabled & \multicolumn{4}{|l|}{ Enabled } \\
\hline Cooling COP & 3.5 & \multicolumn{2}{|l|}{4} & \multicolumn{2}{|l|}{5} \\
\hline Boiler efficiency & $90 \%$ & \multicolumn{2}{|l|}{$85 \%$} & \multicolumn{2}{|c|}{$95 \%$} \\
\hline
\end{tabular}


CHAPTER 4

\begin{tabular}{|c|c|c|c|c|}
\hline $\begin{array}{l}\text { Energy recovery } \\
\text { ventilator (ERV) } \\
\text { effectiveness }\end{array}$ & $\begin{array}{l}\text { At } 100 \%=0.85 \\
\text { At } 75 \%=0.7\end{array}$ & $\begin{array}{l}\text { At } 100 \%= \\
0.88 \\
\text { At } 75 \%= \\
0.78\end{array}$ & $\begin{array}{l}\text { At } 100 \%= \\
0.8 \\
\text { At } 75 \%= \\
0.7\end{array}$ & $\begin{array}{l}\text { At } 100 \%= \\
0.75 \\
\text { At } 75 \%= \\
0.65\end{array}$ \\
\hline $\begin{array}{l}\text { Pump motor } \\
\text { efficiency }\end{array}$ & $90 \%$ & \multirow{2}{*}{\multicolumn{2}{|c|}{$5.8 \mathrm{~W} / \mathrm{m}^{2}$}} & $95 \%$ \\
\hline Light power density & $3.9 \mathrm{~W} / \mathrm{m}^{2}$ & & 7.75 & $/ \mathrm{m}^{2}$ \\
\hline
\end{tabular}

\subsection{Results}

This section presents the results of the documentation of occupant-related assumption and the simulation-based investigation of the case study.

\subsubsection{The case study design documentation}

The outcomes of the interviews were summarized and classified into three main categories: (1) the occupant-related assumptions during design including the type, the source and the use of the assumptions, (2) the design process work flow, (3) communication amongst design stakeholders and (4) challenges and limitations of the modelling process.

\subsubsection{Occupant-related assumptions during design}

\section{Type of assumptions}

The role of the client in the design process is to specify the intended function of the building and the expected form of building use. For this case study, the building was planned to be an office building with typical open space offices that are left for the 
CHAPTER 4

tenants to fit-out based on their needs. At this phase, the client had only an overall vision for the project and an approximate number of occupants. Thereafter, the architect was hired to develop the architectural design starting with schematic designs that outlined the building's size, massing, orientation and elevations including windows geometry. Because the tenants were unknown during design, the architect used the Ontario Building Code occupancy density (20 m²/person) (Government of Ontario 2018; Ministry of Municipal Affairs Ontario 2011). In parallel, the architect performed in-house energy modelling using Sefaira software to help develop the architectural design to achieve one of the design objectives: energy efficiency. The code-prescribed number of people, lighting loads, and plug-in equipment loads were used at this stage of the design.

As shown in Table 4.4, the mechanical engineer made several conservative assumptions regarding the building occupants in designing the HVAC system. These conservative assumptions were used to design systems that can withstand the highest expected HVAC loads. The maximum and minimum occupant-related assumptions were used to calculate cooling and heating loads, respectively. For instance, the peak heating loads were computed neglecting the casual and solar heat gains. In contrast, the peak cooling loads were computed by assuming the casual heat gains indicated in Table 4.4 . 
CHAPTER 4

Table 4.4: Occupant-related assumptions made by design stakeholders during the case study design.

\begin{tabular}{|l|l|l|l|l|}
\hline & & & \multicolumn{2}{|l|}{$\begin{array}{l}\text { Mechanical engineer } \\
\text { (design day load } \\
\text { calculations })\end{array}$} \\
\cline { 3 - 5 } & Architect & Modeller & $\begin{array}{l}\text { Cooling } \\
\text { calculations }\end{array}$ & $\begin{array}{l}\text { Heating } \\
\text { calculations }\end{array}$ \\
\hline $\begin{array}{l}\text { People } \\
\text { density }\end{array}$ & $\begin{array}{l}20 \mathrm{~m}^{2} / \text { person } \\
14 \mathrm{~m}^{2} / \text { person } \\
\text { (BPS default })\end{array}$ & $20 \mathrm{~m}^{2} /$ person & $9.3 \mathrm{~m}^{2} /$ person & $0 \mathrm{~m}^{2} /$ person \\
\hline $\begin{array}{l}\text { Light power } \\
\text { density }\end{array}$ & $\begin{array}{l}10 \mathrm{~W} / \mathrm{m}^{2}(\mathrm{BPS} \\
\text { default })\end{array}$ & $3.87 \mathrm{~W} / \mathrm{m}^{2}$ & $5.4 \mathrm{~W} / \mathrm{m}^{2}$ & $0 \mathrm{~W} / \mathrm{m} 2$ \\
\hline $\begin{array}{l}\text { Equipment } \\
\text { power density }\end{array}$ & $\begin{array}{l}25 \mathrm{~W} / \mathrm{m}^{2}(\mathrm{BPS} \\
\text { default })\end{array}$ & $9.87 \mathrm{~W} / \mathrm{m}^{2}$ & $17.2 \mathrm{~W} / \mathrm{m}^{2}$ & $0 \mathrm{~W} / \mathrm{m}^{2}$ \\
\hline $\begin{array}{l}\text { Window } \\
\text { blinds use }\end{array}$ & NA & Always open & Always open & Always open \\
\hline
\end{tabular}

Partly sponsored by an independent incentive program, the energy modeller was involved starting from the early design phase. The incentive program required that all stakeholders participate in a full-day design charrette to promote communication and exchange of information to develop a more efficient design. The occupant-related assumptions used at this stage were the number of people per floor area, the standard light power density (LPD), the standard equipment plug loads, and the standard temporal schedules indicating the occupant presence and building operation. At a later stage, the modeller updated the LPD based on the selected light fixtures (from 8.07 to $3.87 \mathrm{~W} / \mathrm{m}^{2}$ ). The number of people and the plug-in equipment power density remained the same. Table 4.4 and Figure 4.6 present the different occupant-related assumptions and schedules used by each stakeholder. 

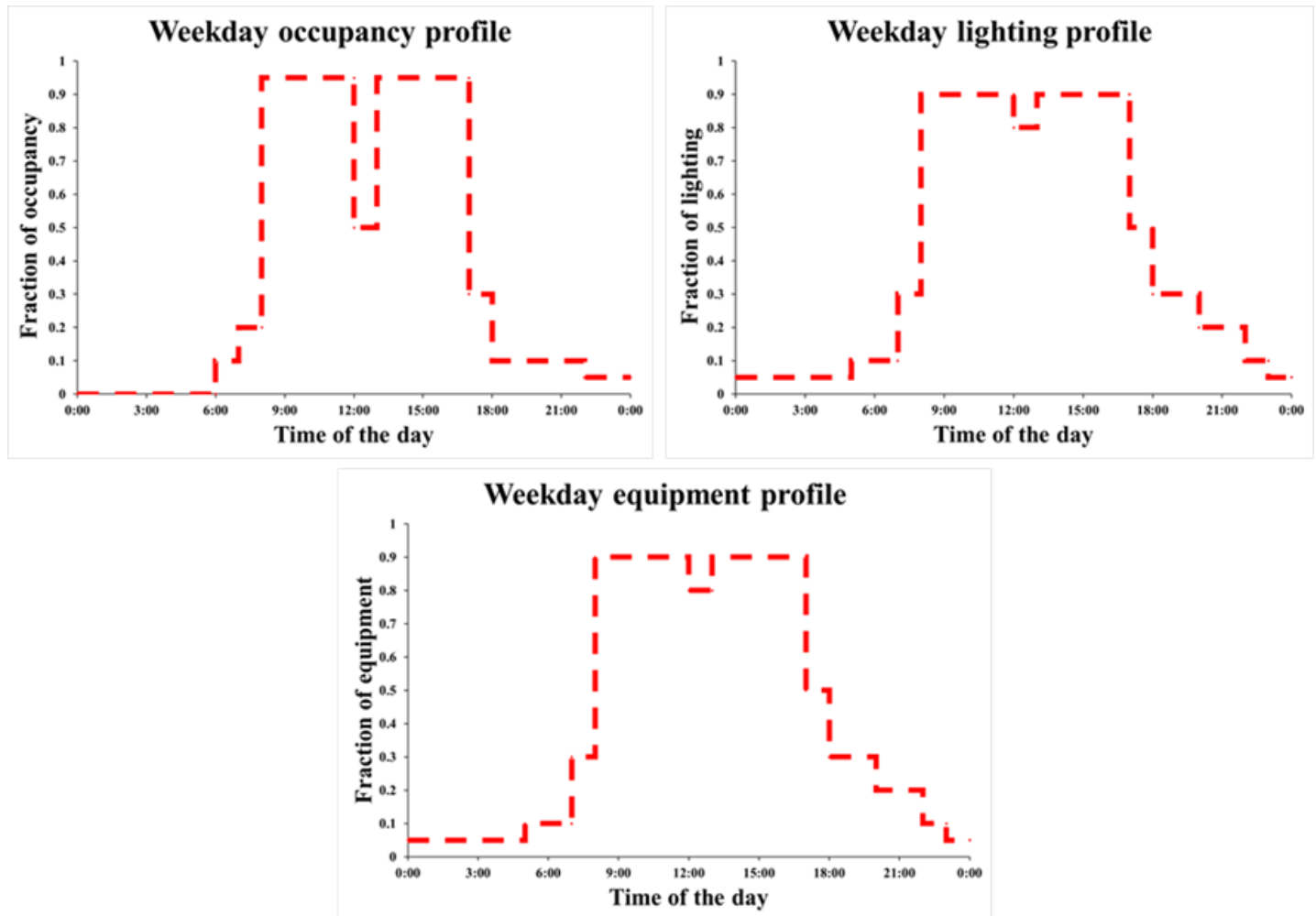

Figure 4.6: People, lighting and equipment profiles used for energy modelling

\section{Source of assumptions}

The architect and the project manager stated, 'The building was designed as a generic building' and added 'tenants came halfway or a little bit less than halfway through the construction'. Hence, the major source of occupant-related assumptions is the National Energy Code of Canada for Buildings (NECB), Ontario Building Code (OBC) and the ASHRAE Standard 90.1. These codes and standards provide values for the number of people per floor area, LPD and equipment power density. In addition, they provide the diversity schedules for occupancy, lights and equipment. Table 4.5 lists the common sources and types of assumptions. In addition 
CHAPTER 4

to NECB, OBC and ASHRAE Standard 90.1, the mechanical engineer and the energy modeller refined some of these assumptions based on the selected lighting technology or controls technology. This approach of obtaining occupant-related assumptions limits the data to a narrow set of standard numbers and temporal schedules that are not comprehensive enough to represent occupants or to capture differences between different buildings. In addition, these schedules and densities were created based on data collected few decades ago (1980s) and are not necessarily representative of the current occupancy and operation of buildings (D'Oca \& Hong 2015).

Table 4.5: Sources of assumptions per stakeholder

\begin{tabular}{|l|l|l|}
\hline Stakeholder & Source of assumptions & Type of assumptions \\
\hline Architect & $\begin{array}{l}\text { Building code, experience, the } \\
\text { client }\end{array}$ & Number of people per floor area \\
\hline Mech. engineer & $\begin{array}{l}\text { Building energy codes, building } \\
\text { standards, experience }\end{array}$ & $\begin{array}{l}\text { Occupant load, equipment loads, } \\
\text { lighting loads }\end{array}$ \\
\hline $\begin{array}{l}\text { Energy } \\
\text { modeller }\end{array}$ & $\begin{array}{l}\text { Building energy codes, building } \\
\text { standards, the architect, } \\
\text { mechanical engineer }\end{array}$ & $\begin{array}{l}\text { Operation and occupancy schedules, } \\
\text { lighting power density, equipment } \\
\text { density }\end{array}$ \\
\hline
\end{tabular}

\section{Use of assumptions}

The architect relied on the occupant-related assumptions for determining the building floor area and planning for access, circulation and egress. In addition, the type and nature of intended occupant assisted in developing interior design layouts for the future leaseholders. The mechanical engineer stated that 'The type of 
CHAPTER 4

mechanical system is often driven by the owner and the upfront cost'. Occupantrelated assumptions were used by the mechanical engineer to calculate the cooling and heating loads which lead to HVAC equipment sizing accordingly. A ten percent $(10 \%)$ safety factor was applied to the heating load calculation. No such safety factor was applied in sizing the cooling equipment to avoid inefficient operation of the cooling equipment at part loads. HVAC equipment sizing was then provided to the energy modeller.

The energy modeller used the standard occupant-related assumptions as one of the inputs in creating the energy model and generating the energy performance report. This process typically takes place at the stage of building permit as it is a requirement to demonstrate that the intended design performs better than the minimally code compliant reference office building. Occupants, lights and equipment are treated as a source of heat during the modelling process. Blinds also were assumed to be always open as indicated in Table 4.4.

\section{The design process workflow}

The design process for the case study was intended to adopt the main features of the integrated design process (IDP) which is a holistic approach to sustainability in buildings (Larsson 2004; Reed et al. 2010). As such, all stakeholders were involved 
from the early design stages. However, the core of the energy modelling process was done at a later stage (as a requirement for obtaining a building permit) after most of the important design decisions were made independently by other design disciplines (e.g. architect, mechanical engineer). This led to a limited impact of the energy modelling in making major design decisions (e.g. HVAC selection). The limited or late involvement of energy modelling by project stakeholders can be attributed to a number of factors such as lack of client interest and willingness, understanding of the actual role of energy modelling, stakeholders' personal views and lack of interest to adopt new technologies (Oliveira et al. 2017).

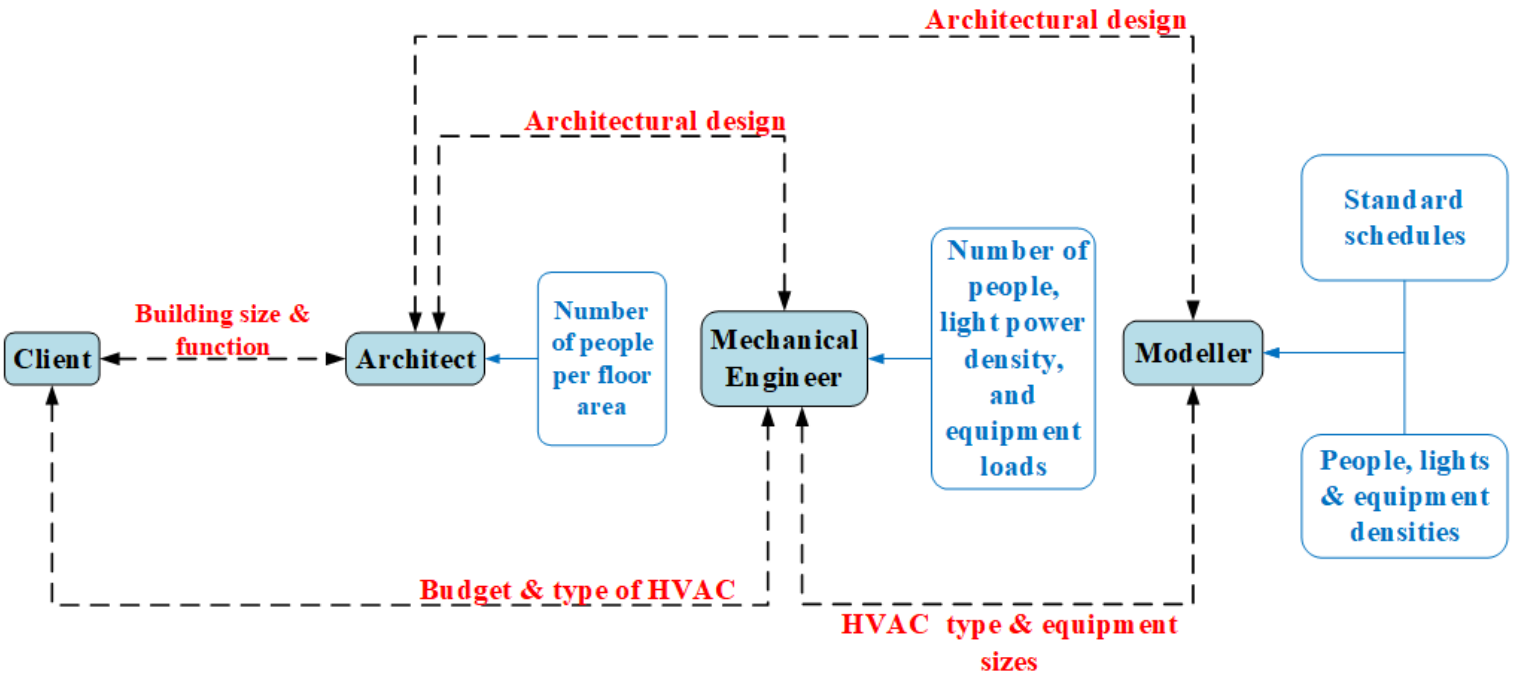

Figure 4.7: Occupant-related assumptions by different design stakeholders

Furthermore, the energy modelling work was carried out independently, with no integration to the mechanical design scope as it was not part of HVAC equipment 
CHAPTER 4

sizing. The workflow was set up for the mechanical engineer to use his assumptions including occupants-related ones to complete his design scope then provide the final sizing numbers to the modeller as shown in Figure 4.7.

Thereafter, the modeller carried out his modelling work based on the HVAC specifications generated by the mechanical engineer and using his own standard occupant-related assumptions and a different modelling software. The inconsistency in using occupant-related assumptions and modelling and design tools can be problematic and lead to different design strategies. In addition, even though the project was participating in an energy performance incentive program that requires post-construction modelling to verify performance, the modeller was not involved during the construction detailing and construction phase. The modeller noted that "We are not even involved in the shop drawings review at this phase".

\section{Communication amongst design stakeholders}

Communication among the design team members (i.e. the architect and the engineers) was maintained during the design of the case study building. Typically, the communications were in the form of regular meetings (bi-weekly or monthly), phone calls and emails. The client was contacted by the design team members for updates regarding major decisions that have tangible impact on the design or cost. 
The project energy modeller stated 'We had few conversations with the owner, who was only engaged when decisions needed to be made'. The design team members shared the outcomes of their design scopes in form of drawings, reports and computer models. For example, the architect provided the architectural drawings and specs to the mechanical engineer and the modeller as a starting point for their work. The mechanical engineer shared the HVAC sizing details with the energy modeller to be used in creating the energy model. While the design stakeholders kept sharing the outcomes of their design tasks, they did not effectively communicate the assumptions they used to reach their design objectives.

On the other hand, the level of communication was not kept at the same level with the energy modeller. The mechanical engineer noted that communication with the energy modeller was at its highest level once major design decisions were made and semi-finalized. Therefore, energy modelling played an important role in increasing efficiencies of building components and the designed systems components (e.g. systems efficiencies) but did not have a major role in the major design decisions (e.g. HVAC type) that take place at the early design phases. The late engagement of the modeller can be attributed to the fact that local authorities require energy modelling only at the building permit stage. Figure 4.7 outlines the information exchange among the different design team member and the type of information exchanged. 
CHAPTER 4

\section{Challenges and limitations of the modelling process}

The study confirmed that time constraints are one of the major challenges that most design stakeholders face. Practitioners typically assign a timeline for a given project and assign resources to complete the scope. This time assignment is not always flexible and typically out of the design team members' control. For example, the energy modeller is not hired at the onset of the design process and has a limited time to complete the energy modelling scope. At this stage, the modeller has to deal with a semi-finalized design and consequently has a limited ability to influence the final design. In addition, time allocated for modelling restricts mechanical and architectural designers from seeking detailed simulation analysis and examining different building use scenarios. Both of which could lead to better design decisions.

According to both the mechanical engineer and the energy modeller, time and cost were among the major restrictions to considering different design scenarios or technologies. For example, some technologies that can adapt to variable occupancy and operation and save energy such as demand-controlled ventilation (DCV) were not considered due to cost related reasons. 
CHAPTER 4

\subsubsection{The simulation results}

The results of the EnergyPlus simulations are presented in this section based on two criteria: (1) impact on design alternative ranking (see Figure 4.8) and (2) impact on energy use savings (see Figure 4.9). The results of the design alternatives that performed worse than the base of the scenario (producing negative savings) were eliminated from the graphs and the ranking lists. The results of the simulations showed multiple changes in ranking of the design alternatives and to a differential energy savings potential and trends.

\section{Impact on design alternatives ranking}

The results of the simulations are shown in Figures 4.8 and 4.9. The figures present the results of the simulation of 20 design alternatives out of the 32 alternatives simulated for each building use scenario. The remaining 12 design alternative results were disregarded as they did not show any energy savings. Figure 4.8 and Figure 4.9.(a) show the results of simulating design alternatives with altered occupancy, lights and plug-in equipment use schedules by applying $0.4,0.6,0.8$ and 1.2 multipliers to the original design default schedules. The multiplier values reflect different typical occupancy scenarios similar to other studies from the literature. For example, Liang, Hong, and Shen (2016) were able to identify, through analysing measured annual occupancy data, four different occupancy patterns. The ranking 
CHAPTER 4

changes occurred in both alternatives with envelope-related design parameters (e.g. WWR) and the ones with systems-related design parameters (e.g. HVAC). For example, the demand-controlled ventilation (DCV) system has become more beneficial with lower occupancy, lighting and plug-in equipment schedules (0.4 and 0.6 schedules), as it moved up on the ranking list (see Figure 4.8).

Contrary to that, the same technology has become less effective when the default occupancy, lighting and equipment schedules were exceeded (1.2 multipliers). DCV technology allows the supply of ventilation based on the occupancy rates and the associated $\mathrm{CO}_{2}$ levels. In other words, more occupancy, lights and plug-in equipment lead to higher cooling demand and consequently more energy use; however, for low occupancy scenarios, the DCV reduces ventilation compared to the nominal case (Lawrence 2004).

Windows with a higher U-Factor and SHGC were more beneficial with lower occupancy (i.e. 0.4 and 0.6 schedules). The increased solar gains through windows compensates for the decrease in internal gains, due to the reduced occupancy, lighting and equipment loads. 


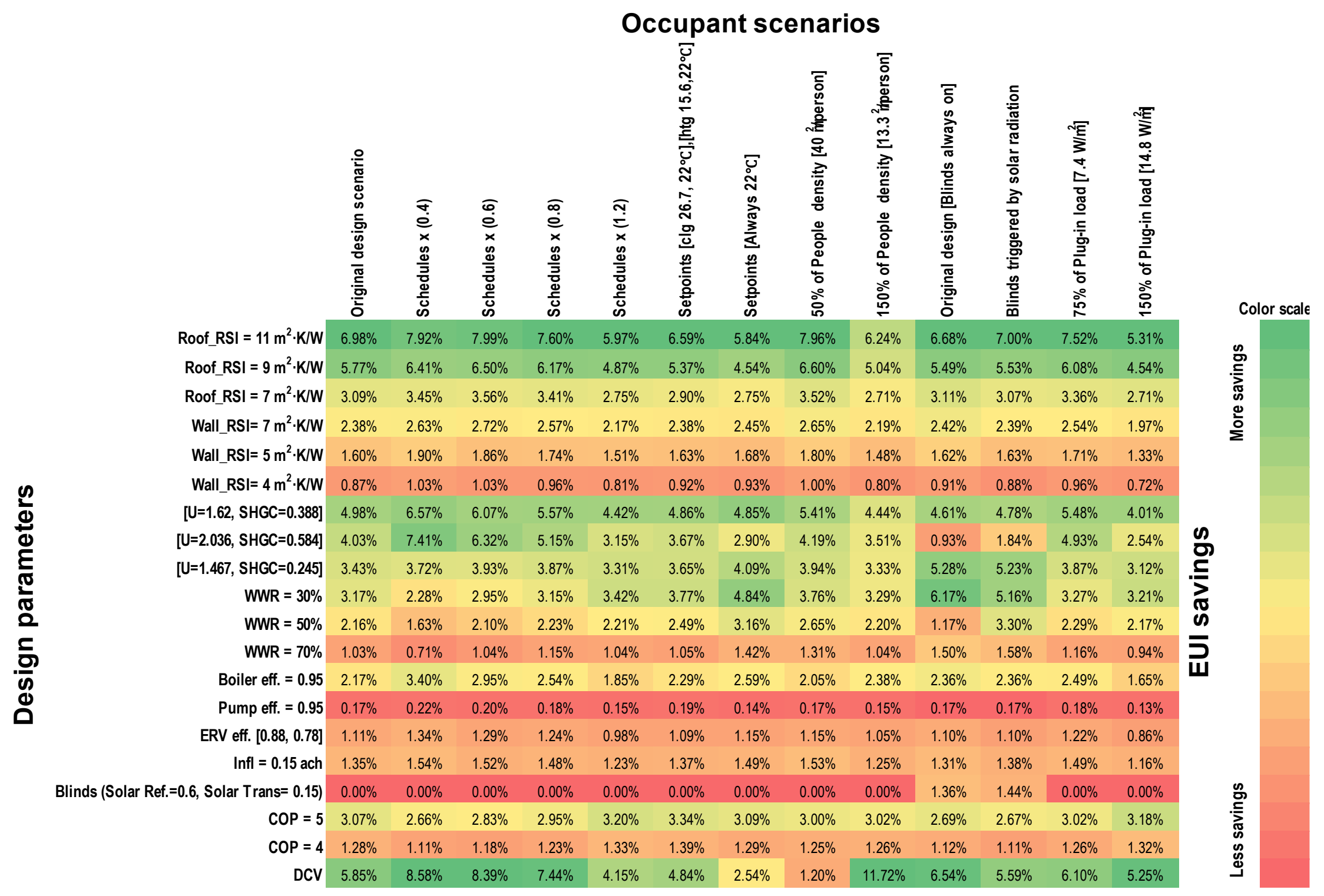

Figure 4.8: Ranking of design alternatives 

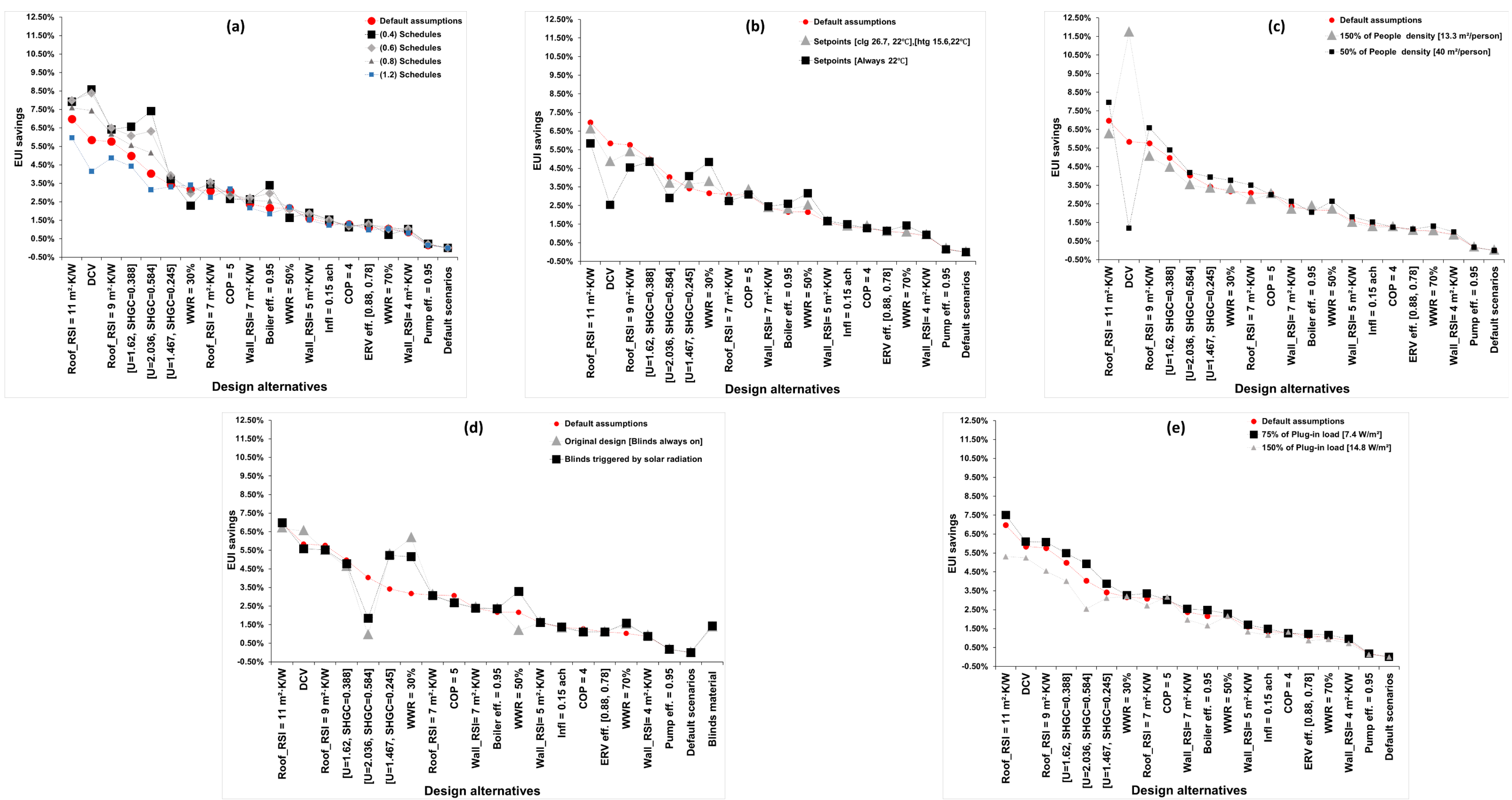

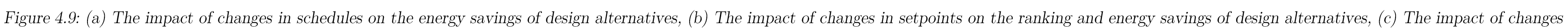
in number of people on the energy savings of design alternatives, (d) The impact of changes in blind use on the energy savings of design alternatives, (e) The impact of changes in equipment loads on the energy savings of design alternatives. 
CHAPTER 4

Two different scenarios of indoor air temperature setpoints were simulated, as shown in Figure 4.8 and Figure 4.9.(b). The first scenario assumed lower unoccupied cooling setpoint setback $\left(26.7^{\circ} \mathrm{C}\right.$ instead of $\left.32^{\circ} \mathrm{C}\right)$, a lower cooling setpoint $\left(22^{\circ} \mathrm{C}\right.$ instead of $24^{\circ} \mathrm{C}$ ) and a higher heating setpoint $\left(22^{\circ} \mathrm{C}\right.$ instead of $\left.21^{\circ} \mathrm{C}\right)$. The second scenario assumed that there is a constant setpoint of $22^{\circ} \mathrm{C}$ all the time. The first scenario results, as shown in Figure 4.8 and Figure 4.9.(b), indicated that the cooling coefficient of performance (COP) has become a more important design parameter with the decreased cooling setpoint and setback. In addition, the improved windows assemblies (lower U-factor and solar heat gain coefficients 'SHGC') and envelope insulation (higher roof and wall R-value) gained significance as they prevented excessive heat gain to or loss from the building and assisted in maintaining the prescribed setpoints. The second scenario results, the constant setpoint of $22^{\circ} \mathrm{C}$ as shown in Figure 4.9.(b), indicated that the challenging condition of maintaining a constant setpoint, the boiler efficiency, COP, the envelope insulation and the upgraded window properties are the most important design parameters. The constant setpoint, which is typically an occupant preference or an operator decision, imposed additional demands on the heating and cooling systems. Accordingly, efficient HVAC equipment along with upgraded building envelope are essential for energy saving. 
As shown in Figure 4.8 and Figure 4.9.(c), DCV is less influential as a design parameter with the reduced number of people (50\% of the default number). In contrast, DCV gained priority as a design parameter with the increased number of people (50\% more than the default number) and achieved five times more energy savings than the constant setpoint scenario and by a factor of 10 larger than low occupant density scenario (50\% of default number of people). The DCV managed the supply of required ventilation to the over-occupied building to maintain acceptable IEQ while the increase in internal gains from occupants led to lowering the heating loads. The improved COP of the cooling system has become more beneficial in the case of increased number of people $(50 \%$ more than the default number) where the increase in the number of people is associated with increased internal gains. These additional internal gains impose burdens on the cooling system. Hence, a more efficient cooling system acquired priority.

Figure 4.8 and Figure 4.9.(d) demonstrate two scenarios of windows blinds use in buildings. The first scenario is assuming that the internal window blinds are kept closed all the time, which is not a typical modelling assumption but is a plausible occupant behaviour (Karjalainen 2019; Van Den Wymelenberg 2012). The second scenario is a case in which the blinds are triggered by the solar radiation on windows $\left(50 \mathrm{~W} / \mathrm{m}^{2}\right)$. Two alternative window blind materials with different solar 
CHAPTER 4

transmittance and solar reflectance were used as shown in Table 4.3. Design alternatives in both scenarios experienced a considerable number of ranking changes.

When the blinds were assumed always closed, the marginal benefit of having windows with high SHGC diminishes. On the other hand, the boiler efficiency and the envelope insulation become more effective as their design alternatives moved up in the ranking list. Deploying the windows blinds permanently would block a considerable fraction of the direct solar gain and daylight (Bellia et al. 2014). Consequently, the heating and lighting will be primarily dependent on the efficiency of the heating system, envelope air tightness, insulation and the efficiency of light fixtures. A better insulated envelope along with a more efficient heating system will be required to compensate for the reduced solar gains. In the second scenario, where the blinds are triggered by high solar radiation on the window, decreased WWR on the south façade leads to reduced solar gains during the overheating times and block glare. The high solar-triggered blinds blocked the solar radiation and glare at the times of overheating with smaller WWR (e.g. 30\%) and consequently reduced demand on cooling. It also allowed the useful solar gains which contribute to heating the building and illuminating the indoor space (i.e. daylight). That finding aligns with a study by Shen and Tzempelikos (2012) that conclude that automated interior shading can reduce HVAC energy demand in buildings with WWR $=30-50 \%$. 
CHAPTER 4

Additionally, two window blinds materials were evaluated as design parameters with the two window blind use scenarios. A reduction in energy use was obtained when the blinds were assumed closed or triggered with the solar radiation on the window. A change in ranking was also observed as shown in Figure 4.8 and Figure 4.9.(d). Decreasing the plug-in equipment loads to $75 \%$ of the original design value $(9.87$ $\mathrm{W} / \mathrm{m}^{2}$ ) resulted in a minimal ranking change as shown in Figure 4.8 and Figure 4.9.(e). With a decrease in the internal gains from the equipment, the benefits to increasing the roof insulation level became slightly more influential design parameter.

On contrary, increasing the plug-in equipment loads by $50 \%$ led to the cooling COP and the reduced WWR on the south façade to gain more significance and move up on the ranking list as shown in Figure 4.8. The increased internal gains from equipment impose a considerable burden on the cooling system and a more efficient system (i.e. improved COP) becomes more influential as a design parameter. The reduced WWR on the south façade reduces the amount of solar gain and consequently reduces the demand on cooling.

\section{Impact on energy use savings}

This section demonstrates the implications of the different occupant-related assumptions on the potential saving of the design parameters. Figure 4.9.(a) shows that the lower the occupancy and occupant-driven thermal loads were assumed, the 
CHAPTER 4

greater the energy savings potential through the implementation of energy conservation measures became. For instance, DCV achieved its highest energy use savings $(8.6 \%)$ with the lowest occupancy, lighting and plug-in equipment schedules while its lowest saving potential $(4.1 \%)$ was observed with the highest occupancy, lighting and plug-in equipment schedules. However, improving cooling COP and the reduced WWR (30\%) did not follow the same saving trend and experienced a slight saving potential with the increased occupancy. This deviation from the trend can be attributed in part to the fact that cooling equipment operates in a less efficient way at part loads than it does on full load conditions. The reduced WWR helps decrease solar gains through windows and offsets the increased internal gains due to the increased occupancy. As shown in Figure 4.9.(b), two different indoor temperature scenarios were considered, no general saving trend was observed for these scenarios. For instance, DCV have shown greater saving potential (by a factor of 2) with the first setpoint scenario $\left(22^{\circ} \mathrm{C}\right.$ setpoint and after hours 26.7 and $15.6{ }^{\circ} \mathrm{C}$ cooling and heating setbacks respectively) than with a constant setpoint of $22^{\circ} \mathrm{C}$. In Figure 4.9.(c), where two scenarios for the number of people in the building were used in the simulation, differential trends in savings were also observed based on the type of design parameter. For example, upgrading window material properties (i.e. U-Factor and SHGC) showed a decreased saving with the increased number of people. While 
CHAPTER 4

wall and roof insulation indicated different trends as the magnitude of saving increased with the increased number of people. In addition, DCV have shown a substantial saving potential (increased by a factor of 2) with the increased number of people scenario. This increase highlights the importance of this technology when designing a densely occupied building. The BPS tools (in this case EnergyPlus) use the number of people, LPD and EPD in sizing of HVAC equipment. In Figure 4.9.(d), the two scenarios of windows blinds operation, similar trends were observed in energy saving. The smaller WWR (30\%) led to greater energy savings with the permanently closed blinds scenario, while the same scenario had the least saving potential with the high SHGC.

\subsection{Discussion}

Overall, the findings of this study are generally consistent with the findings of a recent building design stakeholder's workshop (Abuimara et al. 2018a). The results of this study are also in agreement with the finding of an international energy modeller's survey (O'Brien et al. 2016).

The interviews with design stakeholders unveiled a number of inefficiencies in the current practice such as the lack of adequate communication mechanisms which led to discrepancies in occupant assumptions amongst key design stakeholders (e.g. the architect and the modeller). Effective communication is fundamental for a successful 
CHAPTER 4

design and construction process (Arditi \& Gunaydin 2002; Mollaoglu-Korkmaz et al. 2013).

Interestingly, the interviews with the stakeholders revealed that some design solutions were not deployed despite their guaranteed operational energy saving due to the project's initial cost constraints. This finding indicates the need to improve the way these design options communicated to the project owners or investors. In addition, it highlights the need to increase the awareness among certain stakeholders (e.g. the owner) about the long-term implications of such early design decisions.

The different occupant-related assumptions used by the different design stakeholders along with the lack of effective communication among design disciplines elevate the degree of uncertainty during the design process and consequently leads to suboptimal design decisions.

Different levels of sensitivity to the changes in occupancy, lighting and plug-in equipment schedules were observed with the highest sensitivity with the extreme scenarios (0.4 and 1.2 multipliers). These findings shed light on the importance of using representative occupant and occupant-related schedules that can be different from the typical used schedules. 
CHAPTER 4

This study also looked at different plug-in equipment use scenarios as a representation of the variety of office equipment use by different office tenants as illustrated by several field studies such as Sarfraz and Bach (2018). The findings highlighted the sensitivity of design parameters to the plug-in equipment load assumptions, which is considered one of the main drivers of energy use in buildings.

The findings demonstrated the sensitivity of the temperature setpoint assumptions to the predicted savings of design parameters. On another front, HVAC control technologies such as DCV showed substantial sensitivity to the different occupant scenarios and demonstrated savings that ranged from $2.5 \%$ to $11.7 \%$. This finding confirms with fact that control technologies such as DCV are more influential with variable occupancy rather than typical (Lawrence 2004).

The study demonstrated how the level of occupant presence and the associated lights and equipment play a tangible role in determining the savings potential from the HVAC-related design parameters such as cooling coefficient of performance (COP). Notably, the findings align with the objectives of the ongoing research efforts to further understand, analyse and quantify the occupancy and occupant behaviour and its implications on building design and building operation (IEA-EBC 2014, 2018). The findings serve as a first step towards recognizing the energy implications of 
CHAPTER 4

occupant-related assumptions during design. They bring the attention of all the concerned stakeholders to this overlooked area of the BPS-aided design. Though the results are expected to be generalizable to a large extent, this study had a number of limitations that restrict the direct application of the findings to other buildings:

(1) The occupant modelling process documentation is limited to the current case study and to the processes followed by the involved stakeholders and their firms.

(2) The findings are specific to the case study, its building type (office) and its location (Toronto, Canada).

(3) All possible combinations were not exhaustively searched, and the occupantrelated assumptions were varied one at a time, rather than considered in combination in order to shed light on the actual impact of the individual occupant scenario. However, in reality, a building can have a number of these occupant scenarios. For example, some buildings operate at a constant setpoint, with low occupancy and automated window blinds.

(4) The design parameters were applied to the base design model one at a time to generate design alternatives. The goal was to highlight the impact of occupant scenarios on individual design parameters in terms of energy saving 
potential and its priority in design process. While in design practice, designers use combinations of design parameters to meet design objectives.

(5) The investigation considered a large number of, but not all possible, occupantrelated assumptions or design parameters that may affect the performance and decisions. The approach was focused on the most common and influential design parameters and occupant-related assumptions.

\subsection{Conclusion and future work}

The study showed that stakeholders rely primarily on NECB, ASHRAE Standard 90.1 and BPS default values, which assume a generic operation scenario for a given building type. This indicates the need to update the current building energy codes and standards to cover a broader range of building uses and operation.

Hence, further investigation and surveying of the industry should take place to confirm the findings of this case study. This can inform future changes in building codes and standards so that occupant-related assumptions are explicitly considered during the simulation-aided design process.

On another front, mechanical engineer revealed that the HVAC design and sizing were based on conservative assumptions about a factor of 2 greater than those of the energy modeller. While mechanical engineers face greater liability than energy 
modellers due to the risk of HVAC under sizing, HVAC oversizing comes with numerous consequences (capital and operating costs and challenges, inefficient performance, etc.). Accordingly, building codes could mandate a standardized way occupants are modelled for HVAC sizing using a rigorous, but less conservative, datadriven approach.

The current simulation results demonstrate that the energy use implications of occupant-related assumptions are oversimplified in building codes and standards. The 13 building use scenarios indicated significantly different energy use patterns, savings potential and ranking of design alternatives. This implies that design stakeholders should base their design on case-specific assumptions that recognize different building types, use and occupants. For instance, designers can employ some building control technologies that offer adaptability of buildings to different occupancy patterns. Codes and standards should acknowledge the sensitivity of building energy performance to occupant-related assumption and the variation of energy savings potential associated with the different building use scenarios. Additionally, codes and standards should require modellers to simulate a range of occupant-related assumptions per building type instead of single set of deterministic values during the modelling process. Reporting a range of performance levels for a 
CHAPTER 4

given building prevents performance gap due to occupants' energy-related behaviours (Stevenson et al. 2016).

Technologies such as DCV can become more appealing when non-standard occupant assumptions are used. This may provide opportunities for designers to apply such technologies by helping them justify necessary capital investments. Codes and standards should also incentivize the use of adaptive technologies such as DCV to promote the use of technologies that can help buildings operate more efficiently with different occupancy patterns.

Wall and roof insulation demonstrated robustness to occupant-related assumptions, in terms of ranking, to the different building use scenarios. This robustness makes them ideal candidates to consider as design parameters when designing buildings with unknown use cases. Contrary to wall and roof insulations, different window configurations showed sensitivity to building use scenarios as they experienced ranking changes in most of the cases.

Overall, the study results underlined that building design stakeholders need to look deeper and give more attention to the sensitivity of building design to occupantrelated assumptions. Operating conditions and building controls strategies should also be investigated in order to make the appropriate design decisions. Furthermore, 
stakeholders need to improve the level, the timing and the quality of communication. This should ensure the proper exchange of design data and the consistency of assumptions. The following research needs were identified for future work:

(1) Conducting more comprehensive documentation of building design and occupant modelling processes to produce results that can be generalized.

(2) Applying a modelling approach to different case study buildings in different locations to quantify the implications of occupant-related assumptions in different designs and contexts.

(3) Using simultaneous combinations of occupant-related assumptions and design parameters in the modelling process. This can demonstrate possible interactions amongst occupant-related assumptions and design parameters.

(4) Devoting more research to investigate occupant-related assumptions in the mechanical engineers' design scope including the tools they use to size and design HVAC equipment. 


\section{Occupant-centric design optimization}

\section{This chapter has been published as:}

Abuimara, T., Gunay, B., \& O'Brien, W. (2021). An occupant-centric method for window and shading design optimization in office buildings, Science and Technology for the Built Environment, 27:2, 181-194, DOI: 10.1080/23744731.2020.1840217

\subsection{Abstract}

Building performance optimization is a powerful technique that assists designers in identifying optimal design solutions. However, occupant-related uncertainty is considered a major challenge that can influence the credibility of the selected optimal design. This paper proposes an occupant-centric method for window and shading design optimization in office buildings that assists designers in evaluating and handling the impact of occupant-related assumptions. The method consists of three major steps: generating occupant scenarios, conducting occupant-centric mathematical optimization, and deriving rules for selecting optimal design parameters using decision trees. An office building model with numerous possible window-related parameters was used to demonstrate the proposed optimization process. Sixty-four different occupant scenarios were considered. The results of the optimization process demonstrated that occupant-related assumptions are crucial in determining optimal window and shading design, as different occupant scenarios led to different optimal solutions. The study findings also provided insights to building 
CHAPTER 5

designers regarding classifying and selecting window and shading design parameters under varying occupant scenarios.

\subsection{Introduction}

Achieving energy efficiency in buildings has been gaining momentum with the growing international interest in mitigating the effects of climate change, fighting depletion of resources, and decreasing pollution. Professionals in architectural, engineering and construction (AEC) industry employ various tools and techniques to achieve efficiency in building designs such as building performance simulation (BPS). BPS equips designers with the ability to evaluate, improve and optimize the performance of their designs (Attia et al. 2012). Using BPS, designers can perform sensitivity analysis for different design parameters to determine the most influential ones and to propose optimal designs based on combinations of these parameters (Machairas et al. 2014). However, the process of selecting optimal design parameters among a large number of possible design parameter combinations can be time consuming and may not feasible in some cases due to time, budget, and technical constraints.

Therefore, coupling BPS with optimization (i.e. building performance optimization $(\mathrm{BPO})$ ) has become a promising technique for searching for the optimal or nearoptimal design options while complying with constraints (Attia et al. 2015; Brown 
et al. 2010; Bucking et al. 2013). Optimization algorithms automatically search and identify the combination of design parameters that lead to the optimal solution among a large number of possible combination of design parameters in a reasonable time (Bucking 2016). Generally, optimization problems minimize the value of a specified cost/objective function subject to one or more constraints. Optimization can have a single objective such as trying to minimize the total annual energy use of a building, or multiple objectives, which might be sometimes conflicting, such as trying to minimize total annual energy use of a building while minimizing initial or operating costs (Evins 2013). Single objective problems yield a single optimal solution while multi-objective optimization results come as a set of optimal design solutions distributed on a Pareto front that contains trade-offs of solutions (Hoes, Trcka, Hensen, and Hoekstra Bonnema 2011). Optimization can also be performed under constraints which limit the selection domain such as optimizing energy use without violating comfort metric thresholds for thermal, visual and acoustic comfort and indoor air quality (IAQ) (Snyman 2005).

Evolutionary algorithms are the most commonly used optimization algorithms because of their ability to handle the discontinuous and discrete nature of the building design optimization process (Hamdy et al. 2016). Genetic algorithms (GAs) are one of the most commonly used evolutionary optimization algorithms; they use 
CHAPTER 5

Darwinian principles of survival where the weakest in parameter population are eliminated at each generation (Attia et al. 2015; Evins 2013; Zang et al. 2010). The GAs adopt three main natural selection techniques: selection, crossover, and mutation. GA first creates a random population of candidate solutions for the proposed optimization. Then, selection occurs by evaluating the fitness of the solutions using a fitness function. Thereafter, a new population is generated based on the outcomes of the first generation and the generation and evaluation process continues until the termination criteria are met (Fogel 1994; Wright et al. 2002; Zang et al. 2010). Genetic algorithms were proven to be among the most efficient optimization algorithms in solving building design-related problems (Tuhus-Dubrow and Krarti 2010; Wetter and Wright 2003, 2004). While GAs have been used in a large number of optimization problems with objectives such as minimizing building energy use and/or life-cycle costs (Evins 2013; Machairas et al. 2014), the majority did not account for uncertainties that are involved in the process (Lu et al. 2017).

BPS-aided design is known for involving a certain degree of uncertainty due to a number of factors such as weather data, occupant-related assumptions and occupants' behaviors, accuracy of BPS tools, and errors of BPS user (de Wit and Augenbroe 2002). Performing BPS-aided design and optimization requires designers to manage a large number of inputs to create an energy model. These inputs are 
CHAPTER 5

related to building geometry, building systems (e.g. HVAC equipment), occupantrelated assumptions (e.g. number of people), internal loads (e.g. light power density, equipment power density, and schedules of operation), and weather data. When creating energy models, designers usually make assumptions about building occupants and their behavior. Typically, these assumptions are sourced from codes, standards (e.g., ASHRAE Standard 90.1), and/or designers' experience. The occupant-related assumptions are usually in the form of schedules and densities that indicate the fraction and the number of people that are present and fractions of lights and equipment that are in use. However, these schedules and densities are known to be outdated and not necessarily representative of today's buildings as they were developed during 1980s and were not developed using measured data (Abushakra et al. 2004; Claridge et al. 2004). In addition, these standard assumptions are recognized amongst researchers and some practitioners as a major source of uncertainty in the design process as they overlook the variations in occupancy patterns, building types, and climates (Gaetani et al. 2016; Hoes et al. 2009; Schweiker et al. 2011). Quantifying and handling occupant-related uncertainty is a challenge that influences the outcomes of the BPS-aided design and consequently BPO (Delzendeh et al. 2017). 
CHAPTER 5

To this end, this paper investigates the implications of occupant-related uncertainty on the building energy performance optimization process with emphasis on the façade design parameters:

(1) Proposing a method to evaluate the impact of different occupant scenarios on façade design optimization process in office building.

(2) Providing guidance for the selection of window and shading design parameters based on a given occupant scenario. These guidelines are derived from the outcomes of testing the proposed method on a case study office building model.

Note that this study is not meant to create a new optimization algorithm but rather to develop and demonstrate a method to evaluate occupant-related uncertainty during the optimization process. This paper first presents a three-step method to optimize window and shading design in buildings in presence of occupant behaviorand occupancy-induced uncertainty. Thereafter, the proposed method is demonstrated on a real office building in Toronto, Canada. The application includes generating occupant scenarios, running window and shading design optimization for each scenario, and consolidating and representing results in the form of occupantcentric design rules. 
CHAPTER 5

\subsection{Literature review}

Over the last two decades, a large number of studies have focused on building energy optimization (Shi et al. 2016) and energy-related occupant behaviors in buildings (Hong et al. 2017; Yan et al. 2015). Several papers have also focused on assessing the impact of occupant interactions with building components and systems such as windows, blinds, lights or thermostats on building energy and comfort performance (Gaetani et al. 2018; Gilani et al. 2018; Yan et al. 2017). However, only a few studies looked at occupant-related uncertainty during the optimization process; and, none of these studies developed an easy to implement occupant-centric building design optimization approach that can be adopted by practitioners. For example, Ouf et al. (2019) conducted a study to demonstrate the impact of occupant behavior and the occupant modeling approach on the building design optimization. They deployed a set of deterministic and stochastic occupant models on an office building model. The deterministic models did not account for occupant-related uncertainty while the stochastic models did. The deterministic models were the occupancy schedules and densities reported in ASHRAE Standard 90.1 (2016). The stochastic models were the occupancy model developed by Wang et al.(2005), the blind use model by Haldi and Robinson (2011) and the light-switch model by Reinhart (2004). The GA algorithm was employed to search for the optimal design scenario with the deterministic 
CHAPTER 5

occupant models as well as the stochastic ones. The objective of this study was to assess the influence of occupant-related uncertainty on the optimal design. The study used energy use intensity as a cost function in the case of deterministic modeling of occupants (i.e. schedules), and mean energy use intensity in the case of stochastic modeling of occupants. The results indicated similar building energy performance with both occupant modeling approaches but also that the different occupant modeling approaches led to different optimal design solutions.

Hoes et al. (2011) conducted a multi-objective optimization study considering occupant-related uncertainty during the optimization process. The objective of the study was to find the optimal window size in combination with the optimal amount of thermal mass during the shoulder season. A residential building model was used in the optimization process to investigate two design variables: window-to-wall ratio (WWR) and thermal mass. Two performance indicators were used in this study: heating energy demand intensity and the summed weighted under/overheated hours as a function of percentage of people dissatisfied (PPD). The model was simulated with nine different occupant scenarios. The scenarios included changing heating temperature setpoints, changing the magnitude of internal gains and changing the ventilation rates per person. The optimization process was first conducted without considering occupant-related uncertainty and a set of optimal design solutions were 
CHAPTER 5

generated based on their energy demand and their summed weighted under /overheated hours. Then, the same process was iterated using different occupantrelated scenarios and new sets of solutions were generated and selected based on their mean energy demand and their mean summed weighted under / overheated hours. The results of the study indicated that changes in occupant behavior can have a significant impact on performance indicators (e.g. heating energy demand) and consequently optimization results. In addition, the study concluded that some discarded solution in traditional optimization process can become one of the most robust solutions of the optimization under uncertainty (Hoes, Trcka, Hensen, and Bonnema 2011).

Bucking et al. (2011) conducted a community level optimization study to maximize electricity generation as well as to minimize energy consumption under three different occupant scenarios in a net zero energy (NZE) community. A net-zero energy (NZE) community in Montreal, Canada was used as a case study. Three occupant scenarios were considered in this study by varying the heating setpoints, cooling setpoints, and lighting and domestic hot water (DHW) energy use and appliances use and their share of internal gains. The results indicated that changing heating and cooling setpoints can shift NZE community from energy producer to an energy consumer. The study concluded that the impact of different occupant scenarios on energy use 
in a single household is significant and highly unpredictable; while from community perspective, different occupant scenarios energy impact becomes more predictable with increase of community size. The findings of this study were in line with a study by Gilani et al. (2018) that concluded that the impact of occupant behavior on lighting energy use tended to diminish with increased number of occupants.

Gang et al. (2015) studied the impact of occupant-related uncertainties on the optimization of design of cooling systems. The study looked at uncertainties associated with cooling system design parameters and proposed a design optimization method to improve the sizing and configuration of these systems. The uncertainties caused by nine different factors classified under three main categories: indoor conditions (occupancy, lighting/equipment/ventilation, temperature, relative humidity), building (envelope material, window-to-wall ratio, floor area, orientation, surface-to-volume ratio), and weather (dry-bulb temperature, relative humidity, solar radiation, wind speed). The proposed optimization method demonstrated that if uncertainties are not quantified and accounted for during the design of cooling equipment, there is a high probability of system oversizing. Furthermore, the proposed method provides the possibility to quantify the risks and benefits based on the distribution of discomfort hours and capital costs. The method also provided the 
CHAPTER 5

possibility to select the optimal cooling system configuration according to the quantified risks and benefits.

Even though a few studies dealt with occupant-related uncertainty during building design optimization, none of these studies developed an easy-to-implement approach that can be adopted by practitioners in the AEC industry. Hence, this study tries to fill this gap in the literature by proposing a practical method for occupant-centric façade design optimization.

\subsection{Methodology}

\subsubsection{Analysis approach}

To achieve the objectives of this study a three-step method was developed. As shown in Figure 5.1, the proposed method consists of three steps: (1) generating occupant scenarios, (2) initiating and conducting occupant-centric façade design mathematical optimization process, and (3) analyzing and consolidating results by deriving occupant-centric design parameter selection rules. The first step is to generate occupant scenarios, which involves different patterns of occupants' presence in buildings with associated lighting and plug-in equipment schedules. The purpose of this step is to generate a range of plausible occupancy, lighting, and plug load scenarios. In the second step, design parameters are selected and an optimization 
problem to minimize energy use for each occupant scenario is formulated with these design parameters. The third step is to derive rules to select the optimal design parameters based on the outcomes of the optimization runs under different occupant scenarios. Decision trees are trained to consolidate the optimization results to generate design solutions overarching multiple occupant scenarios.

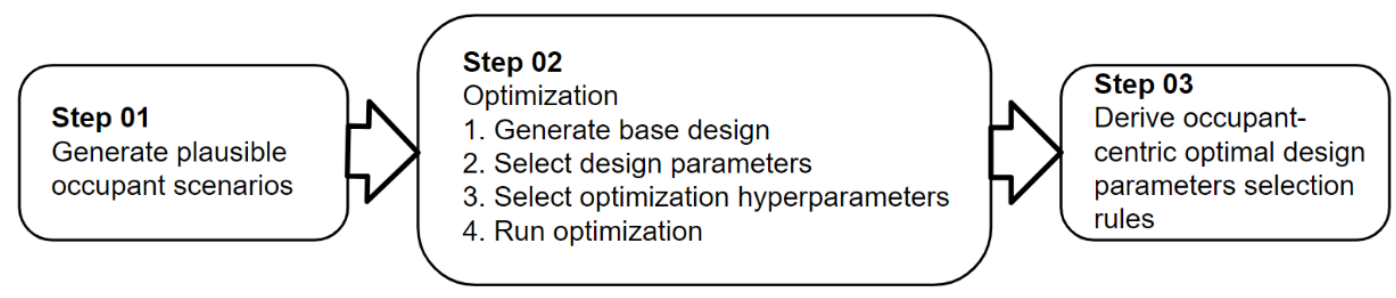

Figure 5.1: The three-step method for occupant-centric building design optimization

\subsubsection{Occupant scenarios}

The first step of implementing the proposed method is to identify possible common occupant scenarios for the building under design. The selected occupant scenarios should include other occupant-related inputs such as lights schedules and plug-in equipment schedules as they can be considered linearly correlated (Hobson et al. 2019; Mahdavi et al. 2016). The selected occupant scenarios should be plausible and easy to implement, recognizing the knowledge of practitioners and limitations of BPS tools. While the state-of-the-art in research focuses on stochastic agent-based models (Yan and Hong 2018), these are not commonly used in practice (O'Brien et al. 2016), are less suitable for the building scale (Gilani et al. 2018), and generally not yet 
available in BPS tools (Ouf et al. 2018). Instead, this paper introduces a practical method to optimize façade design in office buildings, while considering uncertainty in a way that leverages existing BPS tool features and practitioner modelling approaches. In addition, these models were built on relatively small datasets from a small number of occupants and only a few buildings that cannot be generalized for other buildings (Schweiker et al. 2011)

In the application of the method, we used four different occupancy scenarios: code occupancy schedule, low occupancy schedule, morning peak occupancy schedule, and afternoon peak occupancy schedule as shown in Figure 5.2. The four plausible occupancy scenarios were generated as representative for different occupancy patterns in buildings which is very common in office buildings (D'Oca and Hong 2015; Duarte et al. 2013).

Based on these four different occupancy scenarios a number of combinations of occupancy, lighting, and equipment scenarios were generated assuming a linear relationship between occupant counts and lighting and equipment loads (Hobson et al. 2019; Kim and Srebric 2017; Mahdavi et al. 2016). To this end, a line-fit is applied between the hourly occupancy and electricity use values for lighting and equipment based on the code stated values. Then, variations of this relationship are generated by altering the slope and the intercept of this linear regression model as shown in 
CHAPTER 5

Figure 5.4 and Figure 5.5. The relationship between occupancy and lighting/equipment was altered to represent alternative patterns of use such as having a higher fraction of lighting and equipment loads during unoccupied hours and having a lower fraction of lighting and equipment loads during the occupied hours than code stated typical values. These modified schedules represents different plug-in equipment and lighting loads during unoccupied hours in a more realistic fashion than typical code values (Bennet and O'Brien 2017; Hensen and Lamberts 2012; Liang et al. 2016; Masoso and Grobler 2010; Menezes et al. 2014).

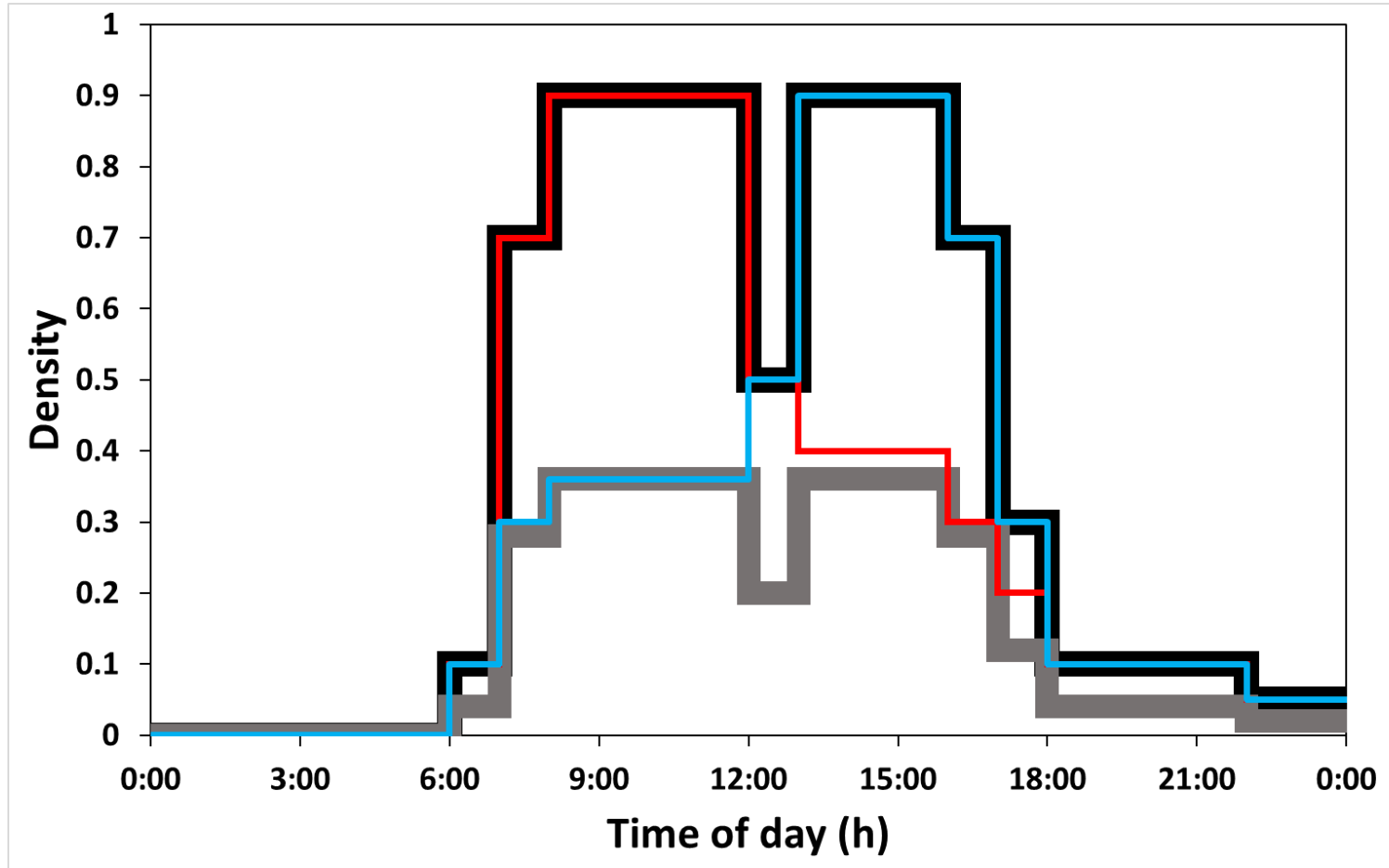

-Typical code occupancy Low occupancy - Morning peak occupancy - Afternoon peak occupancy

Figure 5.2: Occupancy schedule scenarios. 
Sixty-four combinations of the schedules (occupant scenarios) are generated by applying these altered mathematical relationships to the four occupancy scenarios shown in Figure 5.2: code, low-occupancy, morning-peak occupancy, and afternoonpeak occupancy. In the application of step 2 of the proposed method, optimization was performed for each one of the 64 scenarios. The process of generating occupant scenarios that are used in this study is summarized in Figure 5.3.

\begin{tabular}{|c|c|c|}
\hline & & \\
\hline & & Total 64 occupant scenarios \\
\hline $\begin{array}{l}\text { Occupancy scenarios } \\
\text { - Code }\end{array}$ & $\begin{array}{l}4 \text { lighting scenarios } \\
\text { per occupancy scenario }\end{array}$ & $\begin{array}{l}\text {-16 scenarios based on code } \\
\text { occupancy } \\
\text { - } 16 \text { scenarios based on low }\end{array}$ \\
\hline - Low & 4 equipment scenarios & $\begin{array}{l}\text { occupancy } \\
\text { - } 16 \text { scenarios based on morning peak }\end{array}$ \\
\hline • Afternoon peak & per occupancy scenario & $\begin{array}{l}\text { occupancy } \\
\text {-16 scenarios based on afternoon } \\
\text { occupancy }\end{array}$ \\
\hline
\end{tabular}

Figure 5.3: Generating occupant scenarios workflow

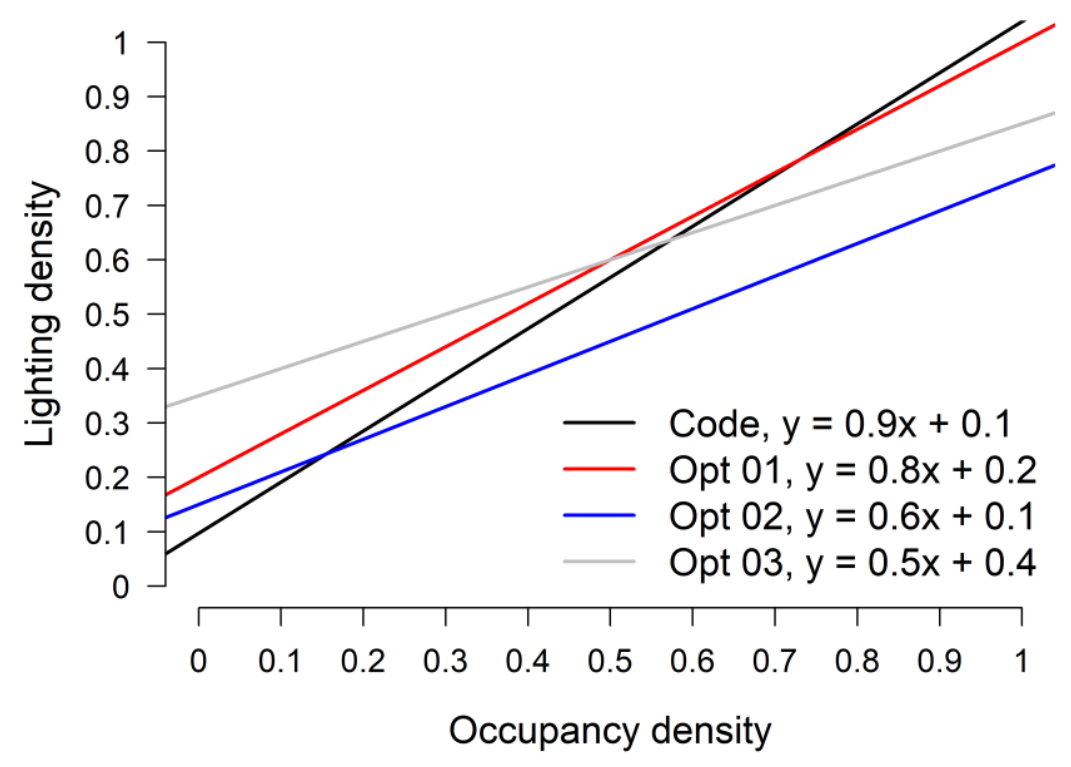

Figure 5.4: Occupancy-lighting mathematical relationship: an example set of alternatives using the building energy code stated values. Each point represents the fraction of lighting load at a given occupied fraction. 


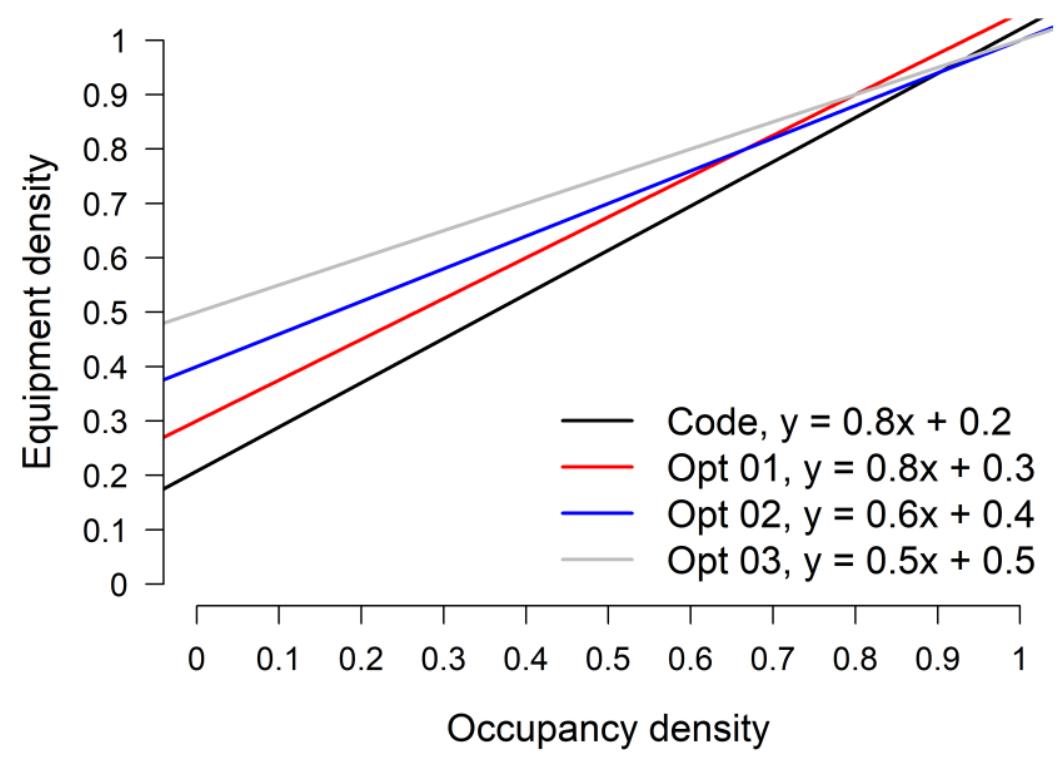

Figure 5.5: Occupancy-equipment mathematical relationship: an example set of alternatives using the building energy code stated values. Each point represents the fraction of equipment load at a given occupied fraction.

\subsubsection{Optimization settings and design parameters}

Brute force search of the optimal design parameters for each of the 64 occupant scenarios would require about $67,000,000$ simulations - which evidently would not be practical considering the computational power required. Thus, we decided to employ a mathematical optimization algorithm to search for the solution space more efficiently.

To this end, a mixed integer GA was used to perform the optimization in MATLAB 2019b. The fraction of crossover, which is a process of mixing candidate solutions to generate a new one, is set to be (0.8). The population size was set to 30 . If the building energy use does not reduce for five consecutive generations or after 20 
CHAPTER 5

generations are reached, the optimization is terminated because it is assumed that a minimum has been reached. The selection of these hyperparameters was based on a sensitivity analysis. In other words, the population size and the number of generations that yields the same optimal design solution when the optimization is run repeatedly were selected. To this end, twelve different hyperparameter combinations ranging from a population size of 15 to 75 and a maximum number of generations from 10 to 30 were tested under three different occupant scenarios.

The GA and the EnergyPlus model were executed using a custom MATLAB script. The objective of the optimization was to minimize the HVAC energy use. A penalty factor was introduced to the cost function which drastically increases the value of cost function when the number of unmet hours in the building for a given design solution exceeds 300 hours per year. The sensitivity to this 300 unmet hour threshold was tested using alternative threshold values of 250 and 350 hours to ensure that no optimal or near optimal solution is excluded because of a slight change in this threshold. The optimization process was executed sixty-four times (one for each occupancy scenario) and the results of each simulation run as well as the optimal design solutions were written to CSV files. 
CHAPTER 5

\subsubsection{Rule extraction}

In the third step of the proposed method, decision trees were trained based on the optimization results to derive overarching design solutions for multiple occupant scenarios. To this end, MATLAB's fitctree function was used. The decision trees were not restricted and were allowed to grow until all decision paths end. The decision trees can serve as design guidelines to inform design stakeholders on how to select optimal design parameters that better suit the occupant scenario of the building they are designing.

\subsubsection{Case study building}

The three-step occupant-centric design optimization method was applied to an office building model located in Toronto, Canada (see Figure 5.6). The model is the top floor of the office building which was modeled with five thermal zones (four parameter zones and one core zone). The model has a rooftop packaged HVAC unit and a hydronic baseboard heating system. The HVAC economizer is controlled based on differential dry-bulb temperature. The HVAC has a heat recovery ventilator (HRV) that has sensible effectiveness of $70 \%$ and $85 \%$ at $100 \%$ and $75 \%$ of heating air flow, respectively. The building envelope has an overall $46 \%$ window-to-wall ratio (WWR), the walls' thermal resistance was $4 \mathrm{~W} / \mathrm{m}^{2} \cdot \mathrm{K}$, and the roof thermal resistance was $7 \mathrm{~W} / \mathrm{m}^{2} \cdot \mathrm{K}$. These values are set to meet the requirements of the 
CHAPTER 5

National Energy Code for Buildings in Canada (NECB) and the values used in designing the actual building in Toronto, Canada. All windows are fixed and interior shading (blinds) was set to be closed when the total incident solar radiation on window exterior surface exceeds $200 \mathrm{~W} / \mathrm{m}^{2}$.

The cooling setpoints were selected to be $24^{\circ} \mathrm{C}$ during occupied hours and $26.7^{\circ} \mathrm{C}$ during unoccupied hours. Heating setpoints were $22^{\circ} \mathrm{C}$ during occupied hours and $16^{\circ} \mathrm{C}$ unoccupied hours. The HVAC was scheduled to be in operation from 5:00 am to 10:00 pm and the seasonal switch-over from heating to cooling and from cooling to heating happens on May $1^{\text {st }}$ and September $30^{\text {th }}$, respectively.

Ten design parameters listed in Figure 2 were used in the optimization process with four values for each design parameter. The design parameters were selected to be window- and shading-related as their energy impact (positive or negative) is not always obvious, thus yielding a more interesting design optimization exercise. Trivial design parameters for which extreme and obvious values are optimal were not included. For example, for boiler and chiller coefficient of performance (COP), a higher value is always better from the energy efficiency perspective (and the cost function). In contrast, overhang geometry affects heating and cooling energy in opposite directions with a relatively unpredictable net benefit or detriment. The same can be said for window-to-wall ratio (WWR) and window material. 


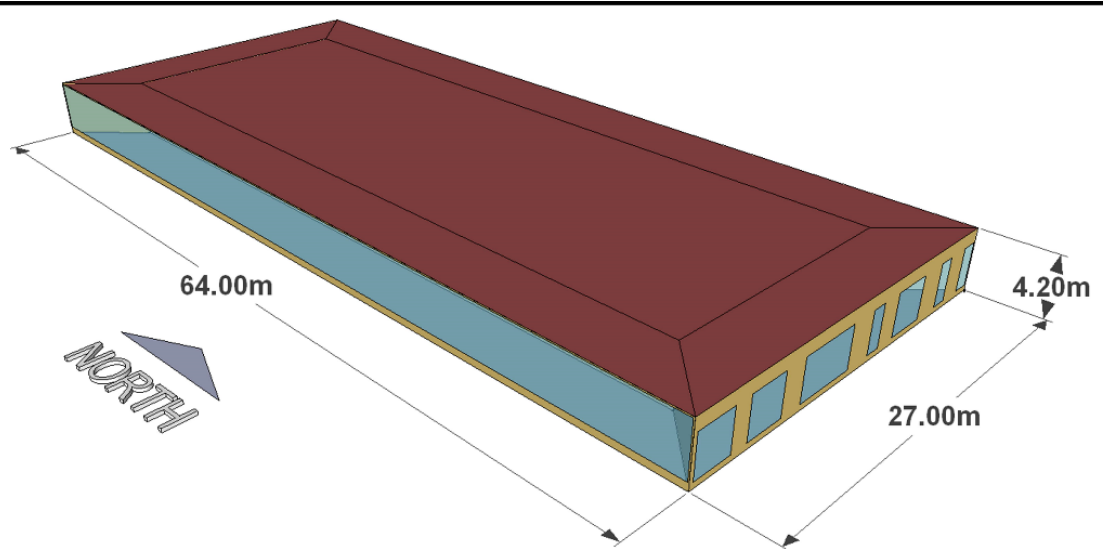

Base model

$1728 \mathrm{~m}^{2}$ office floor located in Toronto, Canada; 5 thermal zones; $46.5 \%$ window-to-wall ratio; RT package unit \& 5 VAV units; ASHRAE 62.1 standard outdoor air rates; baseboard heating; NECB 2015 lighting and plug load densities

\section{Occupancy scenarios \\ 1. Code occupancy schedule \\ 2. Low occupancy schedule \\ 3. Morning peak occupancy schedule \\ 4. Afternoon peak occupancy schedule}

Lighting: 4 alternative lighting scenarios per occupancy scenario

Equipment: 4 alternative equipment scenarios per occupancy scenario

\begin{tabular}{|c|c|c|c|c|c|}
\hline Optimization Parameters & Units & Option 1 & Option 2 & Option 3 & Option 4 \\
\hline $\begin{array}{l}\text { Blind } \\
\text { Solar Transmittance } \\
\text { Solar Reflectance }\end{array}$ & - & $\begin{array}{l}0.05 \\
0.75\end{array}$ & $\begin{array}{l}0.12 \\
0.42\end{array}$ & $\begin{array}{l}0.11 \\
0.38\end{array}$ & $\begin{array}{l}0 \\
0.65\end{array}$ \\
\hline $\begin{array}{l}\text { South windows options } \\
\text { U-factor } \\
\text { SHGC }\end{array}$ & $\mathrm{W} / \mathrm{m}^{2} \cdot \mathrm{K}$ & $\begin{array}{l}\text { Win [01] } \\
1.836 \\
0.493\end{array}$ & $\begin{array}{l}\text { Win [02] } \\
1.532 \\
0.516\end{array}$ & $\begin{array}{l}\text { Win [03] } \\
1.788 \\
0.332\end{array}$ & $\begin{array}{l}\text { Win [04] } \\
1.99 \\
0.294\end{array}$ \\
\hline $\begin{array}{l}\text { North windows options } \\
\text { U-factor } \\
\text { SHGC }\end{array}$ & $\mathrm{W} / \mathrm{m}^{2} \cdot \mathrm{K}$ & $\begin{array}{l}\text { Win [01] } \\
1.836 \\
0.493\end{array}$ & $\begin{array}{l}\text { Win [02] } \\
1.532 \\
0.516\end{array}$ & $\begin{array}{l}\text { Win [03] } \\
1.788 \\
0.332\end{array}$ & $\begin{array}{l}\text { Win [04] } \\
1.99 \\
0.294\end{array}$ \\
\hline $\begin{array}{l}\text { East windows options } \\
\text { U-factor } \\
\text { SHGC }\end{array}$ & $\mathrm{W} / \mathrm{m}^{2} \cdot \mathrm{K}$ & $\begin{array}{l}\text { Win [01] } \\
1.836 \\
0.493\end{array}$ & $\begin{array}{l}\text { Win [02] } \\
1.532 \\
0.516\end{array}$ & $\begin{array}{l}\text { Win [03] } \\
1.788 \\
0.332 \\
\end{array}$ & $\begin{array}{l}\text { Win [04] } \\
1.99 \\
0.294\end{array}$ \\
\hline $\begin{array}{l}\text { West windows options } \\
\text { U-factor } \\
\text { SHGC }\end{array}$ & $\mathrm{W} / \mathrm{m}^{2} \cdot \mathrm{K}$ & $\begin{array}{l}\text { Win [01] } \\
1.836 \\
0.493 \\
\end{array}$ & $\begin{array}{l}\text { Win [02] } \\
1.532 \\
0.516 \\
\end{array}$ & $\begin{array}{l}\text { Win [03] } \\
1.788 \\
0.332 \\
\end{array}$ & $\begin{array}{l}\text { Win [04] } \\
1.99 \\
0.294 \\
\end{array}$ \\
\hline $\begin{array}{l}\text { Window to wall ratio } \\
\text { (south) }\end{array}$ & - & $\begin{array}{l}30 \% \\
\text { (overall WWR } \\
=27.3 \% \text { ) }\end{array}$ & $\begin{array}{l}50 \% \\
\text { (overall } \\
\text { WWR = } \\
34 \% \text { ) }\end{array}$ & $\begin{array}{l}70 \% \\
\text { (overall } \\
\text { WWR = } \\
41 \% \text { ) }\end{array}$ & $\begin{array}{l}85 \% \\
\text { (overall WWR } \\
=46.5 \% \text { ) }\end{array}$ \\
\hline $\begin{array}{l}\text { Exterior shading- } \\
\text { overhangs depth (south) }\end{array}$ & $\mathrm{m}$ & 0 & 1.2 & 1.8 & 2.4 \\
\hline $\begin{array}{l}\text { Exterior shading- } \\
\text { overhangs depth (west) }\end{array}$ & $\mathrm{m}$ & 0 & 1.2 & 1.8 & 2.4 \\
\hline $\begin{array}{l}\text { Exterior shading-fins } \\
\text { depth (south) }\end{array}$ & $\mathrm{m}$ & 0 & 1.2 & 1.8 & 2.4 \\
\hline $\begin{array}{l}\text { Exterior shading-fins } \\
\text { depth (west) }\end{array}$ & $\mathrm{m}$ & 0 & 1.2 & 1.8 & 2.4 \\
\hline
\end{tabular}

Figure 5.6: An overview of the base case EnergyPlus model, occupancy scenarios, lighting and equipment scenarios, and the design parameters for optimization processes. 
CHAPTER 5

\subsection{Results and discussion}

\subsubsection{Optimization results}

For the sixty-four different occupant scenarios resulted from varying lighting and plug-in equipment schedules for the four occupancy scenarios (code, low, morning peak, and afternoon peak schedules), the ten design parameters that were used to obtain the minimum value of the cost function (i.e. HVAC energy use intensity) were determined by the genetic algorithm search process. The genetic algorithm search results were verified by running the optimization iteratively for three different occupant scenarios to ensure that the search process is converging to the same design solution for the same occupant scenario.

Overall, the results of the optimization process demonstrate that occupant scenarios have a significant impact on the results of the optimization process. Figure 5.7 presents the results of the energy performance distributions for the office building model described in Figure 5.6 using the sixty-four different occupant scenarios. Furthermore, the results indicate that with the same occupancy scenario (e.g. code occupancy scenario in Figure 5.7), HVAC energy use intensity can vary drastically as a result of using alternative lighting and plug-in equipment use patterns (i.e. lighting and equipment schedules). Variable plug-in equipment and lighting use 
CHAPTER 5

patterns resulted in variable internal heat gains which affected HVAC sizing, heating and cooling loads, and consequently energy use of the HVAC.

The box and whisker plot in Figure 5.7 reveals that the median of the cost function changes considerably with each different occupant scenario. The plot also indicates the presence of outlier solutions that fall outside the interquartile range of the plot and non-existence of any outliers at the lower part of the population. In other words, the results show that there is a wide range of bad design parameter, though optimal design parameters do not lead to significantly better performance than the near optimal ones. The results presented in Figure 5.10 for each optimization run show that there are a significant number of design parameters combinations that led to an inefficient design as the cost function value (i.e. HVAC energy use intensity) improves substantially during the first two to three generations (with 30 simulations per generation). However, the energy performance of the optimal design in general was only slightly better than of the near optimal design alternatives. This finding can provide insights to building designers and modelers about exploring families of near optimal design parameters instead of a single optimal design. The flexibility in choosing optimal design parameters facilitates trade-offs and assists designers in dealing with constraints such as budget limitations, aesthetics, and construction feasibility. 
Figure 5.8 and Figure 5.9 provide a closer look at the heating and cooling energy use intensities of the optimization results of the case study under the sixty-four occupant scenarios. Overall, Figure 5.8 and Figure 5.9 indicate that both cooling and heating energy use were sensitive to the occupant scenarios. Furthermore, Figure 5.8 and Figure 5.9 indicate that the impact of occupant scenarios on heating is the opposite to the impact on cooling use intensity. For example, with low occupancy scenarios, heating energy use intensities experienced a substantial increase while cooling energy use intensities experienced a substantial decrease. This substantial increase in heating energy and decrease in cooling energy are as result of decreased internal gains from occupants' presence, lights, and plug-in equipment.

Figure 5.11 presents an example of different optimal design solution resulted from running optimization using alternative occupant scenarios. It shows that running optimization under different occupant scenarios can yield different optimal solutions. For example, with the morning peak occupancy scenario, a window with higher thermal resistance (lower U-value) was selected for north-facing windows to reduce heat loss as the building experience reduction in internal gains during the afternoon. In addition, smaller exterior overhang and sidefin shading were selected for the morning peak occupancy scenario compared to code occupancy scenario. Smaller exterior shading increases the solar gains which offsets the decrease in internal gains. 


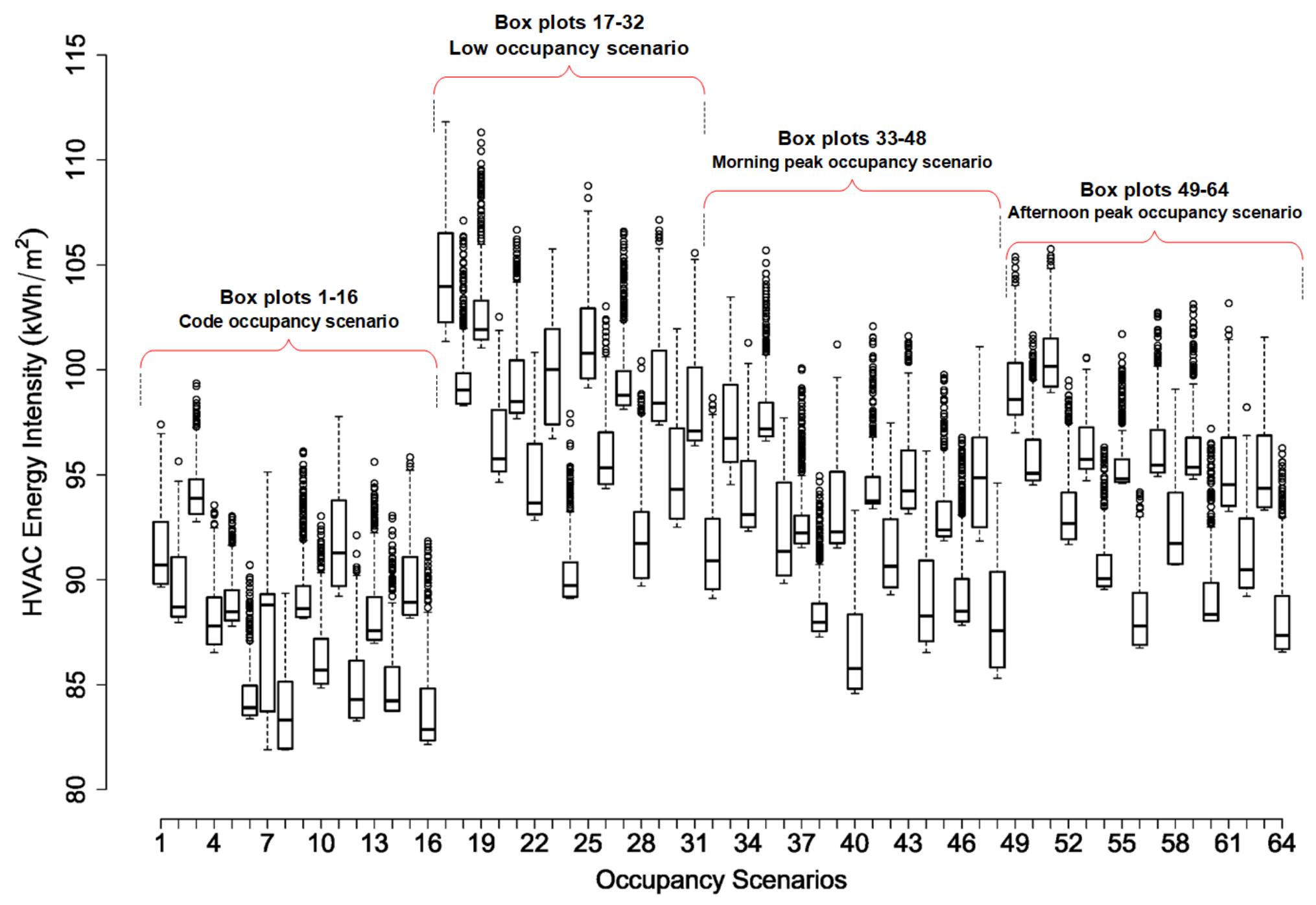

Figure 5.7: Design optimization results under the sixty-four occupant scenarios 


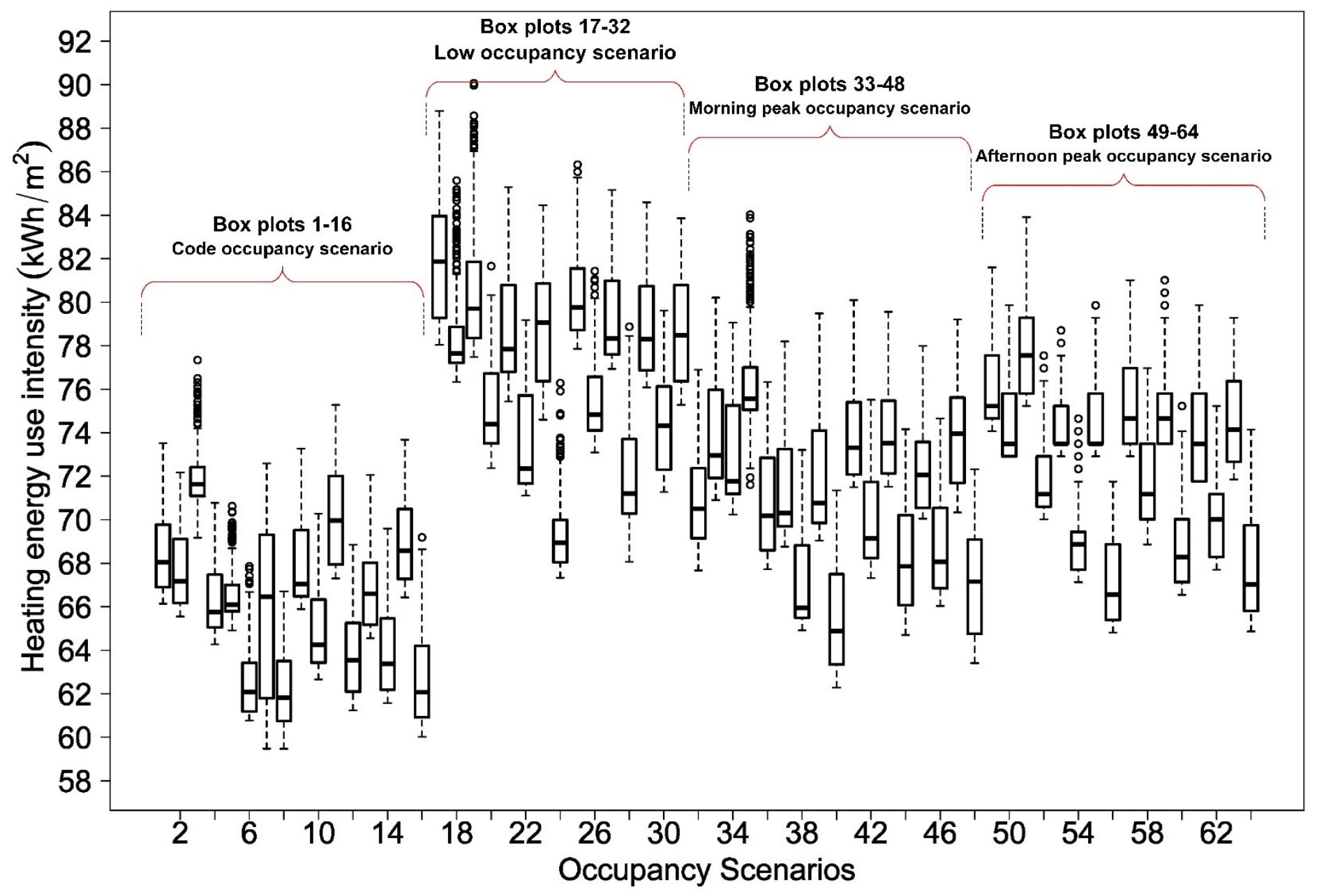

Figure 5.8: Heating energy use intensity of optimization runs under the sixty-four occupant scenarios. 


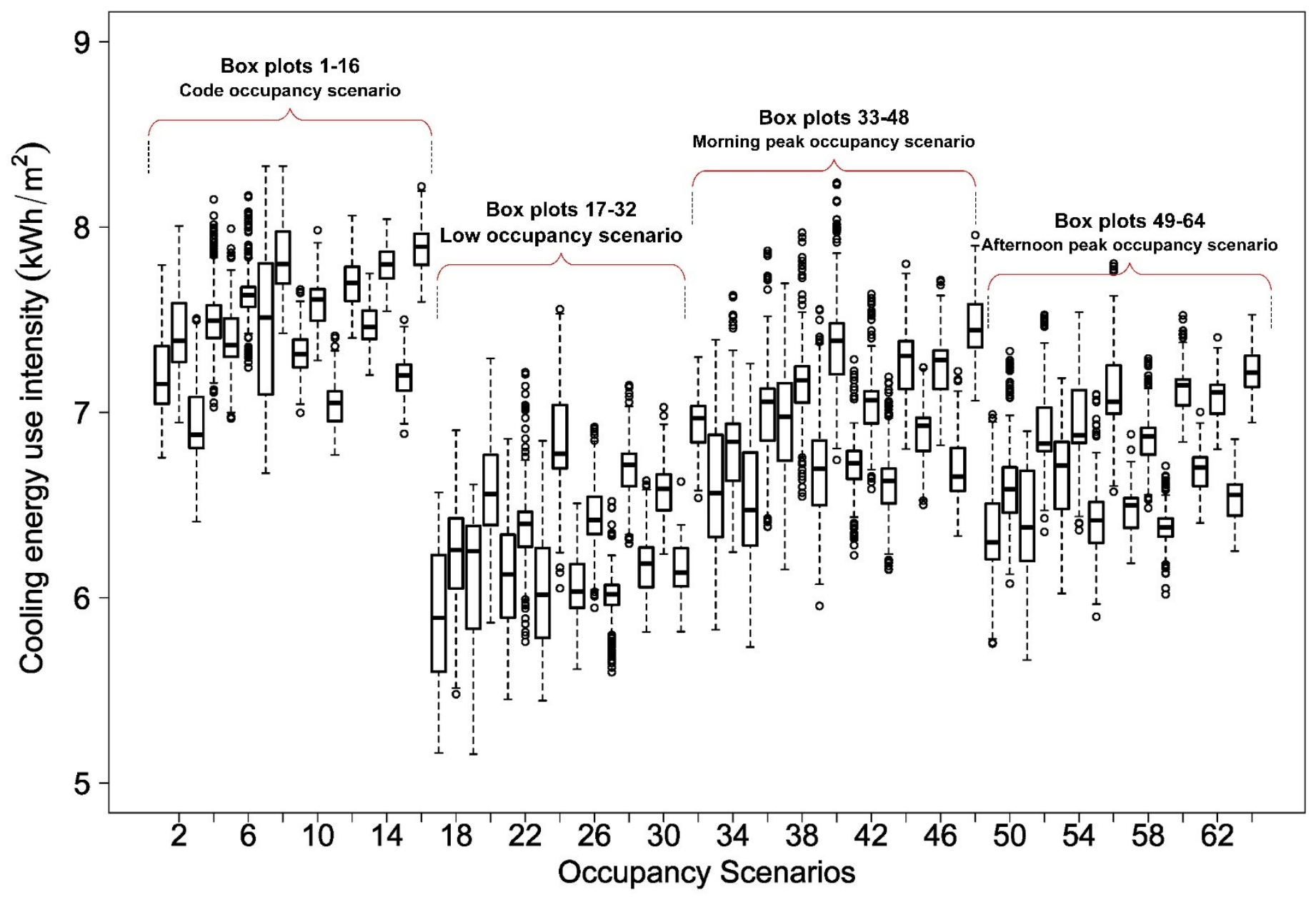

Figure 5.9: Cooling energy use intensity of optimization runs under the sixty-four occupant scenarios. 

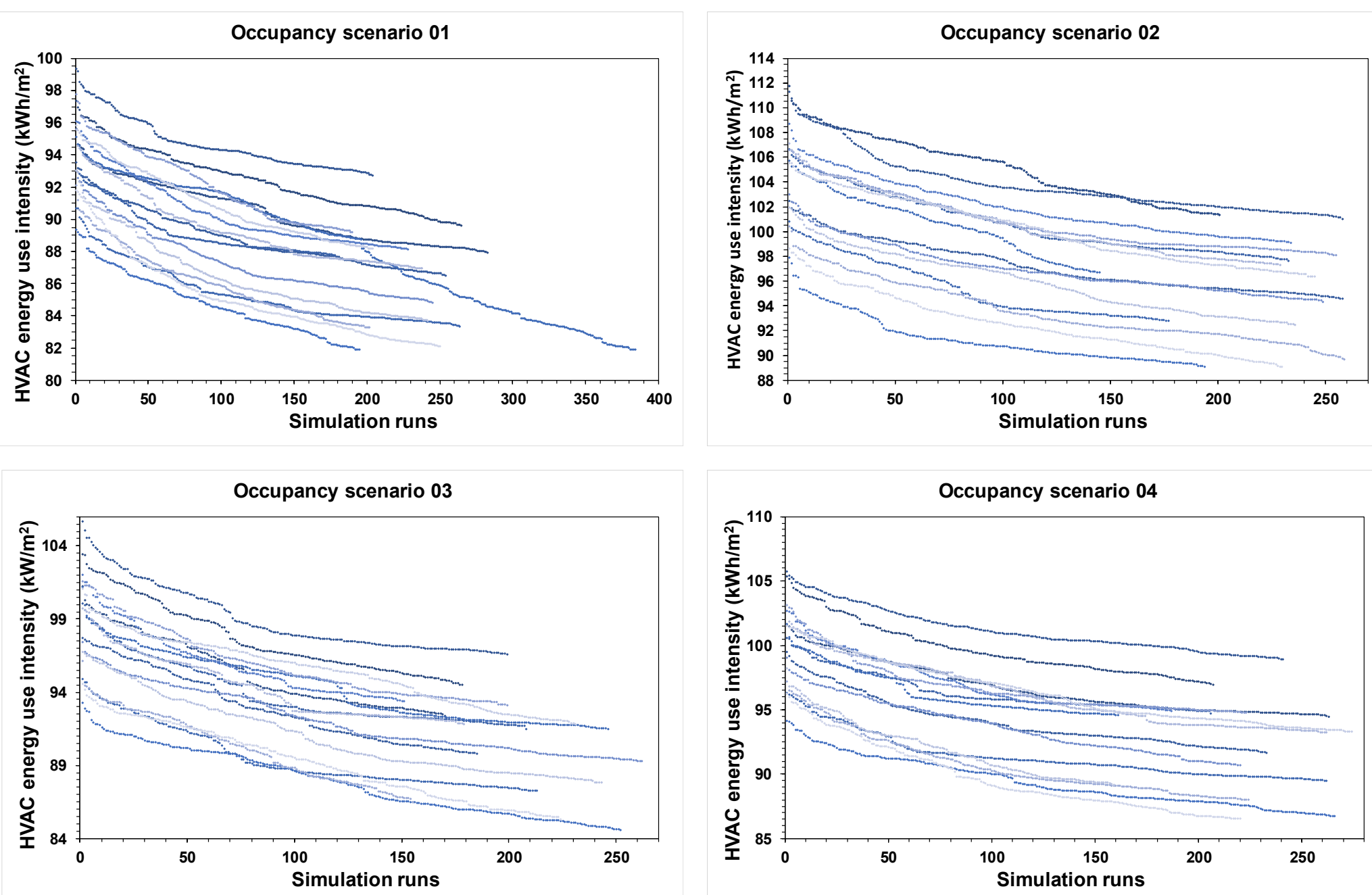

Figure 5.10: Detailed optimization results for each occupant scenario. Each plot has 16 scatter plots. Each scatter plot represents an optimization run for an occupant scenario. The length of the scatter plot indicates where the optimization run converged to the optimal solution. The end part of each scatter plot shows a group of design solutions with similar energy performance. 


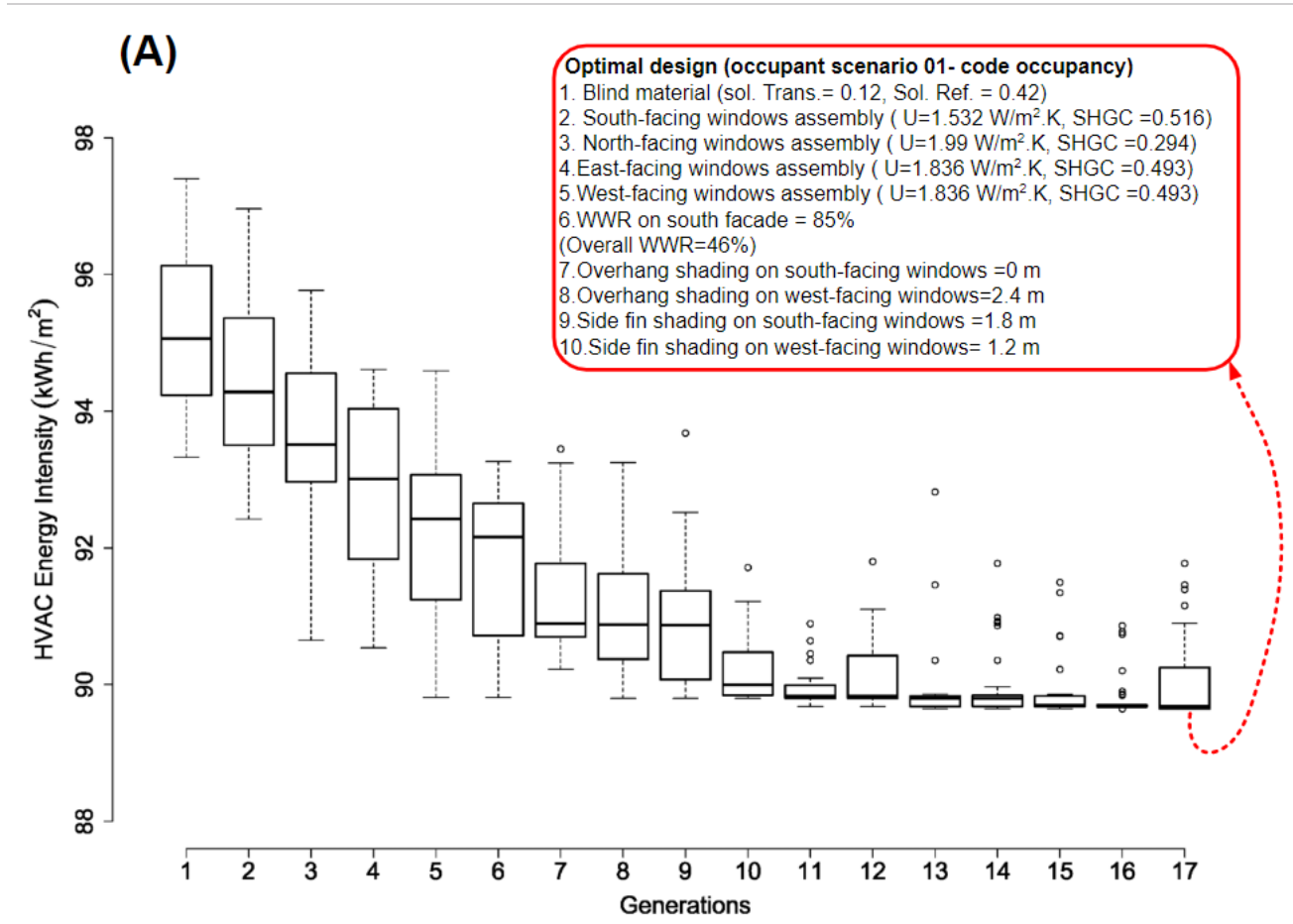

(B)

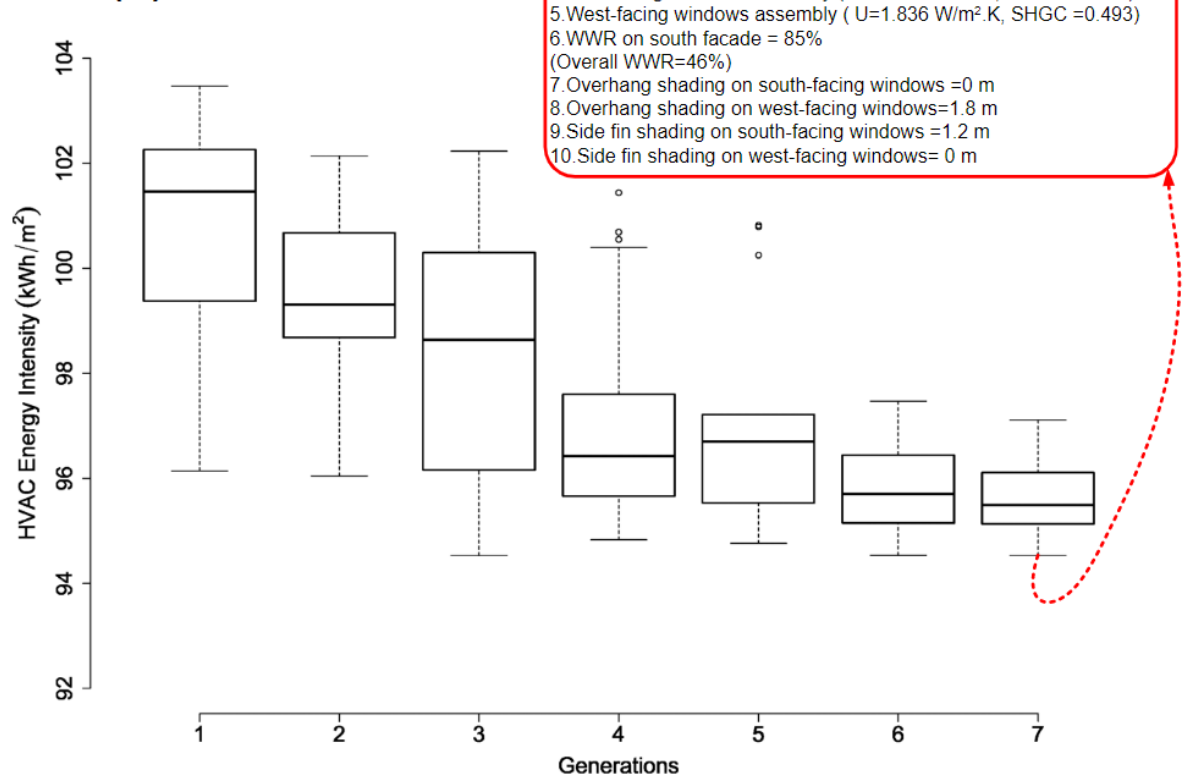

Figure 5.11: Example optimal design solution for two different occupant scenarios: (A) occupant scenario 01 (code occupancy and option 01 of equipment and lights as shown in Figure 5.4 and Figure 5.5) and (B) occupant scenario 33 (morning peak occupancy and option 01 of equipment and lights as shown in Figure 5.4 and Figure 5.5). 
CHAPTER 5

\subsubsection{Decision trees}

After performing the optimization process under the 64 occupant scenarios, the challenge was to utilize and visualize these results. For this purpose, decision trees were generated using the 64 optimal design solutions of the optimization runs as shown in Figure 5.12 to concisely present the relationship between the tested design parameters and the occupant scenarios. Decision trees are useful in visualizing and presenting optimization results as they highlight the design parameters that are sensitive to changing occupant scenarios and the ones that can be considered robust to occupant variables. Designers could use the classification provided by the decision trees to carefully investigate the implications of using certain design feature that demonstrate high sensitivity to different occupant scenario and possibly select the ones that demonstrate robustness to different occupant scenario especially with the absence of data about building occupancy.

Overall, the decisions trees for the results of the case study optimization indicated that occupant scenarios are primary factors that influence the selection of optimal design parameters as shown in Figure 5.12. A, D, E, I, and G. For example, in selecting the size of window sidefin shading on south façade (see Figure 5.12.A), plug-

in equipment schedule scenario was the primary factor in determining the size of the window sidefin shading. Occupancy schedule scenarios (e.g. code, low and afternoon 
CHAPTER 5

peak occupancy) were in the second place as a determining factor for selecting the size of window sidefin shading. Results also indicated that choosing the optimal window-to-wall ratio (WWR) for south-facing façade was not sensitive to any of the tested occupant scenarios as the decision tree in Figure 5.12.B pointed out a single optimal design parameter $(\mathrm{WWR}=85 \%$ on south, overall WWR $=46 \%$ ) with all occupant scenarios. In addition, the overhang size on south-facing windows did not change with all tested occupant scenarios as indicated in Figure 5.12.C. The derived parameter selection rule here indicates that implementing an overhang on southfacing façade is not beneficial in terms of HVAC energy performance in this particular case.

To verify this, a sensitivity analysis was conducted using two different occupancy scenarios: code occupancy and low occupancy scenarios. Figure 5.13 indicates that for this building model applying an overhang shading on south façade regardless its depth resulted in an increase in the HVAC energy use intensity as a result of an increased demand on heating as window overhang shading blocks a portion of the solar radiation and decreases the solar heat gains through the window during the heating season. It also indicates that the design decision to not have an overhang does not change based on occupant scenarios for this building. 
CHAPTER 5

Contrary to the increased heating energy, applying an overhang on south-facing windows resulted in a decreased cooling energy; however, the magnitude of increase in heating energy demand outweighs the decrease in cooling energy demand.

Provided the previous two design parameter selection rule shown in Figure 5.12. B \& $\mathrm{C}$, larger windows on south-facing façade allow higher solar heat gains into the building during heating season; however, larger windows on the south-facing façade with no exterior overhang as recommended by these two rules in Figure 5.12. B \& C might cause visual discomfort because of glare or thermal discomfort for occupants setting next to these windows during sunny days. This study's focus is on energy performance of the building and did not examine visual comfort and daylight which will be a subject of further investigations in the future.

On the other hand, occupancy schedule scenario was the primary influencing factor in selecting west-facing window sidefin shading size followed by lighting schedule scenario as shown in Figure 5.12. D. Further, sizing of overhang on the west-facing windows was primarily dependent on lighting schedule as shown in Figure 5.12.E. followed by equipment and occupancy schedules. 

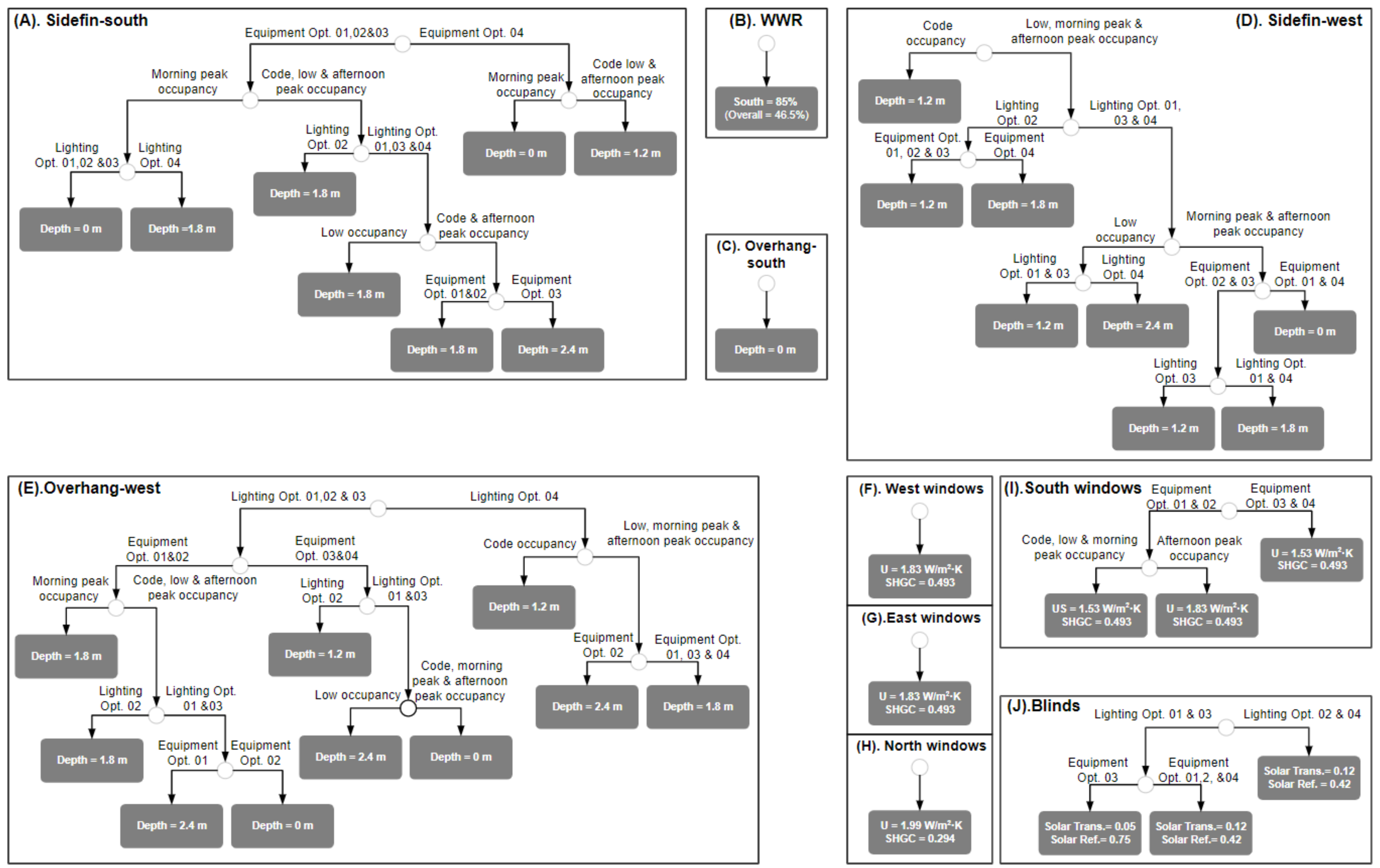

Figure 5.12: Decision trees derived based on the results of the optimization process 
CHAPTER 5

Admitting excessive amounts of solar radiation through west-facing windows along with excessive internal gains including occupants can cause overheating of west-facing spaces in the afternoons. Hence, using sidefins and overhang shading on west-facing windows manage the amount of admitted solar radiation and consequently reduce overheating. Therefore, sizing sidefins and overhangs on west-facing windows is influenced by occupant scenarios as the lower the number of occupants and associated lighting and equipment loads in a westfacing space is the more the need for solar radiation in heating seasons and vice versa.

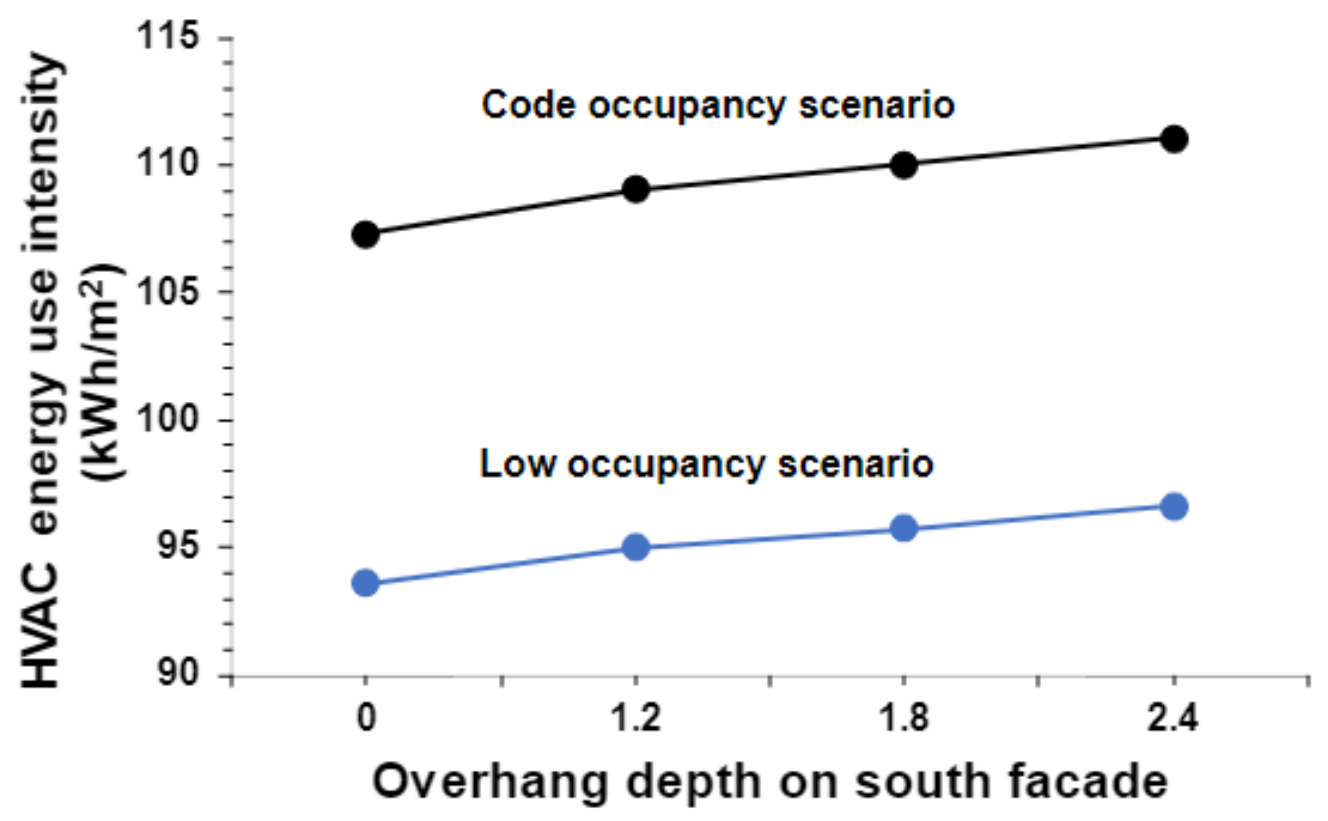

Figure 5.13: Sensitivity analysis for the use of overhang shading on south-facing windows Selecting the optimal window assembly characteristics (i.e. U-value and SHGC) for south-facing windows was in the first place influenced by plug-in equipment schedule scenarios while occupancy schedule scenarios were at second place as shown in Figure 5.12. I. The presence of plug-in equipment is considered one of the main sources of 
CHAPTER 5

internal gains that has a considerable continuous fraction during the unoccupied hours (20\% at the lowest). Windows with higher SHGC on the south façade, which is exposed for the longest to direct solar radiation, along with high equipment loads can lead to an increased demand on cooling and a decreased demand on heating.

In contrast, selecting optimal window assemblies for east, west, and north facing windows was not influenced by any of occupancy, lighting or equipment scenarios (see Figure 5.12.F). Therefore, designers should pay greater attention to occupant scenarios when specifying window assemblies in south-facing building zones.

Aside from the interpretation of the results of the decision trees, the used methodology to visualize and consolidate the optimization outcomes can be deployed further to derive design rules for designing different building types in different contexts. It also can be implemented using different sets of design parameters as only window-related design parameters were tested in this study.

Furthermore, the developed occupant-centric optimization method can be implemented on a broader range of building types, sizes and climate zones to yield rules that can be beneficial in updating building codes and standards in relation to occupants. For instance, building codes can provide guidance for choosing window assemblies (U-factor and SHGC) in light of building occupancy patterns. 


\subsection{Limitations and future work}

The proposed method and the results are associated with several limitations that

will be considered in the future. These limitations include:

(1) The methodology considered only the uncertainties from occupants' presence (occupancy schedules) and their use of lighting and plug-in equipment (lighting and equipment schedules). While other occupant-related uncertainties such as occupants' interactions with operable windows, blinds, and thermostats were not considered as they were found to have minimal effects on large office buildings in the Canadian context (O'Brien et al. 2019).

(2) The cost function included HVAC energy use intensity, with a penalty when unmet hours exceed the permitted level by ASHRAE Standard 90.1. In this study, indoor air temperature was the only metric for evaluating thermal comfort. Other elements of occupants' comfort such as visual comfort, acoustic comfort and indoor air quality (IAQ) were not evaluated.

(3) The cost function used HVAC energy use intensity as a metric for energy performance and did not include any penalty for the timing and magnitude of peak energy demand. 
CHAPTER 5

(4) The selection of genetic algorithm parameters such as population size and the number of generations were determined based on a sensitivity analysis to assess the consistency of the optimal solutions.

(5) Despite the use of decision trees is a useful approach to visualize and derive rules for design parameters selection, it becomes more complex when handling many scenarios as the population of scenarios increases exponentially.

For future work there are tasks that are still unsolved and need to be investigated further such as:

(1) This approach should be applied to other building archetypes (different geometries in other climates) with a larger set of design parameters to develop generalized design recommendations that can be incorporated in building codes/standards. In addition, the sensitivity of design parameters to occupancy scenarios should be evaluated using a variety of cost functions and different optimization algorithms.

(2) Other aspects of occupants' comfort such as visual comfort, acoustic comfort and IAQ should be considered in future occupant-centric optimization studies.

(3) This study focused on mechanically ventilated buildings which are the dominant type in cold climates such as Canada. Future work should consider 
the application of the proposed method in milder climates and include other sources of occupant-related uncertainty such as occupants' interactions with operable windows for natural ventilation.

(4) Herein, we used mixed integer GA to search for the optimal window and shading design solution. While there are other search algorithms in the literature including but not limited to particle swarm, ant colony optimization, simulated annealing, etc, we did not study the impact of optimization algorithm on the results. Future work should investigate other building performance optimization approaches in presence of occupant-driven uncertainties.

\subsection{Conclusion}

A method for occupant-centric façade design optimization in office buildings was presented to evaluate and handle the impact of occupant-related assumptions on design optimization using sixty-four combinations of occupancy, lighting and equipment schedule scenarios. The method consisted of three major steps: generating occupancy scenarios, running the occupant-centric optimization process, and deriving occupant-centric design parameters selection rules that can serve as design guidelines. 
In the first step, sixty-four occupant scenarios were generated by altering the mathematical relationship between occupants' presence and the use of lights and plug-in equipment. Four different patterns of occupants' presences were used: typical code occupancy, low occupancy, morning peak occupancy and afternoon peak occupancy. Sixteen different combinations per occupancy scenarios were created.

The second step involved conducting occupant-centric optimization for each of the sixty-four occupant scenarios. The genetic algorithm was employed to perform the search for the optimal solution for under each occupancy scenario on an office building model. The findings of this step indicated that different assumptions about occupants can lead to different design solutions. In addition, the results demonstrated that even within the same occupancy scenario, different light and equipment use patterns can affect the outcomes of optimization process.

The final step was to derive design parameter selection rules by deriving relationships between the results of the optimization and the occupant scenarios. These relationships were visualized in the The study findings offered insights to building designers on design parameters selection. Designers can, by employing the method presented in this study, choose robust design parameters over the parameters that are sensitive to occupant assumptions. Additionally, the proposed optimization 
CHAPTER 5

method highlights the uncertainty of performance associated with certain design parameters (e.g., side fins).

The proposed method is useful for providing building designers and modelers with a method to follow in selecting optimal design parameters for a given occupant scenario. In addition, it can inform building codes and standards with regards to occupant-related assumptions. 


\section{Evaluating the impact of occupants' spatial distribution on performance}

\section{This chapter was publication as:}

Abuimara, T., O'Brien, W., \& Gunay, B. (2021). Quantifying the impact of occupants' spatial distributions on office buildings energy and comfort performance. Energy and Buildings, 233, 110695.

\subsection{Abstract}

Designers typically follow a simplistic approach regarding occupant distribution in building simulation models, such as a uniform distribution. However, this approach rarely reflects reality, as occupants are often distributed heterogeneously in building spaces. To this end, this study develops a methodology to examine the impact of occupant distribution on energy and comfort performance; it then applies the methodology to an office building model in Toronto, Canada. The building energy model was simulated under a set of seventy-five plausible occupants' distribution scenarios (ODSs). The results indicate that ODSs can have a significant impact on occupants' comfort as densely populated zones experienced significantly higher discomfort hours per occupant compared to the homogeneous distribution. On the other hand, the variable ODSs had a modest impact on energy performance as the highest difference in energy use intensity was observed to be about $9 \%$, given that the model heating, ventilation, and air conditioning was hard-sized for all 
CHAPTER 6

simulations. Finally, the benefits of deploying adaptive technologies such as demandcontrolled ventilation were assessed in terms of mitigating the impact of variable ODSs.

\subsection{Introduction}

The simulation-aided building design process involves making several assumptions about building materials, systems, and occupants that do not necessarily represent reality. This approach can create a considerable level of error that leads to a gap between the simulated and actual performance of buildings and undermine confidence in design predictions ( $\mathrm{Li}$ et al. 2019). Mitigating and managing the uncertainty about occupant-related assumptions during the simulation-aided building design process has garnered the attention of researchers in the field of architecture, engineering, and construction (AEC) over the last few decades (Gunay et al. 2016b; Hong et al. 2017; O’Brien et al. 2020; Yan et al. 2017). Designing buildings with a high level of uncertainty can be a challenging task as mishandling uncertainty and its implications can mislead designers to suboptimal design solutions (Ouf et al. 2019b). Uncertainty during building design can be caused by several factors such as accuracy of weather data, accuracy of modelling tools, accuracy of occupant-related assumptions, physical and thermal properties of construction materials, accuracy of HVAC equipment modelling techniques, and user knowledge 
CHAPTER 6

and input errors (Beausoleil-Morrison 2019; Burman et al. 2014; Chapman et al. 2018; de Wilde 2014).

Among the factors mentioned above, occupant-related assumptions are recognized as one of the most influential sources of uncertainty in the simulation-aided building design process (Azar et al. 2020; Gaetani et al. 2016b; Hoes et al. 2009; Hong et al. 2017; Menezes et al. 2012; Yan et al. 2015).. Occupant-related assumptions are defined as all energy model inputs that define occupant presence (including spatial and temporal aspects) and all occupant behaviours that affect energy or comfort, including but not limited to the following domains: loads and lighting controls, thermostats, operable windows, window shading devices, clothing level, activity level, and plug-in equipment (Schweiker et al. 2017).

Occupant-related assumptions are used for various design tasks. Architects use occupant-related assumptions to determine building size (e.g. built-up area), circulation within the building, egress, and to develop layouts and relations between spaces. Engineers typically use occupant-related assumptions in performing various design tasks such as structural loads calculations, HVAC equipment sizing, and determining electric transformers and panels capacities (Abuimara et al. 2018). 
CHAPTER 6

In the current occupant modelling approach, designers mostly follow binding standards and codes in assuming that occupants have homogenous temporal and spatial distributions across building zones and throughout days, which does not reflect the reality (ASHRAE Standard 90.1 2016; O'Brien et al. 2016). In previous studies, the authors investigated the implications of occupants' presence temporal variations on building design and optimization outcomes using the same case study used in this paper (Abuimara et al. 2019, 2020). This study demonstrates how the current occupant-related assumptions about the spatial distribution of occupants overlook the impact of different ODSs in buildings. For example, office buildings usually have multiple tenants per building or even per floor, which in other words, means having multiple occupancy patterns and different activities in the building. Recently, differences among tenants have increased as many tenants are not reaching their capacity as a result of introducing alternative modes of working, such as teleworking where a considerable number of workforce choose to work from home for most of their working hours (Golden 2001; Zeytinoglu et al. 2009). In contrast, some tenants might exceed their occupancy capacity in case of hosting events, interns, or exceed standard internal heat gains from equipment by, for example, housing computer servers. To verify this, real occupancy data from an institutional building was examined to identify patterns of occupancy across building zones. A wide range 
of occupant densities was observed starting from near-empty zones to densely occupied zones with occupant densities higher than code- specified by a factor of four or five. Figure 6.1 shows how different occupancy levels can be across building zones.

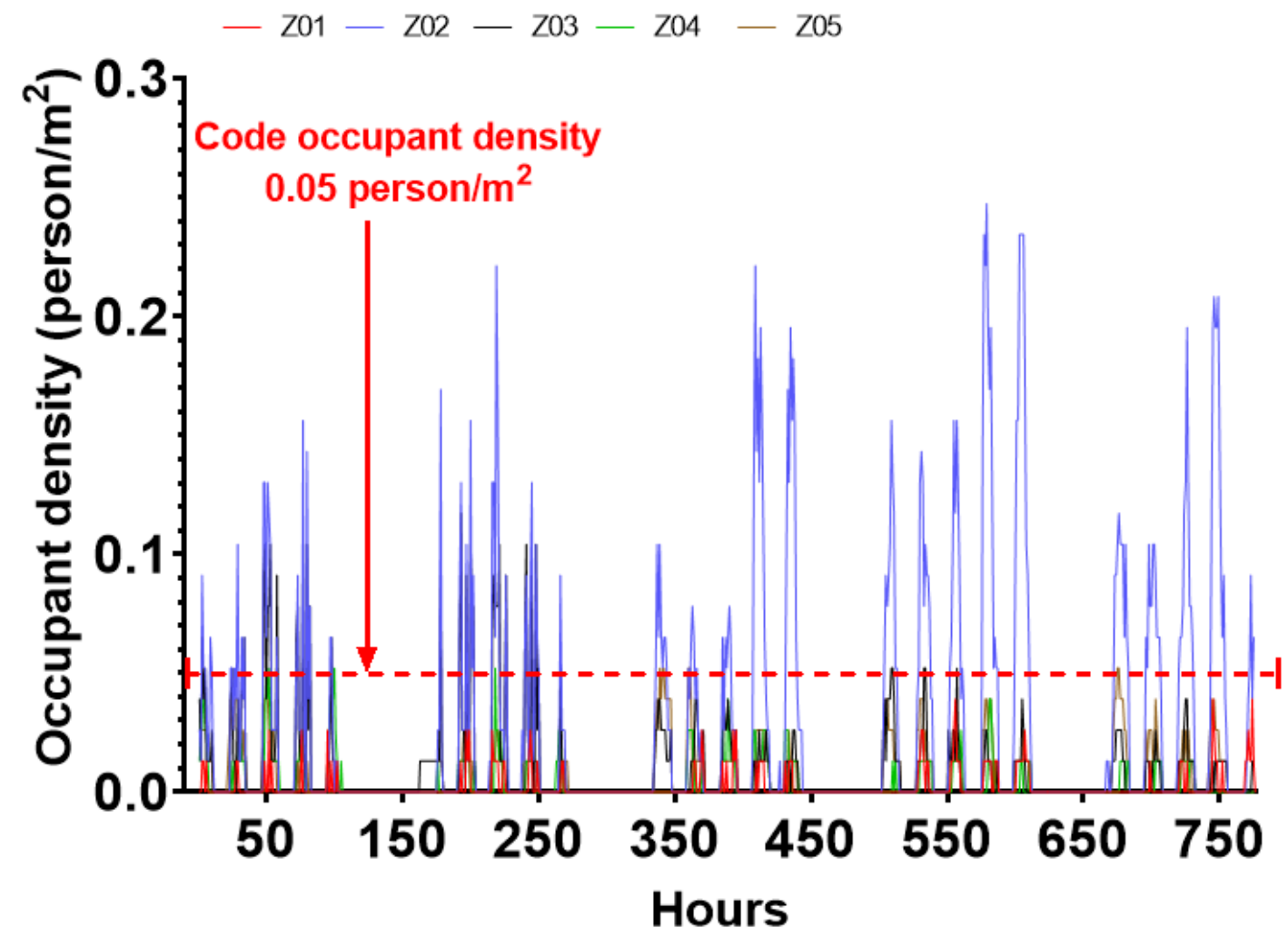

Figure 6.1: Example from an institutional building real occupancy data demonstrating variable spatial and temporal occupancy across building zones.

These differences among tenants/building zones are expected to have implications on energy use and occupants' comfort. Therefore, the hypothesis of this paper is that, if not accounted for, different ODS contribute to increasing uncertainty in building design and can affect the energy and comfort performance of buildings. To this end, this paper's main objectives are: 
CHAPTER 6

(1) Examine the implications of office building ODS on building energy and comfort performance.

(2) Examine the benefits of using adaptive technologies such as demandcontrolled ventilation (DCV) in handling this aspect of occupant-related uncertainty.

With an increased focus on improving occupant modelling and the introduction of occupant-centric building design, this study is expected to contribute to the ongoing research efforts in this field such as Annex 79 "Occupant-centric building design and operation" of the International Energy Agency -Energy in Buildings and Communities (IEA-EBC) (IEA-EBC 2018). In addition, the findings of this paper are intended to serve as guidelines for building design practitioners.

This paper first presents a brief literature review of relevant studies. Then, the study methodology is outlined. Later, results are presented along with discussion. Limitations and unsolved issues for future research are presented thereafter. 
CHAPTER 6

\subsection{Literature review}

Numerous studies have been published over the last two decades in efforts to improve the current occupant modelling approach in building design and operations (e.g. Ding et al. 2016; Gaetani et al. 2016a; Gilani et al. 2016; O'Brien et al. 2016; Sun \& Hong 2017). Studies have focused on developing statistical models for occupants' presence and actions such as occupancy model by Page et al. (2008), window shade use model by Haldi and Robinson (2010), and lights operation model by Reinhart and Voss (2003). These models were developed based on data collected from existing buildings using different sensing technologies. However, these models were yet to be adopted by designers for several reasons, such as complexity of implementation that requires additional skills and training and stochasticity of results (Schweiker et al. 2011). Other studies were focused on developing methods or frameworks for improved modelling during building design, such as studies by Sun and Hong (2017) and Gaetani et al. (2017).

However, only a few studies looked at the impact of occupant distributions on building design and performance. Amongst them is the study by Newsham (1992), who conducted a study aimed at comparing the comfort and energy impact of the traditional approach of modelling occupants where occupants are assumed to be stationary and a more realistic approach where occupants are assumed to be 
CHAPTER 6

nonstationary. The study examined two types of occupants; the first is an occupant who has a fixed location in the space while the second type is an occupant that is freely moving seeking optimal comfort conditions. The study concluded that the impact of occupant movement on energy and comfort could be significant as the nonstationary occupant needed less cooling and experienced about half of the overheated hours compared to the fixed occupant.

Another recent study by Gilani et al. (2019) who conducted a simulation-based study to evaluate the impact of occupants' inter-zone mobility on the building energy and comfort performance. The National Energy Code of Canada for Buildings (NECB) medium reference building model was used as a case study (NRC 2015). The model was simulated under homogenous and heterogeneous ODSs. The study employed random sampling from a normal distribution to generate the number of occupants in each building zone at the beginning of each weekday during the simulation. The study assumed that occupants select their workstation at the beginning of each workday in an open-plan office while maintaining the total number of occupants in the building constant. In addition, equipment loads were assumed to be linearly correlated to occupants' presence, and lights were assumed to be switched on whenever there are any occupants in a zone. The study results demonstrated that occupants' inter-zone mobility and, consequently, distribution affected occupants' 
CHAPTER 6

comfort as the number of setpoints unmet hours increased drastically when variable occupants' distribution was considered in the simulation process. In addition, the study concluded that the zone-level energy consumption is dependent on ODSs.

The review of the literature reveals the lack of studies about practical and easy-toimplement approaches to evaluate the impact of ODSs on energy and comfort that can be communicated to and adopted by design practitioners. Most of the previous studies, including the two presented here, followed complex dynamic approaches in generating occupant distribution scenarios which is time consuming and requires special skills and knowledge of programming and statistics that the majority of practitioners lack.

In previous studies, the authors studied the impact of temporal variation of occupancy on office building energy performance and design decision making. The findings indicated that the temporal variations of occupancy have a considerable impact on selecting energy conservation measures (ECMs) and on the outcomes of building design optimization. However, the spatial variation of occupancy was not considered. Hence, this study is trying to fill this gap by evaluating that impact using similar assumptions and tools used by practitioners. The study findings are expected to guide designers in better accounting for this occupant-related aspect (i.e. variable 
CHAPTER 6

ODSs). In addition, this study offers an easy to implement approach for evaluating building design under various ODSs using the existing tools and data.

\subsection{Methodology}

This section presents the steps that were followed and the assumptions that were made to conduct this simulation-based study. In this section, the study workflow is outlined, followed by a description of the energy and comfort performance metrics used to evaluate the impact of variable ODSs. Then, the case study office building model is described in detail. The methodology that was followed to generate ODSs and a sample of these ODSs are presented thereafter. Finally, details about building performance simulation (BPS) tools that were used to perform the simulations are provided.

\subsubsection{Study workflow}

A five-step reproducible workflow was developed to evaluate the impact of variable ODSs in an office building. The steps of the workflow are listed below:

(1) Create a representative energy model of the building.

(2) Perform HVAC sizing simulation run using the standard ODS (as per NECB), then hard size all HVAC components, air, and water flow rates.

(3) Generate a plausible set of ODS. 
CHAPTER 6

(4) Simulate the building energy model with multiple ODSs and report performance metrics of each run. Examine the benefits of adaptive technologies (e.g., DCV) by repeating the simulation while enabling the adaptive technology.

(5) Evaluate results using the energy and comfort performance metrics.

\subsubsection{Performance metrics}

Performance metrics can be defined as measurable quantities that are used to evaluate the performance of any building aspect (Fowler et al. 2005). For evaluating energy performance, energy use intensity (EUI) was used. EUI is a widely used metric for energy performance among researchers and building designers. In this study also, the impact of variable ODSs on two aspects of occupants' comfort was evaluated: thermal comfort and indoor air quality (IAQ). To assess thermal comfort performance, a new metric for assessing the number of discomfort hours experienced by each occupant was developed. While IAQ was assessed using a new metric that assesses the average number of hours an occupant experience where carbon dioxide $\left(\mathrm{CO}_{2}\right)$ concentration rises above $1000 \mathrm{ppm}$ in the zone. $\mathrm{CO}_{2}$ concentration is a commonly used metric to assess IAQ (Al-Rashidi et al. 2012; Blondeau et al. 2005). 
CHAPTER 6

Developing new comfort metrics was driven by the need to quantify the actual level of discomfort experienced by each occupant. The existing comfort metrics such as ASHRAE Standard 90.1 unmet hours, which is also reported in this study, do not capture the actual level of discomfort as it considers that the whole building has an unmet hour even if one zone of the building has an unmet hour (ASHRAE Standard 90.1 2016). In addition, ASHRAE unmet hours metric does not weigh discomfort by occupants as the weight of discomfort hour where there is one occupant is equivalent to a discomfort hour when the building/zone is at maximum capacity. Traditional metrics are useful when dealing with uniform occupant densities where determining comfort at occupant or zone scale is unnecessary (O'Brien et al. 2017). However, in reality, occupants are rarely uniformly distributed which results in different levels of comfort.

The new metric for assessing thermal comfort is called occupant discomfort hours (ODH). ODH indicates the thermal discomfort hours experienced by an occupant in a given building zone with a specific occupant density, and it is calculated using the formula in Equation (1). It is simply calculated by summing the number of occupant discomfort hours in a building zone then dividing the result by the maximum number of people assigned to that zone. Discomfort occupant hours are calculated based on the number of people present in the zone when thermal comfort levels are not met 
CHAPTER 6

(i.e. indoor air temperature is not within the setpoints $\left(1^{\circ} \mathrm{C}\right)$ tolerance above and below setpoints was allowed). For example, if there are five people in a zone and the comfort levels are not met, the discomfort occupant hours here will equal five (i.e. five people are feeling discomfort for an hour). Summing the occupant discomfort hours for the whole simulated year and dividing the results by the maximum number of people assigned to the zone yields the approximate share of each occupant to discomfort hours or what we called here ODH.

$$
O D H_{z}=\frac{\sum h_{z, t} \times o_{z, t}}{O_{z, \max }}
$$

where $O D H$ is the occupant discomfort hours, $h$ is a discomfort hour at timestep $t$ and $o$ is the number of occupants at timestep $t . O_{z, \max }$ is the maximum number of occupants assigned to zone $z$.

For assessing IAQ, another new metric was developed and called occupant $\mathrm{CO}_{2}$ hours $\left(\mathrm{OH}_{\mathrm{co} 2}\right)$. The $\mathrm{OHcO}_{2}$ indicates the per occupant number of hours when $\mathrm{CO}_{2}$ exceeds $1000 \mathrm{ppm}$ in a building zone. $\mathrm{OHco}_{2}$ is calculated, as shown in Equation (2).

$$
O H_{C o 2}=\frac{\sum\left(\mathrm{Co}_{2} h\right)_{z, t} \times o_{z, t}}{O_{z, \max }}
$$


CHAPTER 6

where $\left(\mathrm{CO}_{2} h\right)_{z, t}$ is the hour in which $\mathrm{CO}_{2}$ concentration exceeds $1000 \mathrm{ppm}$ in zone $\mathrm{z}$ and $o_{z, t}$ is the number of people present during that hour. $\mathrm{OH}_{\mathrm{co} 2}$ is the occupant $\mathrm{CO}_{2}$ hours, and $O_{z, \max }$ is the maximum number of occupants assigned to zone $z$.

\subsubsection{Case study}

A model of a typical office floor was used for the simulation-based investigation (see Figure 6.2 and Table 6.1). The typical office floor is of a newly constructed real office building located in Toronto, Canada. This real office building was used as a case study for previous studies by the authors where the impact of temporal changes in occupancy on building design and optimization was evaluated. The full building consists of four typical office floors and a retail ground floor.

In this study, the typical intermediate floor was divided into fifteen thermal zones model. The zones are defined in a way that represents realistic office thermal zoning with perimeter, core, and corner office spaces. For the sake of energy modelling, service spaces such as stairs, washrooms and corridors were not detailed. The model was simulated first, using the standard homogenous ODS (20 $\mathrm{m}^{2} /$ person) and standard schedules provided in NECB code (NRC 2015), for the purpose of hardsizing HVAC equipment and flow rates (air and water). 


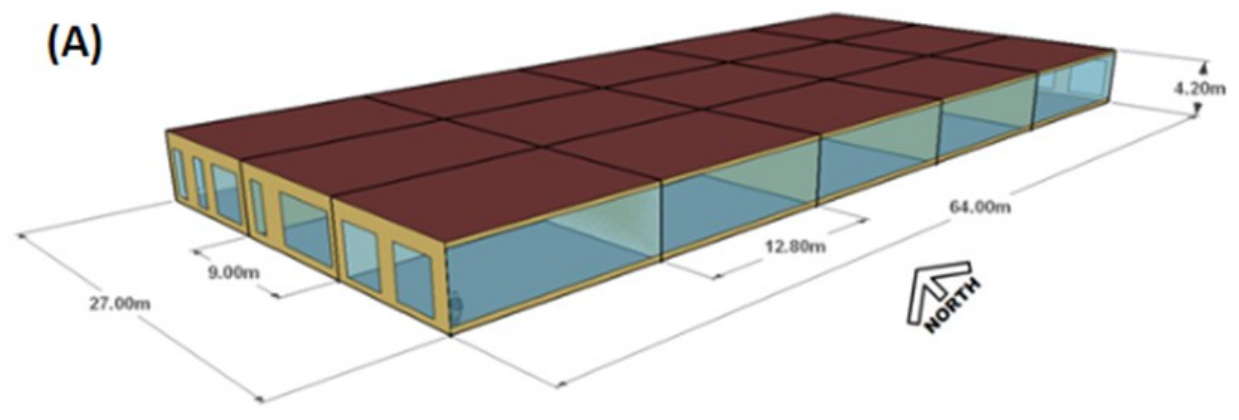

(B)

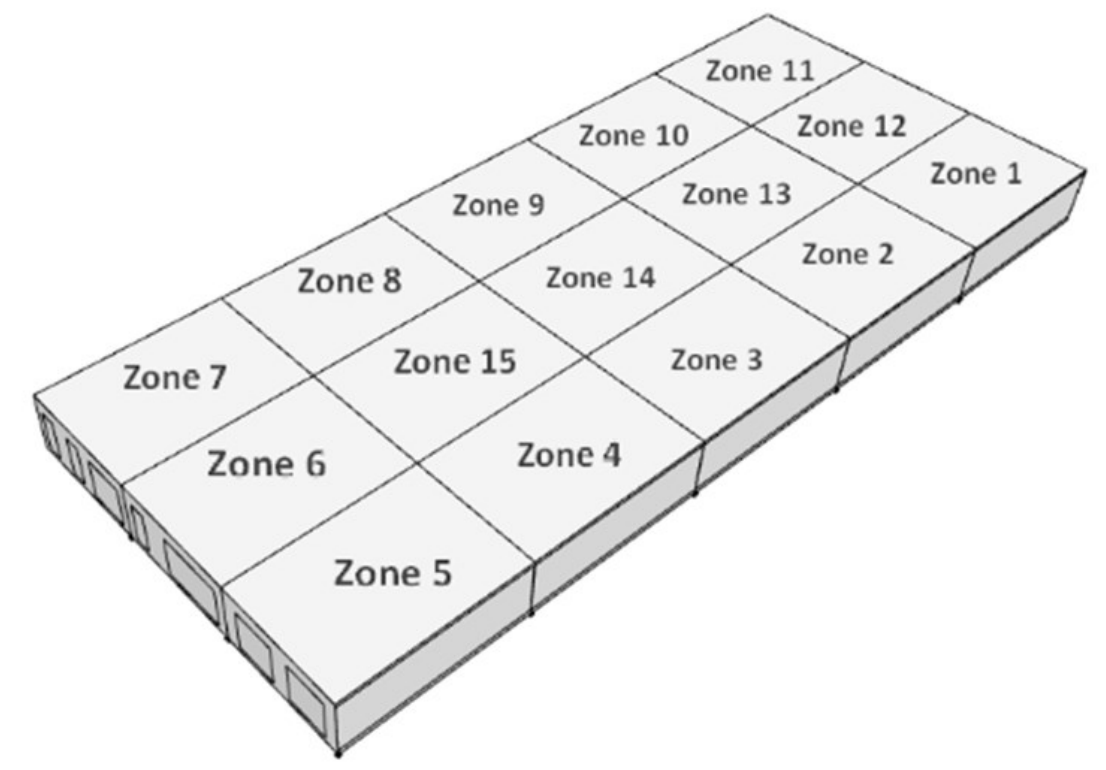

Figure 6.2: (A) The case study model; a fifteen-zone typical office floor, (B) model zone numbering.

Table 6.1: Description of the case study.

\begin{tabular}{|l|l|l|}
\hline No. & Item & Description \\
\hline & Floor area & $1728 \mathrm{~m}^{2}$ \\
\hline & Zoning & 15 thermal zones \\
\hline HVAC & $\begin{array}{l}\text { Rooftop package unit with zone level } \\
\text { variable air volume (VAV) reheat } \\
\text { Hydronic baseboard heating }\end{array}$ \\
\hline $\begin{array}{l}\text { Cooling of coefficient } \\
\text { performance }\end{array}$ & $\begin{array}{l}\mathrm{COP}=4 \\
\text { Boiler (space heating) }\end{array}$ & $\begin{array}{l}\text { Type: condensing boiler } \\
\text { Fuel: natural gas }\end{array}$ \\
\hline
\end{tabular}




\begin{tabular}{|c|c|}
\hline & $\begin{array}{l}\text { Nominal thermal efficiency }=0.8 \\
\text { Nominal capacity }=411 \mathrm{~kW}\end{array}$ \\
\hline Economizer & $\begin{array}{l}\text { Airside economizer is enabled and controlled } \\
\text { based on differential dry-bulb (minimum } \\
\text { outdoor air temperature } 5^{\circ} \mathrm{C} \text { ) }\end{array}$ \\
\hline Heat recovery & $\begin{array}{l}\text { Air-to-air heat exchanger } \\
\text { Sensible effectiveness at } 100 \% \text { heating } \\
\text { /cooling airflow }=70 \% \\
\text { Sensible effectiveness at } 75 \% \text { heating } \\
\text { /cooling air flow }=85 \%\end{array}$ \\
\hline $\begin{array}{l}\text { Indoor temperature setpoints } \\
\text { Heating } \\
\text { Cooling }\end{array}$ & $\begin{array}{l}\text { Setpoint }=22^{\circ} \mathrm{C}, \text { setback }=16^{\circ} \mathrm{C} \\
\text { Setpoint }=24^{\circ} \mathrm{C}, \text { setback }=32^{\circ} \mathrm{C}\end{array}$ \\
\hline $\begin{array}{l}\text { Infiltration rate } \quad \text { (rate } \\
\text { /exterior area) }\end{array}$ & qinfl $=0.35 \mathrm{l} / \mathrm{s} \cdot \mathrm{m} 2 .($ constant rate $)$ \\
\hline $\begin{array}{l}\text { Outdoor air minimum flow } \\
\text { rate }\end{array}$ & $0.000435 \mathrm{~m} 3 / \mathrm{s} . \mathrm{m} 2$ \\
\hline $\begin{array}{l}\text { Variable air volume (VAV) } \\
\text { terminal air flow rate/zone }\end{array}$ & $\begin{array}{l}\text { Maximum air flow }=0.37 \mathrm{~m} 3 / \mathrm{s} \\
\text { Minimum air flow fraction }=0.15\end{array}$ \\
\hline $\begin{array}{l}\text { Central heating supply air } \\
\text { temperature }\end{array}$ & $16^{\circ} \mathrm{C}$ \\
\hline $\begin{array}{l}\text { Central cooling supply air } \\
\text { temperature }\end{array}$ & $12.8^{\circ} \mathrm{C}$ \\
\hline AHU supply fan air pressure & $300 \mathrm{~Pa}$ \\
\hline Windows & $\begin{array}{l}\text { U-factor }=1.9 \mathrm{~W} / \mathrm{m} 2 \cdot \mathrm{K} ; \mathrm{SHGC}=0.33 \\
\text { WWR (overall) }=46.5 \% \\
\text { WWR (south) }=85 \% \\
\text { WWR (north) }=12 \% \\
\text { WWR (east) }=41 \% \\
\text { WWR (west) }=41 \%\end{array}$ \\
\hline Walls & $\mathrm{U}$-value $=0.245 \mathrm{~W} / \mathrm{m} 2 \cdot \mathrm{K}$ \\
\hline Window interior shading & $\begin{array}{l}\text { Interior shading with: } \\
\text { Solar transmittance }=0.05 \\
\text { Solar reflectance }=0.75 \\
\text { Control: Closed when total incident solar } \\
\text { radiation } \geq 200 \mathrm{~W} / \mathrm{m} 2 \text { on window exterior } \\
\text { surface. }\end{array}$ \\
\hline
\end{tabular}


CHAPTER 6

\subsubsection{Occupants' distribution scenarios (ODSs)}

To evaluate the impact of variable ODSs on energy and comfort performance, a set of 75 ODSs were generated and explored in the simulation. In this study, an ODS refers to the allocation of the total number of people in the building across building zones. Occupants' exact locations within the building zone was not considered in this study. In addition, in EnergyPlus and most commonly used BPS tools, occupant location within a zone is not considered because the heat balance is performed at the zone level.

The ODSs were generated by sampling from uniformly distributed large population using a custom script in R. All generated ODSs were set to add up to the same total number of people in the building (the total number was calculated based on occupant density of 0.05 people $/ \mathrm{m}^{2}$ prescribed in the code). In addition, the occupant density in individual zones was allowed to range from 0 person $/ \mathrm{m}^{2}$ (unoccupied zone) to 0.21 person $/ \mathrm{m}^{2}$ (densely populated zone) in an attempt to capture all possible occupancy scenarios for a given zone.

Different ODSs represent distribution scenarios that can exist in real office buildings with tenants with different occupant densities as well as vacant office units. Figure 6.3 illustrates six different ODSs sampled from the simulation ODSs. The six ODSs 
CHAPTER 6

were manually selected to represent scenarios in which zones facing same direction (e.g. south-facing zones) are densely populated.

Since the use of lighting in offices is associated with the presence of occupants, lighting power density (LPD) was defined as a linear function of the number of occupants - though a fraction of the lights was assumed constantly on even with no occupancy. A constant fraction of lighting loads were normalized by floor area $\left(\mathrm{W} / \mathrm{m}^{2}\right)$ while the remaining fraction was normalized per person (W/person), assuming that the increased number of occupants in a zone will be associated with additional lighting loads from, for example, using task lights. Equation (3) shows how the LPD was determined for each building zone.

Plug-in equipment power density (EPD) is defined as a function of the occupant density as the number of computers and office equipment is assumed to be associated with the number of people. Previous studies have found a correlation between occupancy and plug-in equipment loads (Gunay et al. 2016a; Hobson et al. 2019; Mahdavi et al. 2016). Equation (4) shows how the equipment load level was determined for each building zone.

$$
\text { Lighting load level }_{i}=\left(5 \frac{\mathrm{W}}{\mathrm{m}^{2}} \times A_{i}\right)+\left(60 \mathrm{~W} \times O_{i}\right)
$$


where $A_{i}$ is the floor area of zone $(i)$ and $O_{i}$ is the number of occupants in that zone.

The $150 \mathrm{~W}$ is the per occupant plug-in equipment load as per the National Energy

Code of Canada for Buildings (NRC 2015). For the occupants' presence, the standard

NECB occupancy, lighting, and equipment schedules were used in this study. The

objective is to isolate and quantify the impact of ODSs from other occupant-related assumptions (i.e. schedules).
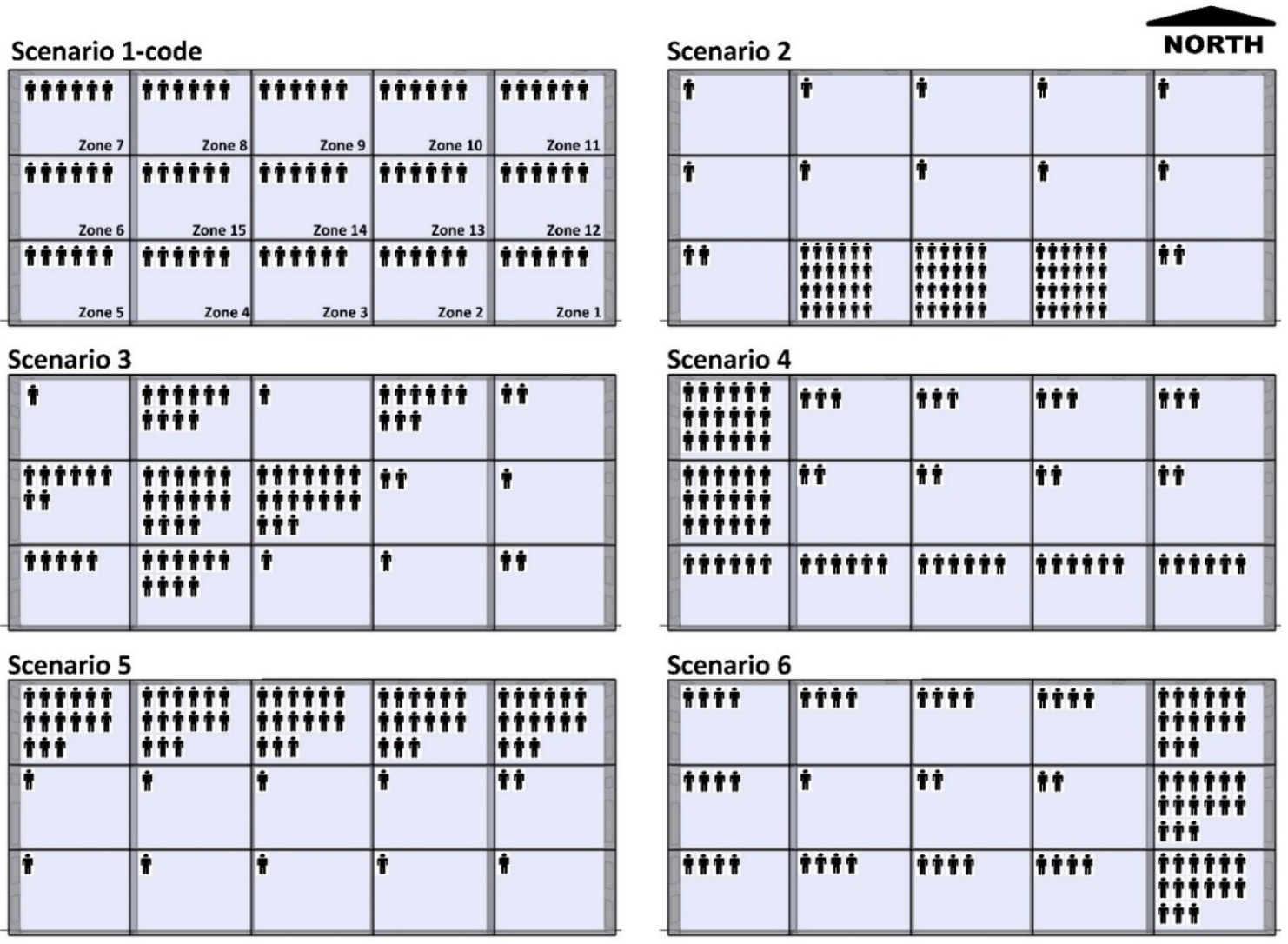

Figure 6.3: Plan view of a sample of ODSs including standard (scenario 1-code), highlypopulated south-facing zones (scenario 2), highly-populated core zones (scenario 3), highly-populated west-facing zones (scenario 4), highly-populated northfacing zones (scenario 5) and highly-populated east-facing zones distribution scenarios (scenario 6). 
CHAPTER 6

\subsubsection{Modelling tools}

Since the objective of this study is to assess the impact of variable ODSs on energy and comfort performance of office buildings, a whole building simulation tool that allows flexibility in inputs and offers a wide range of outputs was needed. EnergyPlus 9.2.0 was selected to be the main simulation engine in this study. EnergyPlus is a whole building performance simulation tool that offers flexibility in inputs and a wide range of outputs (EnergyPlus 2020). EnergyPlus enables the output of hourly per zone energy use (e.g. electricity use, heating, and cooling energy use), comfort (e.g. indoor air temperature), and indoor air quality (IAQ) indices (e.g. $\mathrm{CO}_{2}$ concentration). All EnergyPlus model inputs used in this study are provided in Table 6.1 .

Additionally, due to the relatively large number of simulation runs (a total of 150 runs: 75 without DCV and 75 with DCV), a custom MATLAB script was used to automate simulations and for results extraction and documentation. Computational time was relatively short (a few minutes for each simulation run), and the simulations were performed on a personal computer with core i5-6200U CPU @ 2.4GHz and a RAM of $8.00 \mathrm{~GB}$ 
CHAPTER 6

\subsection{Results and Discussion}

This section presents and discusses the results of simulating the case study model under the 75 ODSs. In addition, it introduces the benefits of deploying adaptive technologies in building such as demand-controlled ventilation (DCV) by presenting the results of repeating the simulation process with enabled DCV.

The implications of variable ODSs on energy use are introduced and discussed first, followed by the implications on occupants' comfort. Then, the results that show the potential benefits of DCV are introduced.

\subsubsection{Implications of ODSs on energy use}

Simulating the case study model under the 75 ODSs resulted in a range of EUI, as it can be seen in Figure 6.4. However, the change in the value of EUI was limited as all HVAC components including air and water flow rates were hard-sized. The moderate variation in EUI happens due to the increased demand for heating or cooling to maintain indoor temperature setpoints. In addition, the EUI increase is related to the increase/decrease in lighting and equipment loads associated with occupants.

The increase in heating demand occurs in underpopulated zones (low occupancy) to compensate for the reduced internal gains from people, plug-in equipment, and 
lighting. In contrast, the increase in cooling loads occurs in overpopulated zones to remove the excessive heat gains from people, plug-in equipment, and lighting.

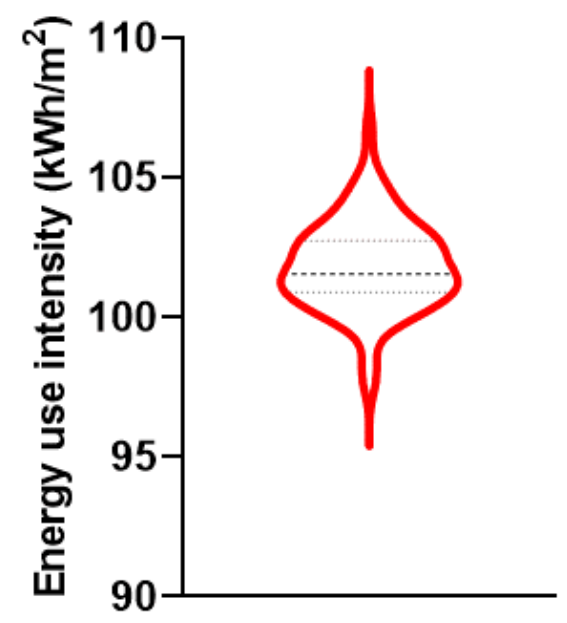

Figure 6.4: Violin plot of the EUI of the case study model under the 75 ODSs.

Despite a modest change (a change of about $5 \mathrm{kWh} / \mathrm{m}^{2}$ and $10 \mathrm{kWh} / \mathrm{m}^{2}$ ) in EUI, the results indicate the level of uncertainty in energy performance caused by only one type of occupant-related assumption "ODS". This impact might be greater when variations of other occupant-related assumptions are considered, such as occupancy schedules, setpoint preferences, LPD, EPD, or window blinds use. Therefore, future investigation should focus on the combined effect of using variable ODSs and other occupant-related assumptions.

Additionally, this change in EUI with variable ODSs emphasizes to some extent the role occupants play in creating the well-known building energy performance gap where actual energy performance mismatches the simulated performance during 
CHAPTER 6

design (Gaetani et al. 2017; Hoes et al. 2009; Sun et al. 2019). Additionally, neglecting variable ODSs during design might lead to overlooking some energy savings opportunities during design, such as deploying adaptive technologies (O’Brien \& Gunay 2019; Ouf et al. 2019a)

\subsubsection{Implications of ODSs on comfort}

This study also looked at building comfort performance. Three different metrics were reported of the simulation runs: unmet hours as per ASHRAE Standard 90.1, ODH, and $\mathrm{OH}_{\mathrm{co} 2}$.

\subsubsection{Unmet hours as per ASHRAE Standard 90.1}

Overall, the results indicated a substantial increase in the numbers of unmet hours, as shown in Error! Reference source not found.. The number of unmet hours ranged $\mathrm{f}$ rom 150 hours with code standard assumptions (i.e. uniform ODS) to 2600 unmet hours with few outliers that reached up to about 3000 unmet hours. ASHRAE Standard 90.1 allows a maximum of 300 unmet hours per year to consider a building having an acceptable comfort performance (ASHRAE Standard 90.1 2016). Given this comfort threshold by ASHRAE Standard 90.1, most of the unmet hours of simulating the case study model under the 75 ODSs do not meet the comfort requirements as only in few cases (about $10 \%$ of the scenarios including the standard ODS) had unmet hours less than 300 as shown in Figure 6.5. For instance, scenarios 
with overpopulated core, south-facing, and west-facing zones were amongst the scenarios of the highest numbers of unmet hours.

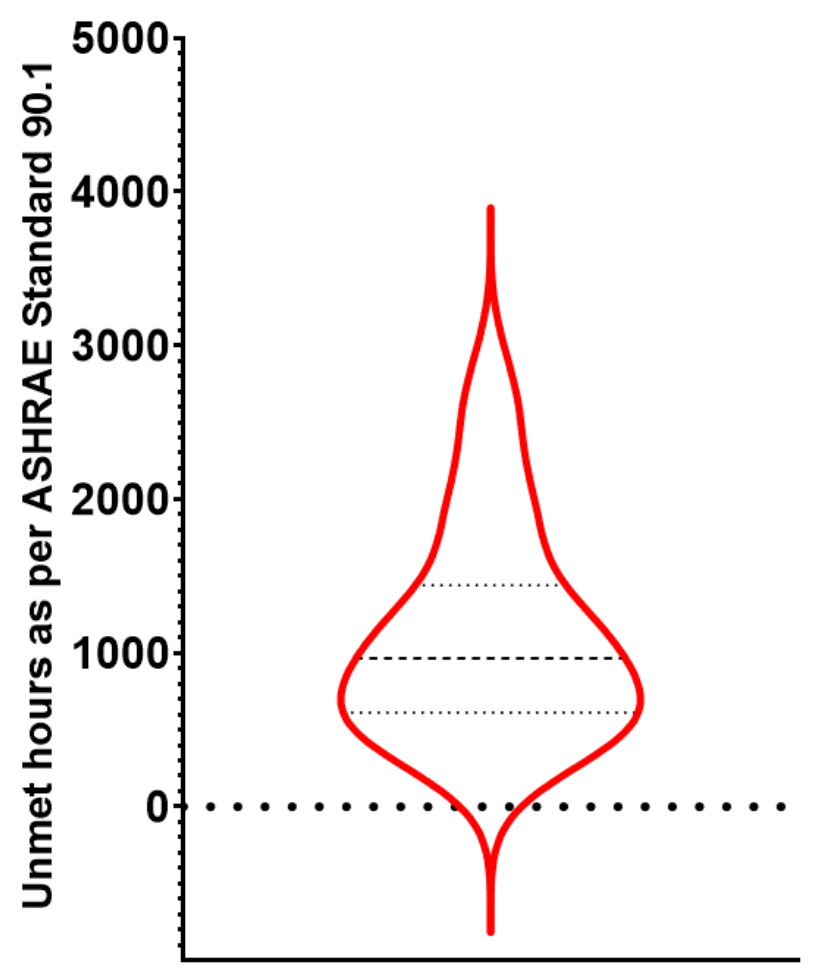

Figure 6.5: Unmet hours of the case study model under the 75 ODSs as per ASHRAE Standard 90.1 definition.

\subsubsection{Occupant discomfort hours (ODH)}

Unmet hours as specified by ASHRAE Standard 90.1 is a useful metric that indicates

a building's overall thermal comfort performance; however, it does not indicate the zones that are mostly affected by discomfort or number of people are suffering from discomfort. Moreover, it overlooks the fact that the occupants themselves may be the cause of discomfort. Ultimately, a densely-occupied space suffers in two 
CHAPTER 6

compounding ways: 1) internal heat gains may cause overheating, and 2) there are more occupants present to suffer from overheating. Therefore, ODH was developed and used in this study as a new approach to quantify discomfort by normalizing the discomfort hours by occupants in different zones. For the sake of clarity of results and in an attempt to interpret the drivers behind discomfort, overheating and overcooling ODH were reported separately.

The overheating ODH shown in Figure 6.6 indicates variable sensitivity of the magnitude of ODH to the zone orientation. The number of ODH of south-facing and core zones was more sensitive to changes in ODSs as they have a wide range of ODH as can be observed in Figure 6.6. This overheating in south-facing zones is driven by two main factors: first is solar gains as window-to-wall ratio (WWR) of the southfacing facade is $85 \%$. The second is internal gains from an increased number of occupants and their associated gains from equipment and lighting. An example of increased overheating ODH in south-facing zones when over-populated is shown in Figure 6.9, where each occupant in these zones had an annual share of approximately 1600 hours of overheating. Generally, south-facing zones are often susceptible to overheating as south-facing facades receive direct solar radiation for a longer period during the day, especially when south-facing façades have high WWR. These findings show that pointing out possible overheating issues in perimeter zones by testing these 
CHAPTER 6

zones under variable ODSs during early design stages can assist designers in making critical decisions related to WWR.

In core zones, the values of ODH were also highly sensitive to changes in ODSs as we can observe the widespread (0 to $400 \mathrm{ODH}$ ) of simulation results in Figure 6.6. Core zones do not lose heat through infiltration and have limited heat exchange with adjacent zones as the difference in indoor temperature is relatively small. Considering a fixed maximum variable air volume (VAV) terminal airflow rate, excessive internal gains from high occupant density and their associated plug-in equipment and lighting loads can cause core zones overheating (i.e. high $\mathrm{ODH}$ ).

In contrast, north-facing zones demonstrated low sensitivity to changing in occupants' distribution scenarios except for some outliers, where the number of occupants was increased drastically, as illustrated in Figure 6.6 and Figure 6.9. Overheating from solar gains in north-facing zones is negligible as they receive much less solar radiation throughout the day, and the glazed area is lower than for the south. Thus, the overheating from additional internal gains was within the capacity of the HVAC equipment in most of the cases.

On the other hand, generally, variable ODSs did not have a substantial impact on overcooling ODH, as shown in Figure 6.7. The maximum ODH was observed in core 
CHAPTER 6

zones, and the maximum values were reported to be around 30-35. In a more indepth analysis, ODH, for one extreme scenario, where one of the cores zones had the highest overcooling $\mathrm{ODH}$, was examined through sensitivity analysis to find out the reason behind the relatively high overcooling $\mathrm{ODH}$ (see Figure 6.8). First, the zone was found to be under-occupied (only one occupant in the zone) and surrounded with under-occupied zones which led to substantial reduction in both internal heat gain in the zone and heat exchange with surrounding zones. Therefore, the zone was suffering from overcooling as zone VAV flow rate including the outdoor air fraction were sized based on zone standard full occupancy.

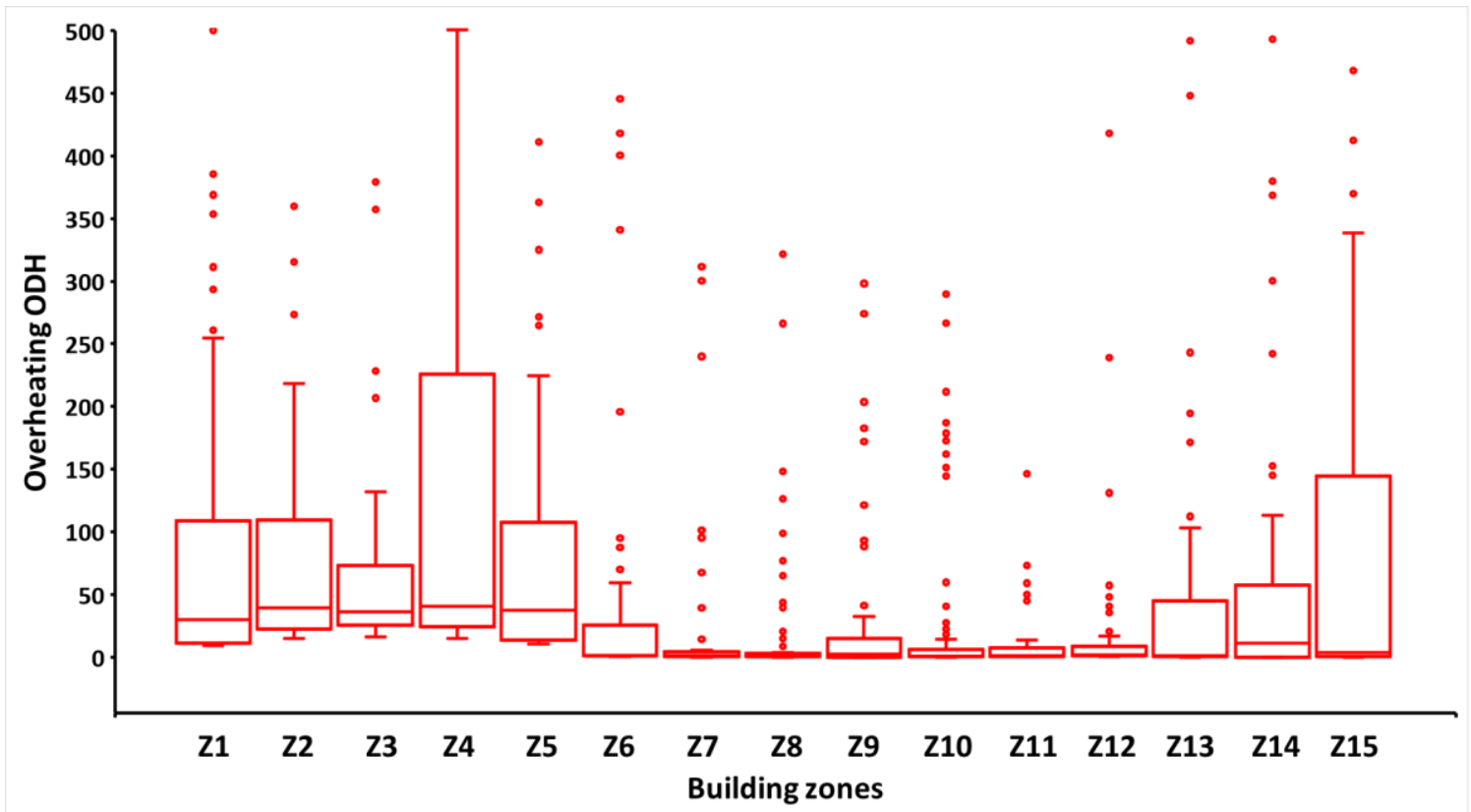

Figure 6.6: Overheating ODH under the 75 ODSs. 
Figure 6.8 shows the results of the sensitivity analysis which demonstrates that by reducing the default $\mathrm{VAV}$ air terminal flow rate for the zone, the total building overcooling ODH decreases, which means that the overcooling is happening due to overventilation when the zone is under-occupied.

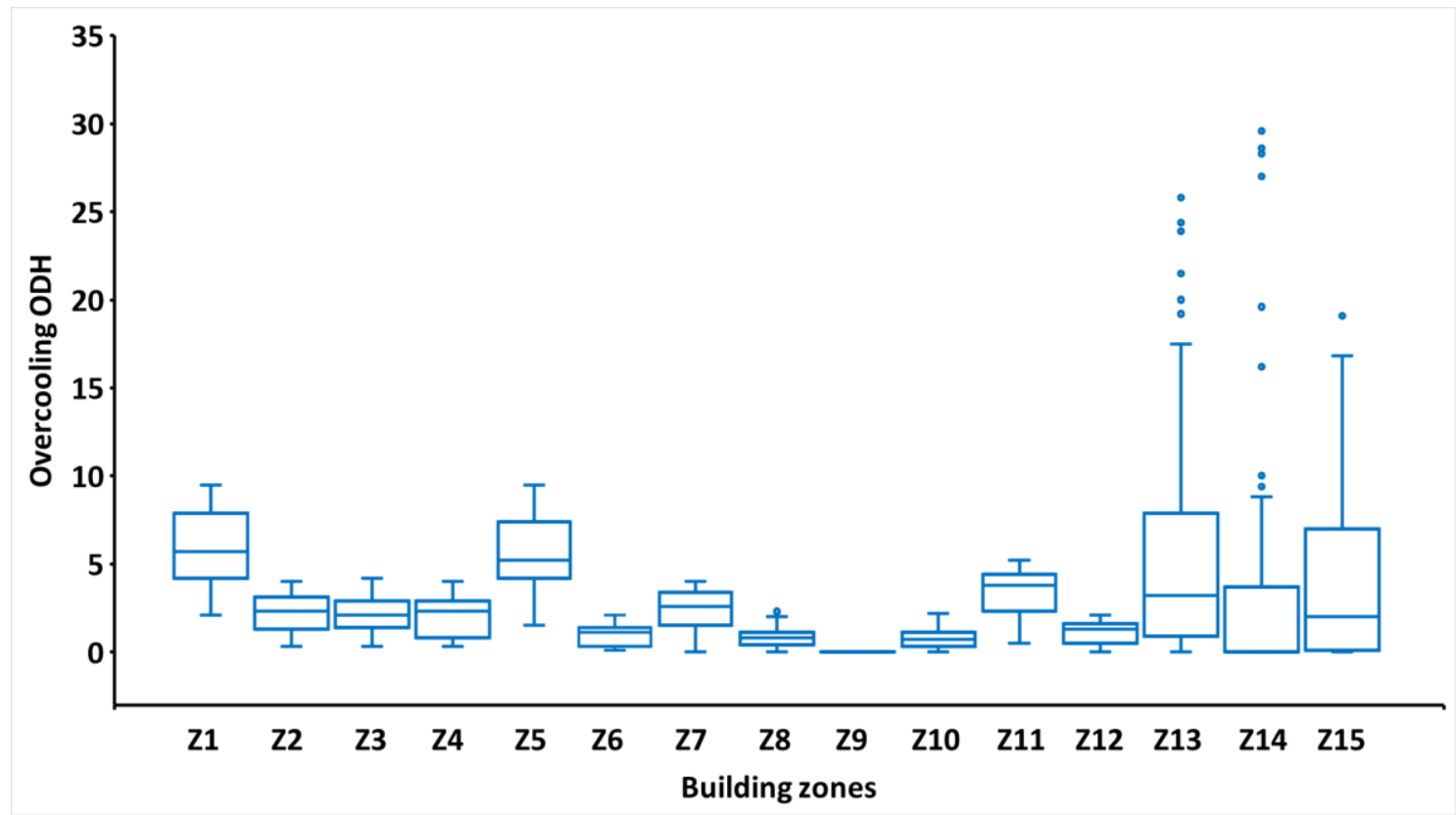

Figure 6.7: Overcooling ODH results under the 75 ODSs.

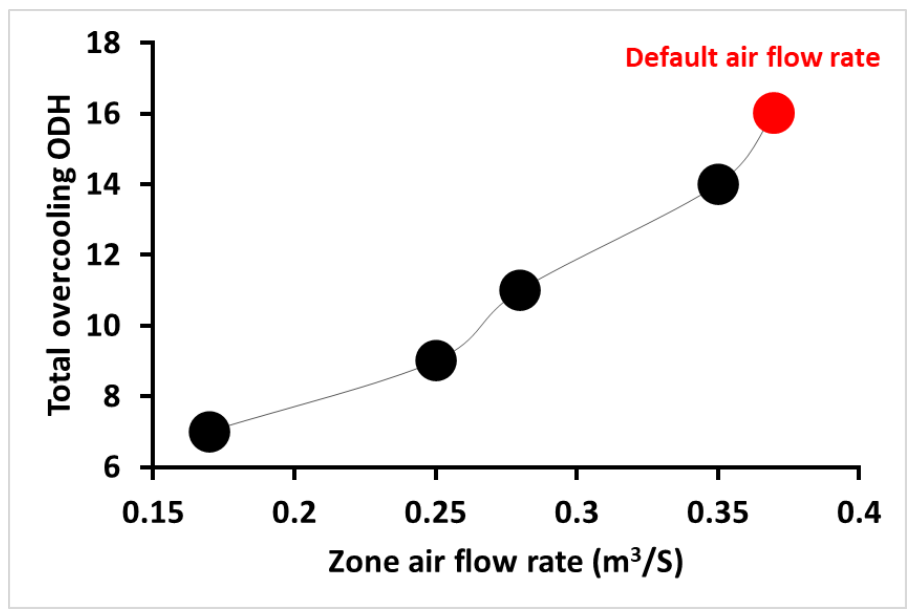

Figure 6.8: Results of sensitivity analysis demonstrates a decrease in total overcooling ODH with decreased airflow rates in a core zone with high $O D H$ range. This zone has low occupant density (0.009 person $\left./ \mathrm{m}^{2}\right)$. 


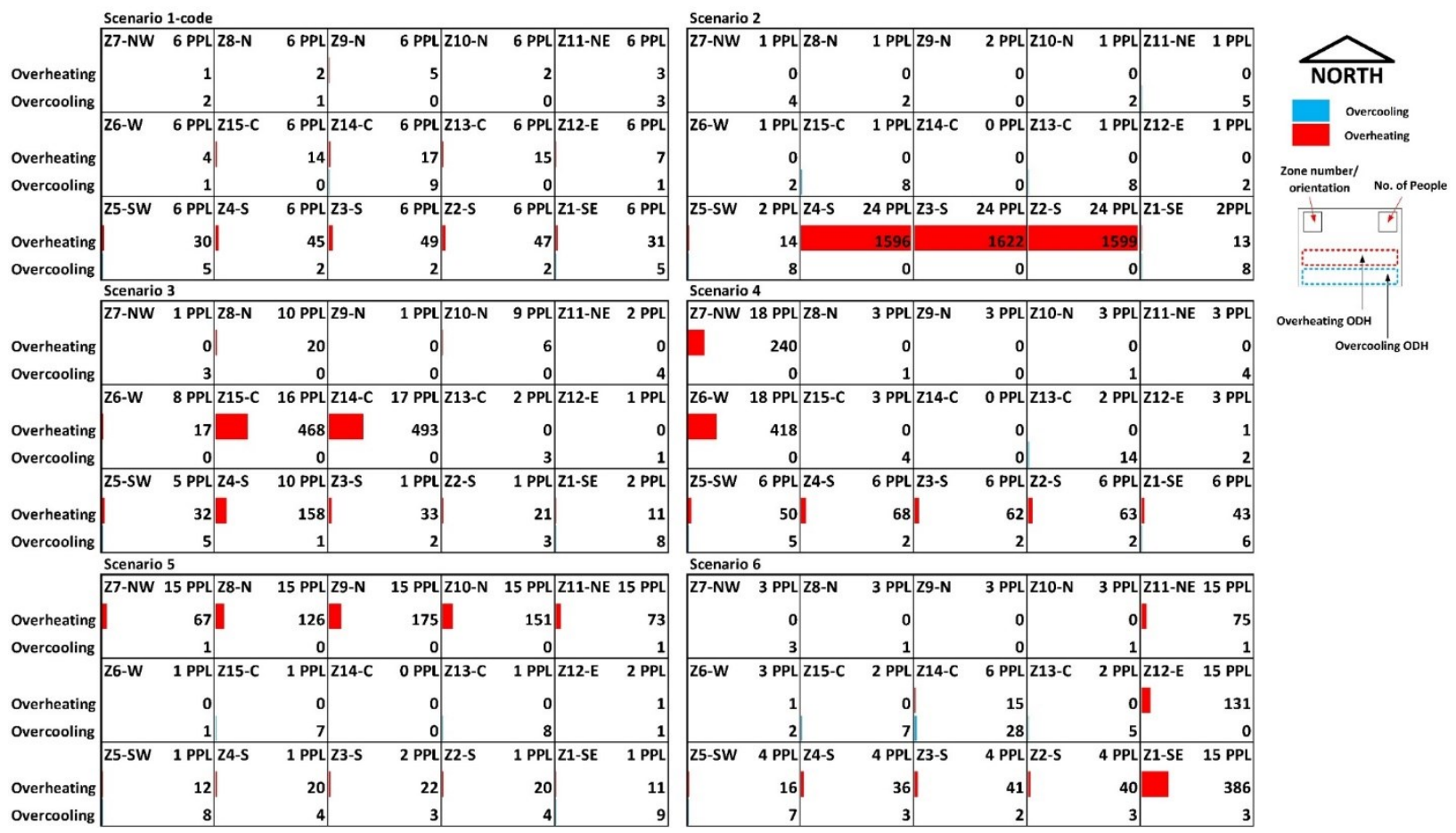

Figure 6.9: Sample results of six different ODSs demonstrating the impact on the value of $\mathrm{ODH}$.

On another front, the unmet hours as per ASHRAE Standard 90.1 were found to be strongly correlated to the $\mathrm{ODH}\left(\mathrm{R}^{2}=0.85\right)$. However, $\mathrm{ODH}$ indicates higher levels of discomfort which is explained by the fact that overcrowded zones are more likely to overheat and more occupants experience that overheating.

This correlation indicates the reliability of the ODH as a thermal comfort metric with the advantage of providing higher results resolution by normalizing discomfort by occupants. In addition, ODH is a zone-specific metric and is dependent on the occupant density and sensitive to the location of the zones (e.g. south-facing, core.) 


\subsubsection{Impact on indoor air quality (IAQ)}

IAQ is another aspect of comfort that was investigated in this study. The number of $\mathrm{OHcO}_{2}$ was tracked throughout the seventy-five simulation runs. Figure 6.10 reveals a notable sensitivity of IAQ to the changes in occupants' distribution scenarios as the number of $\mathrm{OHCO}_{2}$ has increased with variable magnitudes. Despite the small ranges shown on the boxplot for most of the zones, there are still several outlier scenarios that indicate extreme possible scenarios where the acceptable level of $\mathrm{CO}_{2}$ concentration is not met in many hours as the values of $\mathrm{OHcO}_{2}$ were approximately 400 in some scenarios. Hours with high $\mathrm{CO}_{2}$ concentration are often attributed to hours of discomfort and low productivity (Bakó-Biró et al. 2012). $\mathrm{CO}_{2}$ is also used as a proxy for the concentration of contaminants such as infectious aerosols across building zones which can impose a health threat for building occupants.

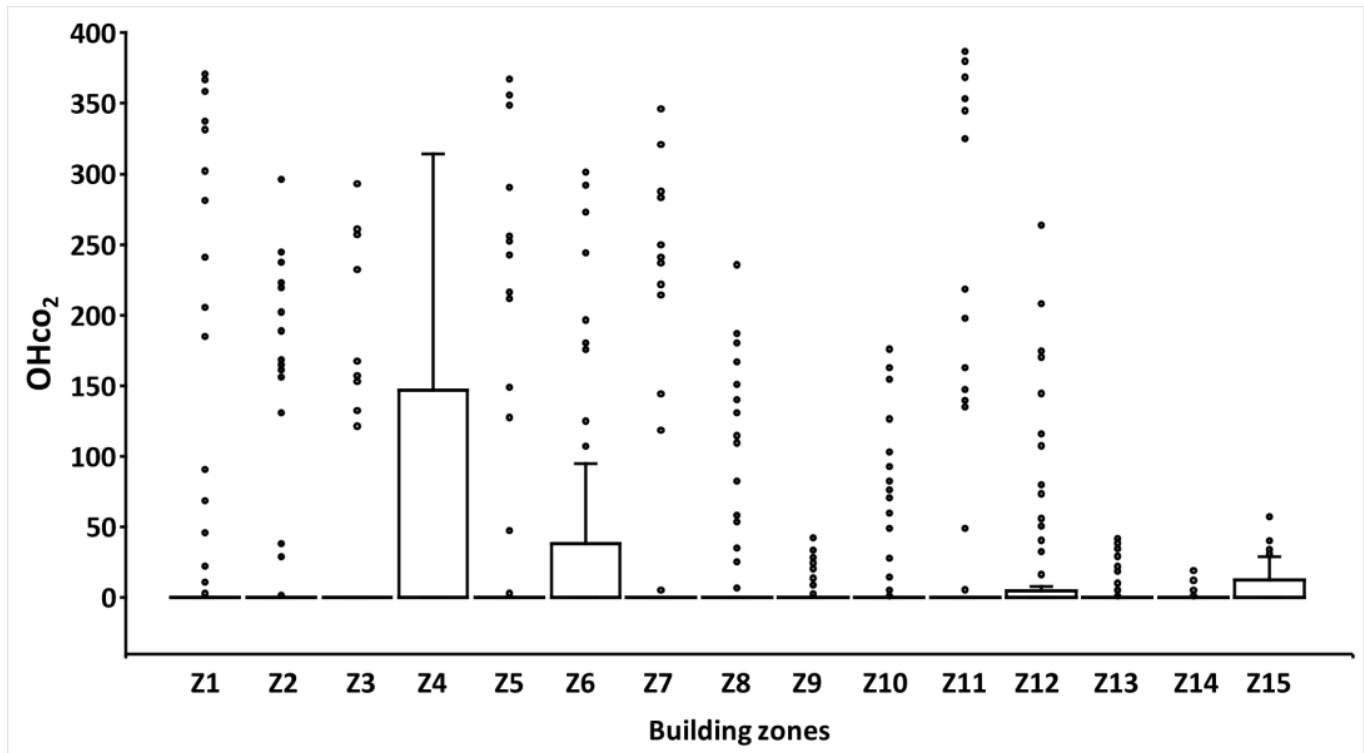

Figure 6.10: A boxplot of the $\mathrm{OHco}_{2}$ under the $75 \mathrm{ODSs}$. 
CHAPTER 6

Although $\mathrm{CO}_{2}$ concentration increases with the increased number of people, no zonespecific trends (e.g. orientation-related trends) can be drawn from the results. However, infiltration in perimeter zones helps dilute air and decrease $\mathrm{CO}_{2}$ concentration especially during the afterhours when the HVAC is turned off as HVAC pressurizes the building with their supply fans during the occupied hours which decreases infiltration.

\subsection{Benefits of adaptive technologies}

Several adaptive technologies that can adapt to variable occupancy in buildings have been developed over the last few decades and are currently available for use in buildings (Erickson et al. 2009; Guillemin \& Molteni 2002; Peng et al. 2018). Occupancy-based lighting controls, demand-controlled ventilation (DCV), and adaptive temperature setpoints and HVAC schedules are examples of technologies that have been adopted by some practitioners in the AEC industry. In this paper, we investigated the potential benefits of using DCV in buildings with heterogeneous occupants' distribution. DCV manages the supply of outdoor air according to actual building occupancy using occupancy sensors such as passive infrared sensors (PIR) or $\mathrm{CO}_{2}$ sensors (Emmerich \& Persily 2001; Schibuola et al. 2016). DCV is known for being a suitable strategy for saving energy while maintaining acceptable IAQ, 
CHAPTER 6

especially in buildings with variable occupancy (Lawrence 2004; Schibuola et al. 2016).

Therefore, in an attempt to investigate the potential benefits of adaptive technologies on building performance (energy and comfort) under variable ODSs, we repeated the simulations of the case study model with enabled DCV (occupancy-based control) under the 75 ODSs. Figure 6.11 introduces a comparison of EUI for the simulations with and without DCV. The comparison reveals savings of about 6-7\% in EUI, which is comparable to what was presented in several studies such as O'Brien and Gunay (2019) and Hong and Fisk (2010). DCV regulates the flow rates of the outdoor air (OA) to be proportional to occupancy needs (Mysen et al. 2003). In other words, it mitigates the unnecessary conditioning of outdoor air.

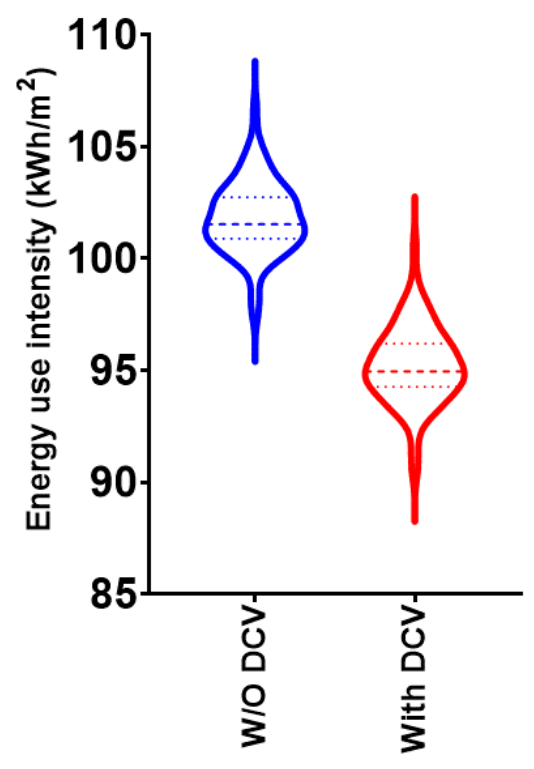

Figure 6.11: A comparison of EUI without and with DCV. 
On another front, using DCV resulted in reducing the range of overcooling ODH by about 50\%, as shown in Figure 6.12. Deploying DCV reduced the amount of outdoor air supply to core zones when under-occupied.

Overall, and based on the findings of this study, using DCV can have promising results in both saving energy and maintaining or improving comfort levels under occupant-related uncertainty.

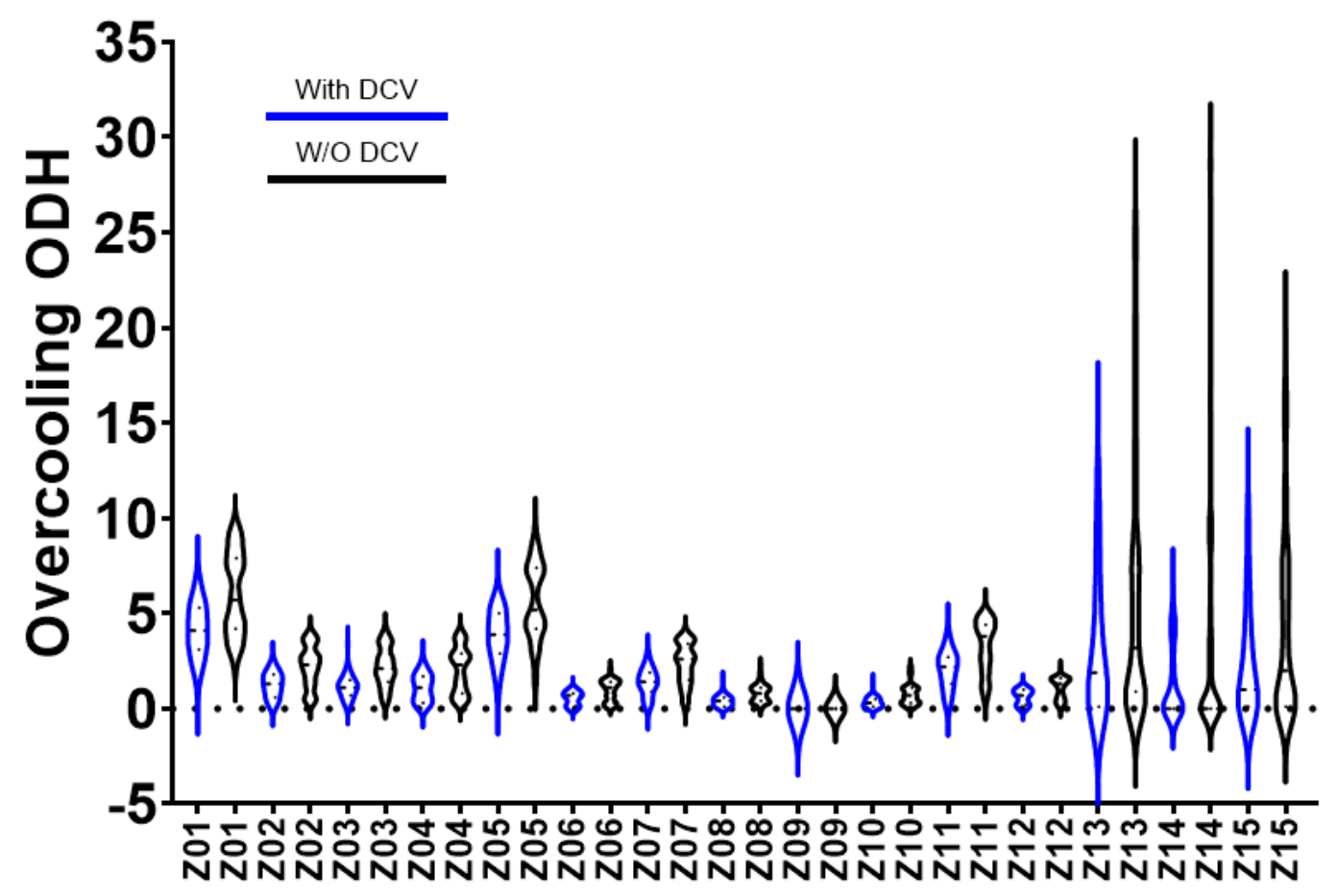

Figure 6.12: A comparison of overcooling $O D H$ without and with DCV. 
CHAPTER 6

\subsection{Limitations and future work}

While this paper presents the impact of office building ODSs on energy and comfort performance, there were some limitations of the methodology followed:

(1) The methodology focused on one type of occupant-related assumption, which is occupants' distribution. Several other occupant-related assumptions are made during design, such as occupancy schedules, plug-in loads, lighting loads, thermostat setpoints, and window blinds use.

(2) In this study, for the sake of simplicity and ease of implementation by designers, the methodology did not consider the mobility of occupants within and between building zones.

(3) The methodology assumed typical occupancy schedules (time of presence) and did not consider variations in working hours schedules.

Therefore, future work should investigate the implications of a wider range of occupant-related assumptions that are typically made by a designer. In addition, the benefits of adaptive technologies other than DCV, such as lighting controls, and shading controls, should be investigated under variable ODSs. 
CHAPTER 6

\subsection{Conclusions and recommendations}

This paper aimed mainly at demonstrating the implications of the current simplified

ODS made by building designers during building energy and comfort performance

modelling. For this study, an energy model of a typical floor of a real office building located in Toronto, Canada was built. The energy model was simulated under seventy-five ODSs. These ODSs were generated to mimic different ODS in real office buildings. Four different metrics were used to assess the impact of variable ODS on building performance. The EUI was used to assess energy performance while unmet hours, $\mathrm{ODH}$, and $\mathrm{OHcO}_{2}$ were used to evaluate comfort performance.

On the one hand, the results indicated a modest variation of EUI $\left(5-10 \mathrm{kWh} / \mathrm{m}^{2}\right)$ when alternative ODSs were used compared to the standard ODS. On the other hand, the results indicated a significant increase in unmet hours (by a factor of 10 or more) with some ODSs. In addition, ODH indicated different discomfort levels experienced by occupants in different zones. The results also indicated that overheating is a major issue with variable ODSs as the overheating ODH results indicated a wide range $(0$ - 500) in south-facing and core zones. Some extreme overheating cases (outliers) were reported with overheating ODH that exceeded 500 . The results also indicated the sensitivity of the IAQ to the variable ODSs as the 
CHAPTER 6

value of $\mathrm{OHCO}_{2}$ changed drastically from 0 with standard occupants' distribution to reach 400 in some zones with some scenarios.

Additionally, the study examined the benefits of DCV, as an adaptive technology, in addressing some issues related to variable ODSs. Deploying DCV resulted in EUI savings of about $6-7 \%$ as well as assisting in mitigating overcooling in core zones due to overventilation when under-occupied.

In accordance with this study findings, the authors recommend the following guidelines to building designers:

(1) Designers should consider the spatial and temporal variations in occupant density and realize the potential compromise to building performance. Although, the ODS variable had a limited impact on energy use, it can have a significant and chronic impact on comfort performance. We recommend that designers should test designs under a few extreme scenarios (at least extreme ODSs where some building zones become densely populated or under-populated/empty) to assess the robustness of design decisions to occupant-related uncertainty.

(2) As the design evolves, designers should keep evaluating design under alternative occupant distribution scenarios throughout design process. 
CHAPTER 6

(3) The benefits of adaptive technologies should not be overlooked during the design process. Designers should consider deploying adaptive technologies such as DCV that can help to handle variable occupancy while saving energy and maintaining comfort.

Overall, these findings should be considered as cautionary for building designers, as using standard assumptions could compromise occupants' comfort and productivity. Office buildings tenants, in reality, are of different occupant densities that might be significantly different from the standard assumptions. Considering alternative distribution scenarios (e.g. extreme low and high densities) should be handy and useful in pointing out possible discomfort issues. 


\section{A method for exploring occupant-related uncertainty during building design}

This chapter has been submitted and accepted as:

Abuimara, T., O'Brien, W., Gunay, B (2021). 7 A Method for Exploring Occupantrelated Uncertainty during Simulation-aided Office Building Design. eSim conference, Vancouver 2021.

\subsection{Abstract}

Quantifying occupant-related uncertainty has been considered a major challenge during simulation-aided building design process. To this end, this paper outlines a reproducible method that aids designers in handling occupant-related inputs during the simulation-aided design process. The proposed method includes three main steps: (1) establishing occupant-related assumptions, (2) evaluating design performance based on the established occupant-related assumptions, and (3) reporting and communicating occupant-related uncertainty to stakeholders. The objective is to provide an easy-to-implement method that can be adopted by building design practitioners and assist in managing uncertainty by identifying opportunities to improve energy and comfort performance during the simulation-aided design process.

\subsection{Introduction}

It is widely recognized amongst researchers and building design practitioners that occupants are a major source of uncertainty during building design and operation 
CHAPTER 7

(Delzendeh et al. 2017; Dong et al. 2018). This uncertainty causes the notable performance gap between simulated and actual performance (Gaetani et al. 2016b;

Hoes et al. 2009; Yan et al. 2017). This uncertainty results from occupant-related assumptions made during design and random/unexpected nature of occupants' behaviour during building operation.

Designers' assumptions about occupants' presence and behaviour treat all occupants in all buildings of the same type alike. They usually assume that occupants are simplistic and deterministic systems that are present for a specified period of time, emit a prescribed amount of heat into space, and are homogeneously distributed in the building (Gilani et al. 2016, 2019). Designers typically use occupant densities and schedules provided in building codes and standards, such as the National Energy Code of Canada for Buildings (NECB) (NRC 2015). However, occupants do not use or occupy buildings the way designers assume. They arrive and depart buildings at different times, have different comfort preferences, and are heterogeneously distributed in buildings. Figure 7.1 demonstrates how occupants influence building design and performance through their interaction with building components and systems. In view of the above issues, the current occupant modelling approaches are considered inaccurate and outdated and require attention from researchers and building designers (Abushakra et al. 2004; Ouf et al. 2018). 


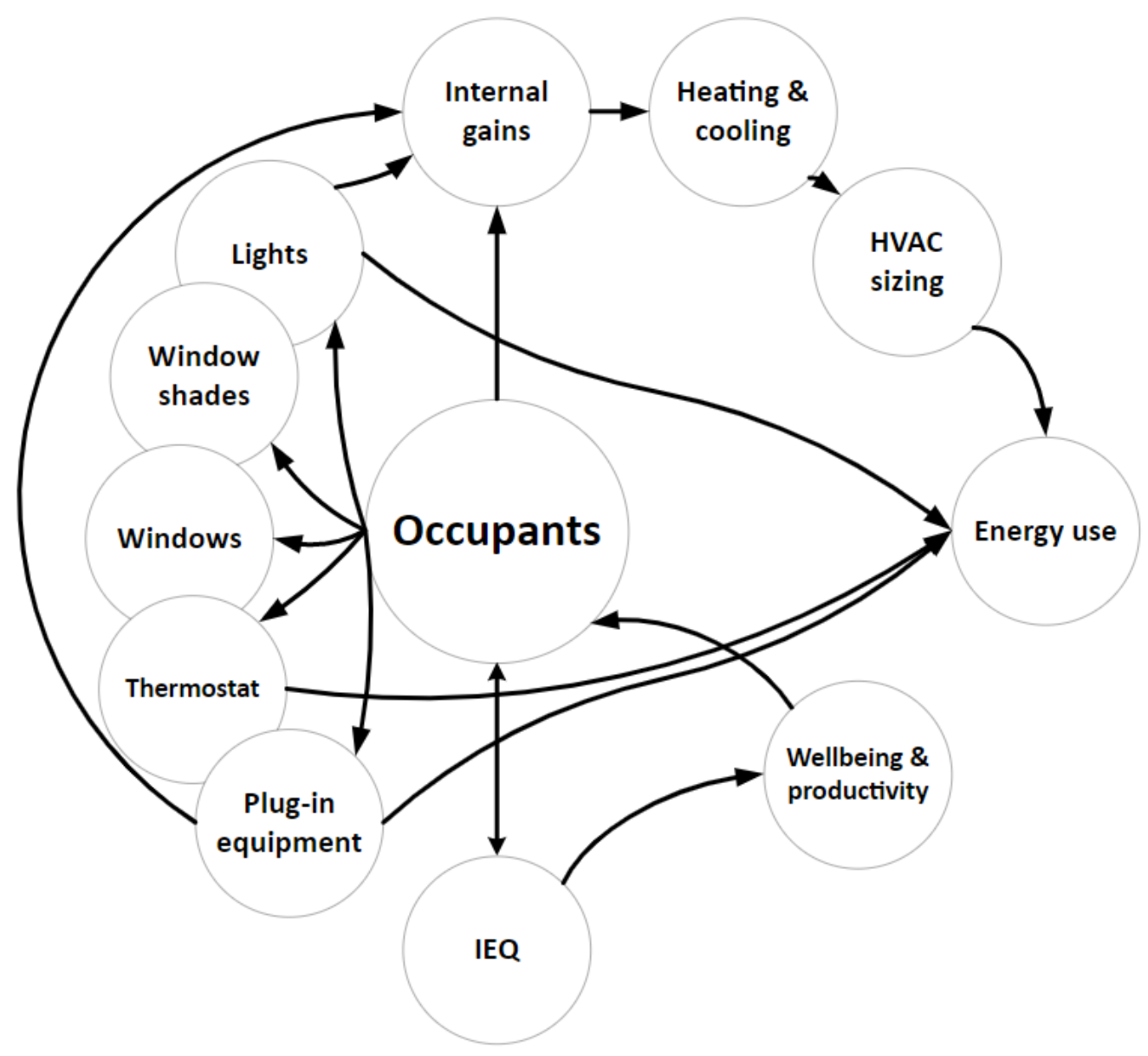

Figure 7.1: Occupants' actual impact on building performance.

To address the consequences of occupant-related uncertainty, researchers have been investigating and quantifying its implications and pursuing improved modelling methods. One approach was to develop data-driven stochastic models in an attempt to accurately model occupants' presence and actions. For instance, statistical models were developed for occupants' lights use such as Lightswitch-2002 model by Reinhart (2004), and window opening by Haldi and Robinson (2009b). However, these approaches are yet to be adopted by designers due to their complexity and 
CHAPTER 7

generalizability as they were developed based on data from single offices under certain conditions (O’Brien et al. 2016; Schweiker et al. 2011).

Other researchers have worked on developing methods to account for occupants' uncertainty by applying adjustments to the current practice by designers. For example, Sun and Hong (2017a) developed a simulation workflow to quantify the impact of occupants on potential energy savings from energy conservation measures (ECMs). The simulation workflow included simulating building energy model under three different occupant behaviour types: austerity, normal, and wasteful. The three behaviour types were developed to reflect three discrete levels of occupants' conscientiousness of the implications of their interactions with building components and systems. The workflow suggested reporting a range of ECM saving as guidance for design decision making.

On another front, Gaetani et al. (2017) argued in a study that the appropriate occupant modelling approach depends largely on the purpose of modelling. The study introduced a strategy to select a fit-for-purpose occupant behaviour modelling (FFPOBm). The proposed FFP-OBm can be summarised in four major steps: (1) choosing model complexity, (2) defining diversity pattern of uncertain occupant behaviours, (3) sensitivity analysis, and (4) decision making. The strategy was tested on a case study on four office cubicles. Several types of occupant behaviours such as equipment, 


\section{CHAPTER 7}

lighting, thermostat, and blinds use were studied. The results indicated that the strategy was useful in determining the required model complexity as it indicated that increased occupant behaviour modelling complexity is useless in two of the four cases. The study concluded that the proposed methodology is still under development and it has the potential of being implemented in building performance simulation (BPS) tools to ease implementation by design practitioners (Gaetani et al. 2017).

Despite the ongoing efforts to develop an improved method to model occupants during the design process, there are still several gaps that need to be addressed. Among them, most studies target improving occupant modelling within an energy modeller's scope. In addition, none of the proposed methods is based on practitioners' feedback on occupant modelling and occupant-related assumptions.

To this end, this paper presents a new method for occupant-centric building design which is based on results of a stakeholders' workshop, simulation-based study and the design process documentation of a real office building in Toronto. The method targets key stakeholders involved in building design process such as architects, engineers, and energy modellers. We did not limit the target audience of this method to energy modellers because in practice most of the critical design decisions are made by architects and engineers prior to the involvement of energy modellers (Méndez Echenagucia et al. 2015; Miles et al. 2001). The late involvement of energy modellers 
CHAPTER 7

limits their influence on design to minimal changes such as changing glazing type or increasing wall insulation (Abuimara et al. 2019).

On the other hand, architects and mechanical engineers who join the design process at early stages can influence the most critical decisions, such as building form, layout and circulation, fenestration sizing and placement, and the heating, ventilation and air conditioning (HVAC) type and configuration. Occupant-related assumptions are typically used in making these decisions, albeit in a relatively coarse and conservative manner. For example, architects use the number of occupants in developing the building layout, planning for egress and determining the overall built-up area. Mechanical engineers use the number of people and their associated lighting and plug-in equipment loads to calculate heating and cooling loads and size HVAC accordingly. The proposed method's ultimate objective is to put occupants' considerations at the core of the building design process.

\subsection{Methodology}

\subsubsection{Approach}

The proposed method is built and validated upon the findings of qualitative and quantitative studies conducted over a period of three years. 
CHAPTER 7

\subsubsection{The qualitative study}

The qualitative study was intended to document and evaluate the current practice in modelling occupants and to identify the needs, barriers and possible improvement approaches. The qualitative study included:

(1) A one-day stakeholders' workshop to obtain practitioners' feedback on occupant modelling and occupant-related assumptions. The workshop topics included discussing the status quo, identifying the challenges and needs, and proposals for advancing the current practice.

(2) Design process documentation of a case study office building located in Toronto, Canada. The documentation took place through interviews with project stakeholders (owner, architect, mechanical engineer, and energy modeller).

\subsubsection{The quantitative Study}

The quantitative study was a simulation-based investigation to evaluate the impact of occupant-related assumptions on the design process outcomes. The quantitative study included:

(1) the establishment of an energy model of the case study based on design documents and energy model created by energy modeller, 
(2) conducting occupant-centric parametric analysis to assess the impact of occupant related assumptions on shortlisting design parameters /ECMs,

(3) an occupant-centric design optimization study to evaluate the impact of occupant-related assumptions on selecting optimal design parameters/ECMs,

(4) and a study of the implications of interzonal occupants' distribution diversity on comfort and building energy use.

\subsubsection{Case study}

The case study is an office building located in Toronto, Canada. Figure 7.2 shows the model for a typical office floor in the building with two different zoning strategies that were used throughout the investigation. Table 7.1 provides details about the building components and systems used to create the energy model. These details were obtained from the building design documents and energy model created by the designer.

Two different zoning strategies were used: five-zones model and fifteen-zones model. The five-zones model represents the zoning strategy used by the energy modeller and was used in our investigation to assess the impact of occupant-related assumption on the selection of design parameters (i.e. ECMs) based on their ranking and 
potential energy savings. The fifteen-zones model was used to assess the impact of occupants' distribution in buildings on occupants' comfort.
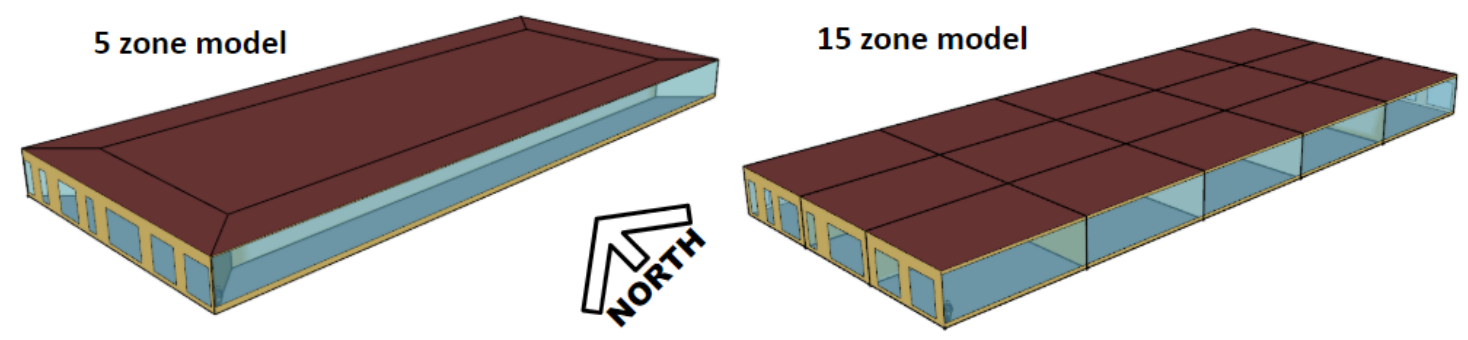

Figure 7.2:The case study models.

Table 7.1: Case study specifications.

\begin{tabular}{|l|l|}
\hline Item & Description \\
\hline Floor area & $1728 \mathrm{~m}^{2}$ \\
\hline $\begin{array}{l}\text { Window to } \\
\text { wall ratio } \\
\text { (WWR) }\end{array}$ & $\begin{array}{l}\text { WWR (overall) }=46.5 \% \\
\text { WWR (north) }=12 \% \\
\text { WWR (east) }=41 \% \\
\text { WWR (west) }=41 \%\end{array}$ \\
\hline $\begin{array}{l}\text { HVAC } \\
\text { Roof-top package unit, natural gas fired condensation boiler, zone level } \\
\text { VAV with reheat, hydronic baseboard heaters }\end{array}$ \\
\hline $\begin{array}{l}\text { Economizer } \\
\text { Heat } \\
\text { recovery }\end{array}$ & $\begin{array}{l}\text { Differential dry-bulb airside economizer } \\
\text { Wall }\end{array}$ \\
\hline $\begin{array}{l}\text { Window } \\
\text { assembly }\end{array}$ & $\begin{array}{l}\text { U-value }=1.9 \mathrm{~W} / \mathrm{m}^{2} \cdot \mathrm{K} \\
\text { SHGC }=0.33\end{array}$ \\
\hline
\end{tabular}




\subsection{The three-step method}

An overview of the proposed three-step method is shown in Figure 7.3. The first step is to establish occupant-related assumptions which are case specific. The second step is to evaluate the design outcomes taking into consideration the assumptions established in the first step. The third step includes reporting design outcomes considering uncertainty from occupants and occupant-related assumptions. The three-step method is presented for implementation throughout the design process and not only during the energy modelling scope

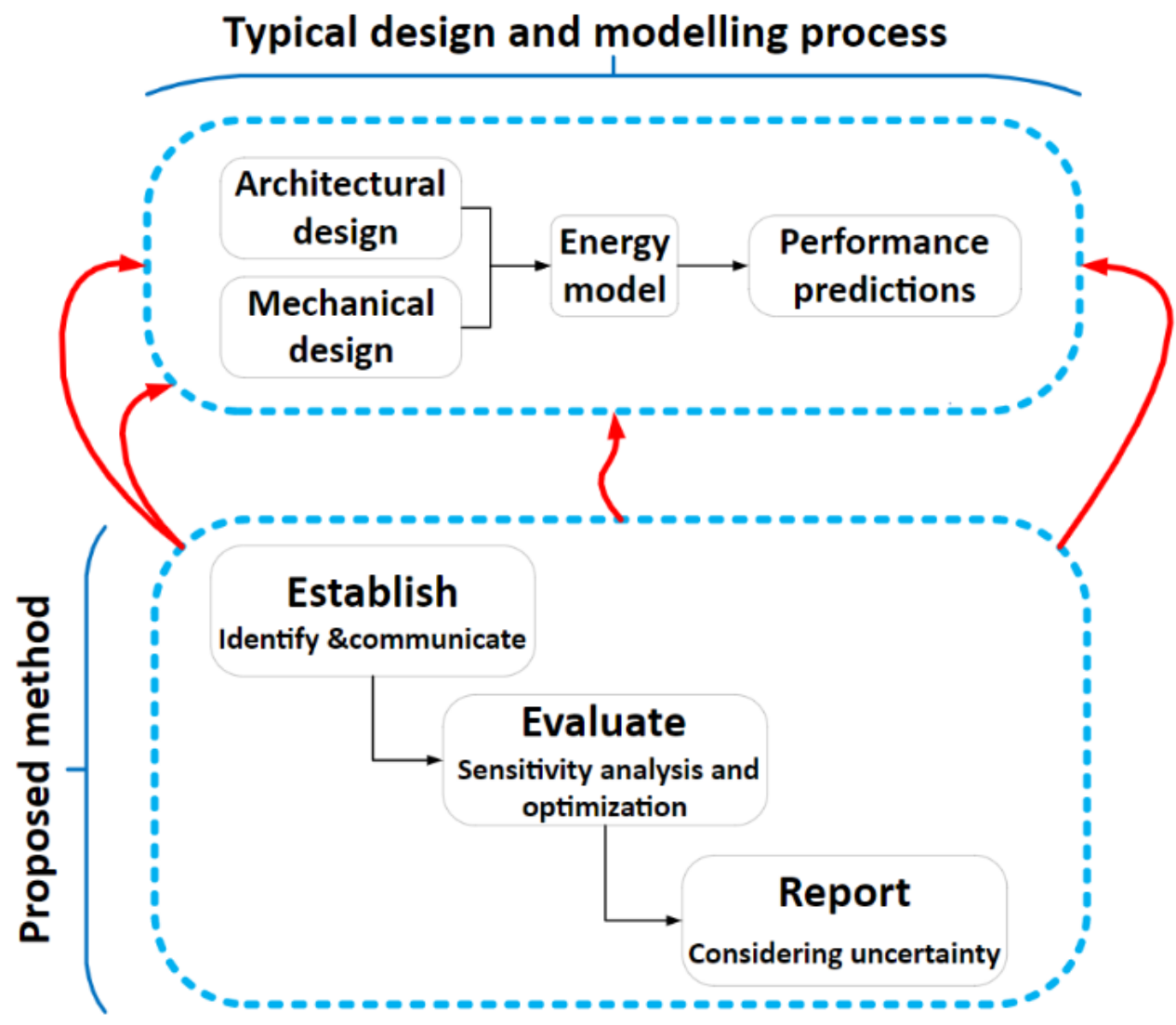

Figure 7.3: An illustration of how the proposed three-step occupant modelling process can feed in and improve the design process. 
CHAPTER 7

\subsubsection{Establishing and communicating assumptions}

The first step of the proposed method is establishing occupant-related assumptions which includes identifying and communicating these assumptions to all design stakeholders. Occupant-related assumptions are generally overlooked during the design process and in particular at the early design stages (Abuimara et al. 2018b; Ouf et al. 2018; Yan et al. 2017).

At early design stages, architects typically use the number and type (e.g. students, office workers) of occupants to determine building size, develop a project program, layout, and plan circulation and egress. Mechanical engineers use people heat gains, and lighting and plug-in equipment loads to perform sizing calculation for the selection of HVAC equipment. However, little attention is paid at this early stage for the possible variations of number of people, occupied periods, plug-in equipment and lighting loads, and use of different window shading devices. Table 7.2 provides examples of common occupant-related assumptions made by designers against reality.

Provided that decisions at early design stages provide an opportunity for initial and operation cost savings (Attia et al. 2012a), designers need to dedicate sufficient time and effort to identify and define building use patterns including the number of people, 
time of occupancy, possible domains of interaction with building components and systems (e.g. windows, blinds, thermostats).

Lack of information about occupants is a common challenge that designers face at early design stages of new buildings. Dealing with this challenge requires efficient communication with owner and occupants, if possible.

Considering occupant-related assumptions on early design team meetings is of great importance as it provides the opportunity to discuss their implications on different design tasks. In addition, it ensures that all stakeholders share their experience, thoughts, and plans regarding the role of occupant-related assumptions in design tasks.

Table 7.2: Occupant related assumption in practice vs reality.

\begin{tabular}{|c|c|c|}
\hline Type of assumption & Default assumption & Reality \\
\hline Occupants' presence & $\begin{array}{l}\text { Identical schedules for all } \\
\text { zones and buildings from } \\
\text { same type }\end{array}$ & Different schedules \\
\hline Occupants' density & $\begin{array}{l}\text { A constant number of people } \\
\text { per } \mathrm{m}^{2} \text { based on a code or } \\
\text { standard }\end{array}$ & $\begin{array}{l}\text { Differs between buildings } \\
\text { and tenants in the same } \\
\text { building }\end{array}$ \\
\hline $\begin{array}{l}\text { Occupants' } \\
\text { distribution }\end{array}$ & Homogeneous & Heterogonous \\
\hline Lighting use & $\begin{array}{l}\text { Constant } \mathrm{W} / \mathrm{m}^{2} \text { as per } \\
\text { building code }\end{array}$ & $\begin{array}{l}\text { Differs based on building use } \\
\text { and type of fixtures }\end{array}$ \\
\hline Plug-in equipment & $\begin{array}{l}\text { Constant } \mathrm{W} / \mathrm{m}^{2} \text { as per } \\
\text { building code }\end{array}$ & $\begin{array}{l}\text { Differs based on building use } \\
\text { and type of plug-in } \\
\text { equipment }\end{array}$ \\
\hline
\end{tabular}


CHAPTER 7

\begin{tabular}{|l|l|l|}
\hline HVAC operation & $\begin{array}{l}\text { Operating hours from 5 am } \\
\text { to } 10 \text { pm as per building code }\end{array}$ & $\begin{array}{l}\text { Differs based on operators' } \\
\text { decisions }\end{array}$ \\
\hline $\begin{array}{l}\text { Temperature } \\
\text { setpoints }\end{array}$ & $\begin{array}{l}\text { Winter (setpoint } 22^{\circ} \mathrm{C}, \\
\left.\text { setback } 16^{\circ} \mathrm{C}\right) \\
\text { Summer (setpoint } 24^{\circ} \mathrm{C} \text {, no } \\
\text { cooling during unoccupied } \\
\text { hours) }\end{array}$ & $\begin{array}{l}\text { Differs based on operators' } \\
\text { interactions } \\
\text { thermostats }\end{array}$ \\
\hline $\begin{array}{l}\text { Shading type and } \\
\text { operation }\end{array}$ & Always open & $\begin{array}{l}\text { Different patterns of use } \\
\text { based on } \\
\text { behaviour occupants } \\
\text { privacy) }\end{array}$ \\
\hline
\end{tabular}

Another essential practice during the first step of the proposed method and throughout the design process is to communicate occupant-related assumptions to other design stakeholders to avoid discrepancies. An example of a discrepancy in assumptions amongst design stakeholders was identified during documenting the case study design process. Figure 7.4 demonstrate the disagreement of assumptions made by different designers.

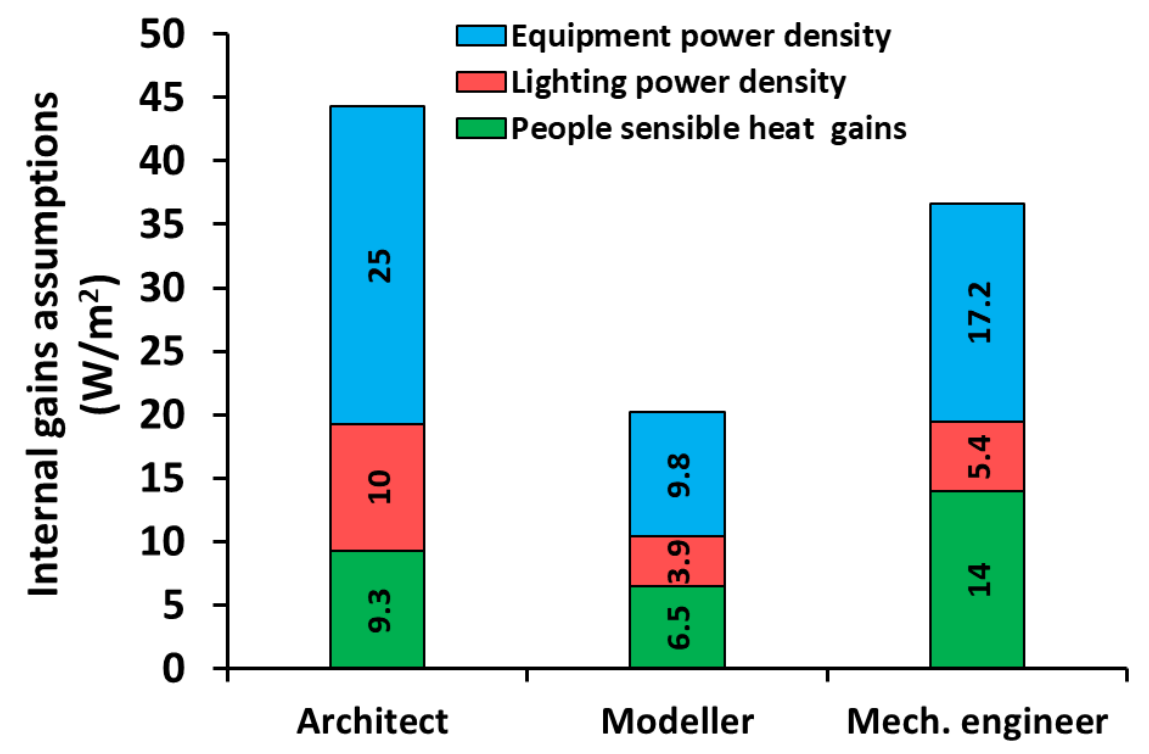

Figure 7.4: Discrepancy in occupant-related assumptions among design stakeholders. 
Thus, the first step of the proposed method should include the following activities:

(1) Identifying occupant-related assumptions based on project type and owner requirements. This includes considering all design milestones, components, and systems that are related to occupants' behaviour.

(2) Collecting occupant-related data from all possible sources. Sources include owner, occupants or occupants' representatives, codes and standards (considering flexibility offered by these codes and standards), and similar buildings in operation. The goal here is to collect as comprehensive information as possible.

(3) Organizing and classifying the collected information to ease the selection of the fit-for-purpose information for modelling.

(4) Developing an information documentation and sharing mechanism to ensure that all design stakeholders are using the same occupant-related assumptions throughout the design process.

\subsubsection{Evaluating design}

Following the establishment of occupant-related assumptions -including communicating them to other design stakeholders- design performance needs to be 
evaluated under different occupant scenarios. The evaluation here refers to testing and further developing building design under variable occupant scenarios. Variable occupant scenarios can be alternative schedules (e.g. low occupancy, high occupancy, and average occupancy) along with lighting use and plug-in equipment use scenarios. It can also include varying the people density, lighting power density, plug-in equipment loads, temperature setpoints, and window blinds control type.

As designers typically choose to abide by building code, building codes (at least in the Canadian context) offer reasonable flexibility when it comes to occupant-related assumptions. For example, the NECB allows adjustments to occupant-related assumptions as long as same assumptions are used in both the building under design and the reference building (NRC 2015).

To have a method that is compatible with designers' approach, the phase has to follow the same workflow of the standard design process. To this end, the simulationbased investigation was conducted in phases that replicates the actual design development workflow. Starting with establishing a representative energy model, selecting design parameters/ECMs the are commonly used in practice (upon a practitioner advice), conducting parametric analysis to shortlist the influential design parameters/ECMs, and design optimization. To this end, this phase includes conducting occupant-centric parametric analysis and design optimization, and 
CHAPTER 7

evaluation of the impact of variable occupant scenarios on occupants' comfort. Conducting occupant-centric parametric analysis is the process of evaluating design parameters/ECMs in terms of energy use savings under variable occupancy scenarios.

Parametric analysis is a common practice in process of searching for most influential ECMs. However, this process indicates deterministic savings potential per design parameter/ECM and does not account for the impact of variations of occupancy and occupant behaviour. Therefore, parametric analysis needs to be verified under variable occupant scenarios to ensure the selection of ECMs that suit design objectives or that demonstrates robustness to occupant scenarios.

Figure 7.5 and Figure 7.6 present results of occupant-centric parametric analysis conducted on the case study model. In this parametric analysis, the impact of occupant-related assumptions on the potential energy use savings of ECMs were evaluated. The design parameters used in the parametric analysis included enveloprelated design parameters such as window glazing type and systems-related parameters such as demand-controlled ventilation (DCV). Figure 7.5 indicates the results of testing the sensitivity of window type selection to occupant-related assumptions. 


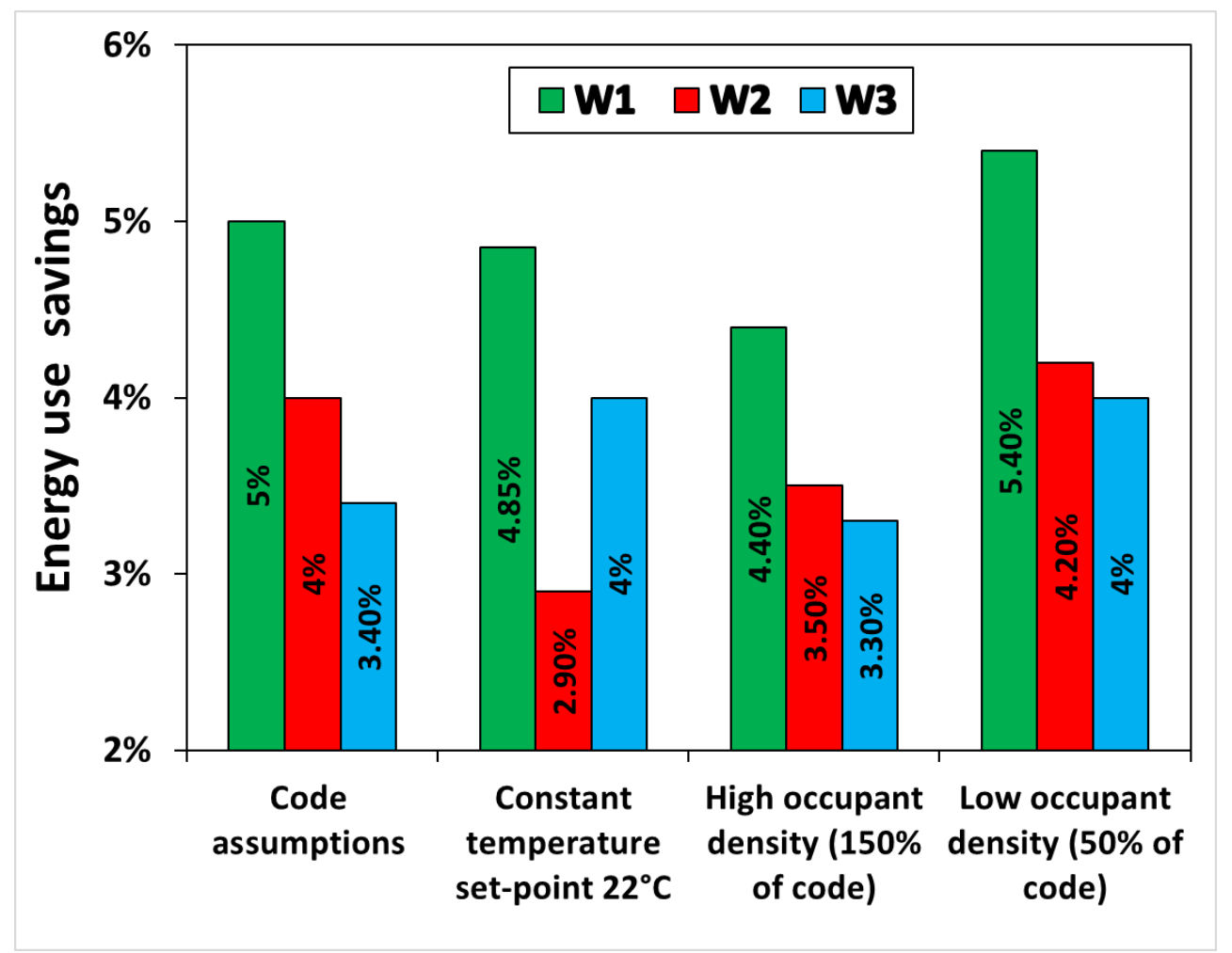

Figure 7.5: Sensitivity of energy-saving potential from three window assemblies to the different occupant related assumptions. $W 1\left(U=1.62 \mathrm{~W} / \mathrm{m}^{2} \cdot K, S H G C=0.39\right)$, $W 2\left(U=2.04 \mathrm{~W} / \mathrm{m}^{2} \cdot K, S H G C=0.58\right)$, and $W 3\left(U=1.47 \mathrm{~W} / \mathrm{m}^{2} \cdot K, S H G C=0.25\right)$.

The results indicate moderate but noticeable sensitivity of window glazing type to four different occupant-related assumptions.While Figure 7.6 demonstrates substantial sensitivity of the deployment of demand-controlled ventilation (DCV) to occupant-related assumptions as potential energy use savings differed by a factor of five or more. Detailed results of this study were published in Abuimara et al. (2019).

In addition to the occupant-centric parametric analysis, this step includes occupantcentric optimization to assess the impact of variable occupant scenarios on selecting combinations of design parameters/ECMs to produce optimal design. Optimization is typically the stage that follows parametric analysis where designers use 
combinations of shortlisted design parameters/ECMs to produce design alternatives and select the optimal combination.

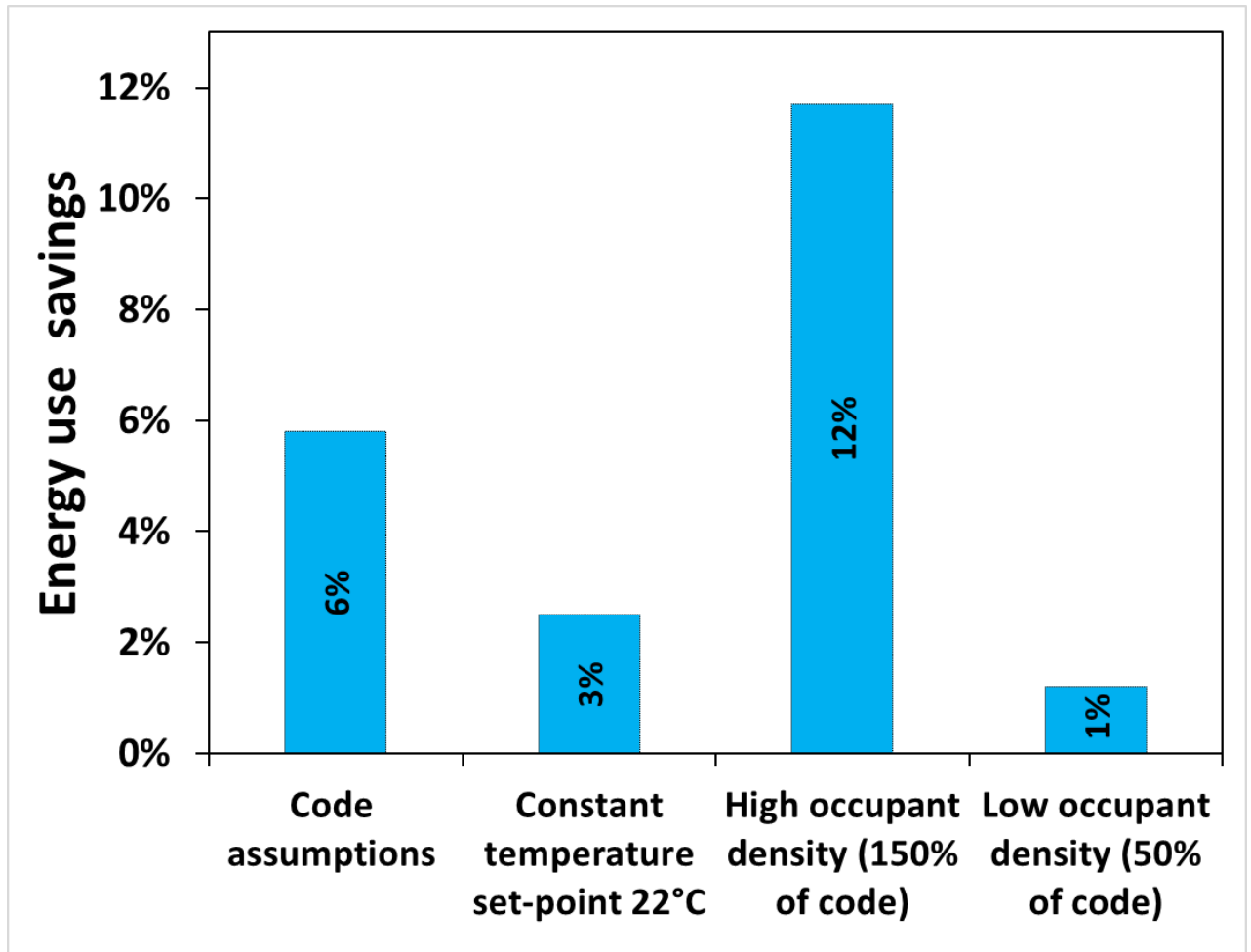

Figure 7.6: Sensitivity of energy-saving potential from DCV to the different occupant related assumptions.

In design optimization, designers usually do not consider the impact of occupantrelated assumptions and conclude the optimization process to a single optimal design.

However, the results of the occupant-centric optimization conducted on the case study model revealed the selection of optimal design was highly sensitive to different occupant scenarios. In the process, occupant scenarios were generated by varying occupancy, lighting, and plug-in equipment schedules. Ten different design parameters/ECMs were used in the optimization process. Figure 7.7 presents sample 
results of design optimization under four different occupant scenarios including the standard scenario typically used by designers. The results indicate differences in HVAC energy use per occupant scenario compared to the standard assumptions (i.e. code scenario). The differences in HVAC energy use intensity (EUI) ranged from $4 \%$ to $15 \%$.

In addition to HVAC energy performance, occupant-centric optimization results can be used to derive rules for selecting optimal design parameters/ECMs. These rules can be derived using decision trees of multiple optimization results.

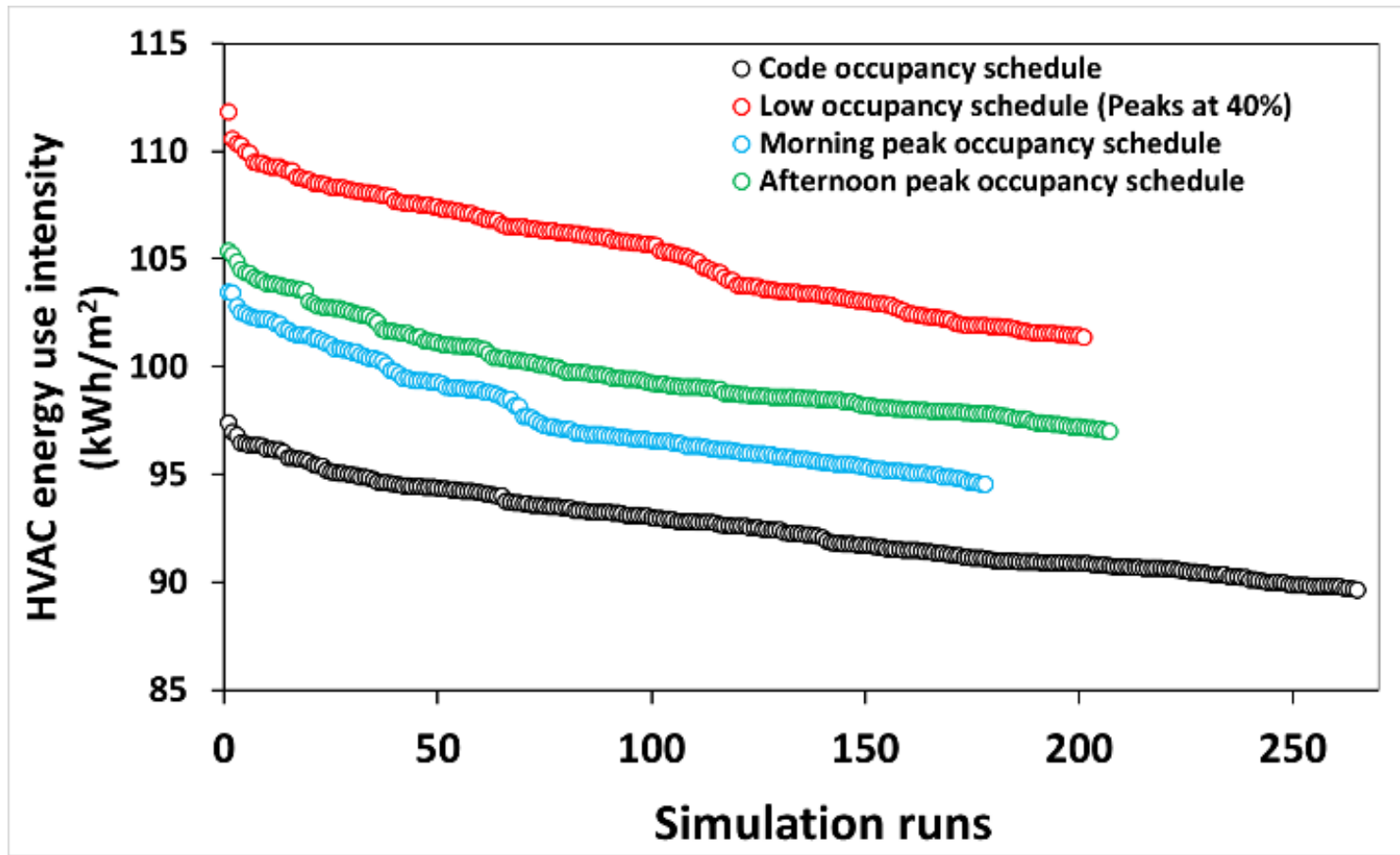

Figure 7.7: HVAC EUI of design optimization from four optimization runs using four different occupancy schedule scenarios. Each scatter point represents an optimization run for an occupant scenario. The length of the scatter plot indicates the number of simulation runs before the optimization algorithm terminates the search for a given scenario. 
Figure 7.8 shows an example of rules for selecting the size of sidefin shading for a west-facing window. The rules were derived based on optimization results of the case study window design under sixty-four different occupant scenarios. Figure 7.8 also shows the importance of occupant-related assumptions on selecting certain optimal design parameters/ECMs.

On the other hand, Figure 7.9 demonstrates that other design parameters/ECMs can show robustness to occupant scenarios as one type of window assembly was found to be the optimal selection for all occupant scenarios.

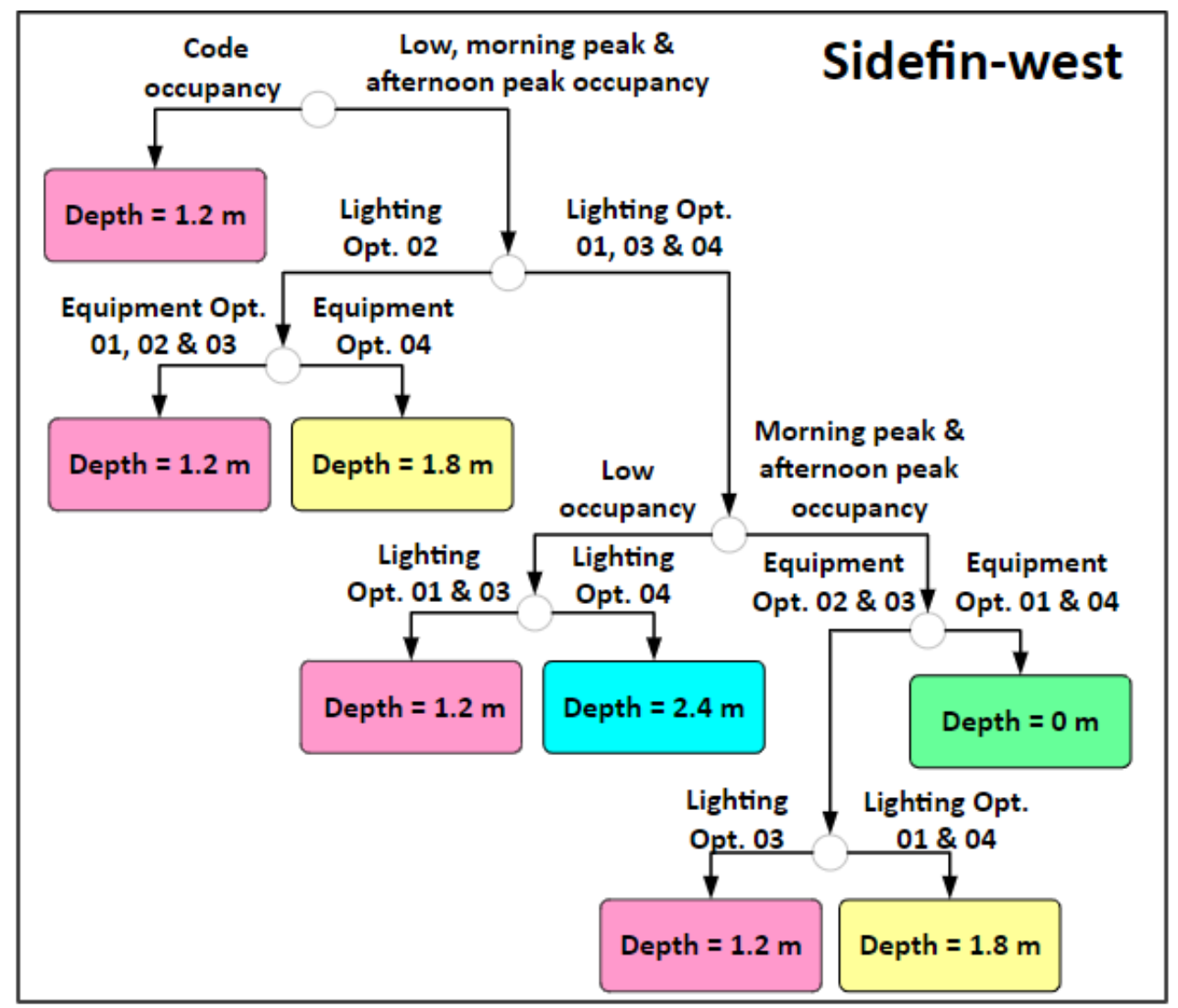

Figure 7.8: A sample decision tree demonstrating guidelines for selecting optimal sidefin shading size on west-facing façade. 
It is worth mentioning here that the results in Figure 7.8 and Figure 7.9 shows that one window type is optimal regardless of occupants, but should be treated as casespecific and should not be generalized without further investigation. However, the methodology followed can be used in the case of office buildings in Canadian and similar contexts.

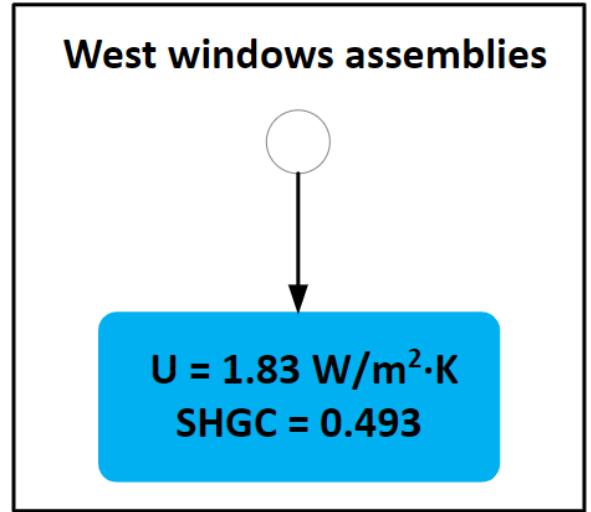

Figure 7.9: A sample decision tree demonstrating guidelines for selecting optimal window assembly material for west-facing façade.

\section{Range of energy use intensity of 64 optimal designs $\left(\mathrm{kWh} / \mathrm{m}^{2}\right)$}

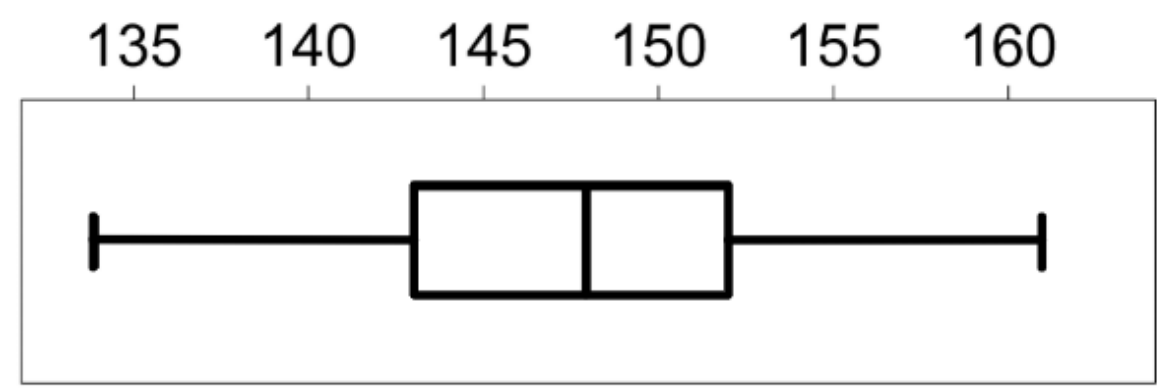

Figure 7.10: Optimization results distribution for sixty-four different occupant scenarios. The distribution is based on the sixty-four optimal designs. 
CHAPTER 7

Figure 7.10 presents the range of EUI for the sixty-four optimal designs of the same case study occupant-centric optimization. The boxplot demonstrates the substantial variation in the energy performance of optimal designs under different occupant scenario.

On another front, during this step of the proposed method, attention should be paid to evaluating the implications of occupants' distribution on comfort. Standard occupant-related assumptions consider that occupants are homogeneously distributed in the building while, in reality, occupants are heterogeneously distributed in the building as a result of usually having different tenants with various staffing and activities in buildings. This heterogeneous distribution is associated with an elevated level of discomfort as overpopulated zones might experience overheating and underpopulated zones will experience underheating. To verify this, the case study was simulated under variable occupants' distributions. The results indicated a substantial increase (by a factor of five) in the number of discomfort occupied hours. In addition, the heterogeneous distribution resulted in a moderate change in EUI. Figure 7.11 shows the results of simulating the case study model under ninety-three different occupants' distribution scenarios. 


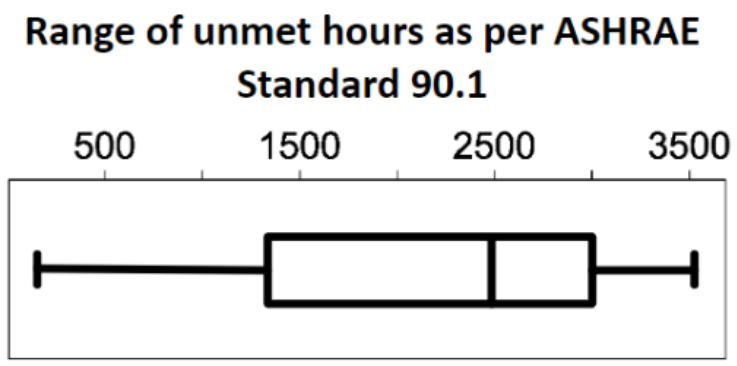

\section{Range of energy use intensity $\left(\mathrm{kWh} / \mathrm{m}^{2}\right)$}

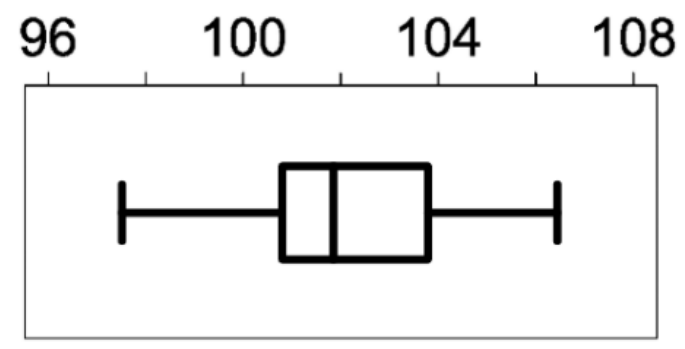

Figure 7.11: Impact of occupants' distribution on energy (top) and comfort performance (bottom).

Therefore, the proposed method suggests the following activities in the second step:

(1) Iterating parametric analysis under variable occupant scenarios to verify the selection of design parameters / ECMs. Here, we propose testing at least two extreme occupant scenarios (low occupancy and high occupancy) in addition to standard assumptions.

(2) Including occupant-related assumptions as one of the optimization variables to ensure the selection of robust or adaptive design parameters.

(3) Incorporating variable occupant-related assumptions in comfort studies during the development of building design. 
CHAPTER 7

\subsubsection{Reporting design outcomes}

Reporting design outcomes is a process that should occur at multiple points starting with presenting an architectural schematic design to clients and ending with final reports and issued for construction drawings. Designers typically tend to report design outcomes with certainty and avoid reporting uncertainty to sustain clients' confidence. This designers' behaviour was reported by practitioners in stakeholders' workshop administered by the author (Abuimara et al. 2018a) and in an international survey by O'Brien et al. (2016). However, this behaviour might have an adverse effect when uncertainty in design outcomes leads to a performance gap during operation.

Therefore, we argue here that owner engagement is of great significance when it comes to occupant-related assumptions as it avoids forgoing opportunities in making informed design decisions (Gunay et al. 2016c).

In early design stages, reporting occupant-related assumptions, their associated uncertainty, and their use in design assists key stakeholders, such as building owners, in making informed decisions. For example, deciding window-to-wall ratio (WWR), adding fixed exterior shading, or selecting the HVAC type, are decided during early design stages and can be influenced by occupant-related assumptions. 
In addition, reporting the implications of occupant-related assumptions on design facilitates persuading clients to accept implementing monitoring infrastructures such as submetering of different tenants and different end use categories (e.g. plug-in equipment). Submetering can help identify opportunities to reduce energy use, through occupant engagement and better controls (Bennet \& O'Brien 2017).

Generally, the third step of the proposed method suggests the following while reporting design outcomes:

(1) Reporting occupant-related uncertainty to design stakeholders and most importantly to building owner.

(2) Demonstrating advantages of adopting adaptive technologies such as DCV and lighting controls.

(3) Introducing benefits of robust design solutions (e.g. fixed exterior window shading) against disadvantages of using occupant-sensitive ones (e.g. interior blind shades).

(4) Presenting the impact of selecting certain design solutions (e.g. high WWR, full automation of building) on comfort.

(5) Reporting results of worst cases scenario, base case (standard assumptions), and best-case performance instead of deterministic values. In addition, 
CHAPTER 7

correlating the performance range to an occupancy range can make a solid case in front of clients.

\subsection{Conclusion}

This study outlines a method for accounting for occupant-related uncertainty throughout the building design process. The proposed method consists of three steps: establishing occupant-related assumptions, evaluating design under the established assumptions, and reporting design outcomes considering these occupant-related assumptions.

The proposed method is designed for implementation by all key design stakeholders and is not limited to the energy modelling scope. A fundamental aspect of the proposed method is initiating the design process based on a unified set of occupantrelated assumptions that are shared among all key stakeholders. In addition, the proposed method is not a standalone method. Instead, it is intended to be incorporated in the integrated design process by placing occupants at the core of the process. The proposed method was developed based on findings of research conducted over a three-year project and included stakeholders' feedback, design process documentation, and a simulation-based investigation. 
The stakeholders' workshop findings and the documentation findings were inline in terms of emphasizing the need to improve the current way of handling occupantrelated assumptions. The improvement includes considering accurate occupantrelated assumptions starting from early design stages where all critical design decisions are made. The findings also indicated the need for developing an effective information exchange mechanism among design stakeholders.

The simulation-based investigation's findings indicated selecting design parameters/ ECMs and deciding the optimal ones can be in several cases sensitive to occupantrelated assumptions such as DCV. While some other design parameters/ ECMs demonstrated robustness to occupant related assumptions such as increasing building envelop insulation. Overall, the findings underscored the importance of occupantrelated assumptions and served as a basis for the method presented in this paper.

In order to facilitate the implementation of the proposed method, future work should consider the following:

(1) Applying the method to buildings of different types and in different contexts to verify generalizability. 
CHAPTER 7

(2) Developing a tool or a web application that can simulate a base model under multiple occupant scenarios and provide comparison of results. Alternatively, incorporating this feature in BPS tools. 
CHAPTER 8

\section{Conclusions and future work}

\subsection{Summary}

In this doctoral thesis, a suite of methods for improved occupant modelling and handling occupant-related uncertainty is introduced. The method is built upon the findings of a thorough qualitative and quantitative investigations that involved building design practitioners and a real case study office building. The method is basically meant to utilize the existing untapped occupant-related data and BPS features to better model occupants and manage occupant-related uncertainty.

The thesis took place in five major steps and are summarized below.

\subsubsection{The status of occupant modelling}

Chapter 3 included qualitatively evaluating and documenting the current status of occupant modelling during building design through a stakeholders' workshop. The stakeholders' workshop hosted architects, engineers, researchers, and BPS developers. The findings of the workshop demonstrated that codes and standards are typically the main source of occupant-related assumptions. It also indicated that there are barriers to adopt an improved approach for occupant modelling such as time and budget limitations. 
CHAPTER 8

Additionally, the findings of the workshop indicated the need to: (1) demonstrate the sensitivity of design decisions to occupant assumptions and occupant behaviour, (2) update the current outdated occupant-related assumptions in codes and standards, (3) incorporate the state-of-the-art occupant modelling developed by researchers in BPS tools.

\subsubsection{Case study documentation and parametric analysis}

Chapter 4 included documenting the design process and testing the sensitivity of a case study office building design to occupant-related assumptions/inputs. This phase included semi-structured interviews with key design stakeholders: the building owner, the architect, the mechanical engineer, and the energy modeller.The findings of design process documentation showed that designers rely primarily on NECB, ASHRAE Standard 90.1 and BPS default values as major sources of occupant-related assumptions.

On another front, discrepancies were reported among the assumptions made by designers. For example, mechanical engineer assumptions were conservative and about a factor of 2 greater than those of the energy modeller. While mechanical engineers face greater liability than energy modellers due to the risk of HVAC under sizing, HVAC oversizing comes with several consequences such as increased capital and operating costs, inefficient performance, etc. 
CHAPTER 8

Testing the sensitivity of the case study building design to occupant-related assumptions demonstrated that the energy use implications of occupant-related assumptions are oversimplified in building codes and standards. The selection of design parameters was tested under 13 different occupant scenarios (i.e. building use scenarios). The 13 building use scenarios indicated significantly different energy use patterns, savings potential and ranking of design alternatives. This implies that design stakeholders should base their design on case-specific assumptions that recognize different building types, use and occupants.

The results also indicated that technologies such as DCV can become more appealing with non-standard occupant assumptions. Other design parameters such as wall and roof insulation demonstrated robustness to the different building use scenarios which makes them ideal candidates to consider as design parameters when designing buildings with unknown use cases. In contrast, different window configurations showed sensitivity to building use scenarios.

Overall, the findings underscored that building designers need to pay more attention to the sensitivity of building design to occupant-related assumptions. Additionally, designers need to maintain proper exchange of design data and consistency of assumptions through improved coordination and information exchange mechanisms. 
CHAPTER 8

\subsubsection{Occupant-centric design optimization}

Chapter 5 included the development and implementation of a method for occupantcentric building design optimization to evaluate and handle the impact of occupantrelated assumptions on building design optimization. The method consisted of three major steps: generating occupancy scenarios, running the occupant-centric optimization process, and deriving design parameters selection rules that can serve as design guidelines.

In the first step, sixty-four occupant scenarios were generated by altering the mathematical relationship between occupants' presence and the use of lights and plug-in equipment. The second step involved conducting occupant-centric optimization for each of the sixty-four occupant scenarios. The search for the optimal solutions was performed by the genetic algorithm.

The findings indicated that different assumptions about occupants can lead to different design solutions. The results demonstrated that even within the same occupancy scenario, different light and equipment use patterns can affect the outcomes of optimization process.

The final step was to derive design parameter selection rules by deriving relationships between the results of the optimization and the occupant scenarios. These 
CHAPTER 8

relationships were visualized in the form of decision trees to serve as design guiding rules.

\subsubsection{Evaluating the impact of occupants' spatial distribution on performance}

Chapter 6 aimed at demonstrating the implications of occupancy spatial distribution assumptions during building energy and comfort performance modelling. The case study energy model was simulated under ninety-three occupants' distribution scenarios. These scenarios were randomly generated to represent inter-tenant diversity in real office buildings. Four different metrics were used to assess the impact of inter-tenant diversity on building performance. EUI was used to assess energy performance while unmet hours, $\mathrm{ODH}$, and $\mathrm{OHco}_{2}$ were used to evaluate comfort performance.

The energy performance was modestly sensitive to different occupants' spatial distributions as it experienced a change of EUI (5-10\%). Comfort performance results indicated a substantial increase in unmet hours with numerous occupant distribution scenarios. ODH values also indicated various discomfort levels experienced by occupants in different zones. Generally, overheating was the major issue with intertenant diversity. The results also indicated the sensitivity of the IAQ to the intertenant diversity as the values of $\mathrm{OHCO}_{2}$ changed significantly in some zones with some scenarios. 
CHAPTER 8

The study also examined the benefits of DCV in addressing some issues related to inter-tenant diversity. Deploying DCV resulted in EUI savings of about 6-7\% as well as assisting in mitigating overcooling in core zones due to overventilation.

\subsubsection{A Method for exploring occupant-related uncertainty during building design}

Chapter 7 outlined a method for accounting for and managing occupant-related uncertainty throughout the building design process by all design stakeholders. The method consists of three steps: establishing occupant-related assumptions, evaluating design under the established assumptions, and reporting design outcomes considering occupant-related uncertainty. A major aspect of the method is initiating the design process based on a unified set of occupant-related assumptions that are shared and used by all key stakeholders.

The first step includes seeking and establishing accurate occupant-related assumptions starting from early design stages where all critical design decisions are made. The second step involves testing the sensitivity of design outcomes to variable occupant-related assumptions. The final step consists of communicating occupantrelated uncertainty among stakeholders throughout the design process until the final reporting stage. 
CHAPTER 8

\subsection{Contributions}

The findings of this research are expected to contribute to two main fields:

\subsubsection{Contributions to the existing literature}

(1) Documentation of the current status, challenges, and needs of occupant modelling practice through a workshop with key stakeholders. The findings of the documentation can inform researchers in the field of the actual issues and priorities that needs to be investigated and addressed. In addition, the findings can provide insights into building codes and standards committees of the actual needs of practitioners.

(2) For the first time, this study documents occupant modelling and occupant-related assumptions of real case study building in the Canadian context. The study analysis provided an overview of occupant modelling throughout the design process while highlighting the shortcomings of the process. The findings can be considered as a basis of any future research with regards to improving occupant modelling in a similar context.

(3) This study added to the bases of any future investigation with regards to occupants' impact on building design and performance as the findings were

evident on how influential occupant-related assumptions on design decision 
making. These findings can contribute to building codes development by highlighting occupants as a major factor that affects building compliance.

(4) This study proposed and implemented an occupant-centric building design optimization method that included selection of optimal design parameters based on building occupancy. The proposed method can be implemented by researchers for verification with different types of buildings and in different contexts. In addition, the findings also can guide codes and standards in imposing occupantcentric measures and requirements.

(5) The study demonstrated the implications of occupants' spatial distributions in commercial buildings on occupants' thermal comfort and IAQ. Two new comfort metrics were introduced: $\mathrm{ODH}$ and $\mathrm{OH}_{\mathrm{co} 2}$ that indicate discomfort on zone and occupant level. These metrics can highlight occupant and zone level potential comfort issues such as overheating during building design.

(6) The study introduced a method for handling occupant-related uncertainty not only in the energy modelling phase, but throughout the design process. The method is based on existing capabilities and resources available to designers. The findings can inform building codes and standards with regards to occupantrelated requirements. 
CHAPTER 8

\subsubsection{Contributions to architecture and engineering profession}

This study contributes to improving the current occupant modelling practice by:

(1) Highlighting the shortcomings of the current occupant modelling process and providing proposals for solutions using the existing untapped knowledge and capabilities that are available for practitioners in a simple and practical way.

(2) Providing a worked example of a real building that demonstrates to practitioners how influential occupants are on design decisions and what can be further done using available tools and data.

(3) Introducing an occupant-centric design optimization method that can be implemented by design practitioners.

(4) Outlining a method for occupant-centric design process to handle occupantrelated uncertainty throughout the building design process.

\subsection{Future work}

Several aspects of occupant-related uncertainty remained unresolved or uncovered in this study and are recommended for future research. The recommendations for future research are listed below:

(1) The finding of this research should be primierely utulized to advance the current occupant modelling approaches through improving relvent clauses in codes and standards. This research demonstrated the lack of a systamtic approach that 
CHAPTER 8

practitioners follow to handle occupant-related uncertainty. In addition, the findings have show that inadequate consideration of occupant-related assumptions leads to dicrepency and increase uncertainty in design decisions. Future research should focus on make recommendations to codes and standards to improve occupant-related requirements by:

a. Allow the customization of the current assumptions to be case-specific

b. Require the documentation, sharing, and reporting of occupant-related assumptions.

c. Enforce the evalution of design decisions under variable occupant scenarios to enhance the roubustness of design.

(2) This study included the documentation of occupant modelling and occupantrelated assumptions of an office building in Canada through interviews with key design stakeholders. Future research should consider a more comprehensive approach by documenting multiple case studies. The documentation should include interviews and/or surveys with key stakeholders to establish a more holistic picture of the shortcomings of the current practice and the needs of design practitioners.

(3) In this study, the investigation took place on an office building model located in climate zone 6A. More case studies in different climate zones and typologies 
CHAPTER 8

should be subjected to similar investigation in order to verify and generalize the findings.

(4) In this research, occupants' impact on only energy performance, thermal comfort, and IAQ were considered for investigation. Future research should consider occupants' impact on other building performance aspects such as daylight and glare performance. Glare is an important factor that triggers occupants' energyintensive behaviours such as closing shades and leaving them closed for an extended period and using electric lights instead.

(5) The study findings briefly highlighted the importance of using some adaptive technologies (e.g. DCV) in handling variable occupancy. Future research should consider a more comprehensive approach to demonstrate the full potential of various technologies such as DCV, lighting controls, and HVAC control strategies. Adaptive building technologies offer opportunities for energy savings while maintaining occupants' comfort.

(6) From the findings of the stakeholders' workshop and the documentation of the case study design process, the ease of implementation and the time of implementation are two major factors that determine the adoption of a method by practitioners. Therefore, future research should consider the development of a 
tool/application that can be used by practitioners to conduct occupant-centric sensitivity analysis.

(7) This research introduced a method to handle occupant-related uncertainty; however, to ensure wide adoption and implementation of this method, building codes should enforce and incentivize better occupant modelling. Future research should consider proposing a design workflow that can be adopted and imposed by building codes to guide the design process in a way that considers occupantrelated uncertainty. Figure 8.1 provides an overview of a preliminary vision of how an occupant-centric design workflow should be.

PROPOSED OCCUPANT-CENTRIC DESIGN WORKFLOW

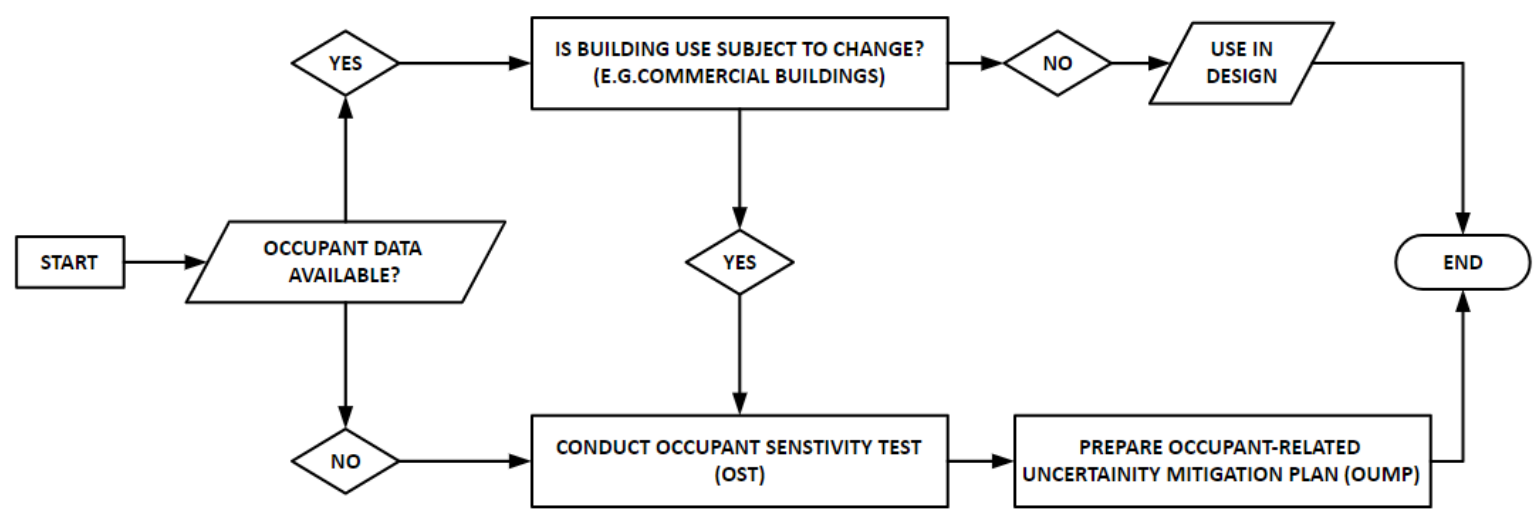

Figure 8.1: A vision of occupant-centric design workflow. 


\section{References}

Abuimara, T., O'Brien, W., \& Gunay, B. (2020a). Optimizing office building design? Watch out for occupants! Science and Technology for the Built Environment.

Abuimara, T., O'Brien, W., Gunay, B., Abdelalim, A., Ouf, M., \& Gilani, S. (2018a). Modelling Occupants in Buildings: Stakeholders' Workshop on Current Barriers, Challenges and Needs. In Proceedings of eSim 2018, the $10^{\text {th }}$ conference of IBPSA-Canada, Montreal,Canada, pp. 312-320.

Abuimara, T., O'Brien, W., Gunay, B., Burpee, H., \& Day, J. K. (2018b). Designing for Occupants: A Review of the Integrated Design Practice. In 2018 ACEEE Summer Study on Energy Efficiency in Buildings, Pacific Grove, CA, pp. $8(1-12)$.

Abuimara, T., O'Brien, W., Gunay, B., \& Carrizo, J. S. (2018c). Assessing the Impact of Occupants On Building Design Decision Making. In Proceedings of eSim 2018, the $10^{\text {th }}$ conference of IBPSA-Canada, Montreal,Canada, pp. 321330 .

Abuimara, T., O'Brien, W., Gunay, B., \& Carrizo, J. S. (2019). Towards occupantcentric simulation-aided building design: a case study. Building Research \& Information, 47(8), 866-882.

Abuimara, T., O'Brien, W., Gunay, B., \& Sebastián Carrizo, J. (2020b). How assumptions about occupants can misinform building design. ASHRAE Journal, 62(1).

Abushakra, B., Haberl, J. S., \& Claridge, D. E. (2004). Overview of existing literature on diversity factors and schedules for energy and cooling load calculations. In 2004 Winter Meeting - Technical and Symposium Papers, American Society of Heating, Refrigerating and Air-Conditioning Engineers, pp. 169-181.

Al-Rashidi, K., Loveday, D., \& Al-Mutawa, N. (2012). Impact of ventilation modes on carbon dioxide concentration levels in Kuwait classrooms. Energy and Buildings, 47, 540-549.

Andrews, C. J., Yi, D., Krogmann, U., Senick, J. A., \& Wener, R. E. (2011). 
Designing buildings for real occupants: An agent-based approach. IEEE Transactions on Systems, Man, and Cybernetics-Part A: Systems and Humans, 41(6), 1077-1091.

Arditi, D., \& Gunaydin, H. M. (2002). Factors That Affect Process Quality in the Life Cycle of Building Projects. Journal of Construction Engineering and Management, 124(3), 194-203.

ASHRAE. (2013). ASHRAE Handbook of Fundimentals; Nonresidential Cooling and Heating. Ashrae Standard.

ASHRAE, AIA, USGBC, IESNA, \& DOE. (2011). Advanced Energy Design Guide for Small to Medium Office Buildings.

ASHRAE Standard 90.1. (2016). ANSI/ASHRAE Standard 90.1-2016 Energy Standard for Buildings Except Low-Rise Residential Buildings.

Athienitis, A., \& O'Brien, W. (2015). Net ZEB case studies. In A. Athienitis \& W. O'Brien, eds., Modeling, design, and optimization of net-zero energy buildings.

Attia, S., Gratia, E., De Herde, A., \& Hensen, J. L. M. (2012a). Simulation-based decision support tool for early stages of zero-energy building design. Energy and Buildings, 49, 2-15.

Attia, S., Hamdy, M., Carlucci, S., Pagliano, L., Bucking, S., \& Hasan, A. (2015). 5 Building performance optimization of net zero-energy buildings.

Attia, S., Hensen, J. L. M. M., Beltrán, L., \& De Herde, A. (2012b). Selection criteria for building performance simulation tools: contrasting architects' and engineers' needs. Journal of Building Performance Simulation, 5(3), 155-169.

Azari, R., \& Kim, Y.-W. (2014). Development and validation of a framework for evaluation of integrated design teams of sustainable high-performance buildings. In Construction Research Congress 2014: Construction in a Global Network - Proceedings of the 2014 Construction Research Congress. doi:10.1061/9780784413517.0060

Babu, P., \& Suthar, G. (2020). Indoor air quality and thermal comfort in green building: A study for measurement, problem and solution strategies. In Lecture Notes in Civil Engineering, Vol. 60, Springer, pp. 139-146.

Bakó-Biró, Z., Clements-Croome, D. J., Kochhar, N., Awbi, H. B., \& Williams, M. J. (2012). Ventilation rates in schools and pupils' performance. Building and Environment, 48, 215-223. 
Beausoleil-Morrison, I. (2019). Learning the fundamentals of building performance simulation through an experiential teaching approach. Journal of Building Performance Simulation, 12(3), 308-325.

Bellia, L., Marino, C., Minichiello, F., \& Pedace, A. (2014). An Overview on Solar Shading Systems for Buildings. Energy Procedia, 62, 309-317.

Bennet, I. E., \& O'Brien, W. (2017). Office building plug and light loads: Comparison of a multi-tenant office tower to conventional assumptions. Energy and Buildings, 153, 461-475.

Billhymer, L., \& Riz, D. (2015). Retrofits and the First Benefits of Integrated Design - DesignIntelligence. Design Intellgence. Retrieved from https://www.di.net/articles/retrofits-and-the-first-benefits-of-integrateddesign/

Blondeau, P., Iordache, V., Poupard, O., Genin, D., \& Allard, F. (2005). Relationship between outdoor and indoor air quality in eight French schools. Indoor Air, 15(1), 2-12.

Bonte, M., Thellier, F., \& Lartigue, B. (2014). Impact of occupant's actions on energy building performance and thermal sensation. Energy and Buildings, 76, 219-227.

Brager, G., \& Arens, E. (2015). Creating high performance buildings: Lower energy, better comfort. In AIP Conference Proceedings, Vol. 1652, pp. 58-69.

Brown, C., Glicksman, L., \& Lehar, M. (2010). Toward Zero Energy Buildings: Optimized for Energy Use and Cost C. SimBuild 2010, 452-457.

Bucking, S. (2016). Optimization under economic uncertainty using a net zero energy commercial office case study. ASHRAE Trans, 122, 444-454.

Bucking, S., Athienitis, A., \& Zmeureanu, R. (2011). Optimization of Net-Zero Energy Solar Communities: Effect of Uncertainty Due To Occupant Factors. ISES World Conference, 1523-1528.

Bucking, S., Zmeureanu, R., \& Athienitis, A. (2013). An information driven hybrid evolutionary algorithm for optimal design of a Net Zero Energy House. Solar Energy, 96, 128-139.

Burman, E., Mumovic, D., \& Kimpian, J. (2014). Towards measurement and verification of energy performance under the framework of the European directive for energy performance of buildings. Energy, 77, 153-163. 
Busby Perkins \& Will, \& Stantec. (2007). Roadmap for The Integrated Design Process.

CEC. (2015). Improving Green Building Construction in North America: Guide to Integrated Design and Delivery, Montreal,Canada, p. 84.

Chapman, J., Siebers, P.-O., \& Robinson, D. (2018). On the multi-agent stochastic simulation of occupants in buildings. Journal of Building Performance Simulation, 11(5), 604-621.

Chen, Y., Liang, X., Hong, T., \& Luo, X. (2017). Simulation and visualization of energy-related occupant behavior in office buildings. Building Simulation, 10(6), 785-798.

Claridge, D. E., Bass Abushakra, P., ASHRAE Member ASHRAE Jeff Haberl, M. S., \& Member ASHRAE, P. (2004). Electricity Diversity Profiles for Energy Simulation of Office Buildings. ASHRAE, 110(AN-04-3-3 (RP-1 093)), 365377.

Clevenger, C. M., Haymaker, J. R., Jalili, M., M., C. C., R., H. J., \& Maral, J. (2014). Demonstrating the Impact of the Occupant on Building Performance. Journal of Computing in Civil Engineering, 28(1), 99-102.

Cole, R. J. (2010). Green buildings and their occupants: a measure of success. Building Research \& Information, 38(5), 589-592.

D'Oca, S., \& Hong, T. (2015). Occupancy schedules learning process through a data mining framework. Energy and Buildings, 88, 395-408.

Day, J. K. (2018). Exploring Occupant Behavior in Buildings. (A. Wagner, W. O'Brien, \& B. Dong, Eds.), 1st edn, Springer International Publishing. doi:10.1007/978-3-319-61464-9

Day, J. K., \& O'Brien, W. (2017). Oh behave! Survey stories and lessons learned from building occupants in high-performance buildings. Energy Research \& Social Science, 31, 11-20.

de Wilde, P. (2014). The gap between predicted and measured energy performance of buildings: A framework for investigation. Automation in Construction, 41, 40-49.

de Wit, S., \& Augenbroe, G. (2002). Analysis of uncertainty in building design evaluations and its implications. Energy and Buildings, 34(9), 951-958. 
Delzendeh, E., Wu, S., Lee, A., \& Zhou, Y. (2017). The impact of occupants' behaviours on building energy analysis: A research review. Renewable and Sustainable Energy Reviews, 80, 1061-1071.

Ding, Y., Wang, Z., Feng, W., Marnay, C., \& Zhou, N. (2016). Influence of occupancy-oriented interior cooling load on building cooling load design. Applied Thermal Engineering, 96, 411-420.

Djunaedy, E., Van den Wymelenberg, K., Acker, B., \& Thimmana, H. (2011). Oversizing of HVAC system: signatures and penalties. Energy and Buildings, 43, 468-475.

DOE, U. S. (2012). EnergyPlus energy simulation software. Ehttp://Apps1. Eere. Energy. Gov/Buildings/Energyplusæ (Mar. 20, 2012).

Dong, B., Yan, D., Li, Z., Jin, Y., Feng, X., \& Fontenot, H. (2018). Modeling occupancy and behavior for better building design and operation-A critical review. Building Simulation, 11(5), 899-921.

Duarte, C., Van Den Wymelenberg, K., \& Rieger, C. (2013). Revealing occupancy patterns in an office building through the use of occupancy sensor data. Energy and Buildings, 67, 587-595.

El-Diraby, T., Krijnen, T., \& Papagelis, M. (2017). BIM-based collaborative design and socio-technical analytics of green buildings. Automation in Construction, $82,59-74$.

Emmerich, S. J., \& Persily, A. K. (2001). State-of-the-Art Review of CO2 Demand Controlled Ventilation Technology and Application. Retrieved from https://pdfs.semanticscholar.org/8590/191ffbce6601d0afb9887a668b2653452fe3 .pdf

EnergyPlus. (2020). EnergyPlus | EnergyPlus. Retrieved March 19, 2020, from https://energyplus.net/

EPA. (1997). An Office Building Occupant's Guide to Indoor Air Quality, 1-10.

Erickson, V. L., Lin, Y., Kamthe, A., ... Narayanan, S. (2009). Energy efficient building environment control strategies using real-time occupancy measurements. In BUILDSYS 2009 - Proceedings of the 1st ACM Workshop on Embedded Sensing Systems for Energy-Efficiency in Buildings, Held in Conjunction with ACM SenSys 2009, New York, New York, USA: ACM Press, pp. $19-24$. 
Evins, R. (2013). A review of computational optimisation methods applied to sustainable building design. Renewable and Sustainable Energy Reviews, 22, 230-245.

Fogel, D. B. (1994). An Introduction to Simulated Evolutionary Optimization. IEEE Transactions on Neural Networks , 5(1). Retrieved from http://l.academicdirect.org/Horticulture/GAs/Refs/_other_Fogel/Fogel_199 4_Evolution.pdf

Fowler, K. M., Solana, A. E., \& Spees, K. (2005). Building Cost and Performance Metrics: Data Collection Protocol. Pacific Northwest National Laboratory, (September). doi:10.2172/885473

Gaetani, I., Hoes, P.-J., \& Hensen, J. L. M. (2017). Introducing and testing a strategy for fit-for-purpose occupant behavior modeling in a simulation-aided building design process. In IBPSA Building Simulation Conference, pp. 761768.

Gaetani, I., Hoes, P.-J., \& Hensen, J. L. M. (2018). Estimating the influence of occupant behavior on building heating and cooling energy in one simulation run. Applied Energy, 223, 159-171.

Gaetani, I., Hoes, P.-J., \& Hensen, J. L. M. M. (2016a). Occupant behavior in building energy simulation: towards a fit-for-purpose modeling strategy. Energy and Buildings, 121, 188-204.

Gaetani, I., Hoes, P.-J., \& Hensen, J. L. M. M. (2016b). On the sensitivity to different aspects of occupant behaviour for selecting the appropriate modelling complexity in building performance predictions. Journal of Building Performance Simulation, 10(5-6), 1-11.

Gagnon, R., Gosselin, L., \& Decker, S. (2018). Sensitivity analysis of energy performance and thermal comfort throughout building design process. Energy and Buildings, 164, 278-294.

Gang, W., Wang, S., Shan, K., \& Gao, D. (2015). Impacts of cooling load calculation uncertainties on the design optimization of building cooling systems. Energy and Buildings, 94, 1-9.

Gilani, S., Goldstein, R., Breslav, S., Tessier, A., \& O'Brien, W. (2019). Building performance implications of occupant mobility. In V. Corrado \& A. Gasparella, eds., Proceedings of Building Simulation 2019: 16th Conference of IBPSA, Rome, Italy. 
Gilani, S., \& O'Brien, W. (2016). Review of current methods, opportunities, and challenges for in-situ monitoring to support occupant modelling in office spaces. Journal of Building Performance Simulation, 10(5-6), 1-27.

Gilani, S., \& O'Brien, W. (2017). Modelling and Simulation of Lighting Use Patterns in Office Spaces. In 15th IBPSA Conference, San Francisco. doi:10.26868/25222708.2017.317

Gilani, S., O'Brien, W., \& Gunay, H. B. (2018a). Simulating occupants' impact on building energy performance at different spatial scales. Building and Environment, 132, 327-337.

Gilani, S., O'Brien, W., \& Gunay, H. B. (2018b). Simulating occupants' impact on building energy performance at different spatial scales. Building and Environment, 132, 327-337.

Gilani, S., O'Brien, W., Gunay, H. B., \& Carrizo, J. S. (2016). Use of dynamic occupant behavior models in the building design and code compliance processes. Energy and Buildings, 117(November), 260-271.

Golden, L. (2001). Flexible Work Schedules: Which Workers Get Them? American Behavioral Scientist, 44(7), 1157-1178.

Government of Ontario. (2018). Ontario Building Code, Toronto.

Gram-Hanssen, K. (2010). Residential heat comfort practices: Understanding users. Building Research and Information, 38(2), 175-186.

Guerra-Santin, O., \& Silvester, S. (2017). Development of Dutch occupancy and heating profiles for building simulation. Building Research and Information, 45(4), 396-413.

Guillemin, A., \& Molteni, S. (2002). An energy-efficient controller for shading devices self-adapting to the user wishes. Building and Environment, 37(11), 1091-1097.

Gunay, B., O'Brien, W., \& Beausoleil-Morrison, I. (2013). A critical review of observation studies, modeling, and simulation of adaptive occupant behaviors in offices. Building and Environment, 70, 31-47.

Gunay, H. B., O’Brien, W., Beausoleil-Morrison, I., \& Gilani, S. (2016a). Modeling plug-in equipment load patterns in private office spaces. Energy and Buildings, $121,234-249$. 
Gunay, H. B., O’Brien, W., Beausoleil-Morrison, I., \& Gilani, S. (2016b). Modeling plug-in equipment load patterns in private office spaces. Energy and Buildings, 121, 234-249.

Gunay, H. B., O’Brien, W., Beausoleil-morrison, I., Gunay, H. B., Brien, W. O., \& Beausoleil-morrison, I. (2016c). Implementation and comparison of existing occupant behaviour models in EnergyPlus, 1493(March).

doi:10.1080/19401493.2015.1102969

Gunay, H. B., Shen, W., Yang, C., Huchuk, B., \& Shi, Z. (2018). A Preliminary Study on Text Mining Operator Logbooks to Develop a Fault-Frequency Model. ASHRAE Transactions, 124.

Haldi, F., \& Robinson, D. (2009a). Interactions with window openings by office occupants. Building and Environment, 44(12), 2378-2395.

Haldi, F., \& Robinson, D. (2009b). Interactions with window openings by office occupants. Building and Environment, 44(12), 2378-2395.

Haldi, F., \& Robinson, D. (2010). Adaptive actions on shading devices in response to local visual stimuli. Journal of Building Performance Simulation, 3(2), 135153.

Haldi, F., \& Robinson, D. (2011). sc. Journal of Building Performance Simulation, $4(4), 323-338$.

Haldi, F., Robinson, D., Fre'de', F., \& Haldi, F. (2011). The impact of occupants' behaviour on building energy demand. Journal of Building Performance Simulation, 4(4), 323-338.

Hamdy, M., Nguyen, A.-T., \& Hensen, J. L. M. (2016). A performance comparison of multi-objective optimization algorithms for solving nearly-zero-energybuilding design problems. Energy and Buildings, 121, 57-71.

Hayter, S. J., Torcellini, P. A., Hayter, R. B., \& Judkoff, R. (2000). The Energy Design Process for Designing and Constructing High-Performance Buildings. Clima.

Hensen, J. L. M., \& Lamberts, R. (2012). Building Performance Simulation for Design and Operation, Spon Press.

Hobson, B. W., Lowcay, D., Gunay, H. B., Ashouri, A., \& Newsham, G. R. (2019). Opportunistic occupancy-count estimation using sensor fusion: A case study. Building and Environment, 159, 106154. 
Hoes, P., Hensen, J. L. M., Loomans, M., De Vries, B., \& Bourgeois, D. (2009). User behavior in whole building simulation. Energy and Buildings, 41(3), 295302.

Hoes, P., Trcka, M., Hensen, J. L. M., \& Bonnema, B. H. (2011a). Optimizing building designs using a robustness indicator with respect to user behavior. Proceedings of the 12th Conference of the International Building Performance Simulation Association, 14-16.

Hoes, P., Trcka, M., Hensen, J. L. M., \& Hoekstra Bonnema, B. (2011b). Optimizing Building Designs Using A Robustness Indicator With Respect to User Behavior. In Proceedings of Building Simulation 2011, Sydney, pp. 1710 1717 .

Hong, T., \& Fisk, W. J. (2010). Assessment of energy savings potential from the use of demand controlled ventilation in general office spaces in California. Building Simulation, 3(2), 117-124.

Hong, T., Yan, D., D’Oca, S., \& Chen, C. fei. (2017). Ten questions concerning occupant behavior in buildings: The big picture. Building and Environment, $114,518-530$.

Hopfe, C. J., \& Hensen, J. L. M. (2011). Uncertainty analysis in building performance simulation for design support. Energy and Buildings, 43(10), 2798-2805.

IEA-EBC. (2014). Annex 66:Definition and Simulation of Occupant Behavior in Buildings. Retrieved November 14, 2018, from https://annex66.org/?q=Introduction

IEA-EBC. (2018). Annex 79 : Occupant -Centric Building Design and Operation. Retrieved November 14, 2018, from http://annex79.iea-ebc.org/

Karjalainen, S. (2019). Be active and consume less - the effect of venetian blind use patterns on energy consumption in single-family houses. Energy Efficiency, $12(3), 787-801$.

Kim, J., Hong, T., Jeong, J., ... Jeong, J. (2017). Establishment of an optimal occupant behavior considering the energy consumption and indoor environmental quality by region. Applied Energy, 204, 1431-1443.

Knight, I., \& Dunn, G. (2004). Size Does Matter. Building Services Journal, 8 (4): 3-6. 
Larsson, N. (2004). The Integrated Design Process, Ottawa. Retrieved from http://www.iisbe.org/down/gbc2005/Other_presentations/IDP_overview.pdf

Lawrence, T. (2004). Demand-controlled ventilation and sustainability. ASHRAE Journal, 46(12), 120-121.

Leaman, A., \& Bordass, B. (1999). Productivity in buildings: The "killer" variables. Building Research and Information, 27(1), 4-19.

Lee, B., Trcka, M., \& Hensen, J. L. M. (2014). Building energy simulation and optimization: a case study of industrial halls with varying process loads and occupancy patterns. In Building Simulation, Vol. 7, Springer Berlin Heidelberg, pp. 229-236.

Levin, H. (2003). Designing for people: What do buildings occupants really want?, keynote lecture. Healthy Buildings 2003, 1-18.

Li, J., Yu, Z. (Jerry), Haghighat, F., \& Zhang, G. (2019). Development and improvement of occupant behavior models towards realistic building performance simulation: A review. Sustainable Cities and Society, 50, 101685.

Liang, X., Hong, T., \& Shen, G. Q. (2016). Occupancy data analytics and prediction: A case study. Building and Environment, 102, 179-192.

Liu, Z., Li, W., Chen, Y., Luo, Y., \& Zhang, L. (2019). Review of energy conservation technologies for fresh air supply in zero energy buildings. Applied Thermal Engineering, 148, 544-556.

Loonen, R. C. G. M., Favoino, F., Hensen, J. L. M., \& Overend, M. (2017). Review of current status, requirements and opportunities for building performance simulation of adaptive facades Review of current status, requirements and opportunities for building performance simulation of adaptive facades $\dagger$. Journal of Building Performance Simulation, 10(2), 205-223.

Lu, Y., Wang, S., Yan, C., \& Huang, Z. (2017). Robust optimal design of renewable energy system in nearly/net zero energy buildings under uncertainties. Applied Energy, 187, 62-71.

Machairas, V., Tsangrassoulis, A., \& Axarli, K. (2014). Algorithms for optimization of building design: A review. Renewable and Sustainable Energy Reviews, Vol. 31. doi:10.1016/j.rser.2013.11.036

Mahdavi, A., Tahmasebi, F., \& Kayalar, M. (2016). Prediction of plug loads in office buildings: Simplified and probabilistic methods. Energy and Buildings, 
$129,322-329$.

Maier, T., Krzaczek, M., \& Tejchman, J. (2009). Comparison of physical performances of the ventilation systems in low-energy residential houses. Energy and Buildings, 41(3), 337-353.

Masoso, O. T., \& Grobler, L. J. (2010). The dark side of occupants' behaviour on building energy use. Energy and Buildings, 42(2), 173-177.

Méndez Echenagucia, T., Capozzoli, A., Cascone, Y., \& Sassone, M. (2015). The early design stage of a building envelope: Multi-objective search through heating, cooling and lighting energy performance analysis. Applied Energy, $154,577-591$.

Menezes, A. C., Cripps, A., Bouchlaghem, D., \& Buswell, R. (2012). Predicted vs. actual energy performance of non-domestic buildings: Using post-occupancy evaluation data to reduce the performance gap. Applied Energy, 97, 355-364.

Menezes, A. C., Cripps, A., Buswell, R. A., Wright, J., \& Bouchlaghem, D. (2014). Estimating the energy consumption and power demand of small power equipment in office buildings. Energy and Buildings, 75, 199-209.

Miles, J. C., Sisk, G. M., \& Moore, C. J. (2001). The conceptual design of commercial buildings using a genetic algorithm. Computers \& Structures, 79(17), 1583-1592.

Mills, E. (2009). Building Commissioning A Golden Opportunity for Reducing Energy Costs and Greenhouse Gas Emissions, Berkeley, CA.

Ministry of Municipal Affairs Ontario. (2011). Ontario Building Code:Supplementary Standard SB-10. Retrieved from http://www.mah.gov.on.ca/AssetFactory.aspx?did=9227

Moazami, A., Carlucci, S., Nik, V. M., \& Geving, S. (2019). Towards climate robust buildings: An innovative method for designing buildings with robust energy performance under climate change. Energy and Buildings, 202, 109378.

Mok, K. Y., Shen, G. Q., \& Yang, R. (2018). Stakeholder complexity in large scale green building projects. Engineering, Construction and Architectural Management, 25(11), 1454-1474.

Mollaoglu-Korkmaz, S., Asce, M., Lipika Swarup, ;, \& Riley, D. (2013). Delivering Sustainable, High-Performance Buildings: Influence of Project Delivery Methods on Integration and Project Outcomes. doi:10.1061/(ASCE)ME.1943 
Mysen, M., Rydock, J. P., \& Tjelflaat, P. O. (2003). Demand controlled ventilation for office cubicles - can it be profitable? Energy and Buildings, 35(7), 657-662.

National Research Council of Canada. (2015). National Energy Code ofCanada 2015NECB .pdf, Ottawa.

Newsham, G. (1992). Occupant movement and the thermal modelling of buildings. Energy and Buildings, 18(1), 57-64.

NRC. (2015). National Energy Code of Canada for Buidings, Ottawa, Canada.

NRCan. (2016). The integrated design process | Natural Resources Canada. Retrieved February 19, 2018, from http://www.nrcan.gc.ca/energy/efficiency/buildings/eenb/integrated-designprocess $/ 4047$

O'Brien, W., Abdelalim, A., Abuimara, T., ... Ouf, M. (2018). Roadmap for Occupant Modelling in Building Codes and Standards. In eSim2018 "Building Simulation to Support Building Sustainability," Vol. 2016, Montreal,Canada, pp. 259-268.

O’Brien, W., Abdelalim, A., \& Gunay, H. B. (2019). Development of an office tenant electricity use model and its application for right-sizing HVAC equipment. Journal of Building Performance Simulation, 12(1), 37-55.

O’Brien, W., Bourdoukan, P., Delisle, V., \& Yip, S. (2015). Modeling, design, and optimization of net-zero energy buildings. In A. K. Athienitis \& L. (William) O'Brien, eds., Modeling, design, and optimization of net-zero energy buildings, pp. $107-173$.

O’Brien, W., Gaetani, I., Carlucci, S., Hoes, P.-J., \& Hensen, J. L. M. (2017). On occupant-centric building performance metrics. Building and Environment, $122,373-385$.

O’Brien, W., Gaetani, I., Gilani, S., Carlucci, S., Hoes, P.-J., \& Hensen, J. (2016). International survey on current occupant modelling approaches in building performance simulation. Journal of Building Performance Simulation, 10(5-6), $653-671$.

O’Brien, W., \& Gunay, H. B. (2015). Mitigating office performance uncertainty of occupant use of window blinds and lighting using robust design. In Building Simulation, Vol. 8, Tsinghua University Press, pp. 621-636.

O’Brien, W., \& Gunay, H. B. (2019). Do building energy codes adequately reward 
buildings that adapt to partial occupancy? Science and Technology for the Built Environment, 25(6), 678-691.

O'Brien, W., Wagner, A., Schweiker, M., ... Berger, C. (2020). Introducing IEA EBC Annex 79: Key challenges and opportunities in the field of occupantcentric building design and operation. Building and Environment, 106738.

Oliveira, S., Marco, E., Gething, B., \& Robertson, C. (2017). Exploring Energy Modelling in Architecture Logics of Investment and Risk. Energy Procedia, $111,61-70$.

Omer Sarfraz, \& Bach, C. K. (2018). Equipment power consumption and load factor profiles for buildings' energy simulation (ASHRAE 1742-RP). Science and Technology for the Built Environment, 24(10), 1054-1063.

Ouf, M. M., O'Brien, W., \& Gunay, B. (2019a). On quantifying building performance adaptability to variable occupancy. Building and Environment, $155,257-267$.

Ouf, M., O'Brien, W., \& Gunay, B. (2019b). Optimizing Building Performance using Stochastic Occupant Models. In ASHRAE Transactions -2019 Winter Conference, Atlanta.

Ouf, M., O'Brien, W., \& Gunay, H. B. (2018). Improving occupant-related features in building performance simulation tools. Building Simulation, 11(4), 803-817.

Page, J., Robinson, D., Morel, N., \& Scartezzini, J.-L. (2008). A generalised stochastic model for the simulation of occupant presence. Energy and Buildings, 40(2), 83-98.

Pearl, D. (2004). An Integrated Design Process (IDP) - Canadian Architect.

Peng, Y., Rysanek, A., Nagy, Z., \& Schlüter, A. (2018). Using machine learning techniques for occupancy-prediction-based cooling control in office buildings. Applied Energy, 211, 1343-1358.

PPP Canada. (2017). About P3s. Retrieved June 2, 2017, from http://www.p3canada.ca/en/about-p3s/

Reed, W. G., Gordon, E. B., \& William G. Reed \& Elliot B. Gordon. (2010). Integrated design and building process: what research and methodologies are needed? Building Research \& Information, 28, 2000(5-6: Cost and value in building green), 325-337. 
Reinhart, C. F. (2004). Lightswitch-2002: a model for manual and automated control of electric lighting and blinds. Solar Energy, 77(1), 15-28.

Reinhart, C., \& Voss, K. (2003). Monitoring manual control of electric lighting and blinds. Lighting Research \& Technology, 35(3), 243-258.

Schibuola, L., Scarpa, M., \& Tambani, C. (2016). Annual Performance Monitoring of a Demand Controlled Ventilation System in a University Library. Energy Procedia, 101, 313-320.

Schweiker, M., Haldi, F., Shukuya, M., \& Robinson, D. (2011). Verification of stochastic models of window opening behaviour for residential buildings. Journal of Building Performance Simulation, 5(1), 55-74.

Shen, H., \& Tzempelikos, A. (2012). Daylighting and energy analysis of private offices with automated interior roller shades. Solar Energy, 86(2), 681-704.

Shi, X., Tian, Z., Chen, W., Si, B., \& Jin, X. (2016). A review on building energy efficient design optimization rom the perspective of architects. Renewable and Sustainable Energy Reviews, 65, 872-884.

Snyman, J. (2005). Practical mathematical optimization. Retrieved from https://link.springer.com/content/pdf/10.1007/978-3-319-77586-9.pdf

Stevenson, F., Baborska-Narozny, M., \& Chatterton, P. (2016). Resilience, redundancy and low-carbon living: co-producing individual and community learning. Building Research and Information, 44(7), 789-803.

Sun, C., Zhang, R., Sharples, S., Han, Y., \& Zhang, H. (2019). Thermal comfort, occupant control behaviour and performance gap - A study of office buildings in north-east China using data mining. Building and Environment, 149, 305321.

Sun, K., \& Hong, T. (2017a). A Framework for Quantifying the Impact of Occupant Behavior on Energy Savings of Energy Conservation Measures A Framework for Quantifying the Impact of Occupant Behavior on Energy Savings of Energy Conservation Measures. Energy and Buildings, 146, 383396.

Sun, K., \& Hong, T. (2017b). A simulation approach to estimate energy savings potential of occupant behavior measures. Energy and Buildings, 136, 43-62.

Tuhus-Dubrow, D., \& Krarti, M. (2010). Genetic-algorithm based approach to optimize building envelope design for residential buildings. Building and 
Environment, 45(7), 1574-1581.

UN Environmental Programme. (2018). 2018 Global Status Report: towards a zeroemission, efficient and resilient buildings and construction sector, 73 .

Van Den Wymelenberg, K. (2012). Patterns of occupant interaction with window blinds: A literature review. Energy and Buildings, 51, 165-176.

Wang, D., Federspiel, C. C., \& Rubinstein, F. (2005). Modeling occupancy in single person offices. Energy and Buildings, 37(2), 121-126.

Wang, Z., Ding, Y., Deng, H., Yang, F., \& Zhu, N. (2018). An Occupant-Oriented Calculation Method of Building Interior Cooling Load Design. Sustainability, 10(6), 1821.

Wate, P., Iglesias, M., Coors, V., \& Robinson, D. (2020). Framework for emulation and uncertainty quantification of a stochastic building performance simulator. Applied Energy, 258, 113759.

WBDG. (2018). Design Objectives |WBDG Whole Building Design Guide. Retrieved March 7, 2018, from https://www.wbdg.org/design-objectives

Wetter, M., \& Wright, J. (2003). Comparison of a generalized pattern search and a genetic algorithm optimization method.

Wetter, M., \& Wright, J. (2004). A comparison of deterministic and probabilistic optimization algorithms for nonsmooth simulation-based optimization. Building and Environment, 39(8), 989-999.

Wright, J. A., Loosemore, H. A., \& Farmani, R. (2002). Optimization of building thermal design and control by multi-criterion genetic algorithm. Energy and Buildings, 34(9), 959-972.

Yan, D., \& Hong, T. (2018). International Energy Agency, EBC Annex 66 Definition and Simulation of Occupant Behavior in Buildings Annex 66 Final Report. Retrieved from www.iea-ebc.org

Yan, D., Hong, T., Dong, B., ... Feng, X. (2017). IEA EBC Annex 66: Definition and simulation of occupant behavior in buildings. Energy and Buildings, 156, 258-270.

Yan, D., O’Brien, W., Hong, T., ... Mahdavi, A. (2015). Occupant behavior modeling for building performance simulation: Current state and future challenges. Energy and Buildings, 107, 264-278. 
Zang, H., Zhang, S., \& Hapeshi, K. (2010). A Review of Nature-Inspired Algorithms. Journal of Bionic Engineering, 7, S232-S237.

Zeytinoglu, I. U., Cooke, G. B., \& Mann, S. L. (2009). Flexibility: Whose Choice Is It Anyway? Relations Industrielles / Industrial Relations, 64(4), 555-574.

Zhang, Y., Bai, X., Mills, F. P., \& Pezzey, J. C. V. (2018). Rethinking the role of occupant behavior in building energy performance: A review. Energy and Buildings, 172, 279-294.

Zhang, Y., \& Barrett, P. (2012). Factors influencing occupants' blind-control behaviour in a naturally ventilated office building. Building and Environment, $54,137-147$.

Zhao, H., \& Magoulès, F. (2012). A review on the prediction of building energy consumption. Renewable and Sustainable Energy Reviews, 16(6), 3586-3592.

Zhuang, J., Hu, M., \& Mousapour, F. (2016). Value-Driven Design Process: A Systematic Decision-Making Framework Considering Different Attribute Preferences From Multiple Stakeholders. Journal of Solar Energy Engineering, $139(2), 021001$.

Zimmerman, A. (2006). Integrated Design Process Guide, Ottawa. Retrieved from https://moodle.polymtl.ca/file.php/1047/IDP-

Charettes/article_design_guide_en_aug23.pdf 


\section{Appendix A: Stakeholders' interviews questions}

Stakeholders survey on occupant modelling in building design practice

(The architect)

\begin{tabular}{|l|l|}
\hline No. & Questions \\
\hline 1. & What were the main goals of your design? \\
\hline 2. & What kind of information was available to you during the design process? \\
\hline 3. & What level of details did you get from the client about the intended design? \\
\hline 4. & $\begin{array}{l}\text { Do you use building performance simulation (BPS) or other tools to quantify } \\
\text { energy or comfort performance during the design process? }\end{array}$ \\
\hline 5. & $\begin{array}{l}\text { How does information about occupants and operation influence your work? } \\
\text { In what way? }\end{array}$ \\
\hline 6. & $\begin{array}{l}\text { Which (sustainability-related) factors affects your early design decisions (such } \\
\text { as orientation, window to wall ratio, shading strategies, space zoning)? }\end{array}$ \\
\hline 7. & $\begin{array}{l}\text { What metrics do you rely on in making the decisions? (aesthetics, } \\
\text { performance, client satisfaction, comfort, etc.)? }\end{array}$ \\
\hline 8. & Are you actively involved in selecting building control strategies? \\
\hline 9. & $\begin{array}{l}\text { Do agree or disagree with granting building users control over their indoor } \\
\text { environment (temperature, ventilation, lighting)? Why? }\end{array}$ \\
\hline 10. & $\begin{array}{l}\text { In general, do you think occupants can be trusted to take actions that improve } \\
\text { energy performance, comfort, and maintenance of a building? }\end{array}$ \\
\hline 11. & $\begin{array}{l}\text { What architectural considerations did you make about energy performance } \\
\text { when designing this building? }\end{array}$ \\
\hline 12. & Are you willing to make compromises to meet sustainability targets? \\
\hline
\end{tabular}


Stakeholders survey on occupant modelling in building design practice (The mechanical engineer)

\begin{tabular}{|c|c|}
\hline No. & Questions \\
\hline 1. & $\begin{array}{l}\text { Could you briefly describe the project design work flow (only your scope)? } \\
\text { Where and when does it take place through the whole design process? }\end{array}$ \\
\hline 2. & $\begin{array}{l}\text { How do you usually perform design and sizing decisions for the mechanical } \\
\text { equipment (HVAC, pumps, fans)? }\end{array}$ \\
\hline 3. & $\begin{array}{l}\text { Do you use building performance simulation (BPS) tools in your design work? } \\
\text { For which tasks? If so, which BPS tool do you use? } \\
\text { What are the strengths and weaknesses of the BPS tools that you use? }\end{array}$ \\
\hline 4. & Do you experience any difficulty in populating the inputs of your BPS tool? \\
\hline 5. & $\begin{array}{l}\text { Which performance indicators do you usually rely on to select design option } \\
\text { (energy use, cost, comfort)? }\end{array}$ \\
\hline 6. & $\begin{array}{l}\text { Where do you need occupancy and occupant-related assumptions in your } \\
\text { work? }\end{array}$ \\
\hline 7. & $\begin{array}{l}\text { Do you use standards such as ASHRAE 90.1in selecting appropriate } \\
\text { occupancy, lighting, and plug load schedules or do you use customized (case- } \\
\text { specific) assumptions? If not, what kind of assumptions do you make } \\
\text { regarding occupants? }\end{array}$ \\
\hline 8. & $\begin{array}{l}\text { Do you usually ask for information related to occupants from other } \\
\text { stakeholders (e.g. client, architect, modellers)? }\end{array}$ \\
\hline 9. & $\begin{array}{l}\text { Do you think accurate occupant-related assumptions would make a tangible } \\
\text { impact on your designs? In what way? }\end{array}$ \\
\hline 10. & $\begin{array}{l}\text { What restricts you from using more detailed occupant-related assumptions in } \\
\text { the design? }\end{array}$ \\
\hline
\end{tabular}

Stakeholders survey on occupant modelling in building design practice (The modeller) 


\begin{tabular}{|l|l|}
\hline No. & Questions \\
\hline 11. & $\begin{array}{l}\text { When did RWDI start the modelling process (which design phase) (concept } \\
\text { design, design development or detailing)? }\end{array}$ \\
\hline 12. & $\begin{array}{l}\text { What was the purpose of modelling? (e.g. code compliance, certification, } \\
\text { P3...). }\end{array}$ \\
\hline 13. & $\begin{array}{l}\text { Were there regular communications with other stakeholders (client, architect, } \\
\text { engineers, etc.)? }\end{array}$ \\
\hline 14. & Please describe the level of communication with other stakeholders? \\
\hline 15. & $\begin{array}{l}\text { How receptive were other stakeholders to new/innovative building } \\
\text { technologies and design strategies? }\end{array}$ \\
\hline 16. & Was the information exchange influential on the modelling process? \\
\hline 17. & Was occupant-related information available upon starting? \\
\hline & $\begin{array}{l}\text { Please specify the sources for the following modelling assumptions used during } \\
\text { modelling: } \\
\text { a. Number of people } \\
\text { b. Light power density (LPD) } \\
\text { c. Plug-in loads } \\
\text { d. Blinds (position and type) } \\
\text { e. Thermostats and setpoints } \\
\text { f. Schedules (for lighting, occupancy, plug loads, thermostat setpoints, fans, } \\
\text { etc.) }\end{array}$ \\
\hline 19. & Were there any other non-standard modelling assumptions made by RWDI? \\
\hline 20. & Were there any occupant data available from any of the stakeholders? \\
\hline 21. & $\begin{array}{l}\text { Please describe the modelling workflow (the building performance simulation } \\
\text { process as it takes place within RWDI). }\end{array}$ \\
\hline 22. & How much time did you dedicate for the modelling process? \\
\hline 23. & $\begin{array}{l}\text { To whom did RWDI report energy modelling results and who did give } \\
\text { feedback on the results? }\end{array}$ \\
\hline 24. & Were there any modifications to the design made based on the feedback? \\
\hline 25. & $\begin{array}{l}\text { Was there any client involvement in the energy modelling process (input, } \\
\text { feedback, requirement)? }\end{array}$ \\
\hline 26. If nhy Did you ask for one?
\end{tabular}




\begin{tabular}{|l|l|}
\hline 27. & $\begin{array}{l}\text { Was there any review for similar buildings' occupant- related data prior to/ } \\
\text { during the modelling process? }\end{array}$ \\
\hline 28. & What are the strengths and weaknesses of the BPS tools that you use? \\
\hline 29. & Did you experience any difficulty in populating the inputs of your BPS tool? \\
\hline 30. & $\begin{array}{l}\text { Which performance indicators do you mostly rely on to select design options } \\
\text { (energy use, cost, comfort)? }\end{array}$ \\
\hline 31. & $\begin{array}{l}\text { In your opinion, what could be the most substantial source of uncertainty in } \\
\text { LPD, etc.) }\end{array}$ \\
\hline 32. & $\begin{array}{l}\text { Do you think accurate occupant-related assumptions would make tangible } \\
\text { impact on the modelling predictions or design decisions? In what way? }\end{array}$ \\
\hline 33. & $\begin{array}{l}\text { What restricts you from using detailed occupant-related assumptions (e.g., } \\
\text { considering individuals' use of blinds, lights, computers, etc.) in the design? }\end{array}$ \\
\hline
\end{tabular}

Stakeholders survey on occupant modelling in building design practice (The client/building owner)

\begin{tabular}{|l|l|}
\hline No. & Questions \\
\hline 34. & $\begin{array}{l}\text { To what extent were you involved in the building design and modelling } \\
\text { process? }\end{array}$ \\
\hline 35. & $\begin{array}{l}\text { Were you seeking code compliance, certification or lowering initial and } \\
\text { operation costs, or for any other goal? }\end{array}$ \\
\hline 36. & $\begin{array}{l}\text { How influential do you think the occupant related assumptions are during } \\
\text { the design phase? }\end{array}$ \\
\hline 37. & $\begin{array}{l}\text { Were there data available about the types of office equipment such as } \\
\text { computers, printers, office fans/heaters, task lights, etc.? }\end{array}$ \\
\hline 38. & $\begin{array}{l}\text { Did the design team inform or ask for information about the anticipated } \\
\text { building occupancy levels, plug-in equipment, lighting, blinds, windows, and } \\
\text { controls? }\end{array}$ \\
\hline 39. & $\begin{array}{l}\text { Did you have any special design requirements regarding building systems } \\
\text { particularly to achieve your sustainability goals? }\end{array}$ \\
\hline 40. & $\begin{array}{l}\text { Have you had any requirements regarding occupants' control on building } \\
\text { components such as operable windows, thermostats, etc.? }\end{array}$ \\
\hline
\end{tabular}




\begin{tabular}{|l|l|}
\hline 41. & $\begin{array}{l}\text { Do you agree or disagree with giving you building users a degree of freedom } \\
\text { on controlling their spaces such as adjusting temperature, opening windows, } \\
\text { etc.? Why? }\end{array}$ \\
\hline 42. & How important do you think occupant comfort is for their productivity? \\
\hline 43. & $\begin{array}{l}\text { Have the designers propose submetering for units and for different end uses } \\
\text { of energy to identify the pattern of energy use and to create a potential } \\
\text { saving during operation? }\end{array}$ \\
\hline 44. & $\begin{array}{l}\text { Do you think that providing detailed occupant-related information can } \\
\text { make a difference to the design process (and ultimate design)? }\end{array}$ \\
\hline 45. & $\begin{array}{l}\text { How do you think better information about occupants can help during the } \\
\text { design process? }\end{array}$ \\
\hline 46. & $\begin{array}{l}\text { After recognizing the importance of occupants' behavior, if you were to } \\
\text { provide more information for designers, what other specifications and } \\
\text { requirements would you have provided for the designers? }\end{array}$ \\
\hline
\end{tabular}

